MÁRIO CÉSAR GIACCO RAMOS

UMA CONTRIBUIÇÃO PARA A ÁREA DE SAÚDE POR MEIO DA VERIFICAÇÃO DO IMPACTO DA QUALIDADE DE ENERGIA E DAS INSTALAÇÕES ELÉTRICAS NOS EQUIPAMENTOS ELETROMÉDICOS 
MÁRIO CÉSAR GIACCO RAMOS

\title{
UMA CONTRIBUIÇÃO PARA A ÁREA DE SAÚDE POR MEIO DA VERIFICAÇÃO DO IMPACTO DA QUALIDADE DE ENERGIA E DAS INSTALAÇÕES ELÉTRICAS NOS EQUIPAMENTOS ELETROMÉDICOS
}

\author{
Tese apresentada à Escola Politécnica da \\ Universidade de São Paulo para obtenção \\ do título de Doutor em Engenharia \\ Área de concentração: \\ Sistemas de Potência \\ Orientador: \\ Prof. Dr. Carlos Márcio Vieira Tahan
}


AUTORIZO A REPRODUÇÃO E DIVULGAÇÃO TOTAL OU PARCIAL DESTE TRABALHO, POR QUALQUER MEIO CONVENCIONAL OU ELETRÔNICO, PARA FINS DE ESTUDO E PESQUISA, DESDE QUE CITADA A FONTE.

Este exemplar foi revisado e alterado em relação à versão original, sob responsabilidade única do autor e com a anuência de seu orientador.

São Paulo, 13 de maio de 2009.

Assinatura do autor

Assinatura do orientador

FICHA CATALOGRÁFICA

Ramos, Mário César Giacco

Uma contribuição para a área de saúde por meio da verificação do impacto da qualidade de energia e das instalações elétricas nos equipamentos eletromédicos / M.C.G. Ramos. -- ed.rev. -- São Paulo, 2009.

$253 \mathrm{p}$.

Tese (Doutorado) - Escola Politécnica da Universidade de São Paulo. Departamento de Engenharia de Energia e Automação Elétricas.

1.Instalações elétricas 2.Energia elétrica 3.Hospitais 4.Equi pamentos elétricos I.Universidade de São Paulo. Escola Politécnica. Departamento de Engenharia de Energia e Automação Elétrica II.t. 
Dedico este trabalho:

aos meus pais: Hugo e Mariquinha

(in memorian);

à minha esposa Vilma $\mathrm{e}$ ao meu filho Marinho, pela paciência, compreensão e ajuda;

Aos meus alunos da Universidade de Mogi das Cruzes, pelo incentivo 


\section{AGRADECIMENTOS}

Em primeiro lugar a Deus por me ter me concedido mais esta oportunidade.

Ao Prof. Dr. Carlos Márcio Vieira Tahan pela confiança, sugestões, leituras e segurança com que conduziu a orientação deste trabalho.

Ao Prof. Dr. Aderbal de Arruda Penteado Júnior, amigo de longa data, pelas contribuições prestadas durante a realização da pesquisa e dos testes.

Ao Prof. Dr. Alexandre Henrique Hermini, pelas sugestões e contribuições prestadas durante o exame de qualificação.

Ao Prof. Dr. Nelson Kagan, pela autorização para realização dos testes no Enerq-ct - Laboratório do Centro Tecnológico de Qualidade de Energia da Escola Politécnica da Universidade de São Paulo.

Aos Estabelecimentos Assistenciais de Saúde que colocaram suas instalações elétricas à disposição para medições e vistorias.

Aos fabricantes e representantes que cederam equipamentos eletromédicos para realização dos testes.

A todos aqueles que de alguma forma contribuíram para a realização deste trabalho. 


\section{RESUMO}

Em todos os segmentos da sociedade, a utilização de equipamentos eletrônicos projetados e construídos com avançadas tecnologias eletrônicas e controlados por microprocessadores aumenta a cada dia. $\mathrm{Na}$ área de saúde, denominados de equipamentos eletromédicos, dão suporte aos setores de diagnóstico, tratamento ou, procedimento cirúrgico, melhorando a qualidade dos serviços e o atendimento aos pacientes. No entanto, o sucesso global do processo deverá considerar a qualidade das instalações elétricas nesses ambientes, bem como a qualidade da energia elétrica fornecida a esses equipamentos. Este trabalho tem como objetivo comprovar, por meio de pesquisa em laboratório, o risco de diagnósticos médicos baseados em informações fornecidas por equipamentos eletromédicos, alimentados em redes elétricas que não atendem às normas vigentes ou, totalmente perturbadas por outros equipamentos típicos dos ambientes médico-hospitalares. A metodologia aplicada consistiu em medições dos parâmetros referentes à qualidade de energia elétrica nos estabelecimentos assistenciais de saúde. Atenção especial foi dada ao conteúdo harmônico de tensão e aos afundamentos de tensão de curta duração produzidos por equipamentos de raios $\mathrm{X}$, mamografia, tomografia computadorizada, ressonância magnética nuclear e motores elétricos de indução. Em seguida, essas perturbações foram reproduzidas em fontes de tensão específicas para essa finalidade, instaladas no Laboratório do Centro Tecnológico de Qualidade de Energia da Escola Politécnica da Universidade de São Paulo, conhecido como Enerq-ct. Equipamentos eletromédicos portáteis, gentilmente cedidos por diversos fabricantes nacionais, foram submetidos a esses sinais para verificação do seu desempenho. Os resultados obtidos demonstram a importância da qualidade de energia elétrica bem como, a qualidade dos serviços de manutenção nas instalações elétricas desses ambientes.

Palavras-chave: Qualidade de Energia Elétrica. Equipamentos Eletromédicos. Estabelecimentos Assistenciais de Saúde. Instalações Elétricas. 


\begin{abstract}
Through all segments of our society, there is a daily increase in the use of electronic equipment designed and built with advanced electronic technology and computerized control. In the health-medical area, designated electromedical equipment, they provide support to sectors in charge of diagnosis, treatment or surgical procedures, improving the quality of services and the manner patients are cared for. However, the global success of this process must take into consideration the quality of electrical installations at these facilities, as well as the electrical power supplied to the equipment. The aim of this work is to attest through laboratory research the risk of medical diagnoses based on information provided by electromedical equipment powered through electrical networks which do not meet the standards in effect, or which are completely disturbed by other equipment typical of electromedical environments. The methodology applied consisted of measurements of the parameters referring to the quality of electrical power in health care facilities. Especial attention was given to the voltage harmonic content and to short duration voltage sags caused by X-ray, mammography, computerized tomography and nuclear magnetic resonance equipment or by induction motors. Later, these disturbances were reproduced in power supplies which are specific to this objective, installed at Laboratório do Centro Tecnológico de Qualidade de Energia da Escola Politécnica da Universidade de São Paulo- Energy Quality Technological Center of the Technical School of the University of Sao Paulo, known as Enerq-ct. Portable electromedical equipment, kindly supplied by national manufacturers, were subjected to these signals for assessment of their performance. The results obtained demonstrate the importance of the quality of electrical power as well as the quality of maintenance of electrical installations within these environments.
\end{abstract}

keywords: Quality of electrical power. Electromedical equipment. Health-care facilities. Electrical installations. 


\section{LISTA DE ILUSTRAÇÕES}

Figura 1.1 - Fonte de tensão Pacific ....................................................... 29

Figura 1.2 - Fonte de tensão Porto-Sag ................................................. 30

Figura 1.3 - Afundamentos de tensão de curta duração aplicados aos equipamentos eletromédicos .............................................. 32

Figura 1.4 - Afundamento de $80 \%$ com duração de 10 ciclos .............................. 33

Figura 2.1 - Afundamento de tensão provocado por uma condição de falta (seis ciclos)

Figura 2.2 - Afundamento de tensão caracterizado pelas Normas IEEE e IEC ......39

Figura 2.3 - Falta fase-terra perto da subestação ....................................... 40

Figura 2.4 - Seqüência de operação típica de um religador .............................. 42

Figura 2.5 - Proteção seletiva entre ramais e o circuito alimentador .....................42

Figura 2.6 - Faixa de sensibilidade dos equipamentos às flutuações de tensão ..... 45

Figura 2.7 - Curvas CBEMA e ITIC .......................................................... 45

Figura 2.8 - Afundamentos de tensão em um sistema de potência, provenientes de várias origens .................................................................... 46

Figura 2.9 - Religador a vácuo com corpo em epóxi....................................56

Figura 2.10 - Religador com o respectivo painel de comando ............................56

Figura 3.1 - Desequilíbrio de tensões em um dos setores administrativos do EAS

Figura 3.2 - Desequilíbrio de correntes em um dos setores administrativos do EAS

Figura 3.3 - Distorções harmônicas totais de correntes em um dos setores administrativos do EAS

Figura 3.4 - Distorções harmônicas individuais de correntes em um dos setores administrativos do EAS

Figura 3.5 - Distorções harmônicas totais de tensões em um dos setores administrativos do EAS

Figura 3.6 - Distorções harmônicas individuais de tensões em um dos setores administrativos do EAS 63

Figura 3.7 - Afundamento de tensão na fase A 
Figura 3.8 - Condutores elétricos sem proteção mecânica ....................................68

Figura 3.9 - Condutores elétricos sem proteção mecânica ...................................69

Figura 3.10 - Instalações improvisadas no interior de EAS ..................................69

Figura 3.11 - Painel de fabricação "caseira" instalado no EAS ..............................70

Figura 3.12 - Instalação de chuveiro no vestiário do EAS …...............................70

Figura 3.13 - Condutores elétricos expostos e utilização incorreta de cordão

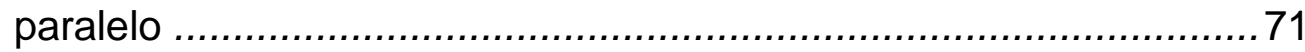

Figura 3.14 - Painel sem porta instalado na entrada do EAS ….......................... 71

Figura 3.15 - Neutro e condutor de proteção interligados .....................................72

Figura 3.16 - Painel sem dispositivo de desligamento geral e com circuitos

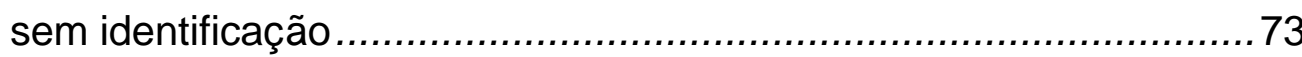

Figura 3.17 - Disjuntores unipolares interligados .............................................. 73

Figura 3.18 - Utilização de sistema de aterramento TN-C em EAS .......................74

Figura 3.19 - Ligações improvisadas em EAS …............................................ 74

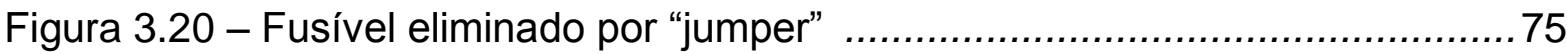

Figura 3.21 - Detalhe ampliado (da figura 3.20) …….................................... 75

Figura 3.22 - Utilização de tomadas com apenas 2 pólos, em EAS........................75

Figura 3.23 - Utilização de tomadas com apenas 2 pólos, em EAS........................ 76

Figura 3.24 - Utilização de tomadas com apenas 2 pólos, em EAS........................76

Figura 3.25 - Unidade de Terapia Intensiva (UTI) …….................................. 76

Figura 3.26 - Plugue sem o condutor de proteção ............................................ 76

Figura 3.27 - Uso de adaptador em tomada tipo Schuko.....................................76

Figura 3.28 - Utilização de régua para alimentação múltipla de

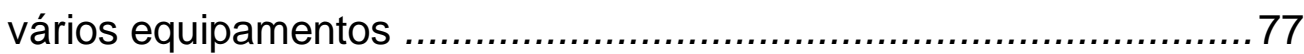

Figura 3.29 - Instalação de condutores isolados sem proteção mecânica ...............78

Figura 3.30 - Instalação de condutores isolados sem proteção mecânica ...............78

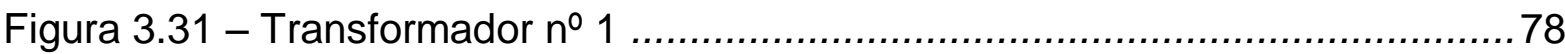

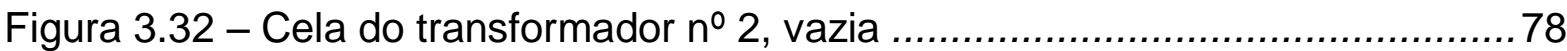

Figura 3.33 - Sistema supervisório controlando todas as instalações do EAS........79

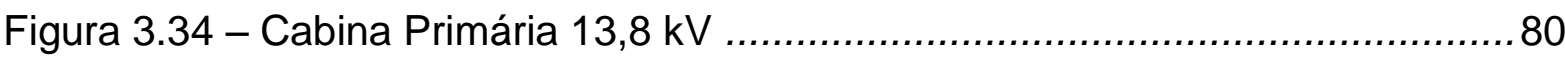

Figura 3.35 - Sistema de proteção dos circuitos de 13,8 kV ............................... 80

Figura 3.36 - Conjunto de disjuntores a vácuo instalados na cabina primária ........81

Figura 3.37 - Vista de um dos três geradores de 2000 kVA/13,8 kV......................81

Figura 3.38 - Conjunto de quatro disjuntores a vácuo $630 \mathrm{~A} / 13,8 \mathrm{kV}$..................... 82 
Figura 3.39 - Transformador com isolamento a epóxi...................................... 82

Figura 3.40 - Painéis de distribuição em baixa tensão - 380/220V ....................... 83

Figura 3.41 - Barramentos para $5000 \mathrm{~A}$ instalados em painéis de baixa tensão -

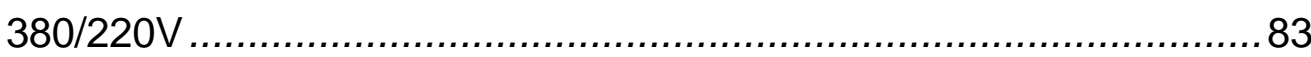

Figura 3.42 - Placa de identificação do sistema de compensação de reativos

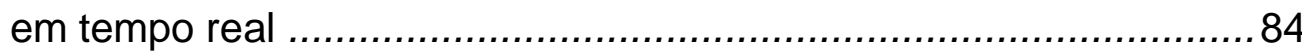

Figura 3.43 - Sistema de UPS das áreas críticas do EAS …................................84

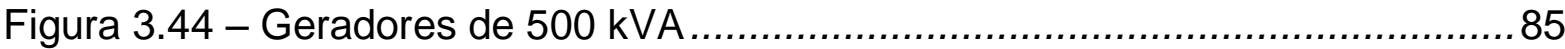

Figura 3.45 - Isolamento acústico nas salas dos geradores .................................. 85

Figura 3.46 - Detectores de fumaça instalados na sala dos geradores ..................86

Figura 3.47 - Painel sinótico do sistema de transferência ................................... 86

Figura 3.48 - Sistema de transferência entre gerador e sistema de alimentação

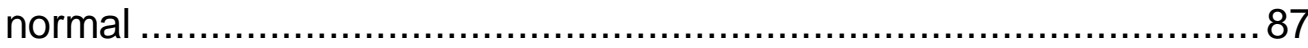

Figura 3.49 - Sistema de sincronismo e controle de carga .................................. 87

Figura 3.50 - Condutores Neutro e de Proteção claramente identificados por cores, no leito de cabos

Figura 3.51 - Neutro e condutor de proteção separados, identificando claramente $\mathrm{O}$ esquema de aterramento TN-S, conforme recomenda a

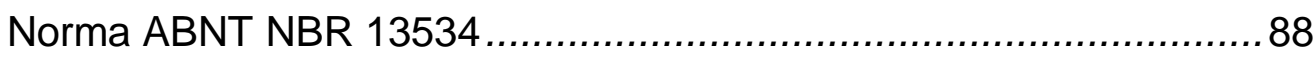

Figura 3.52 - Sistema de distribuição com barramentos blindados (Bus way) .......88

Figura 4.1 - Níveis de Compatibilidade Eletromagnética ...................................100

Figura 5.1 - Tensão e corrente durante o funcionamento em operação contínua (stand-by)

Figura 5.2 - Espectro de harmônicos da corrente durante o funcionamento contínuo

Figura 5.3 - Tela de potência do analisador Fluke 43B - medição monofásica ....112

Figura 5.4 - Intensidade de corrente e o respectivo afundamento de tensão provocado durante o funcionamento momentâneo

Figura 5.5 - Tensão e corrente durante o funcionamento em operação contínua (stand-by)

Figura 5.6 - Espectro de harmônicos de corrente durante o funcionamento contínuo

Figura 5.7 - Tela de potência do analisador Fluke 43B - medição monofásica ....116 Figura 5.8 - Intensidade de corrente durante o funcionamento momentâneo 
Figura 5.9 - Tensão e corrente durante o funcionamento em operação contínua (stand-by)

Figura 5.10 - Espectro de harmônicos da corrente durante o funcionamento contínuo

Figura 5.11 - Tela de potência do analisador Fluke 43B - medição monofásica ..119

Figura 5.12 - Intensidade de corrente durante o funcionamento momentâneo .....120

Figura 5.13 - Tensão e corrente durante a operação...................................... 121

Figura 5.14 - Espectro de harmônicos da corrente, durante a operação .............. 122

Figura 5.15 - Tela de potência do analisador Fluke 43B - medição monofásico .. 123

Figura 5.16 - Variação da corrente durante o funcionamento ............................. 124

Figura 5.17 - Variação da corrente durante a partida ...................................... 126

Figura 5.18 - Variação da corrente durante a partida de um motor de indução aspirador 126

Figura 5.19 - Variação da corrente e afundamentos de tensão provocados durante a partida de um elevador de passageiros

Figura 5.20 - Afundamento de tensão provocado durante a partida - valores instantâneos 128

Figura 5.21 - Variação da corrente durante a partida - valores instantâneos ....... 128

Figura 5.22 - Afundamento de tensão provocado durante a partida - valores eficazes 129

Figura 5.23 - Variação da corrente durante a partida - valores eficazes 129

Figura 5.24 - Formas de onda de tensão e de corrente de um sistema de bombeamento composto por um motor de indução, acionado por conversor de freqüência

Figura 5.25 - Espectro dos harmônicos de corrente do mesmo acionamento ....... 131

Figura 5.26 - Tela de potência do analisador Fluke 43 B - medição monofásica

Figura 6.1 - Corte longitudinal do coração, mostrando as válvulas e os grandes vasos.

Figura 6.2 - Monitor multiparamétrico conectado ao simulador de paciente 140

Figura 6.3 - Forma de onda de tensão distorcida pela presença de harmônicos ensaio no 7

Figura 6.4 - Afundamentos de tensão de curta duração aplicados ao monitor multiparamétrico 


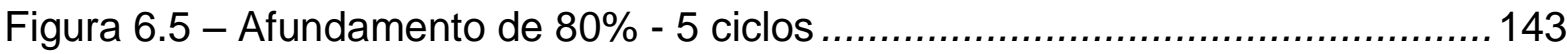

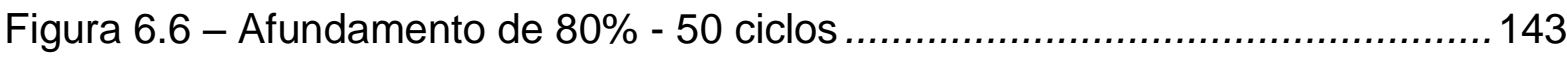

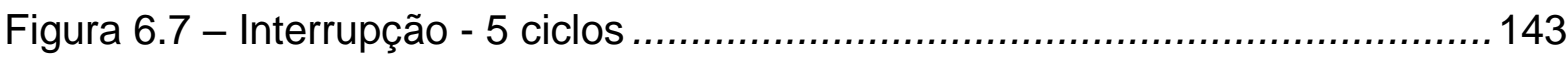



Figura 6.9 - Monitor multiparamétrico - fabricante B …............................... 144

Figura 6.10 - Oxímetro de pulso conectado ao simulador de paciente -

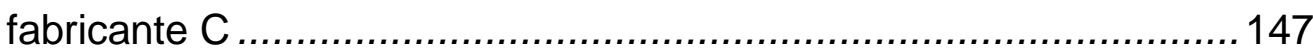

Figura 6.11 - Tela do oxímetro apresentando caracteres aleatórios ....................149

Figura 6.12 - Oxímetro de pulso - fabricante B ............................................150

Figura 6.13 - Ventilador pulmonar - fabricante B, modelo A.............................. 153

Figura 6.14 - Forma de onda da corrente com tensão senoidal.......................... 154

Figura 6.15 - Forma de onda da corrente com tensão distorcida .........................155

Figura 6.16 - Afundamentos de tensão do ensaio nำ5 .....................................156

Figura 6.17 - Afundamentos de tensão do ensaio no6 ….................................156

Figura 6.18 - Afundamento de $80 \%$ - 10 ciclos ........................................... 158

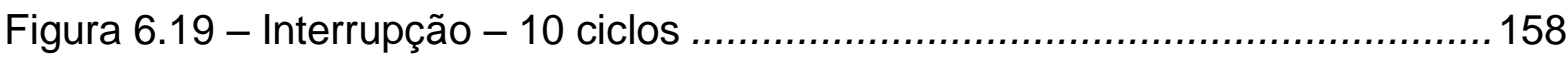

Figura 6.20 - Ventilador pulmonar - fabricante B, modelo B............................. 160

Figura 7.1 - Forma de atuação dos fusíveis limitadores .................................... 167

Figura 7.2 - Princípio de funcionamento da bobina de Petersen .........................173

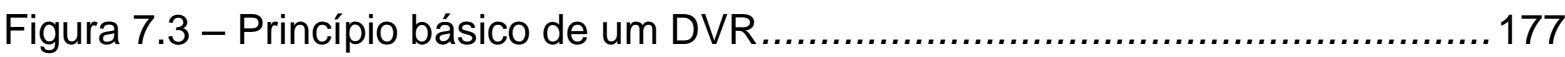

Figura 7.4 - Diagrama de blocos funcional de um DVR ...................................177

Figura 7.5 - Compensador dinâmico com armazenador cinético de energia .........181

Figura 7.6 - Transitório de corrente de um capacitor manobrado por contator ..... 182

Figura 7.7 - Transitório de tensão provocado pela manobra de um capacitor por meio de contator............................................................ 183

Figura 7.8 - Manobra de capacitor, sem e com resistências de amortecimento ... 183

Figura 7.9 - Redução do afundamento de tensão............................................ 184

Figura 7.10 - Afundamentos de tensão durante a partida direta de um motor de

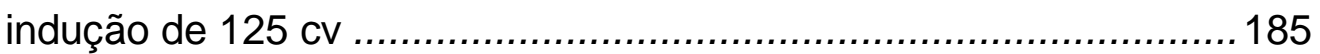

Figura 7.11 - Manobra de capacitores com dispositivo eletromecânico e com chave estática

Figura 7.12 - Sistema de retificação de 24 pulsos …..................................... 188

Figura 7.13 - Circuito de potência típico dos conversores de freqüência .............. 189

Figura 7.14 - Filtro passivo do tipo LC série .................................................192 
Figura 7.15 - Filtros passivos do tipo LC série e paralelo .................................. 192

Figura 7.16 - Configuração básica de um filtro ativo paralelo ............................. 194

Figura 7.17 - Configuração básica de um filtro ativo série .................................. 194

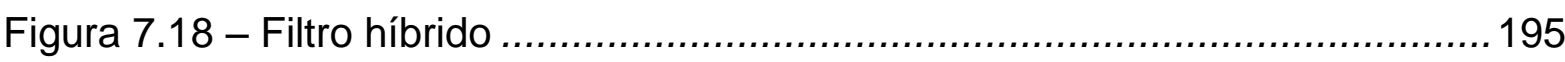

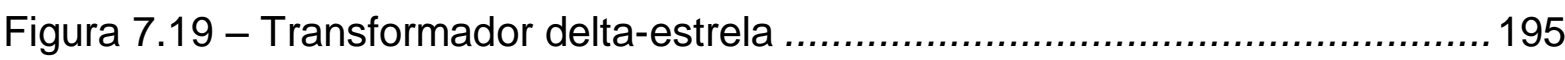

Figura 7.20 - Transformador com secundário em ligação ziguezague.................. 196

Figura 7.21 - Transformador com 2 enrolamentos secundários ..........................197

Figura A.1 - Tensão e corrente em uma carga linear ….................................225

Figura A.2 - Tensão e corrente em uma carga não linear ..................................226

Figura A.3 - Forma de onda distorcida e seus componentes harmônicos.............227

Figura A.4 - Forma de onda distorcida e seu respectivo espectro de



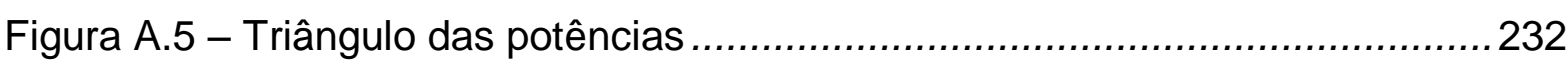

Figura A.6 - Relação entre as potências.................................................234

Figura A.7 - Relação entre o fator de distorção e a distorção harmônica total de

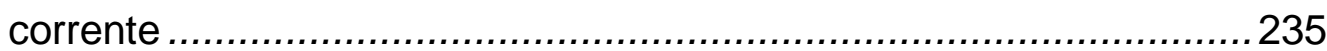

Figura B.1 - Analisador de qualidade de energia - Fluke modelo 43B ................240

Figura B.2 - Medidor de grandezas elétricas Smart Meter ................................242

Figura B.3 - Registrador Eletrônico - Mahr 21 ..............................................243

Figura B.4 - Equipamento instalado na Subestação de um EAS ........................244

Figura C.1 - Valores das componentes simétricas de seqüências, positiva, negativa e zero, obtidas por meio do simulador Vector ....................246

Figura D.1 - Variação da corrente, com a rotação e, no tempo, para uma partida

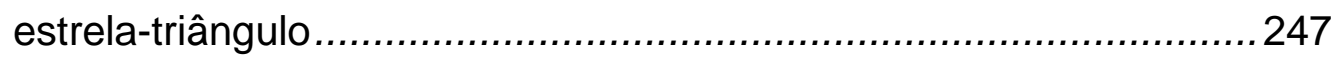

Figura D.2 - Partida estrela-triângulo com problemas de arranque .....................248

Figura D.3 - Variações da corrente com a rotação e com o tempo para uma partida

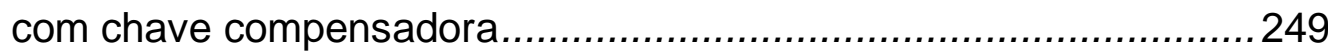

Figura D.4 - Configuração básica da unidade de potência do soft-starter ............251

Figura D.5 - Forma de onda da tensão gerada pelo soft-starter durante o

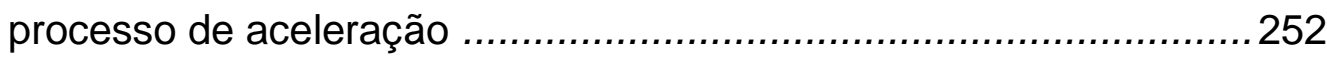

Figura D.6 - Curvas de partida com soft-starter - modo de rampa de tensão.......252

Figura D.7 - Curvas de partida com soft-starter - modo de limitação de corrente 


\section{LISTA DE TABELAS}

Tabela 1.1 - Afundamentos de tensão - Norma IEC 61000-4-11

Tabela 2.1 -Tensões secundárias (pu) durante ocorrência de falta fase-terra no primário de Transformadores.

Tabela 2.2 - Tempos de eliminação das faltas em função do tipo do dispositivo de proteção

Tabela 2.3 - Limites individuais e globais da distorção harmônica de tensão (em função da tensão fundamental)

Tabela 2.4 - Valores de referências globais das distorções harmônicas totais de tensão (em percentagem da tensão fundamental) - Prodist

Tabela 2.5 - Níveis de referência para distorções harmônicas individuais de tensão (em percentagem da tensão fundamental) - Prodist 50

Tabela 2.6 - Classificação dos equipamentos segundo a IEC 61000-3-2 ...............51

Tabela 2.7 - Valores limites para os harmônicos de corrente - IEC 61000-3-2 .....52

Tabela 2.8 - Limites da distorção harmônica individual de corrente em \% da fundamental IEC 61000-3-4

Tabela 2.9 - Limites da distorção harmônica total e individual de corrente em \% da fundamental - IEC 61000-3-4

Tabela 2.10 - Limites de distorção harmônica, de corrente (120 a 69 kV) IEEE Std 519

Tabela 2.11 - Limites de distorção harmônica de tensão no ponto de acoplamento comum - (IEEE Std 519)

Tabela 4.1 - Classificação do local em função do tipo do equipamento eletromédico - ABNT NBR 13534/2008

Tabela 4.2 - Classificação dos serviços de segurança para locais médicos ABNT NBR 13534/2008

Tabela 5.1 - Características operacionais potenciais causadoras de problemas de qualidade da energia elétrica. 134

Tabela 6.1 - Ensaios de harmônicos de tensão aplicados ao monitor multiparamétrico - fabricante $A$ 
Tabela 6.2 - Ensaios de afundamentos de tensão de curta duração aplicados ao monitor Multiparamétrico - fabricante A

Tabela 6.3 - Parâmetros monitorados

Tabela 6.4 - Afundamentos de tensão de curta duração aplicados ao monitor multiparamétrico - fabricante $B$

Tabela 6.5 - Afundamentos de tensão de curta duração recomendados pela Norma IEC 61000-4-11, aplicados ao monitor multiparamétrico fabricante $B$

Tabela 6.6 - Ensaios de harmônicos de tensão aplicados ao oxímetro de pulso fabricante $\mathrm{C}$

Tabela 6.7 - Ensaios de afundamentos de tensão de curta duração aplicados ao oxímetro de pulso - fabricante $\mathrm{C}$

Tabela 6.8 - Ensaio de afundamento de tensão conforme Norma IEC 61000-4-11 e que foram aplicados ao oxímetro de pulso - fabricante $C$

Tabela 6.9 - Afundamentos de tensão de curta duração aplicados ao oxímetro de pulso - fabricante $B$

Tabela 6.10 - Afundamentos de tensão de curta duração recomendados pela Norma IEC 61000-4-11 e que foram aplicados ao oxímetro de pulso - fabricante B 151

Tabela 6.11 - Ensaios com harmônicos de tensão aplicados ao ventilador pulmonar - fabricante $B$, modelo $A$

Tabela 6.12 - Ensaios de afundamentos de tensão de curta duração aplicados ao ventilador Pulmonar - fabricante $B$, modelo $A$ 155

Tabela 6.13 - Afundamentos de tensão de curta duração recomendados pela Norma IEC 61000-4-11 e que foram aplicados ao ventilador pulmonar - fabricante $B$, modelo $A$.

Tabela 7.1 - Comportamento dos sistemas de distribuição em função do aterramento do neutro

Tabela A.1 - Classificação dos harmônicos característicos 228

Tabela B.1 - Valores da tensão de pulso em função da categoria do instrumento de medição 239

Tabela B.2 - Especificações do Fluke 43B 241

Tabela D.1 - Comparação entre partida estrela-triângulo e compensadora 250 


\section{LISTA DE SIGLAS}

$\omega$

$\omega_{1}$

$\phi_{\mathrm{h}}$

$\Delta \mathrm{P}$

$\Delta \mathrm{V}$

V

$\cos \phi_{1}$

D

$E_{c}$

$f$

$f_{1}$

$\mathrm{F}_{\mathrm{C}(\mathrm{V}) ;(\mathrm{I})}$

$f_{h}$

FP

h

$H D_{(1)}$

$H D_{(V)}$

।

$\mathrm{l}_{1}$

$I_{c}$

$I_{h}$

$\mathrm{l}_{\mathrm{i}}$

$I_{m}$

$I_{n}$

$I_{\text {RP }}$

$\mathrm{Isc}_{\mathrm{sc}}$

velocidade angular

freqüência angular da fundamental

defasagem do harmônico de tensão ou de corrente, de ordem $\mathrm{h}$

variação de pressão

variação de volume

fator de distorção

fator de deslocamento

potência reativa de distorção

energia cinética armazenada

freqüência da rede elétrica

freqüência da fundamental

fator de crista da tensão ou da corrente, respectivamente

freqüência do harmônico de ordem $\mathrm{h}$

fator de potência

ordem do harmônico

distorção harmônica individual de corrente, em relação

à fundamental

distorção harmônica individual de tensão, em relação

à fundamental

corrente elétrica de entrada - valor eficaz

corrente fundamental

corrente de corte

harmônico de corrente de ordem $\mathrm{h}$

corrente de interrupção

corrente momentânea

corrente nominal

corrente de regime permanente

corrente de curto circuito máxima no ponto de acoplamento comum 


\begin{tabular}{|c|c|}
\hline $\mathrm{J}$ & momento de inércia \\
\hline $\mathrm{k}$ & números inteiros $(1,2,3 \ldots)$ \\
\hline $\mathrm{K}_{\text {fact }}$ & fator de desclassificação \\
\hline $\mathrm{P}$ & potência ativa \\
\hline $\mathrm{p}$ & número de pulsos do conversor \\
\hline $\mathrm{pu}$ & valor por unidade \\
\hline$Q$ & potência reativa \\
\hline $\mathrm{R}$ & resistência elétrica \\
\hline S & potência aparente \\
\hline $\mathrm{t}$ & tempo \\
\hline $\mathrm{t}_{\mathrm{a}}$ & tempo de arco \\
\hline $\mathrm{THD}_{(\mathrm{l})}$ ou $\mathrm{THD}_{\mathrm{f}(\mathrm{l})}$ & $\begin{array}{l}\text { distorção harmônica total de corrente, em função } \\
\text { da fundamental }\end{array}$ \\
\hline $\operatorname{THD}_{\mathrm{r}(1)}$ & $\begin{array}{l}\text { distorção harmônica total de corrente, em função da } \\
\text { resultante }\end{array}$ \\
\hline $\mathrm{THD}_{(\mathrm{V})}$ & $\begin{array}{l}\text { distorção harmônica total de tensão, em função da } \\
\text { fundamental }\end{array}$ \\
\hline$t_{f}$ & tempo de fusão \\
\hline$t_{i}$ & tempo de interrupção \\
\hline V & tensão \\
\hline $\mathrm{V}_{\mathrm{h}}$ & harmônico de tensão de ordem $\mathrm{h}$ \\
\hline $\mathrm{V}_{\mathrm{n}}$ & tensão nominal \\
\hline$x_{s}$ & reatância equivalente da fonte \\
\hline$x_{t}$ & reatância de curto circuito do transformador \\
\hline$Y_{1(V) ;(1)}$ & $\begin{array}{l}\text { valor eficaz da tensão ou da corrente fundamental, } \\
\text { respectivamente }\end{array}$ \\
\hline $\mathrm{Y}_{\mathrm{h}}$ & $\begin{array}{l}\text { valor eficaz do componente harmônico de tensão ou de } \\
\text { corrente, de ordem } \mathrm{h}\end{array}$ \\
\hline $\mathrm{Y}_{\mathrm{M}(\mathrm{V}) ;(\mathrm{I})}$ & valor máxima da tensão ou da corrente, respectivamente \\
\hline$Y_{0}$ & $\begin{array}{l}\text { valor eficaz do componente de tensão ou de corrente, } \\
\text { contínua }\end{array}$ \\
\hline
\end{tabular}




\section{LISTA DE ABREVIATURAS}

AAMI

ABNT

ANEEL

ANSI

ANVISA

CBEMA

CPFL

CENELEC

CIGRÉ

DIN

DVR

EAS

EDF

EN

EPRI

IEC

IEEE

INMETRO

ISO

ITIC

MTE

ONS

PWM

SMES

SUS

UPS

UTI

Association for the Advancement of Medical Instrumentation Associação Brasileira de Normas Técnicas Agência Nacional de Energia Elétrica American National Standard Institute Agência Nacional de Vigilância Sanitária Computer and Business Equipment Manufacturers Companhia Paulista de Força e Luz European Communittee for Electrotechnical Standardization Conférence Internationale des Grands Réseaux Életriques Deutsches Institut für Normung Dynamic Voltage Restorer Estabelecimentos Assistenciais de Saúde Electricité de France Europäische Norm. Electric Power Research Institute International Electrotechnical Comission Institute of Electrical and Electronics Engineers Instituto Nacional de Metrologia, Normalização e Qualidade Industrial International Organization for Standardization Informations Technology Industry Council Ministério do Trabalho e Emprego Operador Nacional do Sistema Elétrico Pulse Width Modulation Superconducting Magnetic Energy Storage Serviço Único da Saúde Uninterruptable Power Supply Unidade de Terapia Intensiva 


\section{SUMÁRIO}

1 INTRODUÇÃO 23

1.1 A UTILIZAÇÃO DA ELETRICIDADE NOS ESTABELECIMENTOS

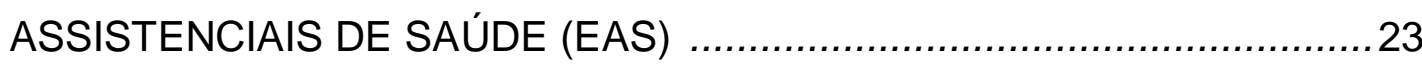

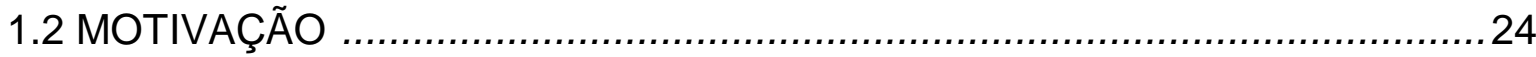

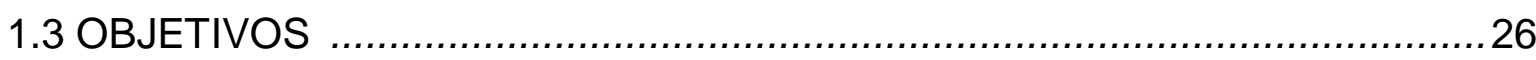

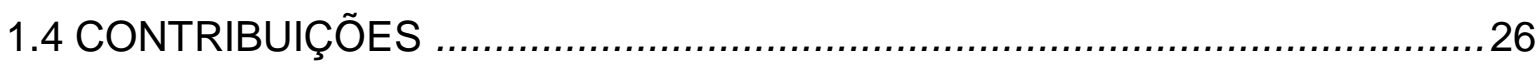



1.6 EQUIPAMENTOS DISPONÍVEIS E TESTES REALIZADOS ........................29

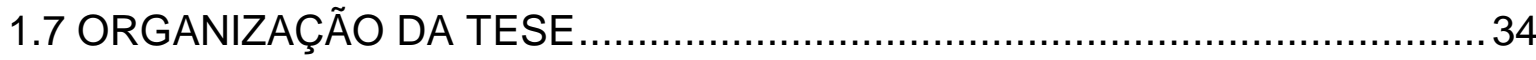

2 AS CONCESSIONÁRIAS E A QUALIDADE DE ENERGIA



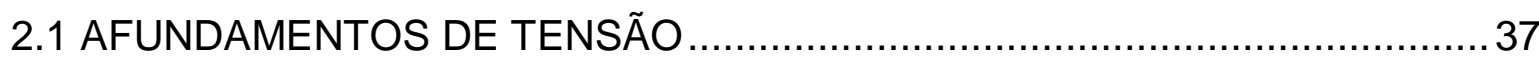

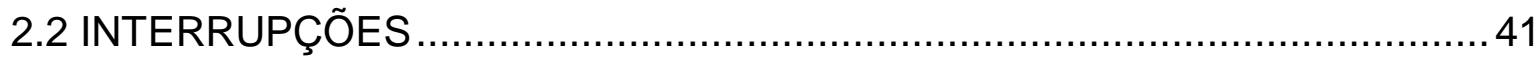

2.3 SOBRETENSÕES TRANSITÓRIAS .................................................... 43

2.4 A SENSIBILIDADE DOS EQUIPAMENTOS ÀS VARIAÇÕES DE

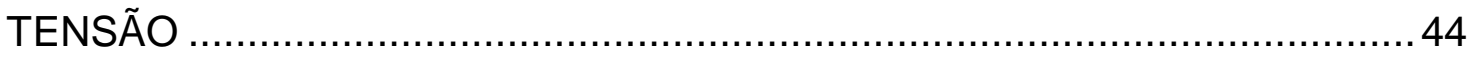

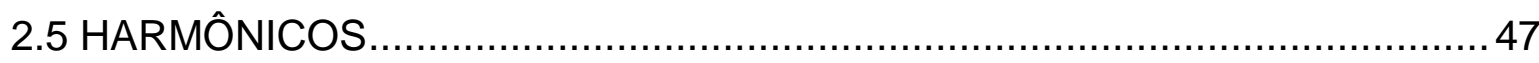



3 A QUALIDADE DE ENERGIA E DAS INSTALAÇÕES ELÉTRICAS NOS ESTABELECIMENTOS ASSISTENCIAIS DE SAÚDE

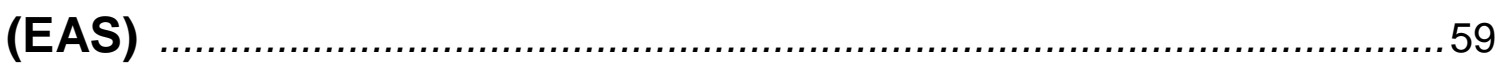

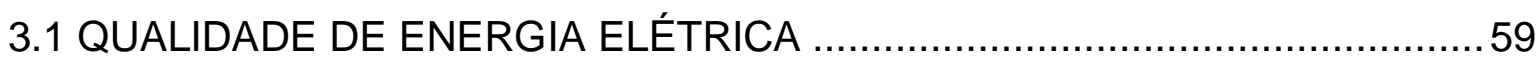

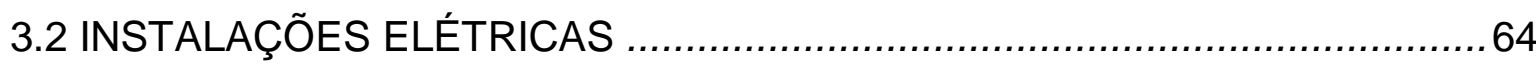

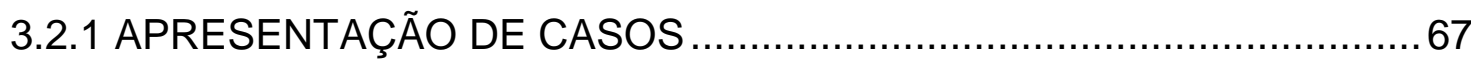


3.2.1.1 Hospital Público $A$ 68

3.2.1.2 Hospital Público B ................................................................. 71

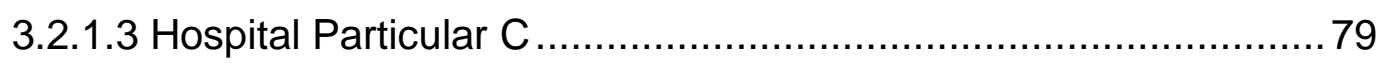

3.3 O ATENDIMENTO DOMICILIAR À SAÚDE: A MAIS NOVA

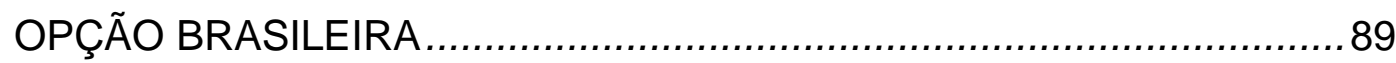

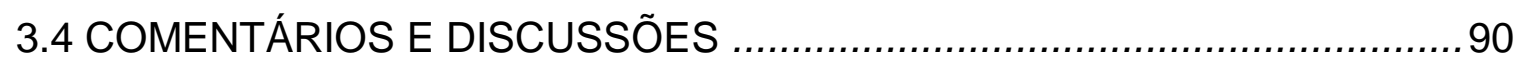

4 NORMAS TÉCNICAS APLICÁVEIS A ESTABELECIMENTOS ASSISTENCIAIS DE SAÚDE (EAS) E A EQUIPAMENTOS ELETROMÉDICOS. 92

4.1 NORMAS DE INSTALAÇÕES ELÉTRICAS ............................................92

4.2 NORMAS DE EQUIPAMENTOS ELETROMÉDICOS …...........................97

4.2.1 A Evolução da Normalização no Brasil .........................................97

4.2.2 Normas Específicas para Ventiladores Pulmonares ....................... 102

4.2.3 Normas Específicas para Equipamentos de Monitorização





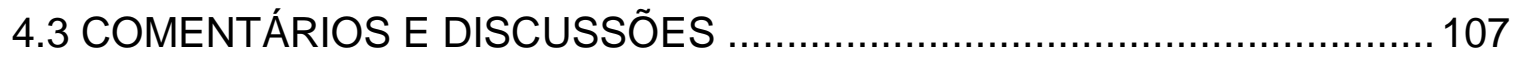

5 PRINCIPAIS CARGAS POLUIDORAS UTILIZADAS NOS

ESTABELECIMENTOS ASSISTENCIAIS DE SAÚDE (EAS) .........109

5.1 RAIOS X

5.2 MAMOGRAFIA

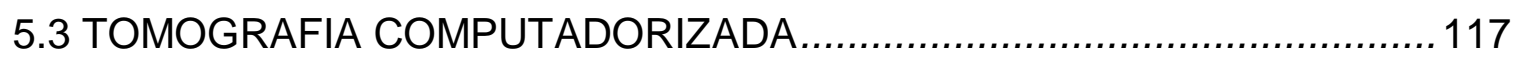

5.4 RESSONÂNCIA MAGNÉTICA NUCLEAR ............................................. 120

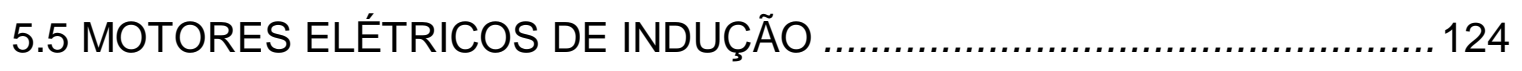

5.6 COMPARAÇÃO ENTRE OS EQUIPAMENTOS ANALISADOS .................133




6.1 MONITOR MULTIPARAMÉTRICO - FABRICANTE A ............................137

6.2 MONITOR MULTIPARAMÉTRICO - FABRICANTE B ............................144

6.3 OXÍMETRO DE PULSO - FABRICANTE C ..........................................146

6.4 OXÍMETRO DE PULSO - FABRICANTE B ........................................... 150

6.5 VENTILADOR PULMONAR - FABRICANTE B - MODELO A ..................152

6.6 VENTILADOR PULMONAR - FABRICANTE B - MODELO B ..................159

6.7 COMENTÁRIOS E DISCUSSÕES ......................................................... 161

\section{MEIOS DE ELIMINAÇÃO OU MINIMIZAÇÃO DAS PERTURBAÇÕES

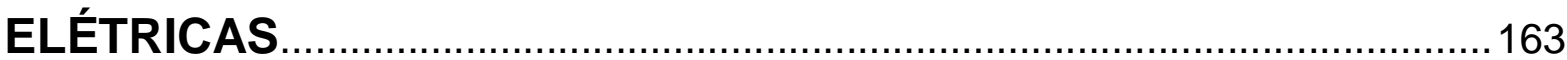

\subsection{AFUNDAMENTOS OU INTERRUPÇÕES DE TENSÃO DE CURTA}



7.1.1 Possíveis causas dos afundamentos de tensão de curta duração ....165



7.1.2.1 Redução da possibilidade de curto-circuito ............................166

7.1.2.2 Redução do tempo de supressão do evento ..........................167



7.1.2.4 Fornecimento de energia elétrica de alta qualidade ............... 168

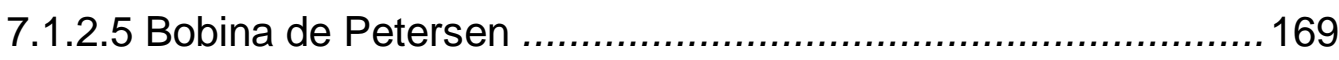

7.1.2.6 Redução da corrente de partida de motores de indução trifásicos

7.1.2.7 Conexão de equipamentos atenuadores entre os equipamentos sensíveis e a rede de alimentação 174

7.1.2.8 Sistemas de compensação de energia reativa em tempo

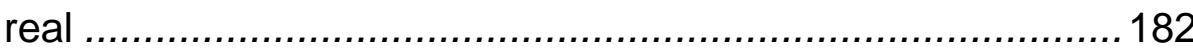

7.1.2.9 Aperfeiçoamento da imunidade dos equipamentos ................186

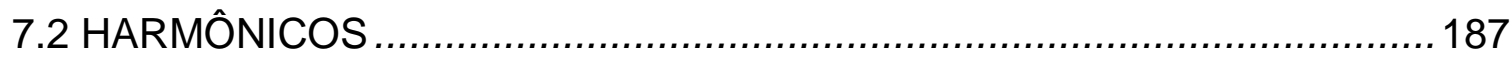

7.2.1 Possíveis causas de harmônicos de corrente ……........................... 187

7.2.2 Meios de eliminação ou minimização ..............................................189 
7.2.2.1 Filtros Passivos 191

7.2.2.2 Filtros Ativos 193

7.2.2.3 Transformadores com ligações especiais 195

8 CONCLUSÕES 198

8.1 A QUALIDADE DA ENERGIA ELÉTRICA NOS ESTABELECIMENTOS

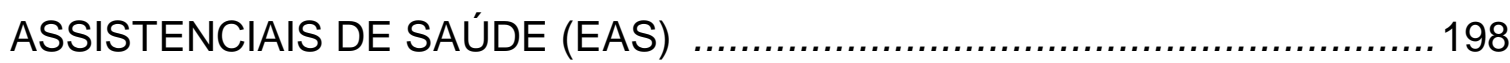

8.2 INSTALAÇÕES ELÉTRICAS DOS ESTABELECIMENTOS ASSISTENCIAIS

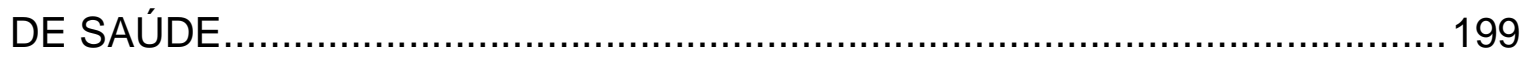

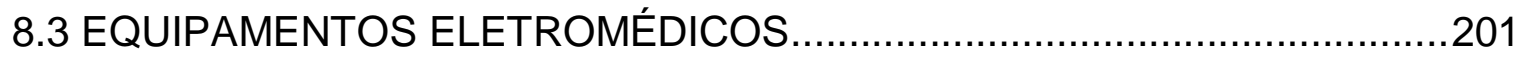

8.4 RELIGAMENTO DE CIRCUITOS DE DISTRIBUIÇÃO ............................203

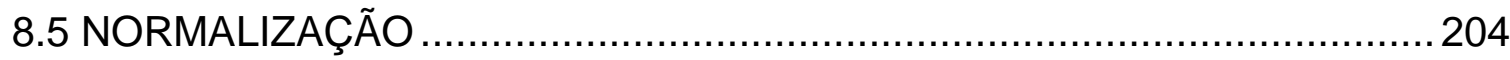



8.7 HOME CARE

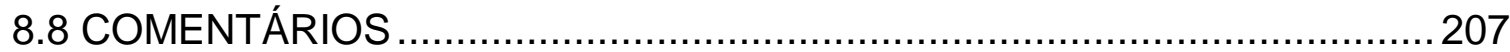

8.8.1 Literatura Técnica a Respeito do Assunto ........................................207

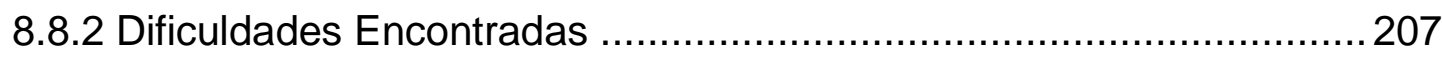





ANEXOS:

ANEXO A - CONCEITOS SOBRE HARMÔNICOS.................................................225



ANEXO C - DETERMINAÇÃO DO GRAU DE DESEQUILÍBRIO DE TENSÃO PELO MÉTODO DAS COMPONENTES SIMÉTRICAS ....................245

ANEXO D - MÉTODOS DE PARTIDA A TENSÃO REDUZIDA PARA MOTORES DE INDUÇÃO COM ROTOR EM GAIOLA 


\section{INTRODUÇÃO}

\subsection{A UTILIZAÇÃO DA ELETRICIDADE NOS ESTABELECIMENTOS ASSISTENCIAIS DE SAÚDE (EAS)}

O avanço da tecnologia e o desenvolvimento da medicina nos dias atuais vêm trazendo grandes benefícios à saúde humana em todo o mundo. Novos processos de diagnóstico médico e modernas técnicas cirúrgicas utilizam, cada vez mais, equipamentos de última geração, projetados e construídos com avançadas tecnologias eletrônicas e controlados por microprocessadores.

Para que seja autorizada a sua comercialização, esses equipamentos devem ser registrados na Anvisa - Agência Nacional de Vigilância Sanitária, após comprovação do atendimento às especificações das normas técnicas nacionais e internacionais pertinentes.

Outro fator que deve ser considerado, para garantir a segurança dos pacientes e a confiabilidade dos resultados, é a qualificação técnica dos usuários de equipamentos eletromédicos, bem como da equipe responsável pela assistência técnica desses equipamentos.

No entanto, o sucesso global do processo deverá incluir a qualidade das instalações elétricas em ambientes médico-hospitalares, assim como a qualidade da energia elétrica fornecida a esses equipamentos.

No caso de energia elétrica, pode-se definir a sua qualidade em função de possíveis perturbações elétricas que podem ocorrer na amplitude ou na freqüência do sinal, além dos desequilíbrios entre fases e as distorções harmônicas, as quais podem interferir na forma de onda de tensão ou corrente (MIGUEL; MEDINA; ANTÓN, 2007; DOUGHERTY; STEBBINS, 1997).

Sob o ponto de vista do nível de qualidade da energia elétrica fornecida pelo sistema da concessionária é muito importante, na rede elétrica de alimentação dos equipamentos eletromédicos, a ausência dessas perturbações na tensão e particularmente, a ausência de desligamentos (ALVES, 1996; SERSEN; VORSIC, 2008). 
Para o consumidor comum, o termo qualidade de energia elétrica é, na maioria das vezes, relacionado à ausência relativa de variações de amplitude de tensão medidas no ponto de entrega de energia.

$\mathrm{Na}$ grande maioria dos casos, as perturbações são provocadas pelos próprios consumidores ou seus vizinhos, como conseqüência da utilização de equipamentos denominados de "tecnologia moderna", implementados com circuitos retificadores ou que possuam componentes não-lineares com a tensão.

A partir da década de 90 , a crescente utilização desses equipamentos em todos os segmentos da sociedade agravou a situação sob o ponto de vista de qualidade de energia elétrica.

$O$ ideal seria que os equipamentos eletromédicos fossem alimentados por uma rede elétrica de alta qualidade para seu correto funcionamento, no entanto, como também são causadores de perturbações, poderão apresentar falhas (BOLLINGER, 1991; COPPER, 2008).

\subsection{MOTIVAÇÃO}

Por mais de trinta anos, atuando como engenheiro industrial, o autor percebeu a preocupação com a perda de produção nos processos automatizados, ocasionada pela interrupção da energia elétrica e, atualmente, também pela presença de perturbações existentes nas redes elétricas de suprimento de energia, fenômeno conhecido como Interferências Eletromagnéticas (IEM) conduzidas.

Grandes investimentos sempre foram direcionados para minimização desses efeitos, tanto por parte do próprio consumidor, quanto pelas concessionárias de energia elétrica.

Seu primeiro contato com instalações da área de saúde ocorreu em 1996, quando foi contratado para participar de um projeto de atualização das instalações de um Hospital Universitário que deveria atender às exigências da NBR 13534 Instalações Elétricas em EAS, publicada em 1995.

Realizando cursos de especialização sobre o assunto e por meio de inúmeras visitas a EAS que se encontravam em funcionamento, o autor observou que as instalações elétricas nesses estabelecimentos não eram projetadas nem mantidas com a mesma qualidade e preocupação que as das atividades industriais. 
Comparando as duas, poder-se-ia até concluir que a vida humana parecia não ser tão importante quanto à perda de faturamento, provocada pela paralisação da produção.

Se essa questão for analisada no contexto atual, parece que nada melhorou e os problemas têm se intensificado gradativamente. A área de saúde no Brasil encontrase com unidades bem mais degradadas, principalmente no quesito das instalações elétricas.

Como conseqüência, um número considerável de óbitos em pacientes poderiam estar ocorrendo em função dos problemas que serão apresentados neste estudo.

Além disso, torna-se pertinente destacar que muitas falhas, denominadas como "erros médicos", podem ter sido atribuídas erroneamente a profissionais da área de saúde, em função do desconhecimento de tais problemas ligados às instalações elétricas, entre os quais se destaca: qualidade de energia, não observação de normas técnicas, manobras de circuitos das concessionárias, além de outros problemas.

Em 2004, quando foi iniciado este trabalho, as normas brasileiras sobre equipamentos eletromédicos não mencionavam ensaios envolvendo perturbações da rede elétrica, fato que ocorreu somente em setembro de 2006, com a adoção da Norma ABNT NBR IEC 60601-1-2 (2006).

No entanto, atualmente alguns fabricantes ainda alegam dificuldades para a realização dos ensaios, em função de custos e disponibilidade de laboratórios certificados (MARRONI, 2007)

A idéia de analisar a influência da qualidade da energia em equipamentos eletromédicos foi apresentada a um grupo de professores da Escola Politécnica da Universidade de São Paulo, que de imediato achou ser muito importante o desenvolvimento deste trabalho.

Para colaborar para a realização desta investigação, foi colocado à disposição do autor o Enerq-ct - Laboratório de Qualidade de Energia Elétrica da Escola Politécnica da Universidade de São Paulo e, além disso, vários fabricantes nacionais cederam seus equipamentos eletromédicos, o que contribuiu para esta idéia tornarse uma realidade. 


\subsection{OBJETIVOS}

A partir de testes realizados em laboratório, este trabalho tem como objetivo demonstrar que equipamentos eletromédicos, utilizados nos procedimentos médicos nos EAS, podem apresentar dados incorretos ou terem seu funcionamento totalmente interrompido em função de perturbações elétricas na rede de alimentação. Além disso, as precárias condições das instalações elétricas nesses ambientes, podem causar perturbações similares ou eventualmente mais severas do que as avaliadas.

No Brasil, observa-se que a questão da saúde se agrava cada vez mais, principalmente pela necessidade de grandes investimentos, ao mesmo tempo em que se verifica a inobservância das normas vigentes sobre o assunto.

Diante desse quadro, o paciente é o maior prejudicado, cuja sobrevivência pode depender das informações fornecidas por estes aparelhos ou de seu correto funcionamento.

Trata-se, portanto, de uma contribuição para a área de saúde, pois, com os resultados desta investigação, os fabricantes poderão melhorar o desempenho de seus equipamentos eletromédicos.

Da mesma forma, instaladores e mantenedores de EAS terão conhecimento dos riscos provocados por instalações elétricas improvisadas ou em total desacordo com as normas técnicas vigentes. Por outro lado, as concessionárias de energia elétrica terão melhor conhecimento dos problemas ocasionados pela falta de qualidade da energia elétrica, fornecida aos consumidores da área de saúde.

Poder-se-ia também, incluir o governo, que por meio de suas agências e órgãos de fiscalização aumentaria a arrecadação pela aplicação de multas por não conformidades e exposição da vida humana a riscos, em desacordo com os direitos fundamentais.

\subsection{CONTRIBUIÇÕES}

Pretende-se com este trabalho, apresentar as seguintes contribuições:

a) Mostrar, por intermédio de fotos e comentários, as precárias condições que se encontram alguns EAS da Grande São Paulo. Estima-se que este problema se 
estende por todo o País, seja por falta de investimentos ou negligência pela não obediência às normas técnicas pertinentes ou ainda, em alguns casos, pela falta de conhecimento técnico.

b) Apresentar fatos que comprovem a necessidade de implementação de programas de qualidade de energia e manutenção preventiva nas instalações elétricas dos EAS, em função da grande quantidade de equipamentos sensíveis que vêm sendo instalados nesses ambientes.

c) Apresentar fatos que podem servir de suporte para a atualização de normas técnicas, sejam elas relacionadas a equipamentos eletromédicos ou às instalações elétricas dos ambientes onde são instalados.

d) Contribuir com os fabricantes de equipamentos eletromédicos na procura de soluções que reduzam a sensibilidade às perturbações da rede elétrica, dos tipos: afundamentos e interrupções de tensão de curta duração e tensões com conteúdo harmônico.

e) Apresentar uma metodologia de ensaios para equipamentos eletromédicos que utilizem perturbações semelhantes às existentes nas redes das concessionárias fornecedoras de energia elétrica, ou aquelas produzidas internamente aos EAS.

f) Apresentar, às concessionárias, fatos que possam justificar investimentos na melhoria da qualidade da energia elétrica fornecida aos EAS.

\subsection{METODOLOGIA}

A metodologia aplicada neste estudo consistiu em quatro partes bastante distintas, mas relacionadas entre elas, as quais podem ser enumeradas:

1. pesquisa bibliográfica;

2. medições das perturbações elétricas existentes nos EAS;

3. aquisição ou empréstimo de equipamentos eletromédicos;

4. ensaios em laboratório especializado em qualidade de energia elétrica.

Inicialmente, efetuou-se uma pesquisa bibliográfica sobre o assunto proposto, incluindo livros e artigos técnicos apresentados em congressos ou publicados na literatura internacional. 
Desde o início, percebeu-se a escassez de informações técnicas relacionadas às instalações elétricas e à qualidade de energia nos EAS, o que possivelmente pode estar relacionado à despreocupação sobre essas duas questões.

No entanto, na área industrial, uma grande quantidade de informações foi encontrada, o que comprova o maior interesse na publicação de informações direcionadas a esse setor. Como exemplo, pode-se citar a série de livros publicados pelo IEEE, denominados de Color Books, focados para diferentes aspectos dos sistemas elétricos de potência.

Dos doze volumes encontrados, onze são dirigidos às atividades industriais e comerciais, sendo que, apenas um deles, o White Book, apresenta recomendações práticas para projeto e operação de EAS (IEEE Std. 602, 2007).

As principais publicações relacionadas à qualidade de energia, apresentadas nas referências bibliográficas, pouco ou nada mencionam sobre instalações hospitalares e similares.

O trabalho realizado em campo consistiu em medições dos parâmetros referentes à qualidade de energia elétrica, em vários estabelecimentos assistenciais de saúde, tanto do setor público quanto do privado.

Para os testes nos equipamentos, optou-se pela escolha de dois tipos de perturbações, os harmônicos e os afundamentos e interrupções de tensão de curta duração, classificadas como IEM (Interferências Eletromagnéticas) de baixa freqüência, que se deslocam pelas redes elétricas e, portanto, são denominadas de conduzidas. A escolha por essas perturbações deve-se ao fato de que elas não danificam os equipamentos, o que as difere de muitas outras como: sobretensões, surtos, etc.

Devido a esse motivo, sobretensões, flutuações e outros fenômenos que pudessem provocar danificação total ou parcial dos equipamentos ensaiados não foram considerados.

É importante destacar que a preocupação em estudar essas IEM, conduzidas pela rede elétrica, ocorreu pelo fato de se encontrarem poucos trabalhos relacionados a essas interferências, se comparados aos estudos desenvolvidos sobre as irradiadas. Atenção especial foi dada aos equipamentos típicos desses ambientes e passíveis de provocarem essas perturbações e que estão apresentados no capítulo 5.

Em seguida, as perturbações foram reproduzidas em fontes de tensão específicas para essa finalidade, instaladas no Enerq-ct. 
Equipamentos eletromédicos portáteis, gentilmente cedidos por diversos fabricantes nacionais, foram submetidos a essas perturbações para verificação do seu desempenho.

Alguns fabricantes mostraram-se entusiasmados em conhecer o desempenho de seus equipamentos quando submetidos às perturbações que até setembro de 2006 ainda não eram exigidas pelas normas específicas a que deviam atender.

Os que concordaram solicitaram, por intermédio de um "termo de compromisso", que suas identidades não fossem divulgadas e que os resultados fossem enviados ao departamento de engenharia ou desenvolvimento de produto.

Em todos os casos, foram efetuados treinamentos sobre a operação correta desses equipamentos. No entanto, outros fabricantes ignoraram o pedido de empréstimo, alegando que não se interessaram pelo estudo.

Alguns ensaios, como o de afundamentos de tensão de curta duração, foram complementados pelas recomendações da Norma IEC 61000-4-11 (2000).

\subsection{EQUIPAMENTOS DISPONÍVEIS E TESTES REALIZADOS}

Formas de onda distorcidas, contendo harmônicos, foram geradas com uma fonte de fabricação Pacific Power Source modelo 390 AMX com potência de saída igual a 9 kVA. Está equipada com um controlador UMC-31 trifásico, capaz de gerar freqüências entre 45 a $500 \mathrm{~Hz}$. Uma vez fixadas as grandezas, possui operação estável, com precisão de $0,5 \%$ dos valores estabelecidos. A figura 1.1 apresenta uma foto da referida fonte, instalada no Enerq-ct.

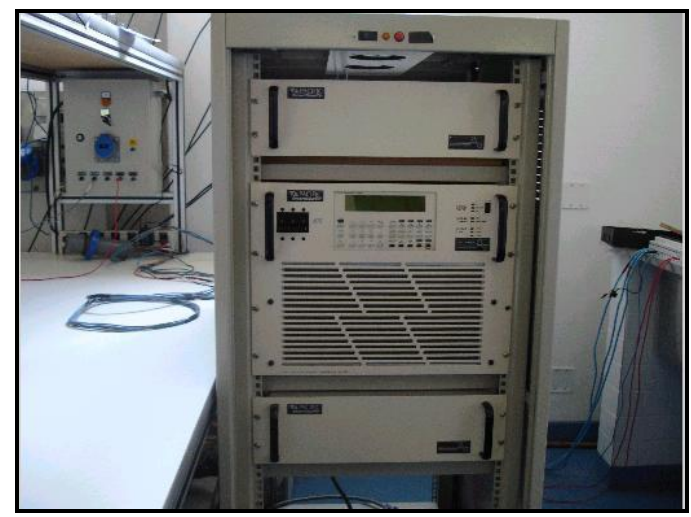

Figura 1.1 - Fonte de tensão Pacific

Fonte: Enerq, 2005 (Equipamento fotografado pelo autor). 
Os afundamentos de tensão de curta duração foram produzidos por uma fonte específica, denominada de Porto-Sag, modelo PS50-3P, de fabricação da EPRIPEAC Corporation, empresa conhecida mundialmente como especialista em testes com afundamentos de tensão em equipamentos de processos totalmente automatizados.

A fonte utilizada tem como principais características a tensão de alimentação entre 90 a 264 VAC e detecção automática de 50 e $60 \mathrm{~Hz}$. Ela é trifásica e possui capacidade para testes de equipamentos com corrente nominal de até $50 \mathrm{~A}$.

O valor da máxima tensão de teste é de $277 \mathrm{~V}$ entre fase e neutro. A duração dos afundamentos de tensão de curta duração que podem ser gerados é de 4 ms até 3 s. A figura 1.2 apresenta a foto dessa fonte.

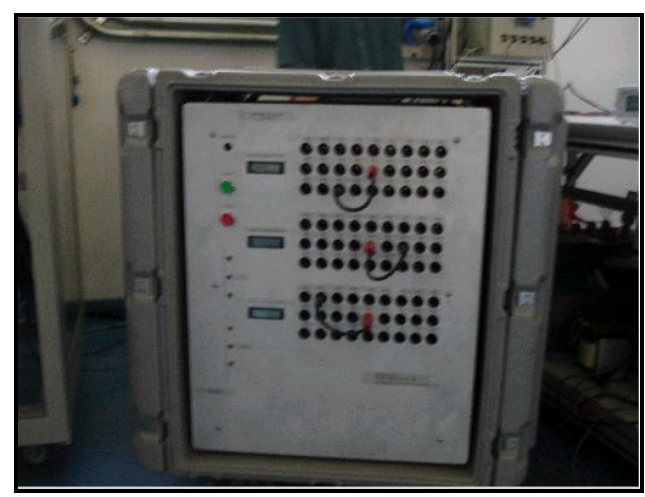

Figura 1.2 - Fonte de tensão Porto-Sag

Fonte: Enerq, 2005 (Equipamento fotografado pelo autor).

Desde 1994, a EPRI vem desenvolvendo testes de imunidade a afundamentos de tensão em mais de uma centena de processos, máquinas-ferramentas e dispositivos específicos em automação.

As medições monofásicas foram efetuadas com um Analisador de Qualidade de Energia Fluke 43 B, adquirido especialmente para essa finalidade.

As trifásicas foram efetuadas com um medidor de grandezas elétricas com memória, denominado de SMART METER, de fabricação IMS, indústria de micro-sistemas eletrônicos.

Os afundamentos de tensão foram gravados com um registrador eletrônico MARH 21, de fabricação RMS, indústria de equipamentos eletrônicos. No Enerq-ct, também foram utilizados vários instrumentos de precisão como, por exemplo, osciloscópio Tektronix TD 1002. 
As características técnicas dos equipamentos utilizados encontram-se no Anexo B. Em todos os casos, os equipamentos foram alimentados com sua tensão de placa, igual a $110 \mathrm{~V}$. Estes três grupos de ensaios foram aplicados aos equipamentos eletromédicos:

1ํ grupo: Tensões de alimentação com conteúdo harmônico:

Os seis equipamentos testados foram alimentados com tensões distorcidas em função do conteúdo harmônico.

As ordens harmônicas de interesse foram a $3^{\mathrm{a}}, 5^{\underline{a}}$ e $7^{\underline{a}}$, pois se mostraram, nas medições de campo, possuírem maior predominância.

O valor da distorção harmônica de tensão foi gradativamente aumentado, para verificar o comportamento do equipamento eletromédico, quando submetido a situações bem mais críticas que as encontradas nesses ambientes.

2o Grupo: Afundamentos de tensão de curta duração, típicos dos EAS:

Por meio de inúmeras medições realizadas em equipamentos de raios $X$, mamografia, tomografia computadorizada, ressonância magnética nuclear e outros, pode-se conhecer o funcionamento desses equipamentos e, conseqüentemente, as perturbações que causam à rede elétrica.

Embora possuam princípios de funcionamento diferentes, provocam o mesmo tipo de perturbação: afundamentos de tensão de curta duração. $O$ valor do afundamento produzido depende da potência de curto-circuito da rede, no local onde o equipamento estiver instalado.

A maioria desses equipamentos, como se pode observar pelos picos de corrente produzidos e que estão apresentados no capítulo 5 , apresenta dois modos de operação bastante distintos: contínuo (stand-by) e o momentâneo.

No modo contínuo, o valor da potência envolvida é bastante reduzido em relação ao modo momentâneo, que ocorre durante o disparo da radiação ou, a aquisição de dados para a obtenção da imagem.

Normalmente, os picos de corrente gerados não ultrapassam 3 ou 4 segundos, e apresentam-se espaçados em função da quantidade de radiografias necessárias e realizadas seqüencialmente. 
Esses equipamentos devem ser alimentados por transformadores exclusivos e dimensionados para a sua potência máxima, permanecendo ocioso durante a maior parte do tempo (SANTANA, 1999).

Para simular essas situações, foram gerados e aplicados aos equipamentos eletromédicos afundamentos de tensão de curta duração de 0,1 pu, até a interrupção. A figura 1.3 apresenta uma seqüência desses eventos, com duração unitária de 3 segundos, com espaçamento de 1 minuto entre eles:

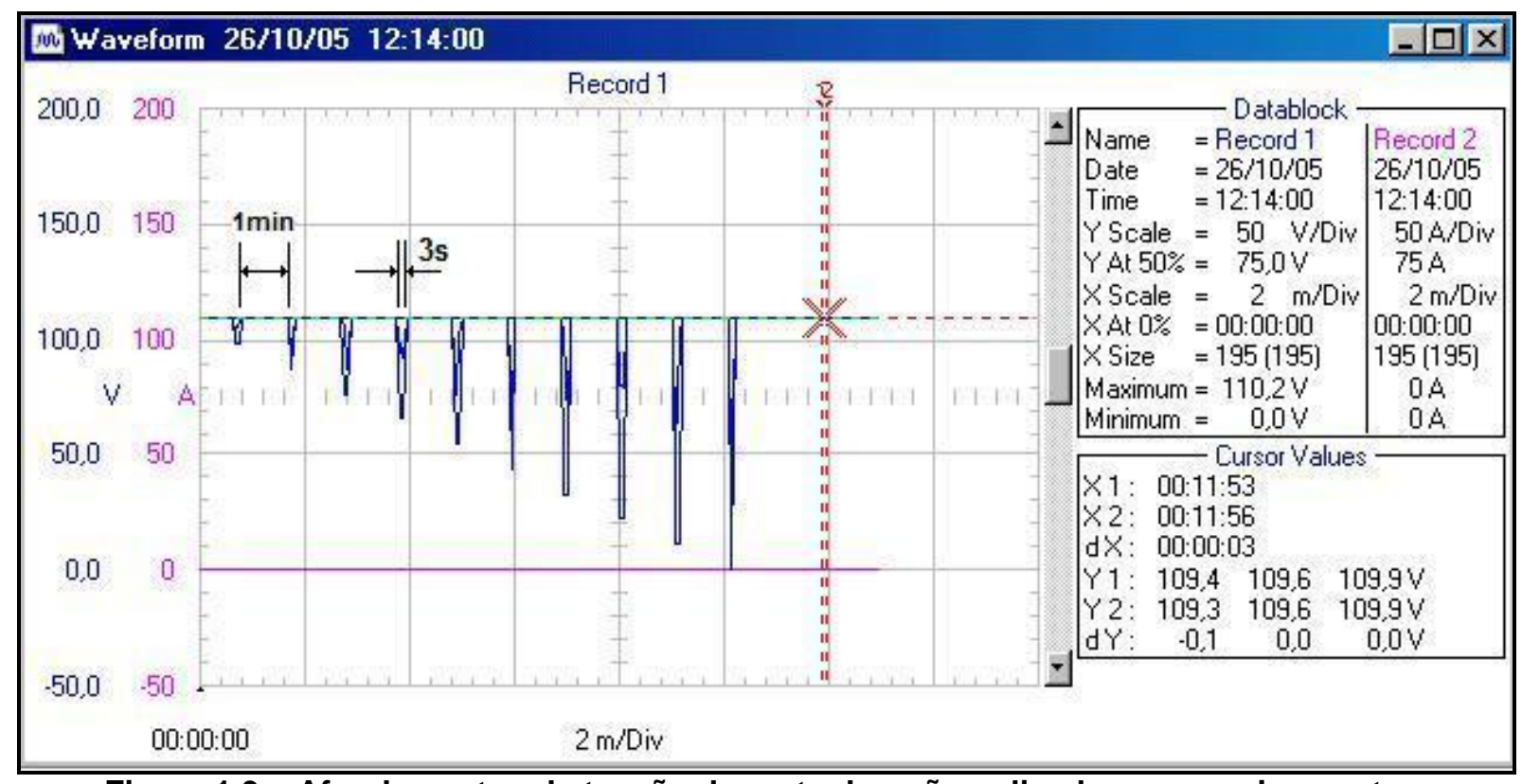

Figura 1.3 - Afundamentos de tensão de curta duração aplicados aos equipamentos eletromédicos

Fonte: Elaborada pelo autor.

Em grande parte dos casos observados, durante a operação do equipamento, produz-se um afundamento de tensão que pode provocar funcionamento irregular em outros equipamentos eletromédicos.

Muitas vezes, equipamentos de raios $X$ são deslocados para as Unidades de Terapia Intensiva e ligados a sistemas de alimentação incompatíveis com a potência do equipamento.

É notório que, se o afundamento de tensão superar valores de $10 \%$ da tensão nominal (HEINTEL; CREDICO, 1997), os equipamentos causadores serão as próprias vítimas, pois a vida útil do equipamento será reduzida além da obtenção de radiografias ou imagens deficientes (HARVEY et al., 1997). 
3o Grupo: Afundamentos e interrupções de tensão de curta duração, conforme IEC 61000-4-11 (2000):

A referida norma recomenda a aplicação de afundamentos de tensão de curta duração, de $30 \%$ e $60 \%$ da tensão nominal $\left(V_{n}\right)$, além da interrupção.

Os tempos de duração de cada evento são de 0,5 ciclo (4,33 ms) a 180 ciclos ( $3 \mathrm{~s}$ ). Para a duração de 0,5 ciclo, o início do evento deve ser verificado para $0^{\circ}$ e $180^{\circ}$. Para melhor verificação do comportamento dos equipamentos eletromédicos, foram incluídos afundamentos de $20 \%$ e $80 \%$ da tensão nominal.

Em todos os casos, os ângulos iniciais considerados foram de $0^{\circ}$ a $315^{\circ}$, em intervalos e 45․ A tabela 1.1 apresenta os afundamentos e os tempos de duração utilizados.

Tabela 1.1 - Afundamentos de tensão - Norma IEC 61000-4-11

\begin{tabular}{|c|c|c|}
\hline $\begin{array}{c}\text { Nível de tensão } \\
\text { remanescente }-\% \mathrm{~V}_{\mathrm{n}}\end{array}$ & $\begin{array}{c}\text { Tensão de } \\
\text { afundamento ou } \\
\text { interrupção-\% } \mathrm{V}_{\mathrm{n}}\end{array}$ & Duração-(ciclos) \\
\hline $80\left(^{*}\right)$ & $20\left(^{*}\right)$ & 0,5 \\
1 \\
570 & 30 & 5 \\
10 \\
\hline 40 & 60 & 25 \\
\hline $20\left(^{*}\right)$ & $80\left(^{*}\right)$ & 180 \\
\hline 0 & 100 & 100 \\
\hline
\end{tabular}

(*) - valores incluídos nos ensaios

Fonte: Norma IEC 61000-4-11, 2000 (adaptação do autor).

A figura 1.4 apresenta a forma de onda provocada pelo afundamento de $80 \%$ do valor da tensão nominal e com 10 ciclos de duração.

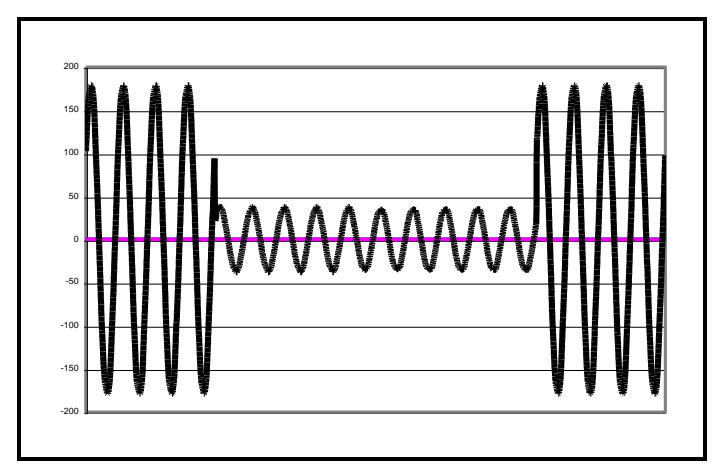

Figura 1.4 - Afundamento de $80 \%$ com duração de 10 ciclos Fonte: Gerada pela fonte Porto-Sag. 


\subsection{ORGANIZAÇÃO DA TESE}

Este trabalho foi dividido em oito capítulos, de forma a projetar uma visão geral do assunto, até chegar ao objetivo final, que é a verificação do comportamento dos equipamentos eletromédicos, quando submetidos a perturbações existentes na rede elétrica de suprimento de energia.

Este capítulo explana sobre a utilização da eletricidade nos EAS, que vem aumentando, e o impacto da qualidade de energia na utilização de equipamentos sensíveis e muitos deles, ligados à sustentação de vida dos pacientes.

De modo complementar, são descritos os cuidados que a qualidade da energia suprida e as instalações elétricas devem ter para proporcionar o bom funcionamento dos equipamentos eletromédicos.

Este capítulo também apresenta a motivação, os objetivos, as contribuições e a metodologia desenvolvida para chegar-se ao objetivo proposto.

O capítulo 2 trata das perturbações elétricas geradas nos sistemas das concessionárias, as quais são altamente prejudiciais às cargas sensíveis instaladas nos EAS.

Com o intuito de contribuir para a redução das interrupções temporárias por meio da utilização de religadores, são apresentadas informações de que cargas sensíveis, como os equipamentos eletromédicos, poderão apresentar erros de informação ou interrupção do seu funcionamento, nesses eventos.

Uma interrupção permanente pode trazer menos riscos que várias tentativas de religamento, principalmente se o intervalo da interrupção situar-se na faixa crítica dos equipamentos eletromédicos. No mesmo capítulo, apresentam-se as normas e regulamentações referentes ao controle das distorções harmônicas nos sistemas de distribuição de energia elétrica.

O capítulo 3 apresenta informações sobre as atuais condições em que se encontram os EAS no tocante aos aspectos da qualidade de energia e das instalações elétricas. Nele são apresentadas situações que mostram que a falta de investimentos, desconhecimento ou desinteresse contribuem para a degradação dos EAS.

O capítulo 4 apresenta as normas técnicas sobre instalações elétricas, aplicáveis nos EAS. Nesse capítulo também são apresentadas as principais normas de fabricação de equipamentos eletromédicos. Uma comparação entre as normas 
internacionais e brasileiras mostra a posição do desenvolvimento tecnológico brasileiro.

O capítulo 5 trata das principais perturbações provocadas nos EAS, por equipamentos típicos desses ambientes, tais como raios $\mathrm{X}$, mamografia, ressonância magnética nuclear, tomografia, além dos motores elétricos, que muitas vezes são os responsáveis pelo funcionamento incorreto dos equipamentos sensíveis instalados nesses locais.

O capítulo 6 apresenta os equipamentos eletromédicos portáteis, os quais foram ensaiados no laboratório do ENERQ-ct.

Foi focado o comportamento desses equipamentos quando submetidos à tensão de alimentação com elevado conteúdo harmônico, e quando influenciados por afundamentos e interrupções de tensão de curta duração.

Como orientação aos administradores e departamentos responsáveis pelo suprimento de energia elétrica nos EAS, o capítulo 7 apresenta os principais meios de eliminação ou minimização das perturbações que foram objeto deste estudo.

No final de cada capítulo incluem-se os comentários e as discussões sobre os temas apresentados.

O capítulo 8 apresenta as contribuições alcançadas, as dificuldades encontradas e as sugestões para os desdobramentos e continuidade do tema abordado neste trabalho.

Quatro anexos complementam o trabalho e auxiliam no entendimento dos assuntos apresentados:

Anexo A - Conceitos sobre harmônicos: apresenta um resumo teórico sobre esse tipo de perturbação provocado por cargas não-lineares ligadas à rede de alimentação, como é o caso dos equipamentos eletromédicos.

Anexo B: Apresenta os instrumentos de medição que foram utilizados para a realização deste trabalho, bem como, suas principais características. Neste anexo também são apresentados os principais parâmetros a serem considerados para a definição dos instrumentos de medidas e informações sobre os cuidados durante as medições, como forma de se evitar acidentes.

Anexo C: Apresenta o cálculo do grau de desequilíbrio de tensões, por intermédio do método das componentes simétricas, existente no setor administrativo do EAS onde as medições foram realizadas. 
Anexo D: Apresenta os métodos de partida à tensão reduzida para motores de indução com rotor em gaiola. 


\section{AS CONCESSIONÁRIAS E A QUALIDADE DE ENERGIA ELÉTRICA}

\subsection{AFUNDAMENTOS DE TENSÃO}

Perturbações elétricas também poderão ser provocadas nas linhas de transmissão e distribuição das concessionárias de energia elétrica. Curtos-circuitos e a conseqüente atuação de dispositivos de proteção, manobras e outros eventos, abertura de conexões elétricas, partida de grandes motores ou energização de transformadores poderão provocar variações de tensão de curta duração (short duration voltage variations), que migram pelas redes elétricas prejudicando os consumidores. Os afundamentos de tensão de curta duração (DRANETZ, 1997; ALDABÓ, 2001) caracterizam-se por uma brusca diminuição no valor da amplitude, entre 0,1 a 0,9 pu, seguida por um restabelecimento após curto intervalo de tempo, conforme pode ser observado na figura 2.1.

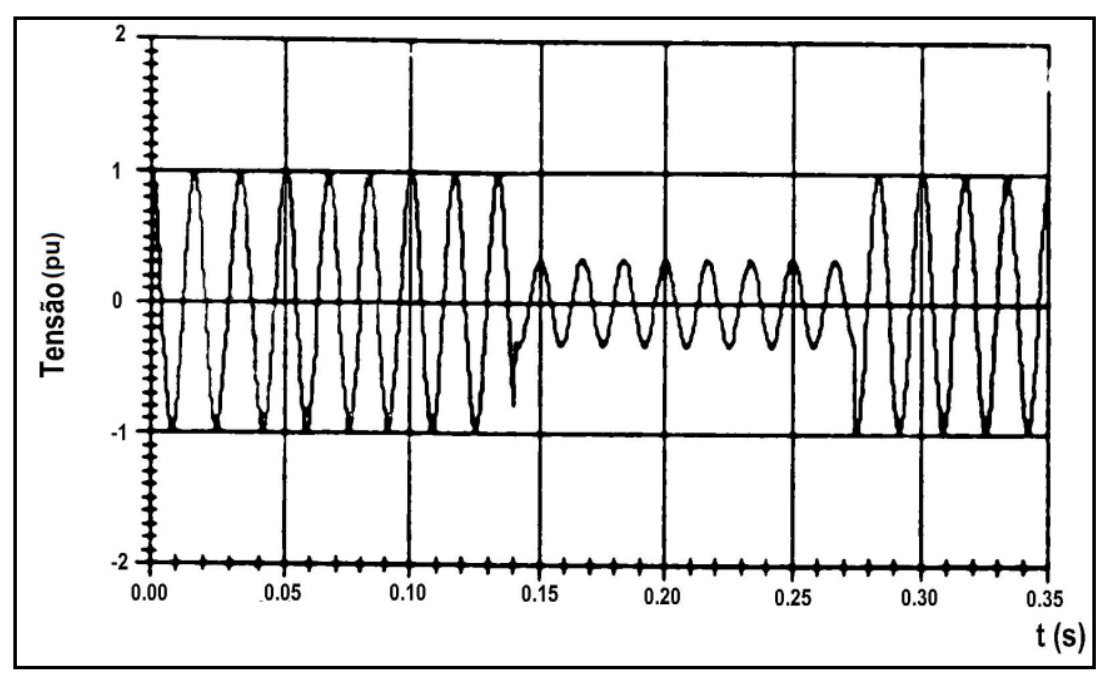

Figura 2.1 - Afundamento de tensão provocado por uma condição de falta (seis ciclos)

Fonte: McGranaghan; Mueller; Samotyj, 1993. (tradução e adaptação do autor)

Seguindo a tendência de muitos países, a França (MARTINON; POISSON; DE CHATEAUVIEUX, 2000) tem se esforçado nos últimos quinze anos para melhorar a qualidade do fornecimento de energia, desenvolvendo programas essencialmente para a redução do número e da duração de interrupções longas, em geral superiores a três minutos, sofridas pelos consumidores, especialmente aqueles que possuem cargas críticas. 
Atualmente, com o surgimento de novas aplicações da eletricidade, pode-se notar o crescente aumento da sensibilidade dos consumidores no que se refere aos afundamentos de tensão e interrupções momentâneas, com menos de três minutos. Pesquisa realizada pela EDF - Électricité de France, em 1994, revelou que 44\% dos consumidores industriais acreditam que os afundamentos de tensão causam grandes prejuízos em suas linhas de produção, de forma que essas perturbações são motivo de grande preocupação para uma concessionária que procura a satisfação de seus clientes.

$\mathrm{Na}$ área da saúde, não se encontram estatísticas que demonstram os prejuízos causados, mas é fácil aceitar que a interrupção de uma cirurgia, que utiliza equipamentos sensíveis, ou a falha de um equipamento de sustentação de vida, ocasionam prejuízos incomensuráveis.

Da mesma forma que outros aspectos relacionados à qualidade de energia elétrica, os afundamentos de tensão de curta duração também estão ligados a duas filosofias: a primeira, estabelecida pelo IEEE - Institute of Electric and Electronics Engineers; e a segunda, pela IEC - International Electrotechnical Comission.

Observa-se, comparando as duas, que os termos utilizados possuem definições diferentes para o mesmo evento, considerando a magnitude e seu tempo de duração (BOLLEN, 2000). As definições do IEEE são provenientes da Norma IEEE Std. 1159 (1995), enquanto o IEC utiliza o documento EN 50160 (1994) do Cenelec.

A Recomendação IEEE 1159, que tem como objetivo a monitoração dos fenômenos de qualidade de energia elétrica, define afundamento de tensão como a redução do valor eficaz da tensão para um valor compreendido entre 0,1 a 0,9 pu, durante um período de tempo compreendido entre 0,5 ciclo a $60 \mathrm{~s}$. São classificados de acordo com a duração e o valor da variação da tensão, e denominados de voltage sag.

A mesma norma classifica os afundamentos de tensão de curta duração em três categorias, dependendo do tempo de sua ocorrência:

1) instantâneos: entre 0,5 ciclo e 30 ciclos;

2) momentâneos: entre 30 ciclos e $3 \mathrm{~s}$;

3) temporários: entre $3 \mathrm{~s}$ e $60 \mathrm{~s}$.

Esse documento está dividido em três partes principais, e tem como objetivo auxiliar a monitoração e a correta interpretação dos resultados obtidos durante as medidas dessas perturbações. 
A referida norma também esclarece que a intensidade de um afundamento é definida pelo menor valor da tensão remanescente durante a ocorrência da perturbação (voltage sag). Assim, tensão de afundamento de 0,2 pu, significa que a tensão se reduziu para $80 \%$ do valor da tensão nominal (valor remanescente). 0 IEEE considera como interrupções, afundamentos inferiores a 0,1 pu.

A IEC, por sua vez, define a intensidade do afundamento de tensão como a queda do valor eficaz da tensão, entre 0,10 e 0,99 pu, durante um período de tempo compreendido entre 0,5 ciclo a $1 \mathrm{~min}$, sendo denominados de voltage dip. A figura 2.2 apresenta as duas formas mencionadas para a caracterização desse evento.



Figura 2.2 - Afundamento de tensão caracterizado pelas Normas IEEE e IEC

Fonte: Leborgne, 2003.

Nota: Informações complementadas pelo autor.

Portanto, os principais parâmetros que caracterizam um afundamento de tensão monofásico são a amplitude e a sua duração. Esses fatores associados à freqüência de ocorrência fornecem informações importantes para estudos de minimização dessas perturbações. No estudo de afundamentos de tensão trifásicos, além dos apresentados, outros parâmetros deverão ser considerados, como a assimetria e o desequilíbrio de tensão entre as fases.

A tensão no sistema elétrico interno do consumidor depende do tipo do curtocircuito, de sua localização no sistema da concessionária, bem como da conexão do transformador de acoplamento da concessionária com o consumidor. A tabela 2.1 apresenta as tensões no secundário do transformador para um curto-circuito fase a- 
terra no primário, conforme se apresenta na figura 2.3 (MCGRANAGHAN; MUELLER; SAMOTYJ, 1993).

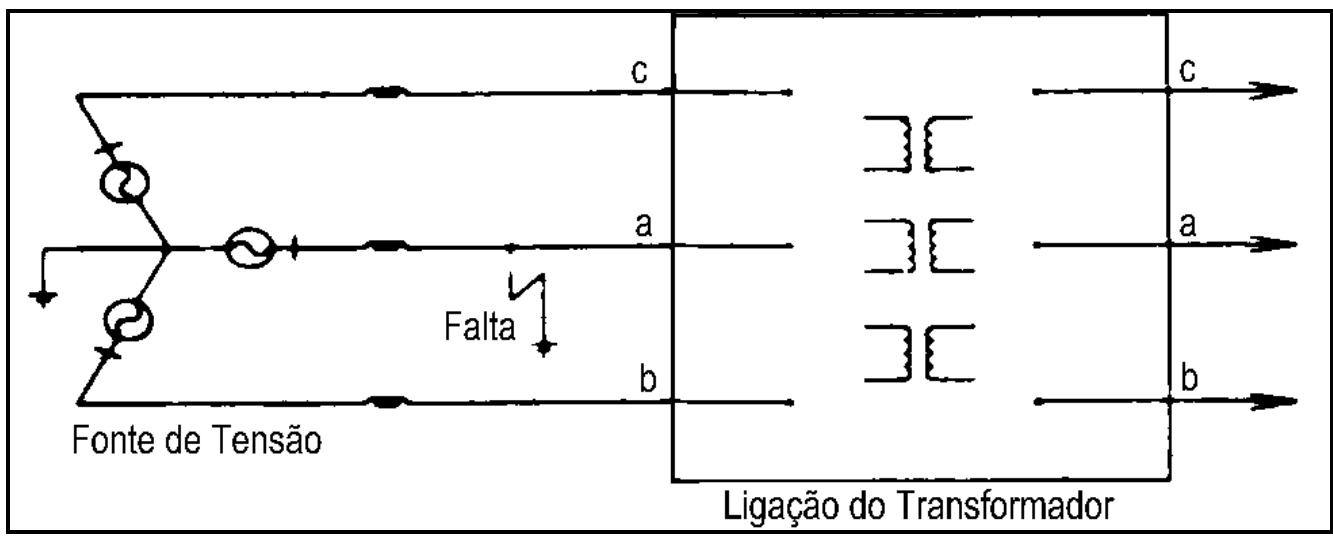

Figura 2.3 - Falta fase-terra perto da subestação

Fonte: McGranaghan; Mueller; Samotyj, 1993. (tradução e adaptação do autor)

Tabela 2.1 - Tensões secundárias (pu) durante ocorrência de falta fase-terra no primário de transformadores

\begin{tabular}{|c|c|c|c|c|c|c|c|}
\hline $\begin{array}{l}\text { Ligação do } \\
\text { Transformador }\end{array}$ & \multicolumn{3}{|c|}{$\begin{array}{l}\text { Fase / Fase } \\
V_{a b} V_{b c} \quad V_{c a}\end{array}$} & \multicolumn{3}{|c|}{$\begin{array}{l}\text { Fase / Neutro } \\
\text { Van Vbn Van }\end{array}$} & $\begin{array}{c}\text { Diagrama de } \\
\text { Fasores } \\
\end{array}$ \\
\hline$a$ & 0.58 & 1.00 & 0.58 & 0.00 & 1.00 & 1.00 & \\
\hline & 0.58 & 1.00 & 0.58 & 0.33 & 0,88 & 0,88 & \\
\hline & 0.33 & 0,88 & 0,88 & - & - & - & \\
\hline & 0.88 & 0.33 & 0,33 & 0.58 & 1,00 & 0,58 & \\
\hline & & & & & & & \\
\hline
\end{tabular}

Fonte: McGranaghan; Mueller; Samotyj, 1993. (tradução e adaptação do autor)

O Valor do afundamento de tensão depende da seguinte relação:

$$
\beta=\frac{x_{t}}{x_{t}+x_{s}} \quad ; \quad 0<\beta<1
$$


onde:

$x_{t}$ - reatância de curto-circuito do transformador;

$x_{s}$ - reatância equivalente do sistema de alimentação.

Para instalações industriais, o valor de $\beta$ será muito próximo da unidade, e os valores apresentados na tabela 2.1 aplicam-se a estes casos.

Equipamentos utilizados em modernas instalações elétricas, tais como: controladores de processos, acionamentos com velocidade variável, robótica, equipamentos eletromédicos, etc. são extremamente sensíveis aos afundamentos de tensão, uma vez que operam com programas pré-estabelecidos e poderão deixar de realizar satisfatoriamente suas funções (DRANETZ, 1998).

\subsection{INTERRUPÇÕES}

Os sistemas de distribuição são normalmente projetados de forma a minimizar o número de interrupções no suprimento de energia, suas durações e o número de consumidores afetados (ALVES, 1996).

As faltas são classificadas como temporárias ou permanentes. Por um lado, as faltas temporárias poderão ser causadas por descargas atmosféricas, ação do vento, etc. Neste caso a linha é aberta pela ação de um religador, de forma a interromper a falta e, após algum tempo, fecha o circuito, com objetivo de restabelecer a continuidade do suprimento. Este ciclo poderá se repetir várias vezes em uma mesma falta.

Até alguns anos atrás, este procedimento não era percebido pela maioria dos consumidores, principalmente quando na primeira operação de religamento a continuidade era restabelecida. Entretanto, atualmente, para as cargas sensíveis, o tempo de abertura e fechamento do religador é equivalente a uma interrupção, a menos que sejam instalados equipamentos para condicionamento de energia, tais como: UPS - Uninterruptible Power Supply ou DVR - Dynamic Voltage Restorer.

As faltas permanentes, por outro lado, resultam em interrupções no suprimento de energia, com duração de minutos a horas. Nessa condição, o religador, após operar de três a quatro vezes na tentativa de restabelecer o fornecimento de energia, abre a linha permanentemente, conforme mostra a figura 2.4 . 


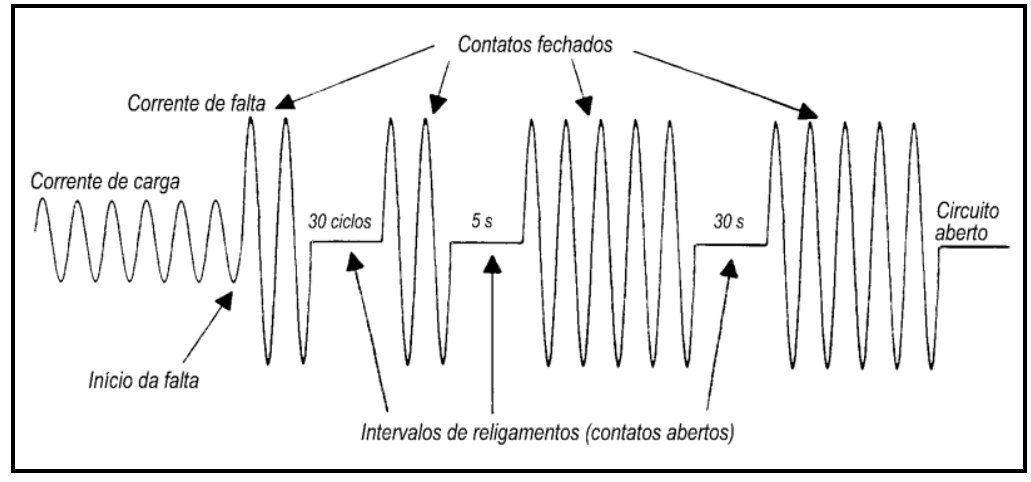

Figura 2.4 - Seqüência de operação típica de um religador

Fonte: McGranaghan; Mueller; Samotyj, 1993. (tradução e adaptação do autor)

A maior parte das faltas que ocorrem nos sistemas de distribuição é de natureza temporária (MCGRANAGHAN; MUELLER; SAMOTYJ, 1993), principalmente as fase-terra, ocasionadas pelos fenômenos naturais já mencionados.

Contaminação de isoladores, ação de animais e acidentes envolvendo construções e atividades de transporte também causam esse tipo de falta. Faltas trifásicas são mais severas, mas, de menor probabilidade de ocorrência.

Com a crescente utilização de equipamentos sensíveis, torna-se necessária uma reavaliação do conceito dos sistemas de proteção dos alimentadores dos circuitos de distribuição, principalmente no que concerne à questão da seletividade.

Normalmente, a filosofia de proteção adotada para o circuito da figura 2.5 considera que os fusíveis, localizados nos ramais secundários, devem atuar para faltas permanentes e o religador do alimentador principal deve operar mais rápido para faltas temporárias.

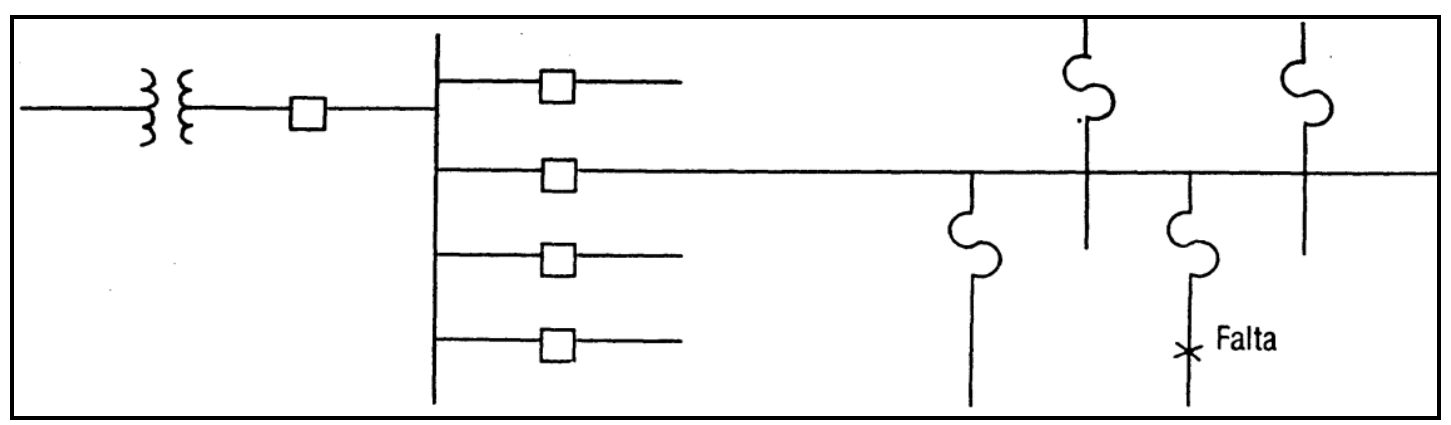

Figura 2.5 - Proteção seletiva entre ramais e o circuito alimentador Fonte: Elaborada pelo autor 
Quando ocorre uma falta em um dos ramais, todos os demais ficam sujeitos a interrupções de tensão de curta duração. Observa-se, portanto, que os consumidores em um determinado ramal estão expostos às perturbações na tensão provocadas por faltas em outros ramais ligados ao mesmo alimentador.

No caso da existência de um grande número de cargas sensíveis em um determinado ramal, é preferível permitir inicialmente a atuação dos fusíveis do ramal com falta, mesmo se tratando de faltas temporárias, evitando que o religador opere e perturbe todos os demais ramais ligados ao mesmo alimentador (MCGRANAGHAN; MUELLER; SAMOTYJ, 1993).

É importante entender a diferença entre as interrupções (completa ausência de tensão) e os afundamentos de tensão de curta duração. A primeira ocorre, por exemplo, após a atuação do sistema de proteção, interrompendo a alimentação de um determinado circuito, enquanto a segunda ocorre durante o tempo necessário à atuação do dispositivo de proteção.

\subsection{SOBRETENSÕES TRANSITÓRIAS}

Esta modalidade de sobretensão está relacionada a eventos de curta duração (DRANETZ, 1997; DRANETZ, 1998), denominados de swells. Normalmente essas sobretensões são causadas pela entrada em operação de grupos geradores, comutação de banco de capacitores, conexões e desconexões de certos tipos de equipamentos, operação de retificadores controlados, variadores de velocidade, atuação de dispositivos de proteção, ação de descargas atmosféricas, entre outros, levando o valor da tensão a valores entre 1,1 a 1,8 pu.

De modo geral, transformadores e motores elétricos suportam impulsos transitórios de tensão, desde que dentro de certos limites, porém, dependendo da quantidade e intensidade, a sua vida útil pode ser seriamente comprometida.

Os equipamentos de eletrônica de potência, fontes de alimentação de computadores ou retificadores, são bem mais sensíveis que os primeiros, podendo ocorrer a sua total danificação ou perda de programas de controle, dados, destruição de placas de comunicação e os discos rígidos desses equipamentos.

Todo equipamento é projetado para operar dentro de uma certa faixa de tensão. A maioria dos problemas de tensão associados aos computadores e outras cargas 
sensíveis não está relacionado simplesmente à ocorrência de tensões de regime fora da faixa tolerável de operação, mas sim devido a elevadas variações de tensão de curta duração (DECKMAN, 2001; MIGUEL; MEDINA; ANTÓN, 2007).

\subsection{A SENSIBILIDADE DOS EQUIPAMENTOS ÀS VARIAÇÕES DE TENSÃO}

A sensibilidade apresentada pelos equipamentos às variações de tensão, difere consideravelmente, dependendo do fabricante, da aplicação e também da rede elétrica onde se encontram instalados, por exemplo (MCGRANAGHAN; MUELLER; SAMOTYJ, 1993; LEBORGNE,2003):

- $\quad$ contatores e relés eletromecânicos: desarmam com tensões compreendidas entre 50 a $70 \%$ de seus valores nominais;

- conversores para acionamento de motores elétricos: alguns modelos são projetados para ignorar flutuações por um tempo determinado, variando de 0,05 a $0,5 \mathrm{~s}$, dependendo do fabricante. Outros modelos suportam até $90 \%$ da tensão nominal por $50 \mathrm{~ms}$;

- controladores lógico programáveis: trata-se de uma categoria de equipamentos muito importante nos processos industriais. A sensibilidade às flutuações de tensão varia em função do fabricante e do modelo; na maioria dos casos, ocorre o desligamento para $90 \%$ da tensão nominal com duração de poucos ciclos;

- lâmpadas de descarga de alta intensidade à alta pressão: com valores de tensão em torno de $80 \%$ do seu valor nominal, a descarga se extingue, sendo necessário um tempo adicional para seu resfriamento e retorno ao funcionamento.

No caso de equipamentos eletromédicos, vários documentos foram encontrados, no entanto, poucos se referem ao comportamento que eles apresentam perante as variações de tensão, que é um dos objetivos deste trabalho.

A figura 2.6 apresenta a faixa de sensibilidade de alguns tipos de equipamentos industriais, juntamente com o tempo necessário para a eliminação da falta. É importante considerar nos processos totalmente automatizados, sejam de produção 
de bens ou de serviços como, por exemplo, num procedimento médico, que todo ele pode depender da sensibilidade de um único equipamento.

Nesses casos, vários componentes ou equipamentos integram o conjunto, sendo necessário o estabelecimento de especificações para a aquisição de equipamentos, considerando as condições reais do sistema de alimentação de energia elétrica.

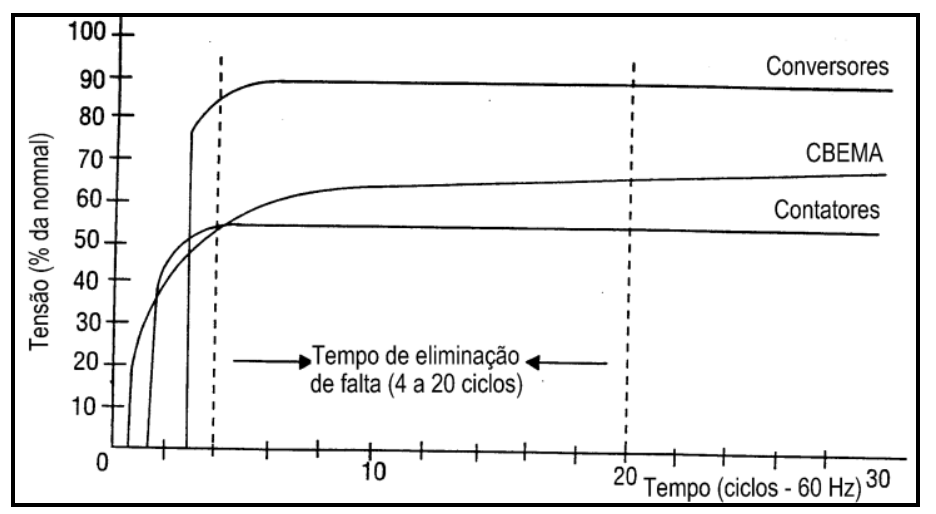

Figura 2.6 - Faixa de sensibilidade dos equipamentos às variações de tensão

Fonte: McGranaghan; Mueller; Samotyj, 1993. (tradução e adaptação do autor)

Como atualmente existem diversas tentativas para a definição das perturbações de tensão, a figura 2.7 apresenta a curva adotada pela ITIC - Information Technology Industry Council, antes conhecida como CBEMA - Computer \& Business Equipment Manufacturers Association (KUSKO; THOMPSON, 2007).

Inicialmente foi desenvolvida para equipamentos de processamento de dados, e mostra que a sensibilidade depende da duração da perturbação.
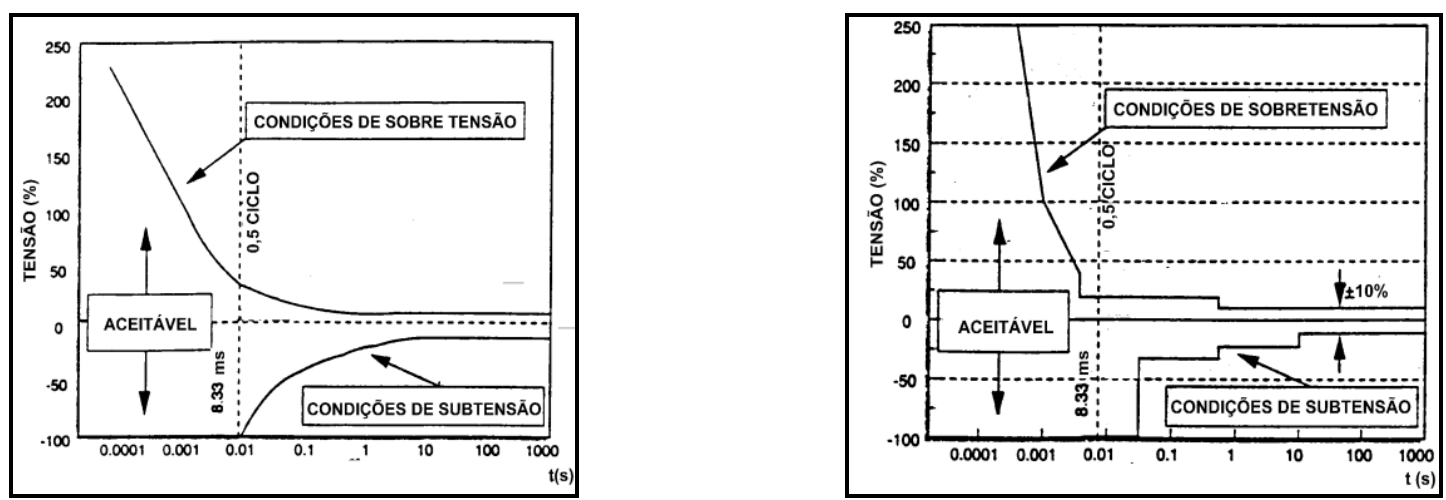

Figura 2.7 - Curvas CBEMA e ITIC

Fonte: Kusko; Thompson, 2007. (tradução e adaptação do autor)

Após extenso trabalho de caracterização dos afundamentos de tensão realizado por meio de inúmeras medições, Bollen (2000) apresentou um gráfico, que o autor adaptou na figura 2.8, e relaciona o valor dos afundamentos de tensão na carga e a 
sua duração, provenientes de várias origens em sistemas de transmissão e distribuição de energia elétrica:

1 - faltas na rede de alta tensão;

2 - faltas remotas no sistema de distribuição;

3 - faltas locais no sistema de distribuição;

4 - partida de grandes motores elétricos de indução;

5 - curtas interrupções;

6 - atuação de fusíveis.
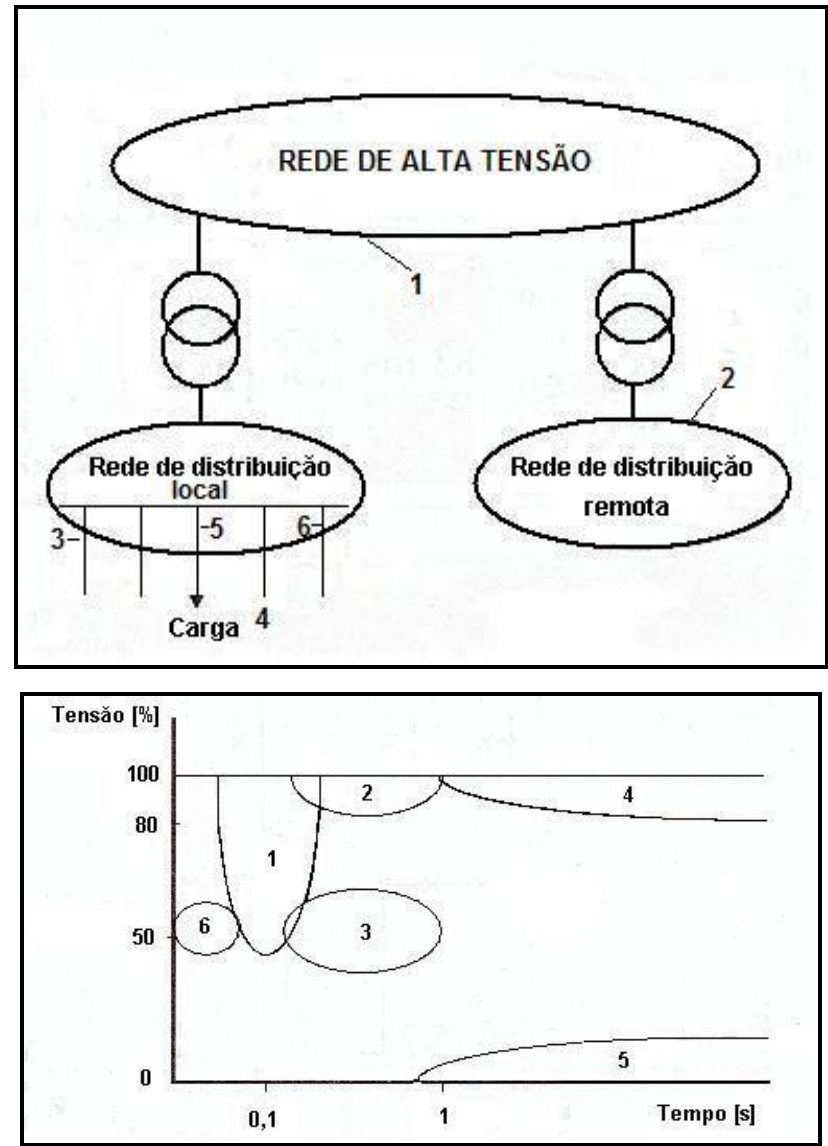

Figura 2.8 - Afundamentos de tensão em um sistema de potência, provenientes de várias origens

Fonte: Bollen, 2000. (adaptação do autor) Nota: Adequada para o sistema brasileiro de distribuição.

Geralmente as faltas nos sistemas de transmissão são eliminadas mais rapidamente que as faltas que ocorrem nos sistemas de distribuição. As faltas críticas nos sistemas de transmissão são abolidas em períodos bastante curtos. Portanto, para essa finalidade são utilizados dispositivos de atuação rápida. 
O processo de transmissão e sub-transmissão utiliza proteção de distância e relés diferenciais, ambos muito rápidos. Nos sistemas de distribuição, a forma preferida de proteção é por intermédio de relés de sobrecorrente que requerem, normalmente, algum tempo para atuação, de modo a oferecer coordenação com fusíveis limitadores de corrente (KOJOVIC; HASSLER, 1997). Em geral, os tempos de eliminação das faltas, dependendo do dispositivo de proteção, são apresentados na tabela 2.2 (CONRAD, 1994).

Tabela 2.2 - Tempos de eliminação das faltas em função do tipo do dispositivo de proteção

\begin{tabular}{|c|c|}
\hline Proteção & Tempo de eliminação da falta (ms) \\
\hline Fusíveis limitadores de corrente & $\leq 16$ \\
\hline Fusíveis de expulsão & 10 a 100 \\
\hline Relé de distância na zona instantânea & $50-100$ \\
\hline Relé de distância na zona 1 & $100-200$ \\
\hline Relé de distância na zona 2 & $200-500$ \\
\hline Relé diferencial & $100-300$ \\
\hline Relé de sobrecorrente & $200-2000$ \\
\hline
\end{tabular}

Fonte: Conrad, 1994. (tradução do autor)

\subsection{HARMÔNICOS}

Muitos dos problemas relativos à qualidade de energia elétrica são provocados internamente às instalações do consumidor, devido ao uso generalizado de cargas não-lineares.

Diversas organizações internacionais possuem normas sobre o assunto, mas não se conseguiu atingir um nível de consenso entre elas (THOMAS; LAI, 1993; ONG; YEONG, 2007).

Portanto, ocorre a necessidade do desenvolvimento de pesquisas envolvendo equipamentos sensíveis e sua interação com os sistemas de suprimento de energia elétrica (MACGRANAGHAN, 2005).

Infelizmente, no Brasil ainda não existem normas específicas e legislação apropriada.

Vários agentes reguladores e normalizadores definem indicadores de desempenho e valores limites para a distorção harmônica. 
A Aneel - Agência Nacional de Energia Elétrica - autorizou a Resolução ํㅜ 675, de 2003, elaborada pelo ONS - Operador Nacional do Sistema Elétrico, que estabelece padrões de qualidade para a tensão suprida da rede básica, correspondentes aos limites individuais de harmônicos e à distorção harmônica total.

A tabela 2.3 apresenta esses valores, que devem ser entendidos como níveis de compatibilidade e, portanto, não devem ser excedidos em nenhum dos pontos do sistema elétrico.

Os limites são aplicáveis no ponto de acoplamento de consumidores que provocam distorções harmônicas, com as redes de transmissão e sub-transmissão.

Tabela 2.3 - Limites individuais e globais da distorção harmônica de tensão (em função da tensão fundamental)

\begin{tabular}{|c|c|c|c|c|c|c|c|}
\hline \multicolumn{4}{|c|}{$V<69 \mathrm{kV}$} & \multicolumn{4}{|c|}{$\mathrm{V} \geq 69 \mathrm{kV}$} \\
\hline \multicolumn{2}{|c|}{ Ímpares } & \multicolumn{2}{|c|}{ Pares } & \multicolumn{2}{|c|}{ Ímpares } & \multicolumn{2}{|c|}{ Pares } \\
\hline $\begin{array}{c}\text { Ordem } \\
h\end{array}$ & $\begin{array}{c}\text { Valor } \\
H D_{V}(\%)\end{array}$ & $\begin{array}{c}\text { Ordem } \\
h\end{array}$ & $\begin{array}{c}\text { Valor } \\
H D_{v}(\%)\end{array}$ & $\begin{array}{c}\text { Ordem } \\
H\end{array}$ & $\begin{array}{c}\text { Valor } \\
H D_{v}(\%)\end{array}$ & $\begin{array}{c}\text { Ordem } \\
h\end{array}$ & $\begin{array}{c}\text { Valor } \\
H D_{v}(\%)\end{array}$ \\
\hline $3,5,7$ & 5 & $2,4,6$ & 2 & $3,5,7$ & 2 & $2,4,6$ & 1 \\
\hline $9,11,13$ & 3 & & & $9,11,13$ & 1,5 & & \\
\hline 15 a 25 & 2 & $\geq 8$ & 1 & 15 a 25 & 1 & $\geq 8$ & 0,5 \\
\hline$\geq 27$ & 1 & & & $\geq 27$ & 0,5 & & \\
\hline \multicolumn{4}{|c|}{$\mathrm{THD}_{(\mathrm{V})}=6 \%$} & \multicolumn{4}{|c|}{$\mathrm{THD}_{(\mathrm{V})}=3 \%$} \\
\hline
\end{tabular}

Fonte: ONS - Operador Nacional do Sistema Elétrico

Em dezembro de 2008, a Aneel publicou o Prodist - Procedimentos de Distribuição de Energia Elétrica no Sistema Elétrico Brasileiro.

O módulo 8 desse documento se refere aos procedimentos relativos à qualidade de energia elétrica, abordando tanto o aspecto da qualidade do produto fornecido (eletricidade) quanto a qualidade do serviço prestado (ANEEL, 2008).

Para a qualidade do produto, o documento define a terminologia, a caracterização de fenômenos, os parâmetros e valores de referência relativos à tensão em regime permanente, estabelecendo meios que possibilitem à Aneel fixar padrões para os indicadores de qualidade de energia elétrica.

Em relação à qualidade dos serviços prestados, o mesmo módulo desse documento estabelece uma metodologia para apuração dos indicadores de continuidade e dos tempos de atendimento a ocorrências emergenciais; e define padrões e responsabilidades.

As informações contidas no referido documento servem como orientação para: 
a) consumidores com instalações alimentadas pelo sistema de distribuição em qualquer classe de tensão;

b) produtores de energia;

c) distribuidoras;

d) agentes importadores e exportadores de energia elétrica;

e) transmissoras.

O item 8.1, que apresenta informações sobre a qualidade do produto, considera os seguintes aspectos em regime permanente ou transitório: tensão em regime permanente; fator de potência; harmônicos; desequilíbrio de tensão; flutuação de tensão; variações de tensão de curta duração e variação de freqüência.

Os valores de referência para as distorções harmônicas totais de tensão, em porcentagem da tensão fundamental, contidos no documento mencionado, estão apresentados na tabela 2.4 .

Tabela 2.4 - Valores de referências globais das distorções harmônicas totais de tensão (em porcentagem da tensão fundamental) - Prodist

\begin{tabular}{|c|c|}
\hline Tensão Nominal do Barramento (Kv) & $\begin{array}{c}\text { Distorção Harmônica Total de Tensão } \\
\text { THD }_{\mathrm{V}}(\%)\end{array}$ \\
\hline $\mathrm{V}_{\mathrm{N}} \leq 1$ & 10 \\
\hline $1<\mathrm{V}_{\mathrm{N}} \leq 13,8$ & 8 \\
\hline $13,8<\mathrm{V}_{\mathrm{N}} \leq 69$ & 6 \\
\hline $69<\mathrm{V}_{\mathrm{N}}<230$ & 3 \\
\hline
\end{tabular}

Fonte: Aneel, 2008.

A tabela 2.5 apresenta os valores das distorções harmônicas individuais, que também devem ser obedecidos. 
Tabela 2.5 - Níveis de referência para distorções harmônicas individuais de tensão (em porcentagem da tensão fundamental) - Prodist

\begin{tabular}{|c|c|c|c|c|c|}
\hline \multirow{2}{*}{$\begin{array}{c}\text { Ordem } \\
\text { do } \\
\text { harmônico }\end{array}$} & \multicolumn{5}{|c|}{ Distorção Harmônica Individual de Tensão (\%) } \\
\hline & $\mathbf{h}$ & 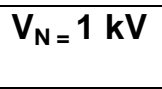 & $\begin{array}{c}1 \mathrm{kV}<V_{\mathrm{N}}= \\
13,8 \mathrm{kV}\end{array}$ & $\begin{array}{c}13,8 \mathrm{kV}<V_{N}= \\
69 \mathrm{kV}\end{array}$ & $\begin{array}{l}69 \mathrm{kV}<\mathrm{V}_{\mathrm{N}} \\
<230 \mathrm{kV}\end{array}$ \\
\hline \multirow{9}{*}{$\begin{array}{l}\text { Ímpares } \\
\text { não } \\
\text { Múltiplas } \\
\text { de } \\
3\end{array}$} & 5 & 7,5 & 6 & 4,5 & 2,5 \\
\hline & 7 & 6,5 & 5 & 4 & 2 \\
\hline & 11 & 4,5 & 3,5 & 3 & 1,5 \\
\hline & 13 & 4 & 3 & 2,5 & 1,5 \\
\hline & 17 & 2,5 & 2 & 1,5 & 1 \\
\hline & 19 & 2 & 1,5 & 1,5 & 1 \\
\hline & 23 & 2 & 1,5 & 1,5 & 1 \\
\hline & 25 & 2 & 1,5 & 1,5 & 1 \\
\hline & $>25$ & 1,5 & 1 & 1 & 0,5 \\
\hline \multirow{5}{*}{$\begin{array}{l}\text { Ímpares } \\
\text { Múltiplas } \\
\text { de } \\
3\end{array}$} & 3 & 6,5 & 5 & 4 & 2 \\
\hline & 9 & 2 & 1,5 & 1,5 & 1 \\
\hline & 15 & 1 & 0,5 & 0,5 & 0,5 \\
\hline & 21 & 1 & 0,5 & 0,5 & 0,5 \\
\hline & $>21$ & 1 & 0,5 & 0,5 & 0,5 \\
\hline \multirow{7}{*}{ Pares } & 2 & 2,5 & 2 & 1,5 & 1 \\
\hline & 4 & 1,5 & 1 & 1 & 0,5 \\
\hline & 6 & 1 & 0,5 & 0,5 & 0,5 \\
\hline & 8 & 1 & 0,5 & 0,5 & 0,5 \\
\hline & 10 & 1 & 0,5 & 0,5 & 0,5 \\
\hline & 12 & 1 & 0,5 & 0,5 & 0,5 \\
\hline & $>12$ & 1 & 0,5 & 0,5 & 0,5 \\
\hline
\end{tabular}

Fonte: Aneel, 2008.

Quanto às variações de tensão de curta duração, mencionadas no item 7 desse documento, apresenta-se a classificação, a terminologia a ser utilizada e a metodologia de medição. No entanto, não são apresentados valores de referência, de forma que não são atribuídos padrões de desempenho a estes fenômenos.

Segundo Pomiglio (2006), do ponto de vista do consumidor, as restrições a serem consideradas serão, na grande maioria das vezes, as do sistema de distribuição.

No âmbito internacional, os limites de emissão de harmônicos de corrente estão contidos nas normas IEC 61000-3-2 (2001) e IEC 61000-3-4 (1998), enquanto o controle de harmônicos de corrente, no sistema elétrico de potência, é apresentado na IEEE Std 519 (1992) e na IEC 61000-3-6 (1996).

A primeira refere-se às limitações dos harmônicos de corrente injetados na rede pública de baixa tensão, provenientes de equipamentos elétricos e eletrônicos que possuam uma corrente de entrada de até $16 \mathrm{~A}$ por fase, com tensão fase-neutro entre 220 e $240 \mathrm{~V}$ em corrente alternada de 50 ou $60 \mathrm{~Hz}$. 
Não incluem tensões inferiores, uma vez que está direcionada à Comunidade Européia, onde as tensões fase-neutro encontram-se exatamente nos valores especificados (POMIGLIO, 2006).

A norma divide os equipamentos em 4 classes, conforme pode ser observado na tabela 2.6.

Tabela 2.6 - Classificação dos equipamentos segundo a IEC 61000-3-2

\begin{tabular}{|c|l|}
\hline CLASSE & \multicolumn{1}{|c|}{ TIPO DE EQUIPAMENTO } \\
\hline A & $\begin{array}{l}\text { Com alimentação trifásica equilibrada, aparelhos para uso doméstico } \\
\text { (excluindo os da classe D), dispositivos eletrônicos de controle de } \\
\text { luminosidade, equipamentos de áudio e todos os demais não incluídos nas } \\
\text { demais classes; }\end{array}$ \\
\hline B & Ferramentas portáteis; \\
\hline C & Dispositivos de iluminação; \\
\hline D & $\begin{array}{l}\text { Computadores pessoais, monitores de vídeo, aparelhos de TV. O limite de } \\
\text { potência ativa é de 600 W. A forma de onda da corrente de entrada deve } \\
\text { estar dentro de condições especificadas pela norma. }\end{array}$ \\
\hline
\end{tabular}

Fonte: Norma IEC 61000-3-2, 2001. (tradução do autor)

A tabela 2.7 apresenta os valores máximos para os harmônicos de corrente, nos condutores de fase. 
Tabela 2.7 - Valores limites para os harmônicos de corrente - IEC 61000-3-2

\begin{tabular}{|c|c|c|c|c|}
\hline $\begin{array}{c}\text { Ordem } \\
\text { do } \\
\text { harmônico } \\
\mathrm{h}\end{array}$ & $\begin{array}{c}\text { Classe A } \\
\text { Máxima corrente } \\
\text { (A) }\end{array}$ & $\begin{array}{c}\text { Classe B } \\
\text { Máxima corrente } \\
\text { (A) }\end{array}$ & $\begin{array}{c}\text { Classe C } \\
(>25 \mathrm{~W}) \\
\% \mathrm{da} \\
\text { fundamental }\end{array}$ & $\begin{array}{c}\text { Classe D } \\
(75 \mathrm{~W}<\mathrm{P}<600 \mathrm{~W}) \\
(\mathrm{mA} / \mathrm{W})\end{array}$ \\
\hline \multicolumn{5}{|l|}{ ímpares } \\
\hline 3 & 2,30 & 3,45 & $30 \times \mathrm{FP}$ & 3,4 \\
\hline 5 & 1,14 & 1,71 & 10 & 1,9 \\
\hline 7 & 0,77 & 1,115 & 7 & 1,0 \\
\hline 9 & 0,40 & 0,60 & 5 & 0,5 \\
\hline 11 & 0,33 & 0,495 & 3 & 0,35 \\
\hline 13 & 0,21 & 0,315 & 3 & 0,296 \\
\hline $15 \leq h \leq 39$ & $0,15 \times 15 / h$ & $0,225 \times 15 / h$ & 3 & $3,85 / h$ \\
\hline \multicolumn{5}{|l|}{ pares } \\
\hline 2 & 1,08 & 1,62 & 2 & \\
\hline 4 & 0,43 & 0,645 & & \\
\hline 6 & 0,3 & 0,45 & & \\
\hline $8<h<40$ & $0,23 \times 8 / h$ & $0,35 \times 8 / h$ & & \\
\hline
\end{tabular}

Fonte: Norma IEC 61000-3-2, 2001. (tradução do autor)

Notas: Os valores limites para a classe B são os mesmos da classe A, acrescidos de $50 \%$.

FP - Fator de Potência do circuito.

A IEC 61000-3-4 é aplicada a equipamentos elétricos ou eletrônicos cuja corrente de entrada seja superior a $16 \mathrm{~A}$. Para equipamentos monofásicos, o valor da tensão não deve superar $240 \mathrm{~V}$, e para os trifásicos, $600 \mathrm{~V}$.

A freqüência nominal da rede pode ser de $50 \mathrm{~Hz}$ ou $60 \mathrm{~Hz}$. No documento citado são apresentados os limites para distorção harmônica em equipamentos cuja potência aparente seja inferior a 33 vezes a potência de curto-circuito da instalação.

A potência de curto-circuito pode ser definida como a relação entre a tensão nominal elevada ao quadrado, dividida pela impedância de curto-circuito.

A tabela 2.8 apresenta os limites individuais de harmônicos de corrente, em função da fundamental. 
Tabela 2.8 - Limites da distorção harmônica individual de corrente em \% da fundamental IEC 61000-3-4

\begin{tabular}{|c|c|c|c|}
\hline $\begin{array}{c}\text { Ordem do } \\
\text { harmônico } \\
\mathbf{h}\end{array}$ & $\begin{array}{c}\text { Valor admissível } \\
\mathbf{H D}_{(\mathbf{l})}(\mathbf{\%})\end{array}$ & $\begin{array}{c}\text { Ordem do } \\
\text { harmônico } \\
\mathbf{h}\end{array}$ & $\begin{array}{c}\text { Valor admissível } \\
\mathbf{H D}_{(\mathbf{l})}(\%)\end{array}$ \\
\hline 3 & 21,6 & 21 & $\leq 0,6$ \\
\hline 5 & 10,7 & 23 & 0,9 \\
\hline 7 & 7,2 & 25 & 0,8 \\
\hline 9 & 3,8 & 27 & $\leq 0,6$ \\
\hline 11 & 3,1 & 29 & 0,7 \\
\hline 13 & 2 & 31 & 0,7 \\
\hline 15 & 0,7 & $\leq 33$ & $\leq 0,6$ \\
\hline 17 & 1,2 & & $\leq 8 / \mathrm{h}$ ou $\leq 0,6$ \\
\hline 19 & 1,1 & Sempre & \\
\hline
\end{tabular}

Fonte: IEC 61000-3-4. (tradução do autor)

Caso o equipamento analisado apresente valores de distorção harmônica que excedam aos informados na tabela 2.8, e a potência de curto-circuito permitir outros, podem ser aplicados os limites informados na tabela 2.9. Ressalta-se que isso se aplica a equipamentos monofásicos ou trifásicos desbalanceados.

Nela, pode-se observar que os limites da distorção tolerados aumentam à medida que a potência de curto-circuito cresce.

Tabela 2.9 - Limites da distorção harmônica total e individual de corrente em \% da fundamental - IEC 61000-3-4

\begin{tabular}{|c|c|c|c|c|c|c|c|}
\hline \multirow{2}{*}{$\mathbf{P}_{\mathbf{c c m}} / \mathbf{P}_{\mathbf{e}}$} & THD $_{(\mathbf{l})}(\%)$ & \multicolumn{7}{|c|}{ HD $_{(\mathbf{l})}(\%)$} \\
\cline { 3 - 8 } & & $\mathbf{I}_{\mathbf{3}}$ & $\mathbf{I}_{\mathbf{5}}$ & $\mathbf{I}_{\mathbf{7}}$ & $\mathbf{I}_{\mathbf{9}}$ & $\mathbf{I}_{\mathbf{1 1}}$ & $\mathbf{I}_{\mathbf{1 3}}$ \\
\hline 66 & 25 & 23 & 11 & 8 & 6 & 5 & 4 \\
\hline 120 & 29 & 25 & 12 & 10 & 7 & 6 & 5 \\
\hline 175 & 33 & 29 & 14 & 11 & 8 & 7 & 6 \\
\hline 250 & 39 & 34 & 18 & 12 & 10 & 8 & 7 \\
\hline 350 & 46 & 40 & 24 & 15 & 12 & 9 & 8 \\
\hline 450 & 51 & 40 & 30 & 20 & 14 & 12 & 10 \\
\hline 600 & 57 & 40 & 30 & 20 & 14 & 12 & 10 \\
\hline
\end{tabular}

Fonte: Norma IEC 61000-3-4. (tradução do autor)

Notas: $\mathrm{P}_{\mathrm{CCm}}$ - potência de curto-circuito mínima.

$P_{e}$ - potência aparente do equipamento.

A IEEE Std 519/92 é uma recomendação norte-americana a ser aplicada, de forma mais apropriada, aos grandes consumidores de energia elétrica, comerciais ou industriais, responsabilizando-os pelo controle da geração de harmônicos de 
corrente, enquanto a concessionária fica com a responsabilidade pelo controle dos níveis de distorção de tensão em seu sistema, particularmente no ponto de acoplamento comum com o consumidor. Ao contrário das normas IEC, ela não se preocupa individualmente com os equipamentos, mas sim, com a influência que um consumidor pode provocar em outros ligados ao mesmo sistema de alimentação.

A tabela 2.10 apresenta os valores limites da distorção harmônica de corrente, individualmente por consumidor:

Tabela 2.10 - Limites de distorção harmônica, de corrente (120 a 69 kV) - IEEE Std 519

\begin{tabular}{|c|c|c|c|c|c|c|}
\hline \multicolumn{7}{|c|}{ Distorção harmônica individual, de corrente (valor máximo em \% da fundamental) } \\
\hline \multicolumn{7}{|c|}{ Ordem dos harmônicos (harmônicas ímpares) } \\
\hline $\mathbf{I}_{\mathbf{s c}} / \mathbf{I}_{\mathbf{L}}$ & $\mathbf{h}<\mathbf{1 1}$ & $\mathbf{1 1} \leq \mathbf{h}<\mathbf{1 7}$ & $\mathbf{1 7} \leq \mathbf{h}<\mathbf{2 3}$ & $\mathbf{2 3} \leq \mathbf{h}<\mathbf{3 5}$ & $\mathbf{3 5} \leq \mathbf{h}$ & $\mathbf{T H D}_{(\mathbf{l})}$ \\
\hline$<\mathbf{2 0}$ & 4,0 & 2,0 & 1,5 & 0,6 & 0,3 & 5,0 \\
\hline $\mathbf{2 0 - 5 0}$ & 7,0 & 3,5 & 2,5 & 1,0 & 0,5 & 8,0 \\
$\mathbf{5 0 - 1 0 0}$ & 10,0 & 4,5 & 4,0 & 1,5 & 0,7 & 12,0 \\
\hline $\mathbf{1 0 0 - 1 0 0 0}$ & 12,0 & 5,5 & 5,0 & 2,0 & 1,0 & 15,0 \\
\hline$>\mathbf{1 0 0 0}$ & 15,0 & 7,0 & 6,0 & 2,5 & 1,4 & 20,0 \\
\hline
\end{tabular}

Fonte: Recomendação IEEE Std 519. (tradução do autor)

Notas: Os harmônicos pares são limitados a 25\% dos valores indicados para os harmônicos ímpares imediatamente superiores;

$\mathrm{I}_{\mathrm{sc}}$ - corrente de curto-circuito máxima no ponto de acoplamento comum;

$\mathrm{I}_{\mathrm{L}}$ - corrente média (período de 12 meses) correspondente à demanda máxima da carga.

A tabela 2.11 apresenta os valores limites da distorção harmônica de tensão, individual e total.

Tabela 2.11 - Limites de distorção harmônica de tensão no ponto de acoplamento comum - (IEEE Std 519)

\begin{tabular}{|c|c|c|}
\hline $\begin{array}{c}\text { Tensão no ponto de } \\
\text { acoplamento comum }\end{array}$ & \multicolumn{2}{|c|}{ Distorção harmônica de tensão - THD $_{(\mathrm{V})}$} \\
\hline & $\mathbf{H D}_{(\mathrm{V})}(\%)$ & THD $_{(\mathrm{V})}(\%)$ \\
\hline Abaixo de $\mathbf{6 9} \mathbf{~ k V}$ & 3,0 & 5,0 \\
\hline $\mathbf{6 9}$ a 138 kV & 1,5 & 2,5 \\
\hline $\mathbf{1 3 8} \mathbf{~ k V ~ e ~ a c i m a ~}$ & 1,0 & 1,5 \\
\hline
\end{tabular}

Fonte: Recomendação IEEE Std 519. (tradução do autor)

A Norma IEC 61000-3-6 (1996) estabelece níveis de compatibilidade de tensões harmônicas pares, ímpares, triplas, e não triplas, para sistemas de média tensão $\left(1 \mathrm{kV} \leq \mathrm{U}_{\mathrm{N}} \leq 35 \mathrm{kV}\right)$ e alta tensão $\left(35 \mathrm{kV}<\mathrm{U}_{\mathrm{N}} \leq 230 \mathrm{kV}\right)$. 
No entanto, a natureza variável no tempo, das tensões e correntes harmônicas, fenômeno atualmente conhecido e praticamente sempre presente, exige um tratamento probabilístico, que deverá ser incorporado na revisão da IEEE Std 519.

Essas variações no tempo ocorrem em função das constantes mudanças na forma de operação de cargas não-lineares, configurações dos sistemas elétricos, entre outras variáveis.

Recentes revisões em outras normas, como na IEC 61000-3-6 já incorporam limites probabilísticos para os fenômenos harmônicos, tanto de tensão quanto de corrente.

Problemas associados aos harmônicos, relacionados à sua natureza variável no tempo, e sugestões para tratamento dessa situação, são apresentadas por pesquisadores do assunto (CARPINELLI, 2000; RIBEIRO, 2005).

Com base nesses estudos, realizados por um grupo de trabalho do IEEE, denominados de "Aspectos probabilísticos de harmônicas", chegou-se à conclusão de que os limites de harmônicos, estabelecidos em norma, devem ser atribuídos em função dos efeitos causados, que dependem da característica dos equipamentos afetados (IEEE PART I, 1998; IEEE PART II, 1998).

Esses efeitos poderão ocorrer a longo prazo, como pode ser observado nos casos em que ocorre a deterioração do isolamento de um motor elétrico ou, instantaneamente, com o mau funcionamento de um equipamento eletrônico, quando submetido a uma distorção harmônica ocasional, mas, de elevado valor.

A maioria dos estudos encontrados privilegia os efeitos dos harmônicos em regime permanente. No entanto, o crescimento cada vez maior das cargas não-lineares, nas mais diversas formas de operação, exige que as normas incluam uma abordagem probabilística, considerando a distorção harmônica variável no tempo.

\subsection{COMENTÁRIOS E DISCUSSÕES}

Com o objetivo de atender às exigências da Resolução nำ 24 da Aneel - Agência Nacional de Energia Elétrica, a respeito da continuidade do fornecimento, as concessionárias estão aumentando a quantidade de religadores instalados nas redes aéreas de distribuição (ANEEL, 2000). Por exemplo, a Empresa Bandeirante Energia, com área de concessão em 28 municípios da região do Alto Tietê e do Vale do Paraíba - São Paulo, possui atualmente 450 unidades, que estão totalmente 
automatizadas e controladas remotamente por sistema de telefonia celular (PIRES NETO et al., 2002).

Segundo o setor de engenharia e planejamento dessa concessionária, a quantidade de religadores instalados nos próximos anos poderá alcançar a 1400 unidades. Possuem o corpo moldado em epóxi, o meio extintor utilizado é o vácuo e todo o mecanismo externo e a caixa de comando são fabricados em aço inoxidável para suportar os agentes atmosféricos.

Atualmente, esse equipamento representa o estado da arte tecnológica em religadores para sistemas de distribuição. A figura 2.9 apresenta uma das inúmeras unidades instaladas nos circuitos de distribuição dessa concessionária:



Figura 2.9 - Religador a vácuo com corpo em epóxi

Fonte: Cidade de Mogi das Cruzes - SP, 2008. (equipamento fotografado pelo autor).

A figura 2.10 apresenta um religador com o painel de comando sendo testado antes de ser liberado para instalação:



Figura 2.10 - Religador com o respectivo painel de comando

Fonte: Empresa Bandeirante Energia - Mogi das Cruzes - SP, 2008. (equipamento fotografado pelo autor). 
Outras concessionárias como a Eletropaulo e a CPFL - Companhia Paulista de Força e Luz vem instalando chaves automáticas, como forma de melhorar a flexibilidade dos circuitos e garantir o fornecimento de energia a seus clientes de forma mais estável.

Não restam dúvidas de que a presença de religadores nos circuitos de distribuição traz enormes vantagens aos consumidores que terão o restabelecimento de energia o mais rápido possível, na ocorrência de faltas temporárias.

No entanto, cargas sensíveis às interrupções de curta duração poderão apresentar falhas em seu funcionamento, principalmente as que incorporam circuitos microprocessados.

Conforme apresentado teoricamente neste capítulo e em função dos resultados dos ensaios realizados e que serão apresentados no capítulo 6 , sugere-se que em caso de instalação de religadores em circuitos que alimentem EAS, que a concessionária informe e alerte sobre possíveis alterações no desempenho que possam ocorrer em alguns equipamentos eletromédicos.

Além disso, o ideal é que a seqüência de religamentos escolhida para esses circuitos não se situe na faixa crítica, que possa provocar falhas nos equipamentos sensíveis.

Quanto aos harmônicos, entendimentos entre o IEEE e o IEC continuam com objetivo de consolidação das normas publicadas por ambas instituições. No entanto, tornam-se demorados em função de grandes interesses econômicos envolvidos.

Para instalações industriais, o enfoque do IEEE parece ser mais consistente que o do IEC. Para a situação atual, onde se verifica um grande crescimento de cargas não-lineares no setor residencial, as normas IEC parecem adequarem-se melhor, pois objetivam que cada equipamento apresente uma reduzida distorção, resultando num bom comportamento do conjunto de cargas.

No que se refere à regulamentação brasileira, muito mais tolerante do que o do IEEE, questiona-se sobre um possível impacto de distorções significativas em processos industriais sensíveis, que dependem de uma baixa distorção da forma de onda de tensão.

Uma questão importante é a falta de definição dos valores limites para a distorção de corrente, fator imprescindível para a definição de responsabilidades.

Para muitas cargas eletrônicas, a distorção de corrente é altamente dependente da distorção de tensão. Ou seja, uma rede elétrica de distribuição que se encontre com 
elevado valor de distorção de tensão poderá provocar um aumento no valor da distorção de corrente no consumidor. Verifica-se, nesse caso, que a concessionária deveria assumir a responsabilidade (POMIGLIO, 2006). 


\section{A QUALIDADE DE ENERGIA E DAS INSTALAÇÕES ELÉTRICAS NOS ESTABELECIMENTOS ASSISTENCIAIS DE SAÚDE (EAS)}

\subsection{QUALIDADE DE ENERGIA ELÉTRICA}

EAS são edificações destinadas à prestação de assistência à saúde da população, com acesso de pacientes, em regime de internação ou não, qualquer que seja o nível de complexidade (ANVISA, 2002).

A utilização de equipamentos eletromédicos nesses EAS tem aumentado bastante nos últimos tempos, pois, desempenham importantes funções como sistemas de informação sobre o paciente, equipamentos de diagnóstico e tratamento, entre outras. Observa-se, portanto, que a eletricidade no ambiente hospitalar é fonte de vida, podendo interferir na sobrevivência ou não do paciente, pela utilização, por exemplo, de equipamentos de ventilação pulmonar, bombas de infusão de medicamentos, lâmpadas para iluminação cirúrgica, energia de emergência, ar comprimido, oxigênio, etc. (SILVEIRA, 2002).

Embora não estejam ligados diretamente à sobrevivência dos pacientes, outros equipamentos utilizam energia elétrica para fornecer importantes informações sobre o tratamento terapêutico, tais como os equipamentos de laboratório, de imagem, de fisioterapia, ou aqueles que possam contribuir na saúde do paciente.

Além disso, grande quantidade de informações é armazenada em sistemas computadorizados, muitas vezes interligados por meio de redes, de forma que aspectos relacionados à qualidade de energia elétrica tornam-se extremamente importantes.

Medições de grandezas elétricas, realizadas em um conceituado EAS na cidade de São Paulo, apresentaram alguns problemas relacionados à qualidade de energia elétrica. O equipamento utilizado para essa finalidade é fabricado pela IMS Indústria de Micro Sistemas Eletrônicos (Smart Meter), sendo capaz de medir tensões, correntes, freqüência, potências ativa, reativa e aparente, fator de potência, energias ativa, reativa e aparente, além de harmônicos ímpares de tensão e de corrente até a $31^{a}$ ordem. Possui memória interna não volátil, registrando todas as grandezas citadas, mais a corrente de neutro, data e falta de energia na rede 
elétrica. Os dados armazenados são transferidos para um microcomputador por intermédio de um software analisador gráfico. As principais características desse instrumento estão apresentadas no Anexo B.

Várias medições foram efetuadas em diversos painéis de distribuição dos setores administrativos e serão apresentadas aquelas nas quais se identificou algum problema relacionado à qualidade de energia elétrica. $O$ sistema de distribuição é trifásico $380 \mathrm{~V}$ com condutor neutro. A figura 3.1 apresenta um desequilíbrio de tensões ocorrido no dia 22/02/05 às $13 \mathrm{~h} 05$ min00s. Os valores das tensões de fase medidos foram: $\mathrm{V}_{1}=216,8 \mathrm{~V}, \mathrm{~V}_{2}=215,9 \mathrm{~V}$ e $\mathrm{V}_{3}=213,8 \mathrm{~V}$, o que corresponde a um grau de desequilíbrio de tensões, calculado pelo método das componentes simétricas, igual a $0,821 \%$ (Anexo D). Sistemas trifásicos com valores do grau de desequilíbrio de tensão inferiores a $1 \%$ podem ser considerados praticamente equilibrados (ABNT NBR 7094, 2000).

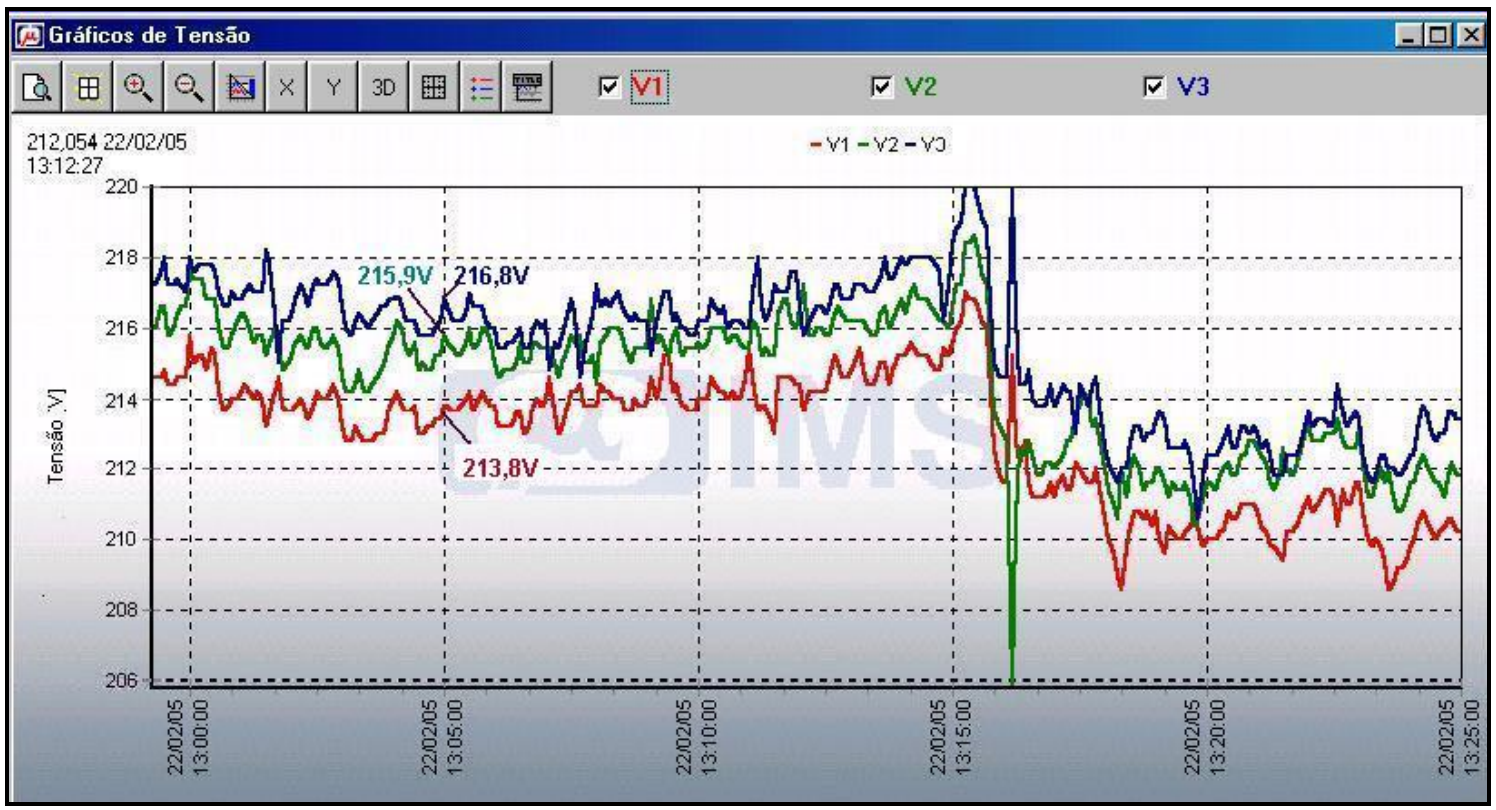

Figura 3.1 - Desequilíbrio de tensões em um dos setores administrativos do EAS Fonte: Pesquisa de campo. Nota: Medição realizada com o instrumento Smart Meter.

A maior parte das cargas é monofásica, e se encontram desigualmente distribuídas entre as fases do sistema de distribuição trifásico, provocando desequilíbrios de corrente, como se observa na figura 3.2. No mesmo instante, os valores das correntes foram: $l_{1}=20,88 \mathrm{~A}, \mathrm{l}_{2}=25,80 \mathrm{~A}$ e $\mathrm{I}_{3}=35,40 \mathrm{~A}$. 
Uma das formas para a minimização do problema seria a utilização de transformador com o secundário ligado em ziguezague. Além de proporcionar maior equilíbrio das correntes, contribuiria também para a redução do harmônico de corrente de $3^{\text {a }}$ ordem, muito predominante em casos de cargas eletrônicas monofásicas alimentadas por fontes chaveadas. No capítulo 7 deste estudo encontram-se informações sobre esta forma de minimização da distorção harmônica, provocada pelo harmônico de corrente de $3^{\text {a }}$ ordem.

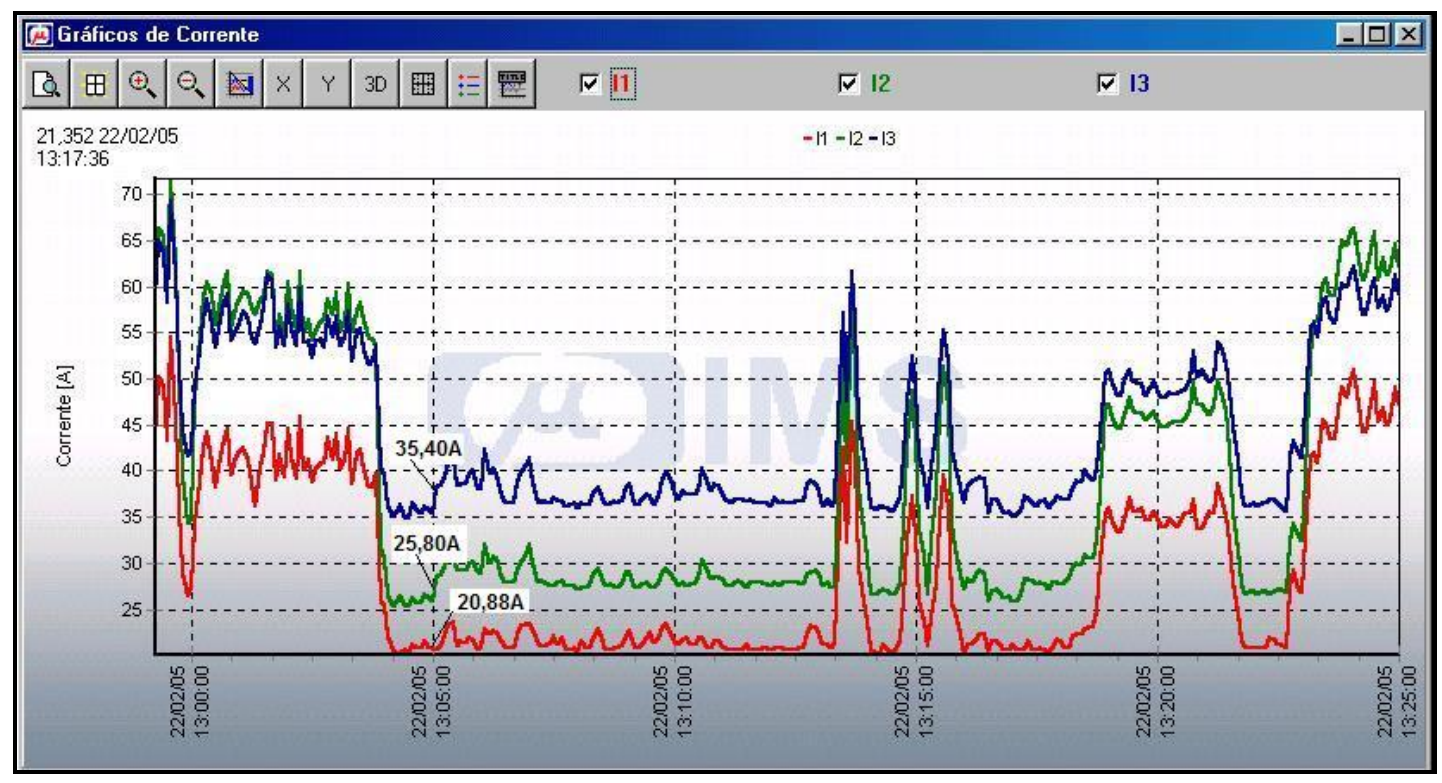

Figura 3.2 - Desequilíbrio de correntes em um dos setores administrativos do EAS

Fonte: Pesquisa de campo.

Nota: Medição realizada com o instrumento Smart Meter.

A distorção harmônica total de corrente (em função da fundamental) apresentou valores elevados, possivelmente devido à grande quantidade de equipamentos de tecnologia de informação utilizados nas áreas administrativas. Às $13 \mathrm{~h} 05 \mathrm{~min} 00 \mathrm{~s}$ os valores foram $\mathrm{THD}_{11}=9,8 \%$, $\mathrm{THD}_{12}=14,8 \%$ e $\mathrm{THD}_{13}=27,5 \%$. 


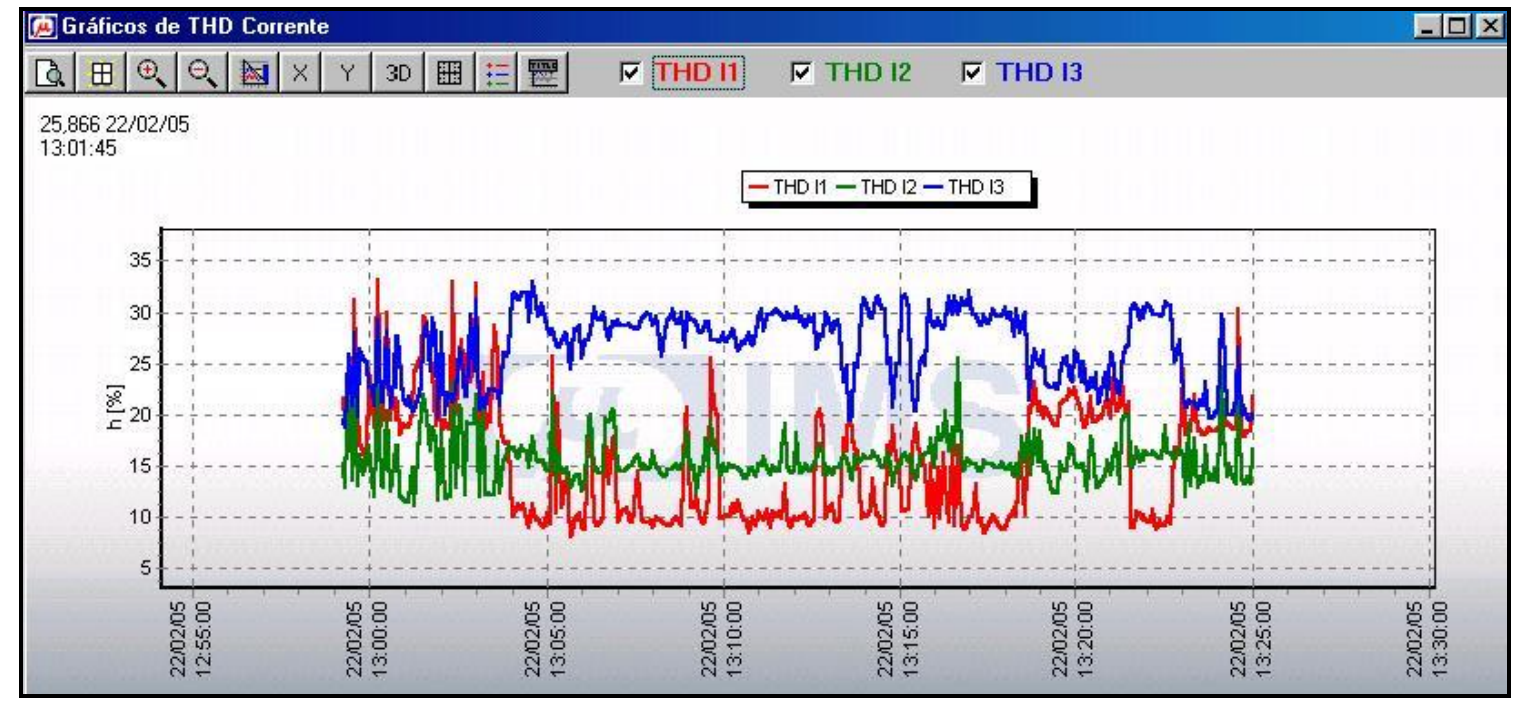

Figura 3.3 - Distorções harmônicas totais de correntes em um dos setores administrativos do EAS

Fonte: Pesquisa de campo.

Nota: Medição realizada com o instrumento Smart Meter.

No mesmo instante, o espectro harmônico de correntes na fase 1 pode ser observado pela figura 3.4 .

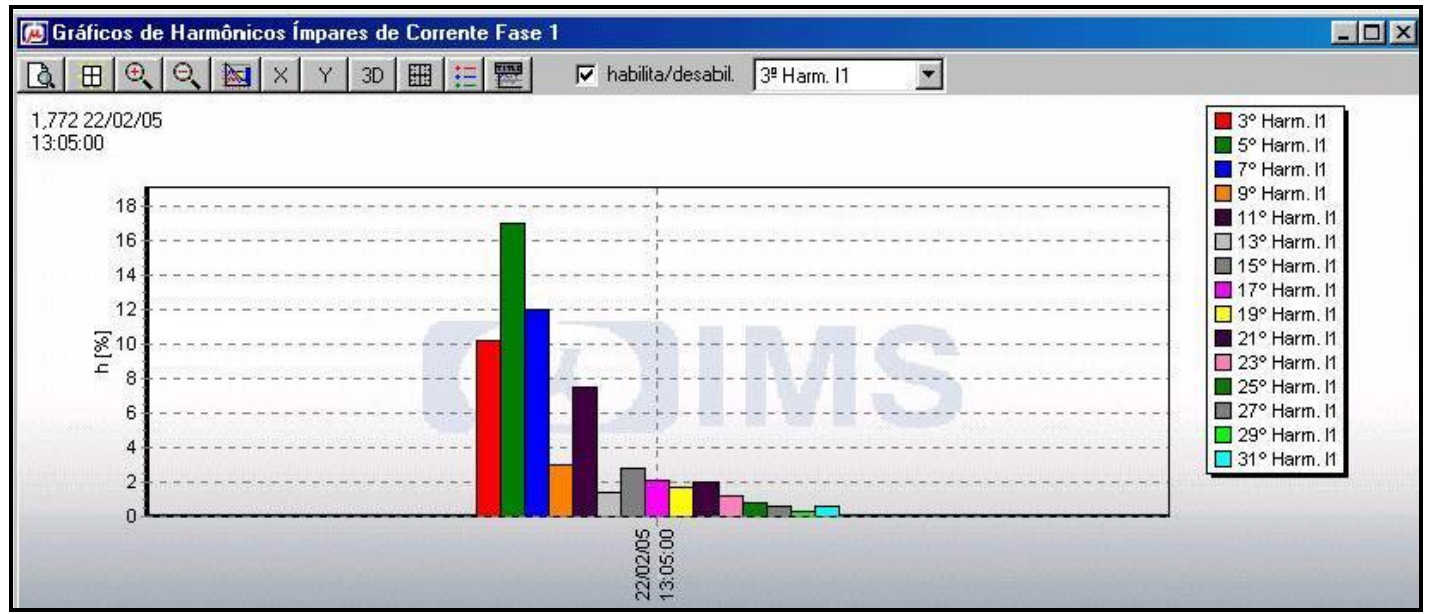

Figura 3.4 - Distorções harmônicas individuais de correntes em um dos setores administrativos do EAS

Fonte: Pesquisa de campo.

Nota: Medição realizada com o instrumento Smart Meter.

A presença de $5^{\underline{a}}$ e $7^{\underline{a}}$ harmônicas identifica a utilização de retificadores trifásicos de seis pulsos, possivelmente nos sistemas para variação de velocidade em motores de indução, nas aplicações de climatização, elevadores de passageiros, etc.

As distorções harmônicas totais de tensões nesses setores atingem, em determinados instantes, valores elevados, conforme se apresenta na figura 3.5. 


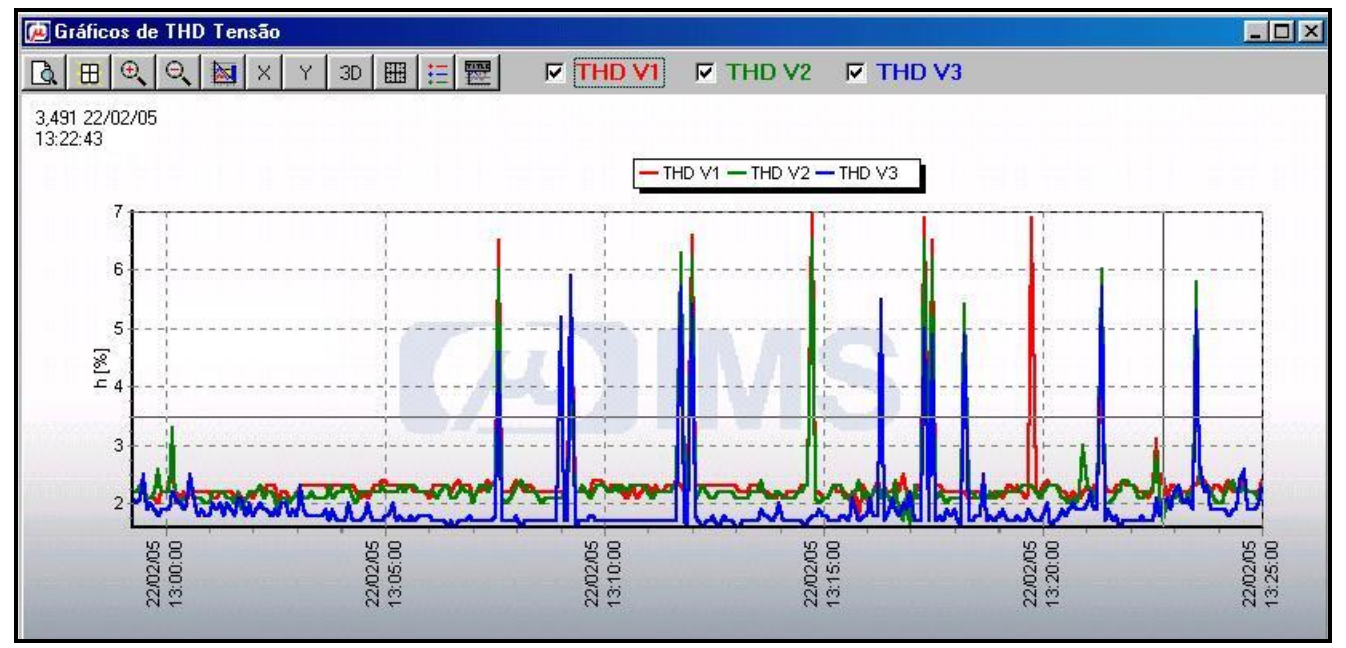

Figura 3.5 - Distorções harmônicas totais de tensões em um dos setores administrativos do EAS

Fonte: Pesquisa de campo.

Nota: Medição realizada com o instrumento Smart Meter.

O espectro harmônico de tensões, no mesmo setor, é apresentado pela figura 3.6.

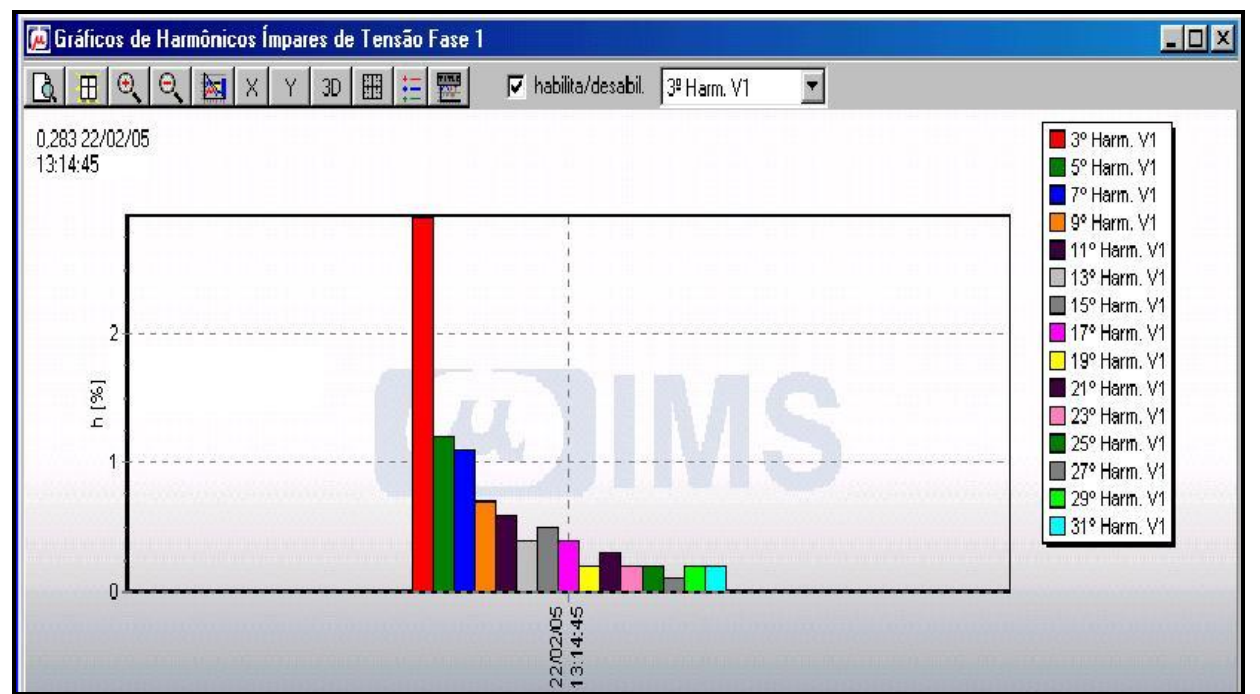

Figura 3.6 - Distorções harmônicas individuais de tensões em um dos setores administrativos do EAS

Fonte: Pesquisa de campo.

Nota: Medição realizada com o instrumento Smart Meter.

Os afundamentos de tensão foram gravados com um registrador eletrônico MARH 21, de fabricação da RMS - Indústria de Equipamentos Eletrônicos, cujas características são apresentadas no Anexo B deste estudo. A figura 3.7 apresenta um afundamento de tensão na fase $A$, com duração de $28 \mathrm{~ms}$. A medição foi efetuada no posto de entrada e medição, em tensão primária de distribuição. 


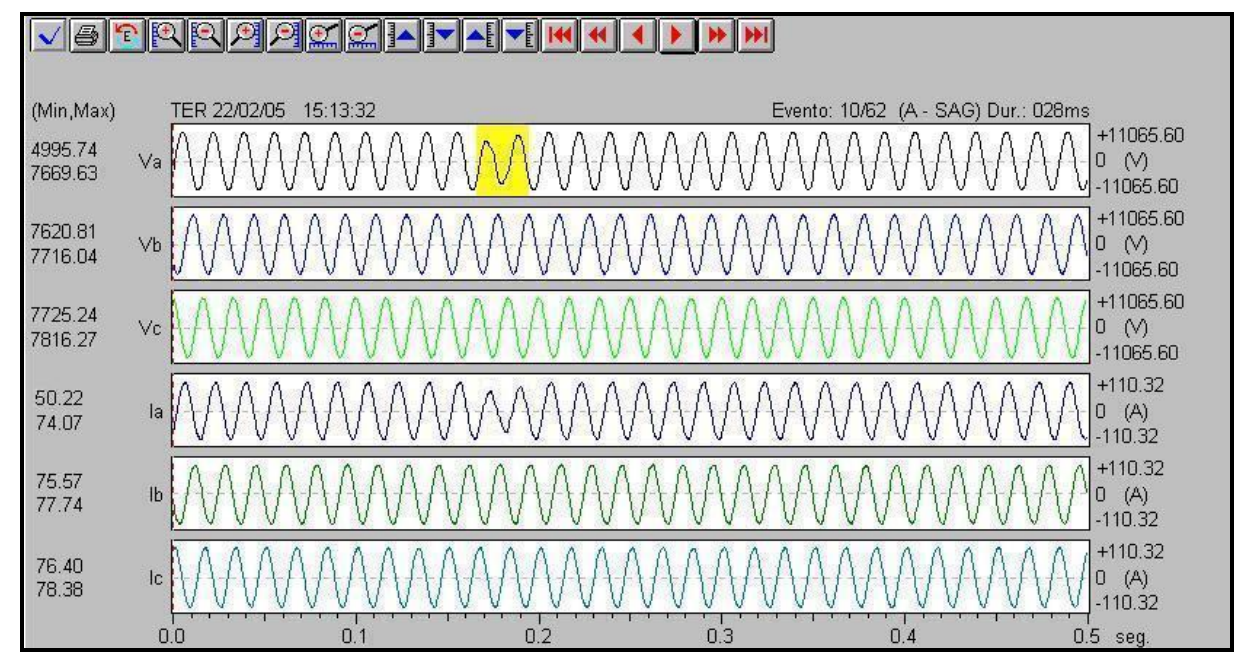

Figura 3.7 - Afundamento de tensão na fase A

Fonte: Pesquisa de campo.

Nota: Medição realizada com o instrumento MARH 21.

Considerando o valor de linha da tensão no ponto de entrega igual a $13200 \mathrm{~V}$, a tensão de fase resultante é de $7621 \mathrm{~V}$, portanto, o afundamento para $4995 \mathrm{~V}$ corresponde a 0,655 pu. Como não ocorreu aumento significativo da corrente que justificasse o afundamento de tensão, conclui-se que houve causa externa, ou seja, provocado no sistema de transmissão ou distribuição.

Em função das medições efetuadas em vários EAS, entre as quais algumas estão aqui apresentadas, chega-se à conclusão de que os EAS poderão apresentar problemas relacionados à qualidade de energia elétrica, que certamente prejudicarão o funcionamento de equipamentos sensíveis utilizados nos mesmos ambientes (KEEBLER, 2007).

\subsection{INSTALAÇÕES ELÉTRICAS}

Embora a norma brasileira ABNT NBR 13534, cuja primeira edição vigorou de 1995 a 2008, especificasse as condições exigíveis às instalações elétricas dos EAS, a fim de garantir a segurança pessoal, principalmente dos pacientes, ainda, após 12 anos, observa-se que, em muitos casos, na prática ocorre exatamente o oposto.

O governo federal, na gestão do presidente Fernando Henrique Cardoso reconheceu, por intermédio das palavras do Secretário de Gestão de Investimentos em Saúde, a necessidade de recuperação da rede física de saúde vinculada ao SUS - Serviço Único da Saúde, que se encontrava totalmente deteriorada e com alta 
obsolescência tecnológica, após longo período de ausência de investimentos significativos (CALIL et al., 2002).

Muitas vezes, equipamentos com tecnologia de ponta, instalados em EAS, são alimentados por instalações elétricas deficientes e isentas de manutenção, podendo fornecer dados incorretos. O maior prejudicado nestes casos é o paciente, cuja sobrevivência pode depender dessas informações.

Dentro do ambiente médico-hospitalar, a falha de um equipamento, seja pela qualidade da energia elétrica de suprimento, instalações elétricas deficientes, ausência de manutenção nos equipamentos e nas instalações, pode provocar a perda de uma vida humana.

Infelizmente não se encontram dados estatísticos relacionados a essas situações, porém, pergunta-se se não cabe discutir a questão de qual seria a taxa de falhas aceitável quando se trata com vidas humanas (SANTANA, 1999).

Observa-se, portanto, a criticidade do problema, uma vez que a adoção de redes de maior segurança normalmente está ligada a elevados investimentos.

Alguns estudos apresentam ocorrências de acidentes atribuídos ao mau uso de equipamentos médicos, erros de procedimentos ou mesmo falhas em equipamentos, porém, são raros os associados à má qualidade das instalações elétricas ou a problemas de qualidade de energia elétrica nesses ambientes (ANVISA, 2004).

A segurança dos pacientes e usuários, a qualidade no atendimento e a maior disponibilidade dos equipamentos médicos são os principais objetivos e preocupações nos EAS.

Nos Estados Unidos da América, nos últimos anos da década de 60, exatamente para atendimento a essas necessidades, foi criado o departamento de engenharia clínica, uma vez que cerca de três pessoas morriam por dia devido a choques elétricos provocados durante procedimentos médicos.

Essa pesquisa, embora jamais comprovada, realizada pelo cirurgião Carl W. Walter, da Harvard Medical School, despertou interesse pela segurança no uso dos equipamentos eletromédicos.

No Brasil, essa mesma consciência começou a despontar por volta da década de 80, embora ainda nos dias de hoje grandes dificuldades são encontradas em função da falta de recursos financeiros, pessoal técnico desqualificado ou, em decorrência da falta de integração entre os profissionais da saúde e os departamentos de engenharia clínica (RAMIREZ, 1996). 
É importante salientar que rotinas fiscalizadoras em EAS devem ser procedimentos de inspeção cuja finalidade é verificar as condições de adequação das instalações físicas prediais (infra-estrutura) e as instalações elétricas específicas, que são fundamentais na garantia da segurança no uso dos equipamentos eletromédicos.

A Anvisa tem como missão institucional a promoção da proteção da saúde da população por intermédio do controle sanitário da produção e da comercialização de produtos e serviços, inclusive dos ambientes, dos processos, dos insumos e das tecnologias a eles relacionadas (ANVISA, 2005).

No entanto, o foco desse atendimento está mais voltado ao aspecto arquitetônico, incluindo o fluxo de materiais e de pessoas com objetivo de se evitar possíveis contaminações hospitalares. Essas informações foram obtidas por intermédio de consulta aos registros de aprovação dos projetos de EAS na região do Alto Tietê. O guia básico para instalações ordinárias nesses ambientes é disponibilizado pela Anvisa, por meio da resolução RDC no 50 (ANVISA, 2002), que de forma bastante organizada, apresenta as exigências para execução das instalações físicas de unidades hospitalares. Embora essa resolução apresente as exigências a serem cumpridas para as instalações elétricas, a inexistência de um corpo técnico especializado inviabiliza uma fiscalização efetiva.

Com a finalidade de minimizar essa situação, a Anvisa exige, após a conclusão da obra, um laudo de conformidade com as normas vigentes. A RDC 50 está estruturada em sete capítulos, possuindo um total de 144 páginas. Com referência às instalações elétricas, a Norma ABNT NBR 13534 é citada na página 112, como norma complementar para os casos não descritos nessa resolução.

Visitas a doze unidades hospitalares, sendo sete do setor público e cinco do privado, na região da Grande São Paulo, foram suficientes para verificar que, em alguns casos, as instalações elétricas não atendem às normas técnicas vigentes. Documentos desatualizados, técnicas inadequadas de manutenção e instalação, além da total falta de qualificação dos eletricistas, foram algumas das situações mais encontradas.

Os administradores dos EAS devem estar conscientes dessa responsabilidade, disponibilizando recursos para qualificação de mão-de-obra e aquisição de materiais que atendam à normalização pertinente.

Ressalta-se que este capítulo não tem como objetivo ensinar a projetar ou manter as instalações elétricas dentro dos padrões aceitáveis, mas sim, apresentar fatores que 
poderão contribuir para a sua degradação, por intermédio da apresentação de casos reais observados pelo próprio autor, durante sua pesquisa de campo.

Como já mencionado, no Brasil, as prescrições gerais para as instalações elétricas de baixa tensão estão contidas na ABNT NBR 5410 (2004), cuja última edição entrou em vigor em março de 2005. A ABNT NBR 13534 (2008) complementa a norma citada no caso de instalações elétricas em EAS.

No âmbito da segurança do trabalho, a publicação em 8 de dezembro de 2004 da nova NR-10 - Segurança em Instalações e Serviços em Eletricidade, colocou o Brasil em igualdade com os padrões internacionais de segurança no trabalho, no setor elétrico. A norma é objetiva e está direcionada ao trabalhador, parte mais importante dos processos produtivos das empresas, regulamentando de forma clara o emprego das boas técnicas nas instalações e nos serviços com eletricidade de forma a preservar a vida e garantir que os ambientes de trabalho sejam mais seguros (PINTO et al., 2008).

Atenção especial deve ser dada ao sistema de aterramento, como forma de garantia da continuidade segura do fornecimento de energia elétrica de forma estável, proporcionando a correta atuação dos dispositivos de proteção e a segurança pessoal, no tocante a acidentes elétricos (SANTANA, 1999; KEEBLER, 2007).

A maioria das instalações elétricas dos EAS é tratada com o mesmo descaso que pode ser observado em outras atividades, sejam industriais, comerciais ou de serviço.

A falta de diagramas elétricos atualizados, identificação nos dispositivos de comando e proteção contidos nos painéis, identificação dos pontos de aterramento, entre outros, também são algumas das causas que comprometem o funcionamento seguro das instalações e provocam acidentes, muitas vezes de elevada gravidade (ATLAS, 2009).

\subsubsection{Apresentação de Casos}

A seguir, apresentam-se algumas fotos relativas às instalações elétricas de três EAS, localizados na região da Grande São Paulo. Comentários sobre os riscos decorrentes das "não conformidades" estão apresentados em cada caso. 


\subsubsection{Hospital Público A}

Trata-se de um estabelecimento público que, como tantos outros, demonstra inúmeras irregularidades na execução e manutenção das instalações elétricas. Muitas vezes, equipamentos modernos com tecnologia avançada, são alimentados por essas instalações, prejudicando totalmente 0 seu funcionamento ou apresentando dados não confiáveis que poderão levar a tratamentos inadequados.

Este hospital, da rede pública estadual, atende a um grande número de pessoas da zona leste da Grande São Paulo.

Condutores elétricos, fabricados em conformidade com a Norma ABNT NBR NM 247-3 (2002) são isentos de cobertura e, portanto, não possuem proteção contra choques mecânicos que possam danificar sua isolação. Como forma de evitar acidentes, que este fato poderia provocar, devem ser instalados somente em condutos fechados, conforme determinação da Norma ABNT 5410.

As emendas e recomposição da isolação também não atendem à referida norma. Condutores com cores diferentes foram emendados, dificultando a identificação e colocando sob risco de acidentes os serviços de manutenção. As figuras 3.8 e 3.9 apresentam essas situações.



Figura 3.8 - Condutores elétricos sem proteção mecânica

Fonte: Pesquisa de campo. 




Figura 3.9 - Condutores elétricos sem proteção mecânica

Fonte: Pesquisa de campo.

No mesmo estabelecimento foram encontrados painéis de distribuição totalmente abertos sem proteção contra contatos diretos, não apresentando, portanto, a proteção básica contra choques elétricos, exigido na ABNT NBR 5410, item 5.1.

Os disjuntores estão montados sob fundo em madeira, interligados por meio de condutores. A inexistência de barramentos provoca desequilíbrios de corrente e eventualmente de tensão, prejudicando o funcionamento correto dos equipamentos ligados a esse painel. As figuras 3.10 e 3.11 apresentam essas situações.

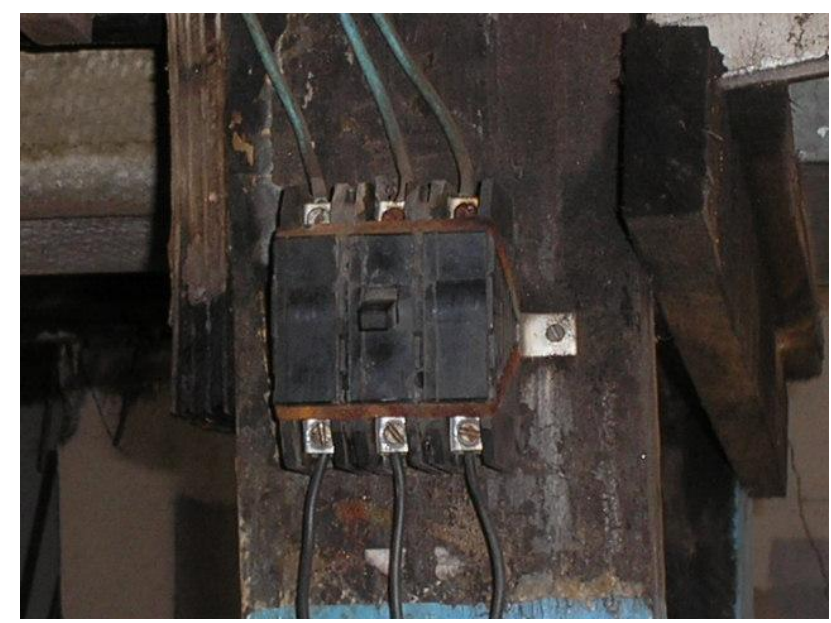

Figura 3.10 - Instalações improvisadas no interior de EAS Fonte: Pesquisa de campo. 




Figura 3.11 - Painel de fabricação "caseira" instalado no EAS

Fonte: Pesquisa de campo.

Nos vestiários administrativos, as instalações dos chuveiros desobedecem todos os conceitos de segurança. Devido à inexistência de caixa de ligação, a penetração de umidade nos condutores da rede elétrica poderá provocar graves acidentes. Os chuveiros não possuem resistência blindada e, o circuito não incorpora dispositivo diferencial residual, não atendendo, portanto, ao item 5.1.3.2 da ABNT NBR 5410. A figura 3.12 apresenta essa situação.



Figura 3.12 - Instalação de chuveiro no vestiário do EAS

Fonte: Pesquisa de campo.

Em muitas partes da instalação hospitalar, encontram-se caixas de derivação sem tampas, com grande quantidade de condutores expostos. Nota-se a presença de cordão paralelo, fabricado conforme as especificações da Norma ABNT NBR 13249 (2000) e instalado no interior de eletroduto. No entanto, o item 6.2.3.2 da ABNT NBR 5410 destaca que esse procedimento não é permitido. A figura 3.13 apresenta um desses casos encontrados. 


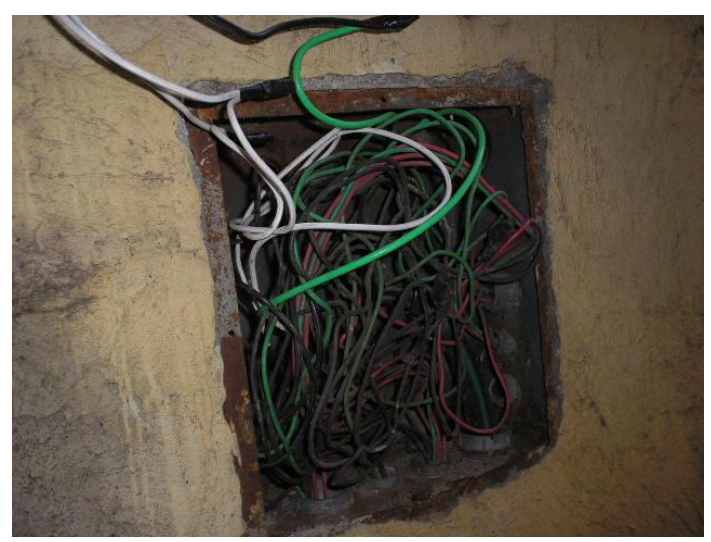

Figura 3.13 - Condutores elétricos expostos e utilização incorreta de cordão paralelo Fonte: Pesquisa de campo.

\subsubsection{Hospital Público B}

O hospital pertence à rede pública municipal e possui 50 leitos.

Logo na entrada do estabelecimento, no setor de atendimento ao público, observase, conforme registra a figura 3.14, um painel sem a barreira de proteção, onde se localiza a chave seccionadora.

Em função de uma alimentação retirada da parte interna, o painel é mantido com a porta aberta, provocando risco de tensão de contato em uma pessoa inadvertida, a exemplo da criança que se encontra nas proximidades.

Essa atitude evidencia a irresponsabilidade do profissional de manutenção que realizou essa ligação.

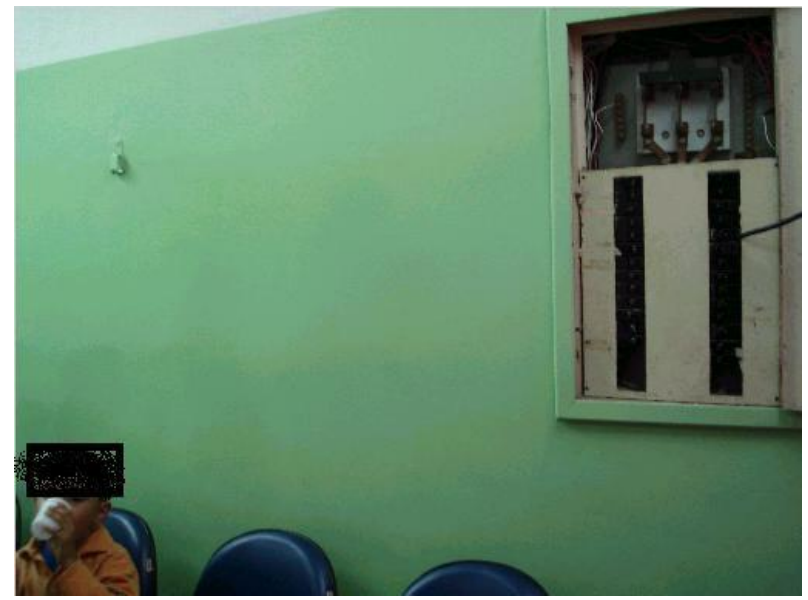

Figura 3.14 - Painel sem porta instalado na entrada do EAS

Fonte: Pesquisa de campo. 
Ainda, no mesmo painel, observa-se uma chave geral do tipo "faca", bloqueada com um pedaço de condutor elétrico para impossibilitar o seu desligamento. Esse tipo de dispositivo, não apropriado para desligamento sob carga, apresenta ainda, elevado risco de choque elétrico.

Além do mais, na parte superior dessa chave foi efetuada uma derivação com cordão paralelo e totalmente sem proteção, executada para a alimentação de alguma carga no interior do complexo hospitalar.

Conforme determina a ABNT NBR 5410, cordões paralelos não devem ser utilizados no interior de eletrodutos, pelos motivos já apresentados.

Outra irregularidade pode ser observada na figura 3.15, pela interligação do condutor de proteção no barramento de neutro, caracterizando um esquema de aterramento TN-C, onde o condutor neutro assume também a função de condutor de proteção, configuração não admitida em EAS, segundo a ABNT NBR 13534, item 4.2.2.2.101.



Figura 3.15 - Neutro e condutor de proteção interligados

Fonte: Pesquisa de campo.

Praticamente em todos os andares, vários painéis de distribuição não possuem identificação dos disjuntores, dificultando a localização de cargas que precisam ser desligadas. Essa incerteza poderá provocar desligamentos indevidos, colocando sob risco setores vitais do hospital. Os painéis também não possuem dispositivo para desligamento geral. A figura 3.16 apresenta uma dessas situações, totalmente em desacordo com a ABNT NBR 5410, item 6.1.5.1. 


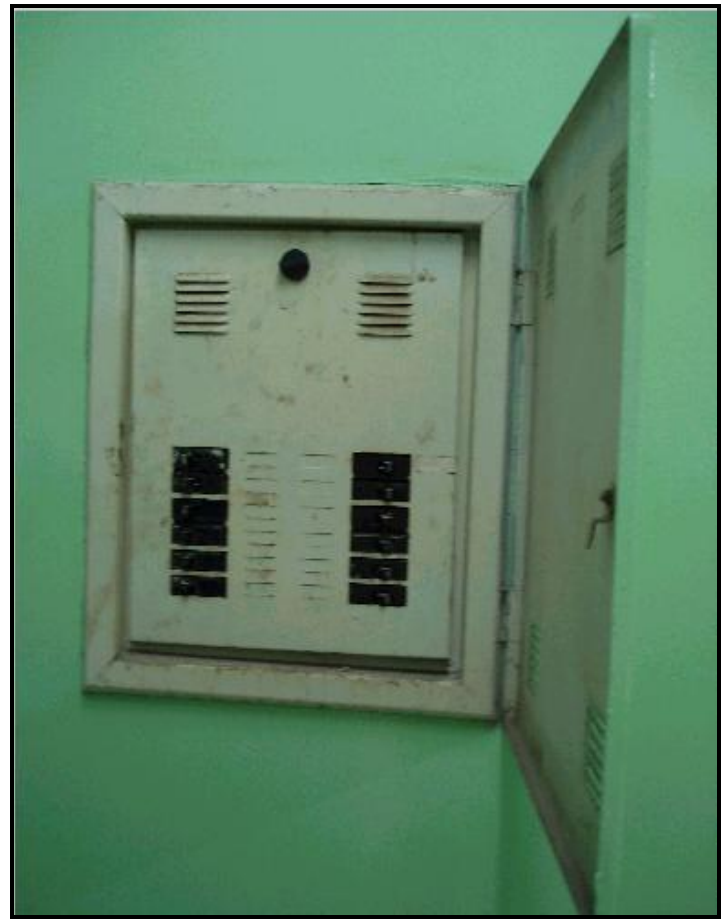

Figura 3.16 - Painel sem dispositivo de desligamento geral e com circuitos sem identificação

Fonte: Pesquisa de campo.

Para a manobra e proteção de cargas alimentadas em duas fases, utilizou-se de disjuntores unipolares interligados por pedaços de condutores, conforme se observa na figura 3.17. Esse procedimento está totalmente em desacordo com a ABNT NBR 5410, item 9.5.4.

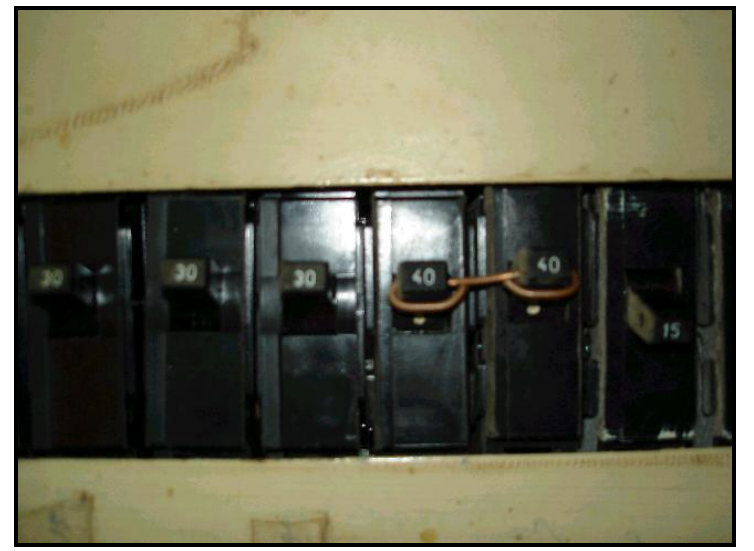

Figura 3.17 - Disjuntores unipolares interligados

Fonte: Pesquisa de campo. 
A figura 3.18 apresenta outro painel de distribuição confirmando o esquema de aterramento ser TN-C, não admitido pela ABNT NBR 13534 e citado pela Anvisa RDC 50, no item 7.2.3.1.

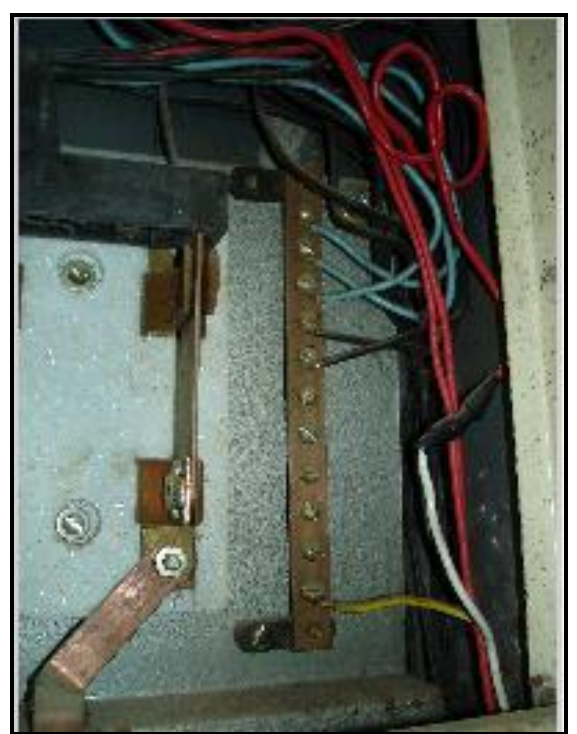

Figura 3.18 - Utilização de sistema de aterramento TN-C em EAS

Fonte: Pesquisa de campo.

Talvez, o caso de maior gravidade observado tenha sido o descaso na execução de dois pontos de alimentação para novas cargas, derivados de uma instalação existente. A figura 3.19 apresenta essa situação.

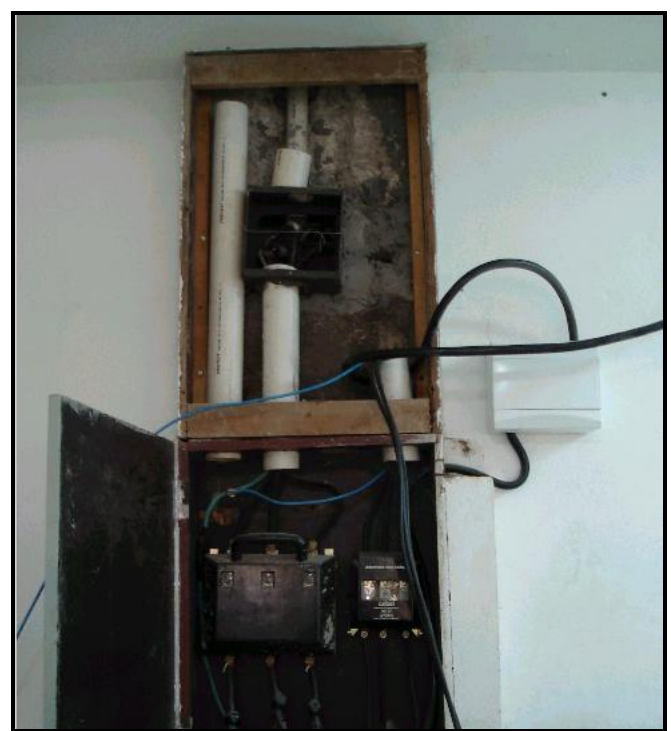

Figura 3.19 - Ligações improvisadas em EAS

Fonte: Pesquisa de campo. 
Outro caso que chamou a atenção foi a utilização de dispositivo DR, totalmente incompatível com o sistema de aterramento TN-C. No mesmo painel, foi localizado um fusível eliminado por um jumper. As figuras 3.20 e 3.21 apresentam essas situações.

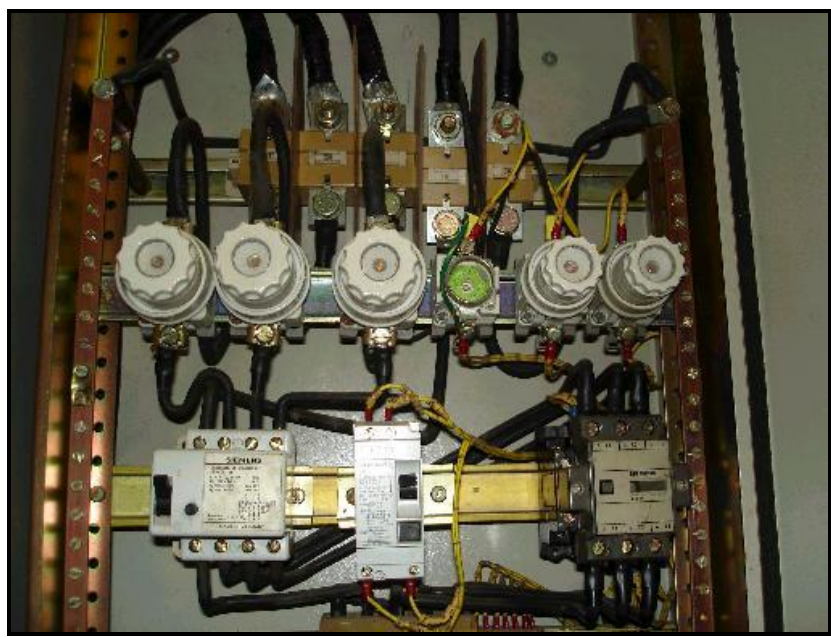

Figura 3.20 - Fusível eliminado por jumper

Fonte: Pesquisa de campo.

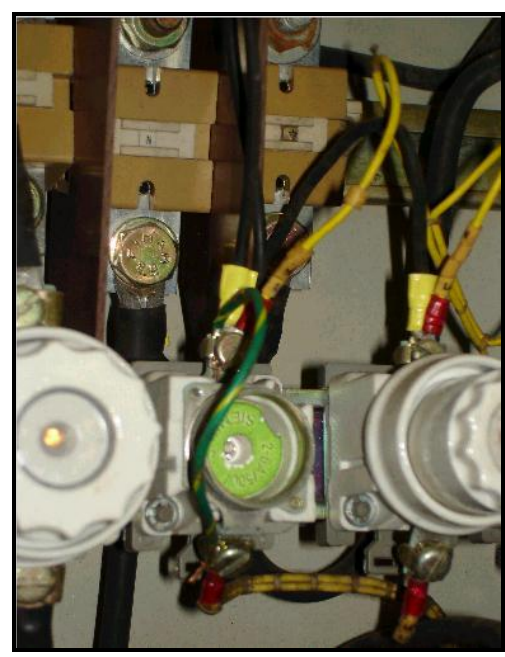

Figura 3.21 - Detalhe ampliado Fonte: Pesquisa de campo.

A maioria das tomadas de corrente não possui o condutor de proteção e encontra-se em péssimo estado de conservação. As figuras 3.22, 3.23 e 3.24 ilustram alguns desses casos. A inexistência do condutor de proteção nas tomadas contraria o item 5.1.2.2.3.6 da ABNT NBR 5410.



Figura 3.22 - Utilização de tomadas com apenas 2 pólos, em EAS Fonte: Pesquisa de campo. 

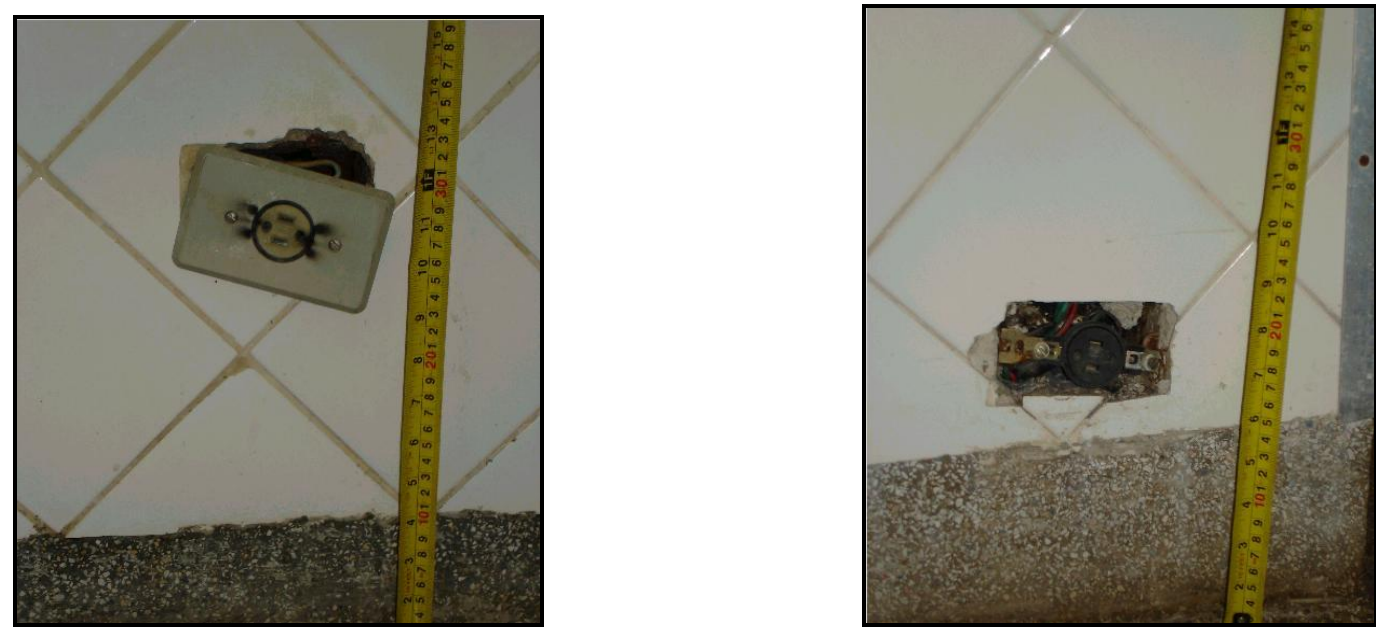

Figuras 3.23 e 3.24 - Utilização de tomadas com apenas 2 pólos, em EAS Fonte: Pesquisa de campo.

Pelo fato das tomadas não possuírem o condutor de proteção, uma prática usual dos eletricistas é a retirada do pino "terra" do plugue do equipamento, ou a utilização de adaptadores. As figuras 3.25, 3.26 e 3.27 apresentam alguns dos casos encontrados.



Figura 3.25 - Unidade de Terapia Intensiva (UTI) Fonte: Pesquisa de campo.

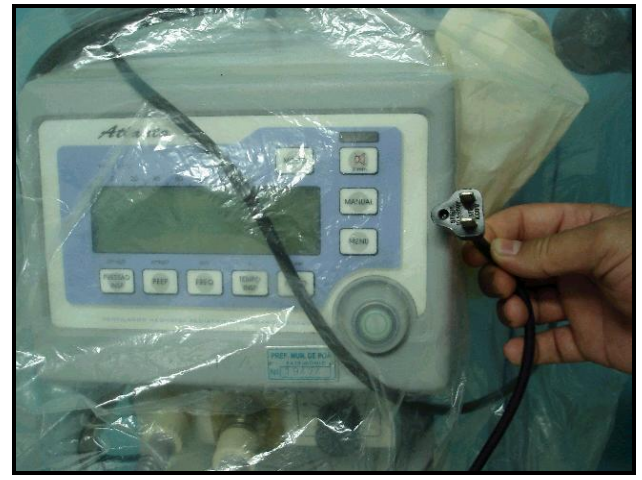

Figura 3.26 - Plugue sem o condutor de proteção

Fonte: Pesquisa de campo.

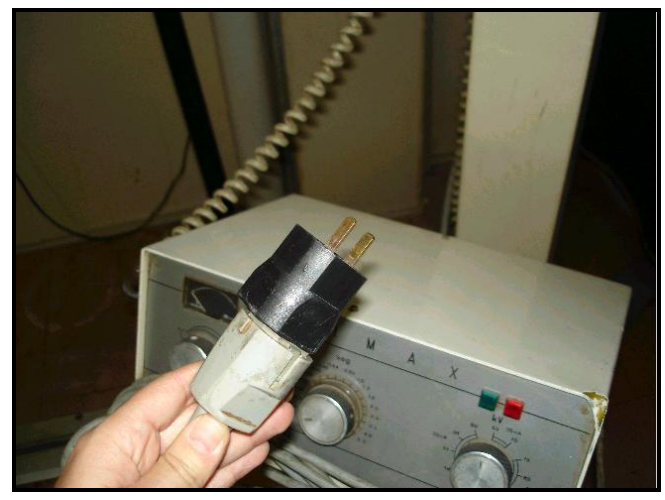

Figura 3.27 - Uso de adaptador em tomada tipo Schuko

Fonte: Pesquisa de campo. 
Um dos equipamentos de raios X apresenta uma "régua de tomadas" totalmente em mau estado de conservação, para ser utilizada na alimentação múltipla de equipamentos. Esse conjunto, sendo alimentado a partir de uma única tomada, certamente provocará sobrecarga que acarretará graves conseqüências. A irregularidade é observada na figura abaixo.

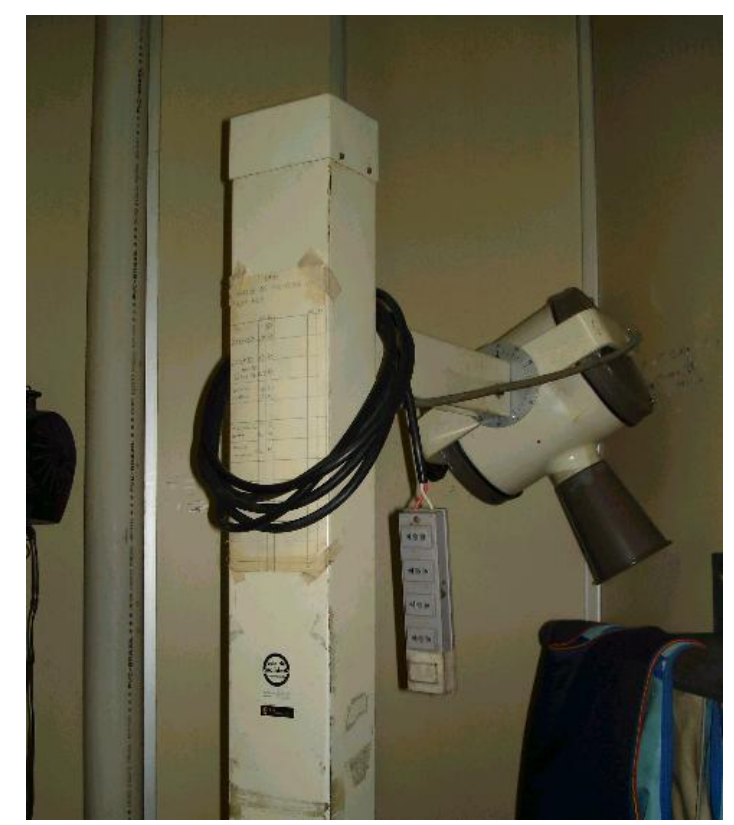

Figuras 3.28 - Utilização de régua para alimentação múltipla de vários equipamentos Fonte: Pesquisa de campo.

O sistema de bombeamento desse EAS é composto por dois motores de indução de $10 \mathrm{cv}$, instalados em compartimento apropriado, mas, com condutores elétricos totalmente aparentes e sem fixação, facilitando a danificação por golpes acidentais e a possibilidade de curto-circuito. Trata-se de instalação atual, mas infelizmente, sem os cuidados básicos necessários. A presença de duas bombas, sendo uma de reserva, demonstra a preocupação do projetista com a continuidade de fornecimento d'água em caso de defeito em uma delas. As figuras 3.29 e 3.30 apresentam esse caso. 

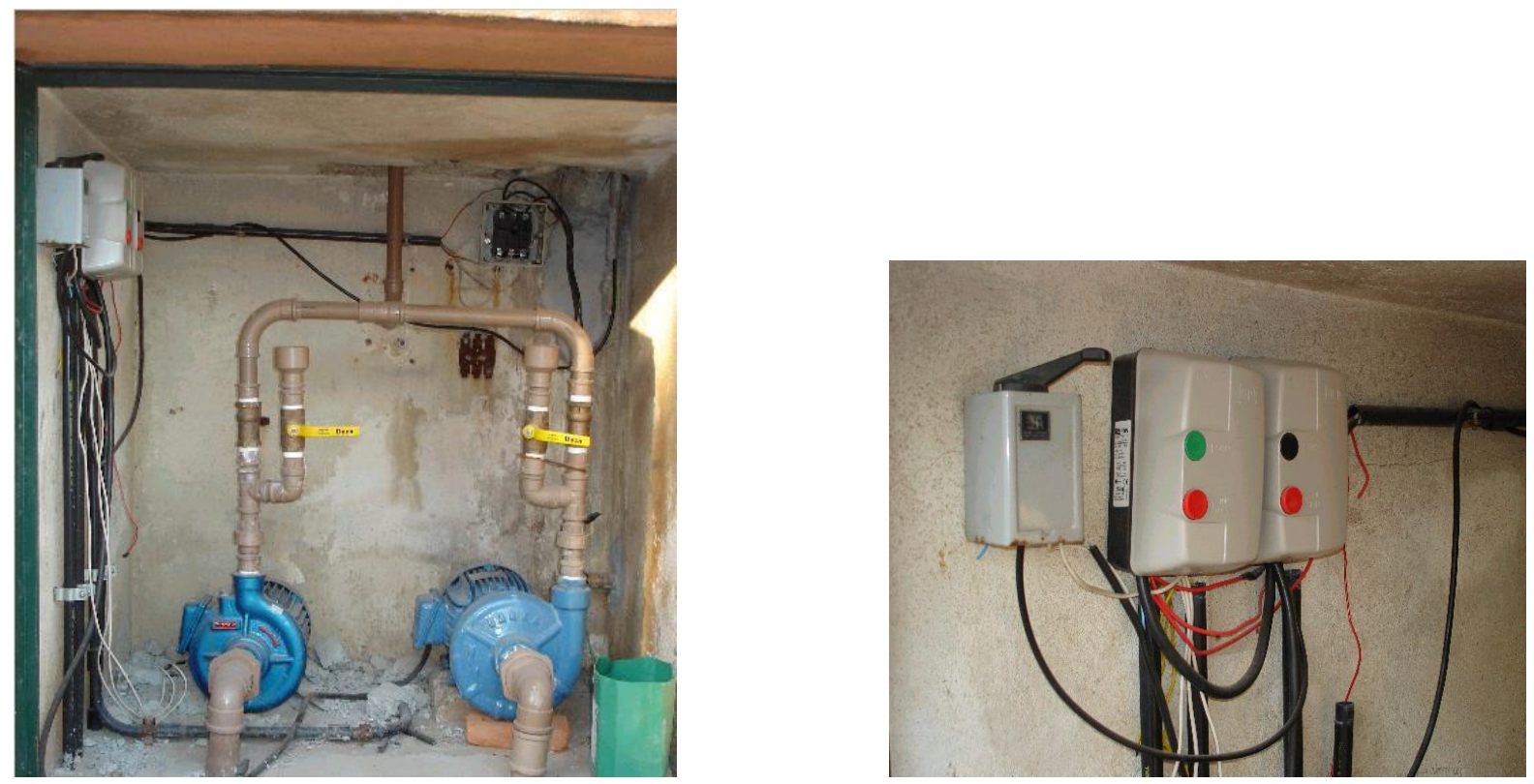

Figuras 3.29 e 3.30 - Instalação de condutores isolados sem proteção mecânica

Fonte: Pesquisa de campo.

A subestação transformadora, responsável pelo suprimento de energia do EAS, possui um único transformador, estando, portanto, em desacordo com a RDC 50 da Anvisa, que no item 7.2.1 exige no mínimo dois transformadores, cada um com capacidade de, no mínimo, metade da carga prevista para a edificação.

As figuras 3.31 e 3.32 apresentam essas condições, mostrando uma cela vazia. $O$ administrador do hospital informou que o segundo transformador foi retirado logo após a conclusão e aprovação da obra.



Figura 3.31 - Transformador no 1

Fonte: Pesquisa de campo.

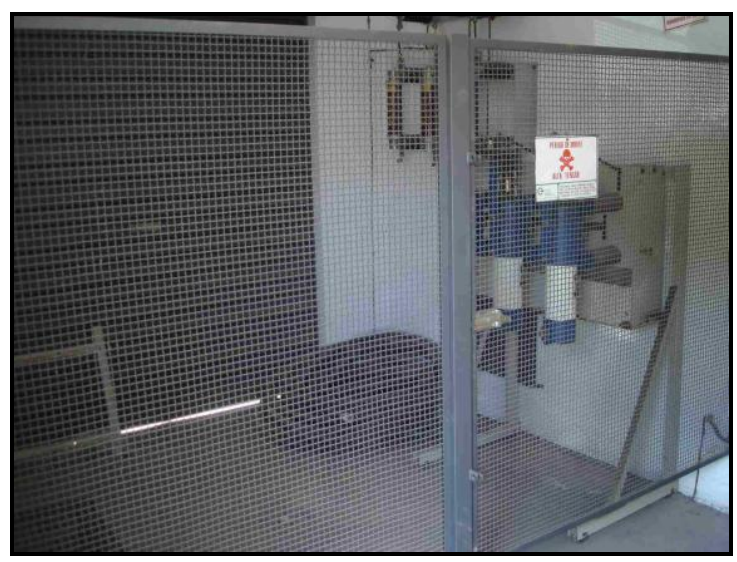

Figura 3.32 - Cela do transformador $n=2$, vazia Fonte: Pesquisa de campo. 


\subsubsection{Hospital Particular C}

Num outro extremo, a cidade de São Paulo conta com importantes hospitais, que apresentam excelentes instalações elétricas, tanto no setor público quanto no privado. Neles, pode-se observar a preocupação com a obediência às normas nacionais e internacionais, pois muitos dos equipamentos utilizados nos procedimentos médicos são sensíveis às perturbações elétricas e exigem redes de excelente qualidade, o que é fundamental para o funcionamento correto.

Entrevista com os responsáveis pelos departamentos de projetos e de manutenção, realizada em um dos EAS do setor privado, mostrou a preocupação com as instalações elétricas, visando sempre garantir uma energia dentro dos parâmetros aceitáveis e isenta de perturbações que possam provocar panes em equipamentos, colocando os pacientes sob riscos.

A unidade hospitalar conta com modernos sistemas de automação, incluindo sistemas supervisórios para controle de energia elétrica, controle de acesso, detecção e extinção de incêndios, sistemas de abastecimento d'água, elevadores, entre outros. A figura 3.33 apresenta uma parte da sala onde esses sistemas encontram-se instalados.

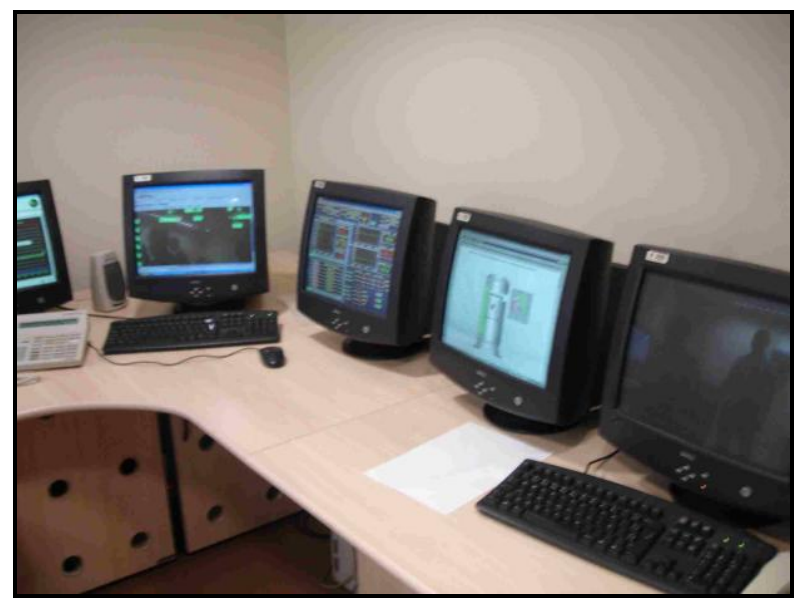

Figura 3.33 - Sistemas supervisórios controlando todas as instalações do EAS Fonte: Pesquisa de campo.

As documentações das instalações são arquivadas em sistemas computadorizados, de fácil acesso aos setores envolvidos e apresentam-se atualizadas. $O$ departamento de manutenção utiliza-se de técnicas preventivas e preditivas, de forma a aumentar a confiabilidade dos equipamentos e evitando paradas não programadas. 
O complexo hospitalar recebe energia elétrica na tensão de $13800 \mathrm{~V}$, convertendo-a em seguida para 380 V. O sistema de iluminação e as tomadas de uso geral são alimentadas na tensão de $220 \mathrm{~V}$, enquanto os equipamentos de maior potência, em sistemas trifásicos, a 380 V. O EAS está dividido em quatro blocos principais, e possui uma demanda contratada de $4000 \mathrm{~kW}$.

A figura 3.34 mostra a cabina primária, onde se localizam os sistemas de medição, proteção, e distribuição em média tensão para alimentação dos quatro blocos. Pela foto, observa-se a preocupação com o atendimento às normas, principalmente no aspecto de segurança.

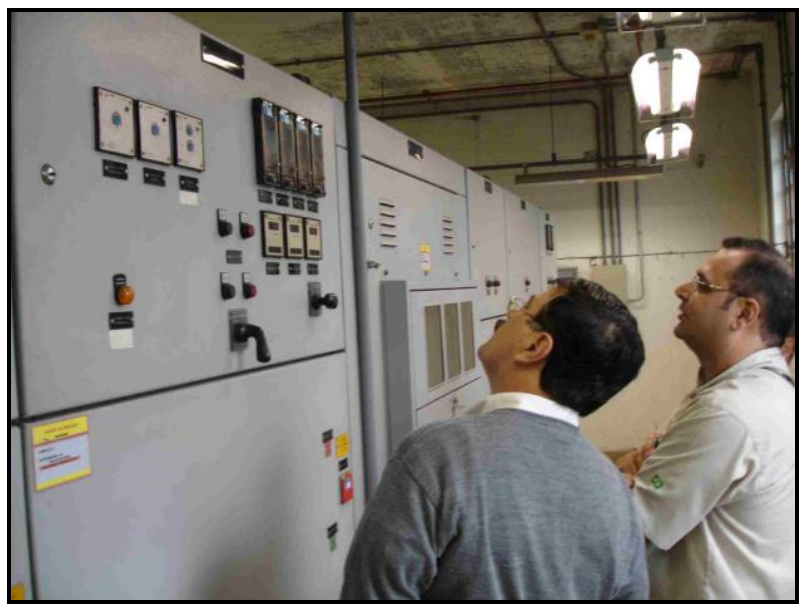

Figura 3.34 - Cabina Primária 13,8 kV

Fonte: Pesquisa de campo.

O sistema de proteção é totalmente automatizado e interligado ao sistema supervisório do EAS.



Figura 3.35 - Sistema de proteção dos circuitos de 13,8 kV

Fonte: Pesquisa de campo. 
Os sete disjuntores existentes são do tipo a vácuo, com capacidade para $630 \mathrm{~A}$. A figura 3.36 apresenta o local mencionado.

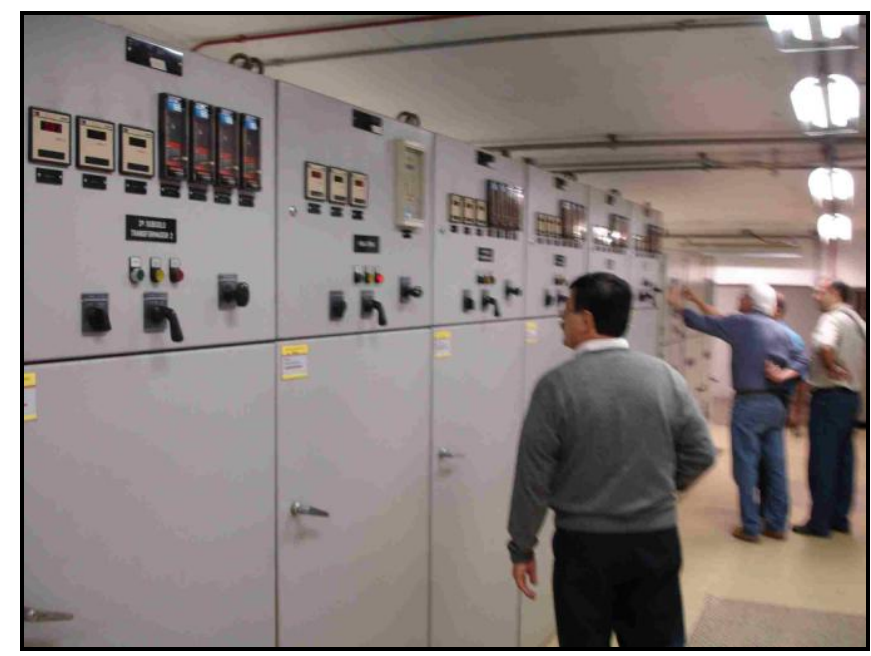

Figura 3.36 - Conjunto de disjuntores a vácuo, instalados na Cabina Primária Fonte: Pesquisa de campo.

Além dos geradores de baixa tensão, o hospital está equipado com mais três geradores de $13,8 \mathrm{kV}$, com potência total de $6000 \mathrm{kVA}$, o que é suficiente para o suprimento de toda a energia elétrica necessária, em caso de emergência. A figura 3.37 apresenta o local onde se encontram instalados esses geradores.

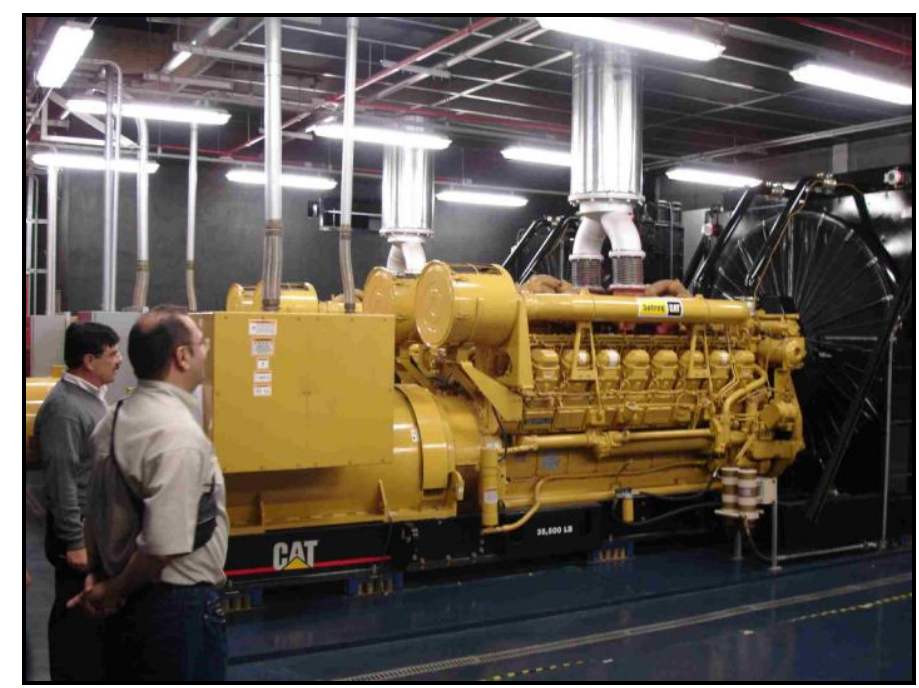

Figura 3.37 - Vista de um dos três geradores de 2000 kVA/13,8 kV Fonte: Pesquisa de campo. 
Num dos blocos visitados, cuja foto é apresentada na figura 3.38, o sistema de distribuição primária conta com quatro disjuntores a vácuo com capacidade para 630 A.

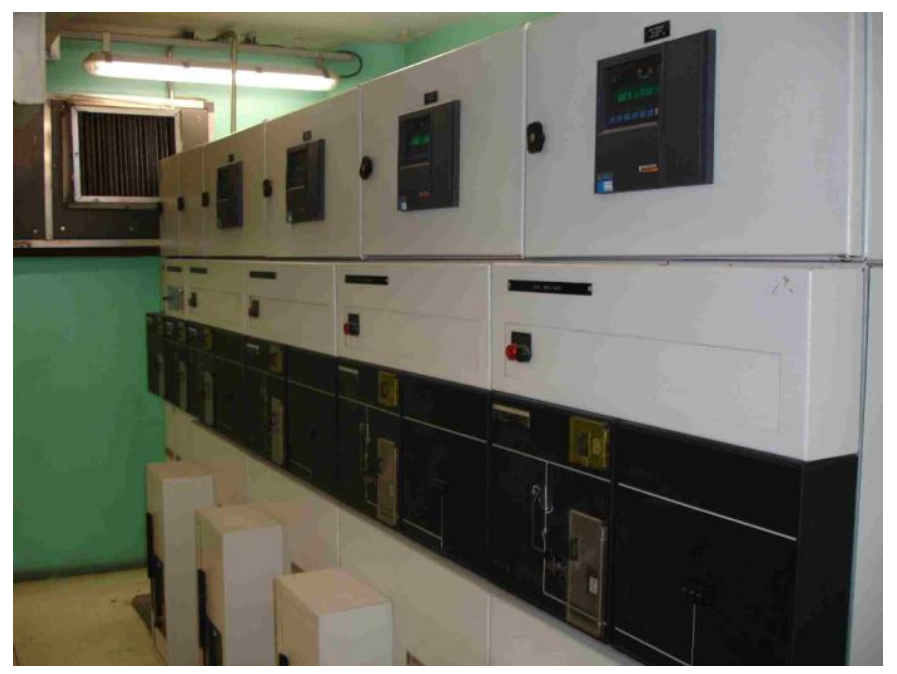

Figura 3.38 - Conjunto de quatro disjuntores a vácuo de 630 A /13,8 kV Fonte: Pesquisa de campo.

Os transformadores, instalados no próprio corpo do edifício, possuem isolamento a seco com potência unitária de 1000 kVA. Portanto, a subestação atende plenamente às recomendações da ABNT NBR 14039 (2005). A figura 3.39 apresenta um transformador de reserva sem o invólucro de proteção.

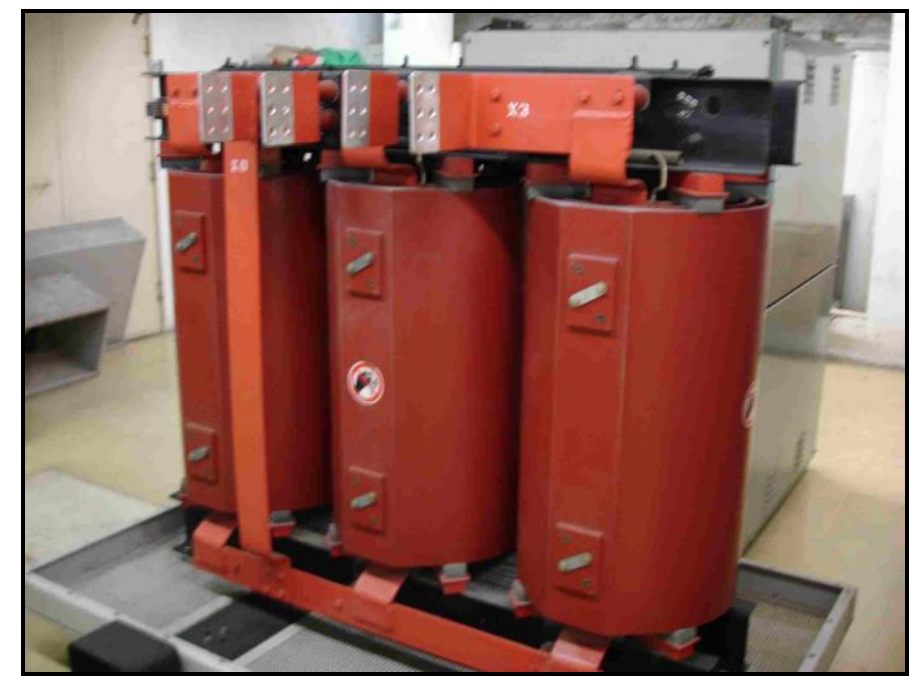

Figura 3.39 - Transformador com isolamento a epóxi Fonte: Pesquisa de campo. 
Os painéis de distribuição em baixa tensão, da mesma subestação, podem ser observados na figura 3.40 .

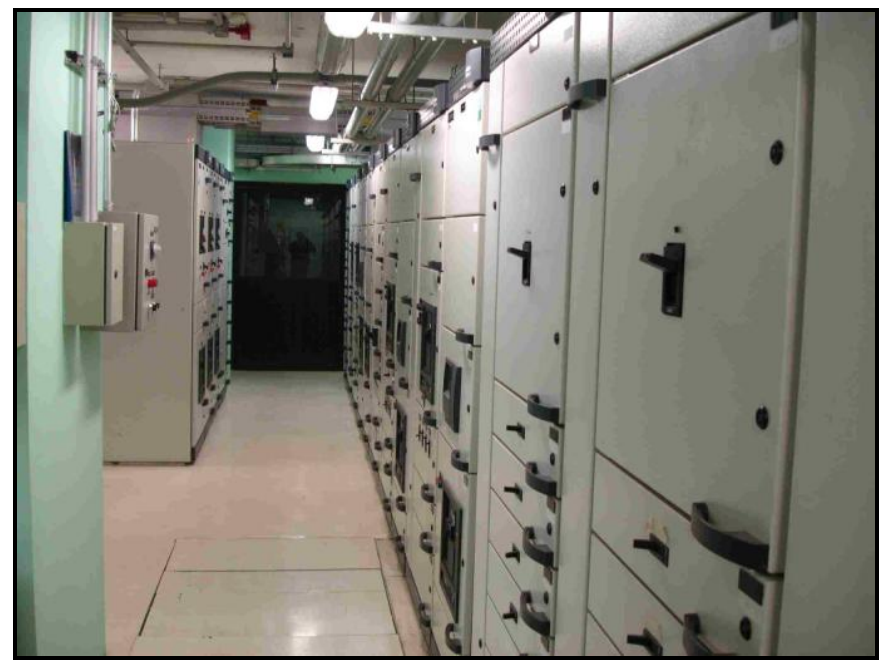

Figura 3.40 - Painéis de distribuição em baixa tensão - 380/220 V

Fonte: Pesquisa de campo.

A figura 3.41 mostra um detalhe interno de um dos inúmeros painéis de baixa tensão, onde se observa os barramentos com capacidade para 5000 A. Denominados de conjuntos de manobra e controle, estão em concordância com a Norma ABNT NBR IEC 60439 (2003).



Figura 3.41 - Barramentos para $5000 \mathrm{~A}$ instalados em painéis de baixa tensão - 380/220 V Fonte: Pesquisa de campo.

O controle do fator de potência é feito por um sistema de compensação de energia reativa em tempo real que utiliza chaves estáticas. Essa técnica está apresentada no 
capítulo 7, e trata-se de um sistema isento de perturbações durante o chaveamento dos capacitores. A figura 3.42 apresenta a placa com as características de uma das quatro unidades instaladas no EAS.

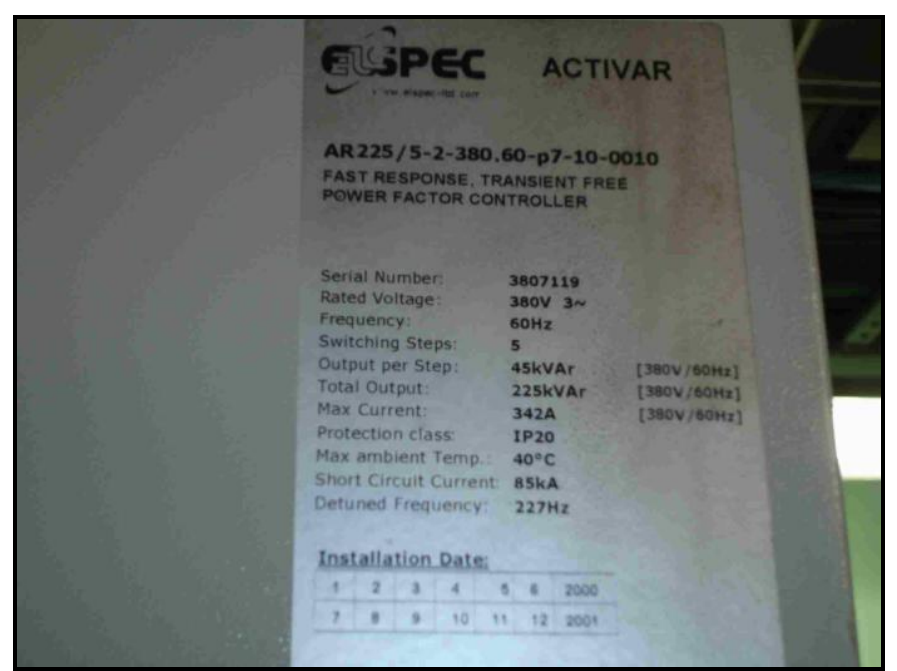

Figura 3.42 - Placa de identificação do sistema de compensação de reativos em tempo real Fonte: Pesquisa de campo.

As cargas críticas das unidades de terapia intensiva, centro de recuperação e centro cirúrgico contam com dois UPS de 160 kVA cada unidade, obedecendo às recomendações da ABNT NBR 13534. Uma dessas unidades é apresentada na figura 3.43 .

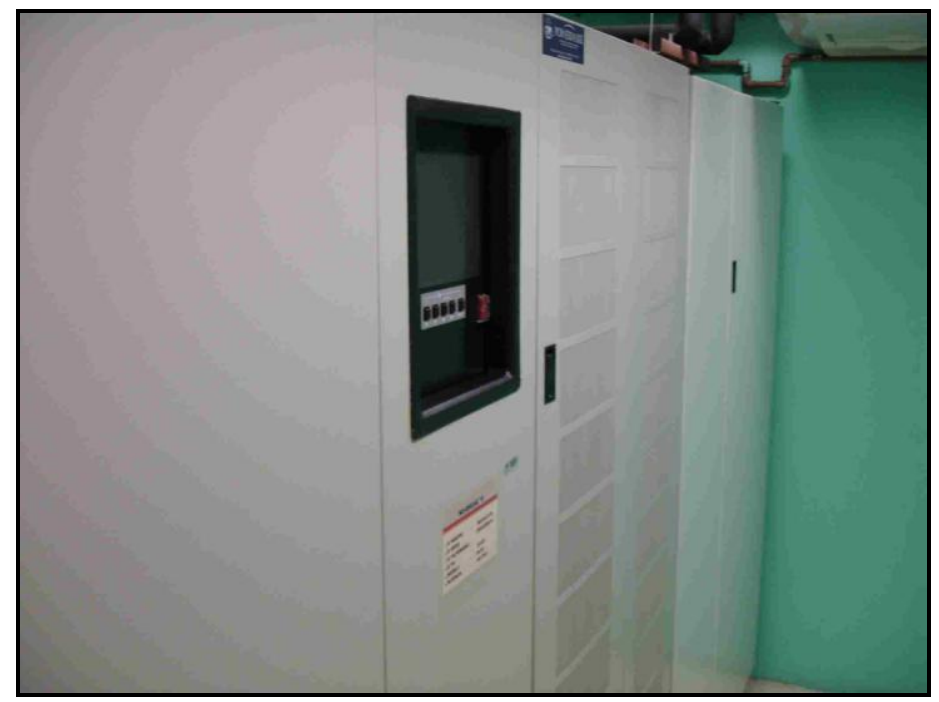

Figura 3.43 - Sistema de UPS das áreas críticas do EAS Fonte: Pesquisa de campo. 
No mesmo bloco, em caso de interrupção de energia, quatro geradores, de 500 kVA cada um, garantem a continuidade dos setores críticos. A figura 3.44 apresenta duas unidades.

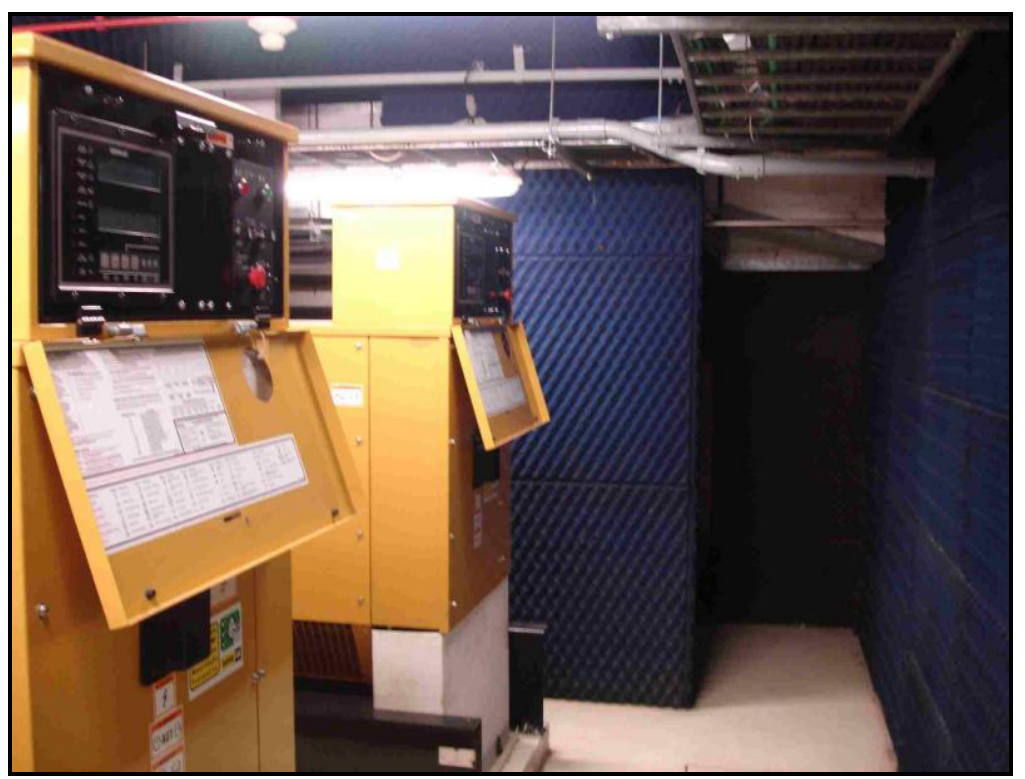

Figura 3.44 - Geradores de 500 kVA

Fonte: Pesquisa de campo.

Todas as salas de geradores possuem absorventes acústicos de espuma de nylon, tipo sonex. A figura 3.45 mostra o detalhe de uma das paredes.



Figura 3.45 - Isolamento acústico na sala dos geradores

Fonte: Pesquisa de campo. 
As salas de geradores e as subestações estão equipadas com detectores de fumaça. A figura 3.46 apresenta uma dessas situações.

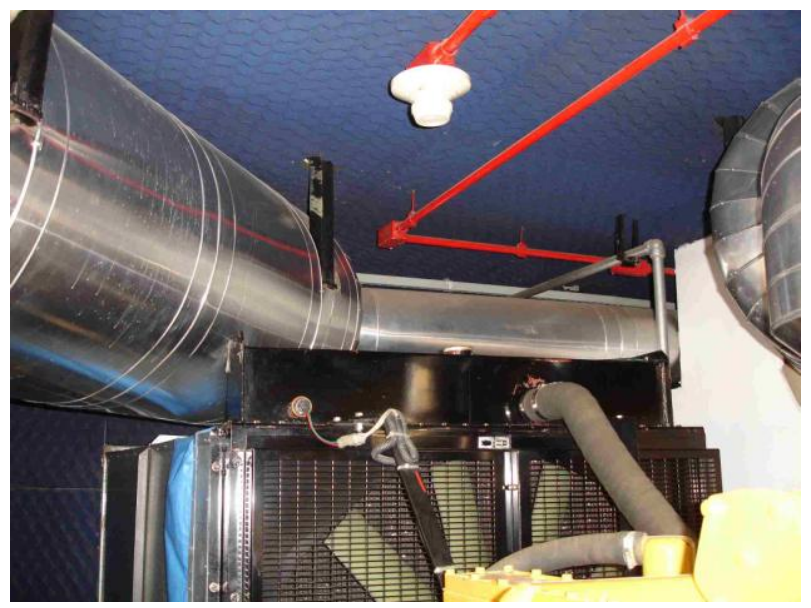

Figura 3.46 - Detectores de fumaça instalados na sala dos geradores Fonte: Pesquisa de campo.

O sistema de transferência entre a rede de alimentação normal e o sistema de emergência é apresentado nas figuras 3.47 e 3.48 .

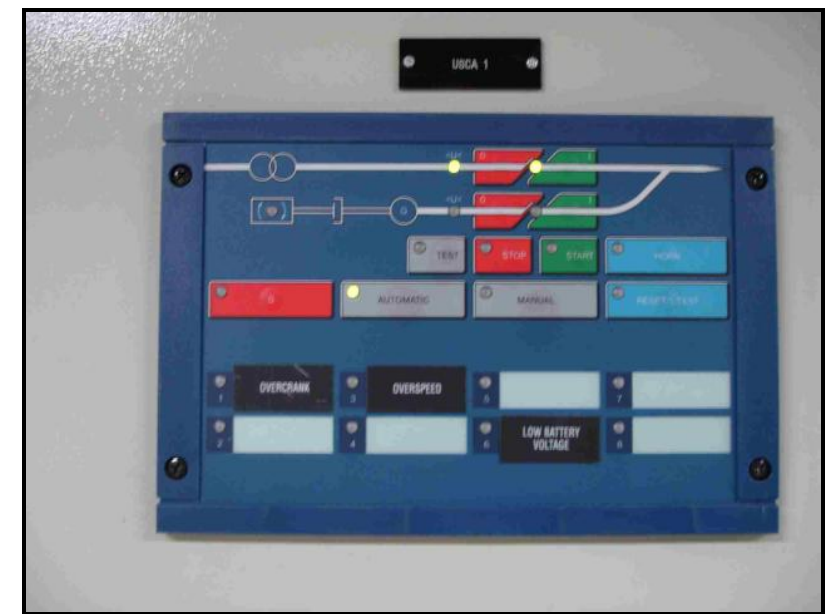

Figuras 3.47 - Painel sinótico do sistema de transferência Fonte: Pesquisa de campo. 


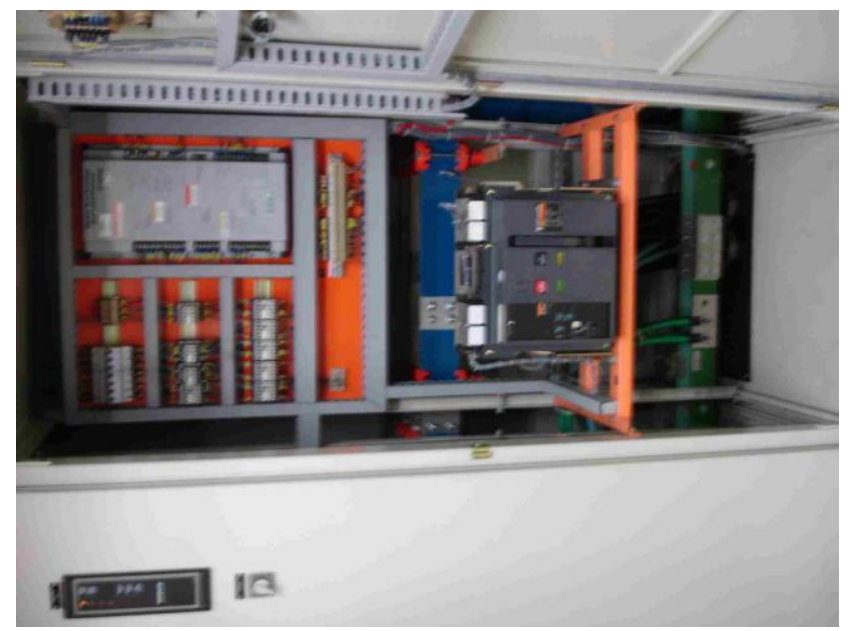

Figura 3.48 - Sistema de transferência entre gerador e sistema de alimentação normal Fonte: Pesquisa de campo.

O sincronismo entre o gerador, a alimentação normal e o controle de carga é efetuado pelo equipamento mostrado na figura 3.49.

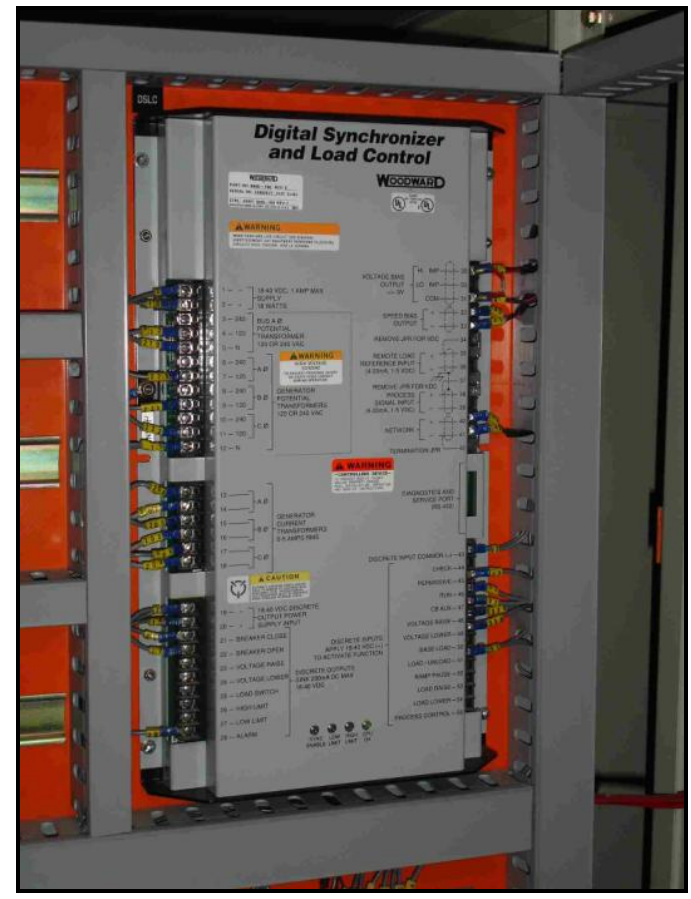

Figuras 3.49 - Sistema de sincronismo e controle de carga Fonte: Pesquisa de campo.

Todo sistema de distribuição em baixa tensão possui esquema de aterramento TN$\mathrm{S}$, conforme recomenda a Norma ABNT NBR 13534. As figuras 3.50 e 3.51 apresentam claramente essa situação. 


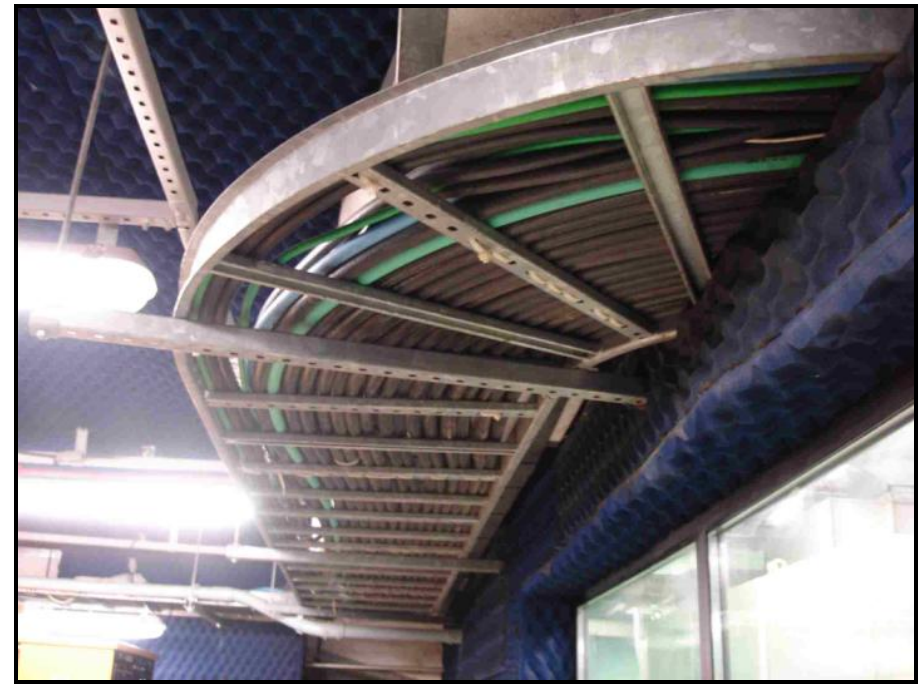

Figuras 3.50 - Condutores neutro e de proteção claramente identificados por cores, no leito de cabos

Fonte: Pesquisa de campo.

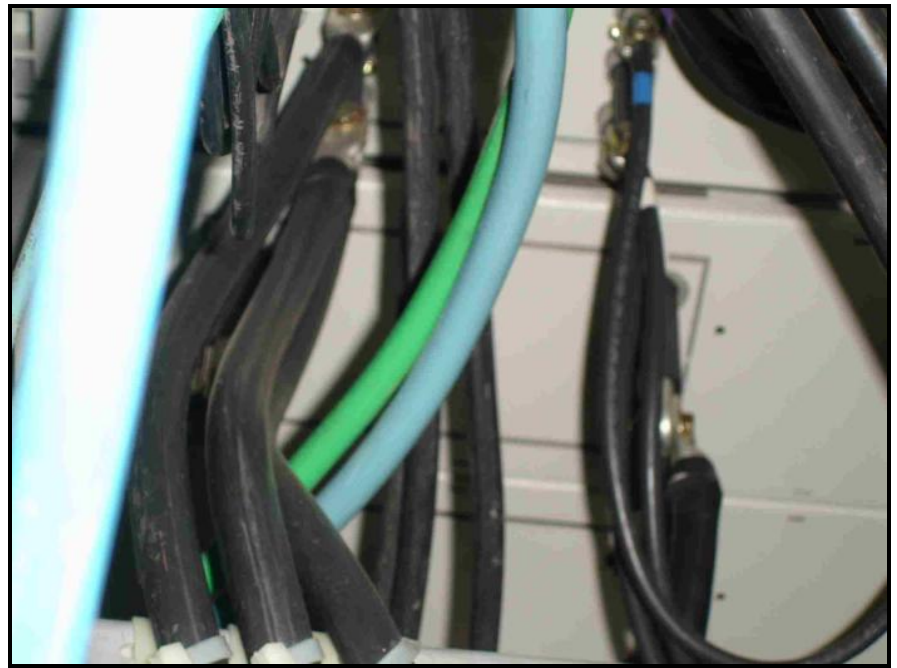

Figuras 3.51 - Neutro e condutor de proteção separados, identificando claramente o esquema de aterramento TN-S, conforme recomenda a Norma ABNT NBR 13534 Fonte: Pesquisa de campo.

Com a finalidade de manter a segurança e praticidade, barramentos blindados são muito utilizados na distribuição em baixa tensão. A figura 3.52 apresenta um circuito com capacidade para $3000 \mathrm{~A}$. 


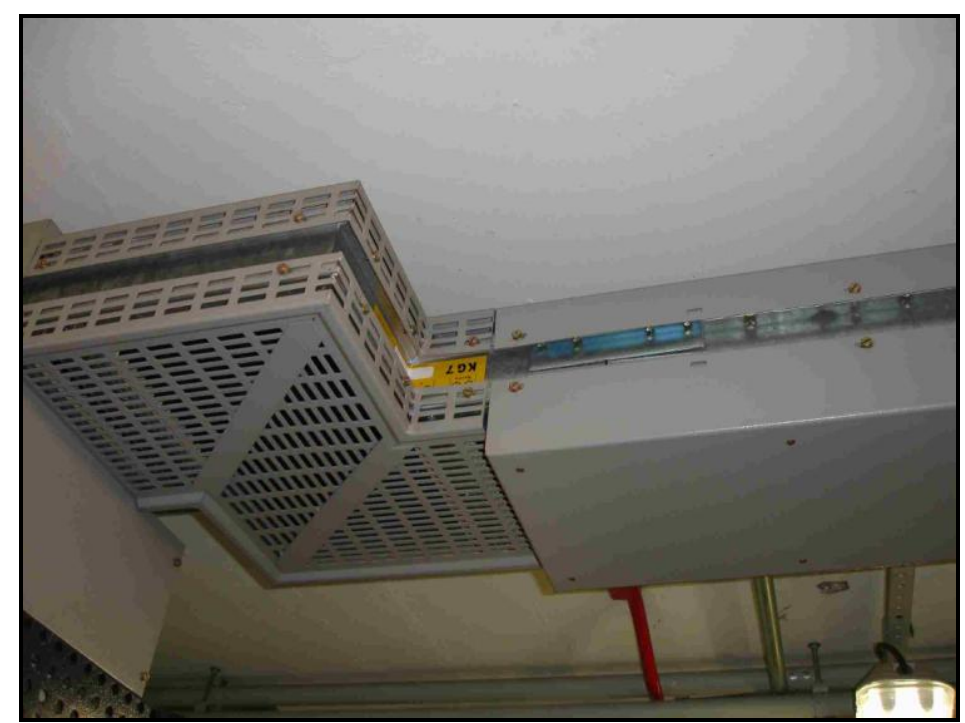

Figuras 3.52 - Sistema de distribuição com barramentos blindados (Bus way) Fonte: Pesquisa de campo.

\subsection{O ATENDIMENTO DOMICILIAR À SAÚDE: A MAIS NOVA OPÇÃO BRASILEIRA}

Conhecida como Home Care, nos Estados Unidos esta opção já existe há 40 anos e atende oito milhões de pessoas por ano, o que corresponde a cerca de $3 \%$ da população norte-americana. É uma alternativa de assistência à saúde, prestada na residência do paciente e gerenciada por um profissional médico (UNIMED, 2009). Em 2005, o setor movimentou mais de 170 bilhões de dólares, ou seja, mais da metade do atual PIB brasileiro, na época. Essa informação foi fornecida pela Interim Home Care, uma das grandes redes norte-americanas nesta modalidade de atendimento. Devido a fatores demográficos, envelhecimento populacional, entre outros motivos, acredita-se que o setor cresça $15 \%$ por ano (HOFFMAN, 2003).

Se, por um lado, nos Estados Unidos existem mais de 20 mil empresas especializadas, por outro lado, no Brasil são apenas 200.

Mas, este tipo de mercado segue em ascensão, pois, além dos hospitais, surgiram interessados que vêem neste tipo de atendimento uma forma de reduzir custos, aumentar a rotatividade nos leitos hospitalares e humanizar 0 atendimento. A partir dos anos 90, essa modalidade tem sido considerada como uma opção em função da deficiência da área de saúde no País. 
Segundo as empresas especializadas, os principais benefícios desta modalidade são:
a) menor risco de infecção hospitalar;
b) maior conforto e privacidade ao paciente no convívio familiar;
c) redução do tempo de recuperação do paciente em função da redução do stress;
d) tratamento humanizado;
e) segurança;
f) maior facilidade para a independência funcional do paciente e;
g) melhor qualidade de vida para o paciente.

Caso haja necessidade, equipamentos eletromédicos serão instalados na residência do paciente, alimentados em suas instalações elétricas. Nesse caso, a empresa responsável por este tipo de atendimento deve antes verificar se as instalações elétricas atendem às normas vigentes. Caso não atendam à exigências da norma, todos os benefícios apresentados tornam-se desprezíveis em função dos riscos existentes, principalmente se houver no local a presença de equipamentos de sustentação de vida, como é o caso de ventiladores pulmonares. Ainda, a concessionária responsável pelo fornecimento de energia elétrica deve ser comunicada, evitando desligamentos para serviços de manutenção e principalmente, operação de religadores.

\subsection{COMENTÁRIOS E DISCUSSÕES}

Supõe-se em que outros inúmeros EAS se repitam os problemas apresentados nos dois primeiros casos, ou seja, de não atender à normalização vigente, colocando as instalações, funcionários e pacientes sob riscos.

Pergunta-se então:

a) como adequá-los, lembrando que o prejuízo pela interrupção do atendimento a pacientes, para sua readequação, poderá ser bem maior que os riscos envolvidos pelo não atendimento às normas de instalações elétricas? 
b) como interromper o funcionamento de uma UTI para reformas e readequações normativas, que possui pacientes ligados a equipamentos de sustentação de vida?

c) qual a importância que se dá às instalações elétricas quando comparadas a outros problemas típicos dos EAS brasileiros, tais como:

c.1) falta de investimentos para aquisição de novos equipamentos;

c.2) falta de mão-de-obra qualificada;

c.2) falta de recursos para treinamentos;

c.3) falta de recursos financeiros para aquisição de medicamentos;

c.4) falta de capacidade para atendimento de pacientes;

c.5) contaminação hospitalar. 


\section{NORMAS TÉCNICAS APLICÁVEIS AOS ESTABELECIMENTOS ASSISTENCIAIS DE SAÚDE (EAS) E A EQUIPAMENTOS ELETROMÉDICOS}

\subsection{NORMAS DE INSTALAÇÕES ELÉTRICAS}

Como subsídio às instalações elétricas, encontra-se a norma internacional IEC 60364 - Electrical Instalations of Buildings, como norma geral, que apresenta no item 7-710 os requisitos para as instalações elétricas em locais médicos e áreas associadas (IEC 60364, 2002).

No Brasil, de forma semelhante, encontram-se as Normas ABNT NBR 5410 (2004) Instalações Elétricas de Baixa Tensão e a ABNT NBR 13534 (2008) - Requisitos Específicos para Instalação em Estabelecimentos Assistenciais de Saúde.

A primeira edição desta última norma, denominada Instalações Elétricas em EAS Requisitos para segurança, tornou-se válida a partir de 29.12.1995, com o objetivo de estabelecer um conjunto de requisitos mínimos de segurança para as instalações elétricas em EAS, com destaque para hospitais, ambulatórios, unidades sanitárias, clínicas médicas e odontológicas, veterinárias, etc.

A segunda edição da ABNT NBR 13534, publicada em 28.01.2008, tornou-se válida a partir de 28.07.2008, ou seja, 180 dias após a sua publicação. Essa norma é baseada na Norma IEC 60364-7-710, e elaborada no Comitê Brasileiro de Eletricidade - ABNT/CB-03, pela Comissão de Estudo de Instalações Elétricas de Baixa Tensão - CE-03:064.01.

Houve dois projetos de atualização, sendo que, o segundo circulou em Consulta Nacional de 21.09 a 20.10.2007.

Os requisitos dessa norma complementam, modificam ou substituem os requisitos de caráter geral contidos na Norma ABNT NBR 5410, cuja 4ª edição entrou em vigor em 31.03.2005.

A ABNT NBR 13534 denomina EAS como qualquer edificação cuja finalidade é a prestação de assistência à saúde da população e que, portanto, inclui o acesso de pacientes em regime de internação ou não, qualquer que seja o seu nível de complexidade. 
A instalação elétrica de um EAS é composta por conjuntos de componentes e equipamentos devidamente interligados, e adequadamente dispostos em áreas e locais específicos para essa finalidade, tendo em vista o suprimento, transformação, armazenamento, distribuição e utilização de energia elétrica.

Em cada caso, o atendimento deverá ser efetuado de modo compatível com as necessidades e a segurança específicas de cada recinto para fins médicos, sejam de diagnósticos ou terapêuticos.

A segunda edição da ABNT NBR 13534 manteve a classificação dos ambientes localizados em EAS, em grupos e classes.

A norma define local médico como aquele espaço destinado à realização de procedimento de diagnóstico, terapêutico, cirúrgico e ainda, de monitoração e de assistência à saúde de pacientes.

Parte aplicada é a parte do equipamento eletromédico, que para cumprir sua função em uso normal, necessariamente deverá entrar em contato físico com o paciente.

O item 4.2.101 orienta que a classificação de um local médico deverá ser feita com a participação da equipe médica e pela consulta à legislação vigente das áreas de saúde e de segurança do trabalho.

Para definição da classificação de um local médico, a equipe médica deverá informar quais os procedimentos que serão realizados e que, em função dessas informações, receberá uma classificação apropriada.

Na possibilidade de utilização do mesmo local para várias finalidades, a classificação adotada será a mais exigente.

O primeiro critério, referente ao grupo, relaciona-se ao tipo de equipamento eletromédico presente no local durante os procedimentos médicos.

Dessa forma, são previstos três grupos, em função de possuírem ou não partes aplicadas ao corpo humano.

A tabela 4.1 apresenta esta classificação, que na norma está localizada no item 3 Termos e definições. 
Tabela 4.1 - Classificação do local em função do tipo do equipamento eletromédico NBR 13534/2008

\begin{tabular}{|c|l|}
\hline LOCAL & \multicolumn{1}{|c|}{ TIPO DO EQUIPAMENTO ELETROMEDICO } \\
\hline Grupo 0 & $\begin{array}{l}\text { Local médico não destinado à utilização de parte aplicada de } \\
\text { equipamento eletromédico. }\end{array}$ \\
\hline Grupo 1 & $\begin{array}{l}\text { Local médico destinado à utilização de partes aplicadas: } \\
\text { a) Externas ao corpo; } \\
\text { b) Partes internas que não incluam as do grupo 2. }\end{array}$ \\
\hline Grupo 2 & $\begin{array}{l}\text { Local médico destinado à utilização de partes aplicadas em } \\
\text { procedimentos intracardíacos, cirúrgicos, de sustentação de } \\
\text { vida de pacientes e outras aplicações em que a } \\
\text { descontinuidade da alimentação elétrica pode resultar em } \\
\text { morte. }\end{array}$ \\
\hline
\end{tabular}

Fonte: NBR 13534/2008.

Os hospitais e ambientes similares devem dispor de fonte de segurança para o caso de falha no sistema de alimentação normal, capaz de alimentar por um período de tempo especificado, considerando ainda, o tempo necessário à transferência.

As instalações de segurança têm como objetivo garantir a continuidade dos serviços essenciais à preservação da vida e manter a segurança; além disso, também são destinadas a funcionar em situações de emergência.

O segundo critério, referente à classe, o qual corresponde às características da alimentação de segurança, é apresentado no item 6.6.6.102 e no Anexo AA da NBR 13534. No item 6.6.6.102 são apresentados os requisitos específicos para a alimentação de segurança, com tempo de comutação de: $\leq 0,5 \mathrm{~s}, \leq 15 \mathrm{~s} \mathrm{e},>15 \mathrm{~s}$.

$\leq \mathbf{0 , 5}$ s: caso houver a ocorrência de falta de tensão em um ou mais condutores localizados no quadro de distribuição, uma fonte de segurança especial deve restabelecer, em $0,5 \mathrm{~s}$ no máximo, a alimentação dos focos cirúrgicos e outras fontes de luz, como, por exemplo, as de endoscopia, e deve ser capaz de manter essa alimentação por $3 \mathrm{~h}$, no mínimo.

$\leq 15$ s: em caso de ocorrência de uma queda de tensão superior a $10 \%$ da tensão nominal, por um tempo superior a $3 \mathrm{~s}$, em um ou mais condutores do quadro de distribuição principal dos serviços de segurança, os equipamentos relacionados em $\left.{ }^{*}{ }^{*}\right)$ devem ter sua alimentação restabelecida por uma fonte de segurança em até 15 s, no máximo. Essa fonte deve ser capaz de manter a alimentação por 24 h, no mínimo.

$>15$ s: este caso refere-se a outros equipamentos, que não aqueles citados em (*), mas igualmente necessários à continuidade dos serviços dos EAS, e que podem ser 
conectados manual ou automaticamente a uma fonte de segurança capaz de manter sua alimentação elétrica por um período mínimo de $24 \mathrm{~h}$. Podem ser mencionados como exemplos: equipamentos de esterilização, de cozinha, de refrigeração; carregadores de bateria; instalações técnicas da edificação, em particular sistemas de ar-condicionado, aquecimento, ventilação e outros serviços prediais e sistemas de eliminação de resíduos.

$\left({ }^{\star}\right)$ :

iluminação de segurança: rotas de fuga, iluminação dos sinais indicativos das saídas de emergência, locais em que se situam os quadros de comando do(s) grupo(s) gerador(es) e os quadros de distribuição principais da alimentação normal e da alimentação de segurança; locais que acomodam serviços essenciais. Ainda incluem-se pelo menos uma luminária para locais do grupo 1 e 50\% das luminárias para locais do grupo 2;

outros serviços: elevadores para brigada de incêndio e bombeiros, sistemas de exaustão de fumaça, sistemas de chamada/busca de pessoas, equipamentos eletromédicos usados em locais do grupo 2 e destinados a cirurgias e outros procedimentos vitais, equipamentos elétricos de suprimento de gases medicinais e instalações de detecção, alarme e extinção de incêndio.

$O$ anexo AA da ABNT NBR 13534, com caráter normativo, apresenta a Tabela AA.101 que classifica os serviços de segurança para locais médicos, aqui apresentados na tabela 4.2:

Tabela 4.2 - Classificação dos serviços de segurança para locais médicos NBR 13534/2008

\begin{tabular}{|c|c|}
\hline CLASSE & TEMPO DE COMUTAÇÃO \\
\hline $\begin{array}{c}0 \\
\text { (sem interrupção) }\end{array}$ & Alimentação disponível automaticamente sem interrupção \\
\hline $\begin{array}{c}0,15 \\
\text { (interrupção muito breve) }\end{array}$ & Alimentação disponível automaticamente em até 0,15s \\
\hline $\begin{array}{c}0,5 \\
\text { (interrupção breve) }\end{array}$ & Alimentação disponível automaticamente em até 0,5s \\
\hline $\begin{array}{c}15 \\
\text { (interrupção média) }\end{array}$ & Alimentação disponível automaticamente em até 15s \\
\hline$>15$ & Alimentação disponível automaticamente em mais de 15s \\
\hline (interrupção longa) & \\
\hline
\end{tabular}

Fonte: NBR 13534/2008 
A Nota 1, contida na tabela AA.101 do Anexo AA da ABNT NBR 13534, informa que, de um modo geral, não é necessário prover alimentação ininterrupta para equipamentos eletromédicos. Entretanto, determinados equipamentos controlados por microprocessadores podem exigir esse tipo de alimentação.

Comparando as duas edições, observa-se que a primeira não incluía as classes 0 e 0,15 , o que vem de encontro a uma das contribuições obtidas a partir dos resultados apresentados neste trabalho, sobre o comportamento dos equipamentos eletromédicos quando submetidos a perturbações da rede elétrica.

No Anexo BB da norma encontra-se a tabela B.101, que orienta a aplicação dos critérios de grupos e classes para locais médicos.

Quanto aos equipamentos eletromédicos, não são encontrados estudos sobre a sua interação com as instalações elétricas dos EAS e a qualidade da energia elétrica fornecida a esses equipamentos (SILVEIRA, 2002).

Muitos desses estabelecimentos possuem suas instalações elétricas totalmente adaptadas, não obedecendo à ABNT NBR 13534.

Por outro lado, essa norma não especifica quesitos de qualidade de energia nesses estabelecimentos, deixando uma dúvida bastante grande quanto às informações fornecidas pelos equipamentos eletromédicos, sejam para fins de diagnóstico ou tratamento médico.

No Brasil, a Anvisa - Agência Nacional de Vigilância Sanitária é o órgão regulador do setor de saúde responsável por coordenar a aplicação desta norma, que por intermédio de suas secretarias estaduais aprovam os projetos de instalações elétricas para os EAS.

Nos Estados Unidos da América do Norte, a recomendação prática sobre projeto e operação de sistemas elétricos em EAS é a IEEE 602 (2007). A última edição, publicada em 2007, consistiu em uma revisão da edição de 1996.

Tradicionalmente conhecida com IEEE White Book, possui 482 páginas de informações divididas em nove capítulos.

Essa norma norte-americana foi elaborada voluntariamente por profissionais da área como: engenheiros de projetos, usuários finais de instalações em EAS e fabricantes de equipamentos eletromédicos, que formaram o "Grupo de trabalho do livro branco", juntamente com os Subcomitês de projeto de sistemas de potência e de engenharia de sistemas de potência do IEEE. 
Embora tenha sido elaborada por experientes profissionais, não deve ser utilizada em substituição aos tradicionais manuais e livros encontrados no mercado e sim como um guia geral.

Esse documento abrange os seguintes tópicos:

a) considerações sobre projeto, operação e manutenção;

b) cargas elétricas: características e custo de energia elétrica;

c) distribuição de energia: considerações sobre a tensão e a corrente; aterramento e sistemas de proteção e coordenação;

d) sistemas elétricos para atendimento aos pacientes;

e) sistemas de emergência: geradores, chaves de transferência, UPS, etc.;

f) iluminação: projeto e aplicações;

g) sistemas de comunicação: redes sem fio, telefones, comunicação interna, sistemas de rádio, etc.;

h) equipamentos médicos e instrumentação: tendência e evolução, descrição dos principais tipos.

No capítulo 1 é mencionada a elevada dependência da energia elétrica, que esses ambientes possuem, onde diariamente são introduzidos sofisticados métodos de diagnóstico e de tratamento. Em geral, utilizam equipamentos sensíveis a distúrbios e, portanto, requerem energia elétrica de alta qualidade.

\subsection{NORMAS DE EQUIPAMENTOS ELETROMÉDICOS}

\subsubsection{A Evolução da Normalização no Brasil}

Existem diversos organismos no mundo que elaboram e controlam regulamentações para garantir a padronização de construção de equipamentos eletromédicos. $\mathrm{Na}$ verdade, a maioria dos países possui um acervo de normas técnicas destinadas a esse seguimento.

Os mais conceituados e adotados são: ISO - International Organization for Standardization; IEC - International Electrotechnical Comission; DIN - Deutsches Institut für Normung; AAMI - Association for the Advancement of Medical 
Instrumentation; ANSI - American National Standards Institute; EN - Europäische Norm.

No Brasil, o organismo responsável pelo gerenciamento de normas brasileiras é a ABNT - Associação Brasileira de Normas Técnicas, que codifica suas normas por meio da sigla NBR.

No setor de construção de equipamentos eletromédicos, a ABNT adotou os critérios da IEC para normalização por intermédio de um consenso com a Anvisa por meio da Resolução RDC 32 de 2007, a qual substituiu a Portaria 444 de 1999.

Mesmo antes de 1999, a Portaria 2663/1995 já adotava os critérios da IEC por meio de traduções de suas normas técnicas em seu conteúdo integral e sem alterações ou adaptações gerando uma nova classificação de normas, "NBR IEC".

A normalização brasileira utilizou como base a série de normas internacionais IEC 60601, cujo objetivo principal é o estabelecimento das condições mínimas de segurança e o desempenho essencial dos equipamentos eletromédicos.

A Resolução RDC 32 regulamenta que esses dispositivos devem atender à família de normas NBR IEC para receberem a certificação do Inmetro - Instituto Nacional de Metrologia, Normalização e Qualidade Industrial e, conseqüentemente, obter do Ministério da Saúde a autorização para sua comercialização no Brasil.

A estrutura da família de normas da série ABNT NBR IEC 60601 segue o seguinte critério:

a) Norma Geral: ABNT NBR IEC 60601-1 (1997) - Parte 1 - Prescrições gerais para segurança - apresenta os requisitos básicos para qualquer tipo de equipamento eletromédico.

b) Normas Colaterais: ABNT NBR IEC 60601-1-X - são aplicadas de forma complementar à norma geral:

$\mathrm{X}=1$ - prescrições de segurança para sistemas eletromédicos;

$\mathrm{X}=2$ - compatibilidade eletromagnética - prescrições e ensaios;

$\mathrm{X}=3$ - prescrições gerais para proteção contra radiação de equipamentos de raios

$\mathrm{X}$ para fins diagnósticos;

$\mathrm{X}=4$ - sistemas eletromédicos programáveis. 
c) Normas Particulares: ABNT NBR IEC 60601-2-XX - possuem requisitos específicos para cada tipo de equipamento eletromédico; as prescrições dessas normas se sobrepõem às das normas, geral e colaterais, conforme pode ser observado abaixo:

$X=1$ - prescrições particulares de segurança para equipamento cirúrgico de alta freqüência;

$\mathrm{X}=2$ - idem para equipamento de terapia de ondas curtas;

(...)

$\mathrm{X}=51$ - idem para eletrocardiógrafos gravador e analisador monocanal e multicanal.

d) Normas de Desempenho: ABNT IEC 60601-3-X.

A primeira edição da ABNT NBR IEC 60601-1 (Norma Geral) foi publicada em novembro de 1994, e é equivalente à IEC 60601-1 editada em 1988. Neste último caso, observa-se uma distância tecnológica de seis anos, uma vez que uma norma técnica representa o estado da arte da tecnologia de uma nação.

Em outubro de 1997, a ABNT publicou uma emenda para essa norma, equivalente à emenda 2, de 1995 da IEC 60601-1. Essa emenda tem como objetivo facilitar a interpretação e aplicação da norma geral. Em caráter complementar, também identifica aspectos adicionais de segurança que não foram cobertos previamente pela referida norma.

A seção 3 da Norma Geral apresenta informações relativas à proteção contra riscos de choques elétricos, contendo prescrições sobre o aterramento; limitação de tensão e/ou energia no plugue de alimentação, logo após o desligamento e informações sobre os valores permissíveis de corrente de fuga pelo corpo do paciente.

A Norma ABNT NBR IEC 60601-1-1 é um regulamento colateral que apresenta as prescrições de segurança para sistemas eletromédicos. Teve sua primeira edição publicada em 1997, e foi substituída após uma revisão técnica, pela edição de 2004, que é equivalente à IEC 60601-1-1 de 2000.

Uma das normas colaterais, bastante relacionada a este trabalho é a ABNT NBR IEC 60601-1-2, que trata das prescrições relativas à compatibilidade eletromagnética.

A primeira edição desta última norma foi publicada em outubro de 1997, sendo equivalente à IEC 60601-1-2 de 1993. Essa edição não apresentava prescrições 
sobre os limites de emissão de harmônicos de corrente e a imunidade a afundamentos e/ou interrupções de tensão de curta duração. Como essa norma vigorou até setembro de 2006, os equipamentos nacionais fabricados até essa data não eram submetidos aos respectivos ensaios.

Entende-se por compatibilidade eletromagnética a habilidade que um equipamento ou sistema possui em funcionar corretamente no seu ambiente eletromagnético sem, no entanto, gerar interferências eletromagnéticas nesse ambiente (IEC 60050-161, 1990).

Os níveis de perturbação relacionados à compatibilidade eletromagnética de equipamentos sensíveis ou cargas não-lineares são apresentados na figura 4.1 (BETTEGA; FIORINA, 1999).

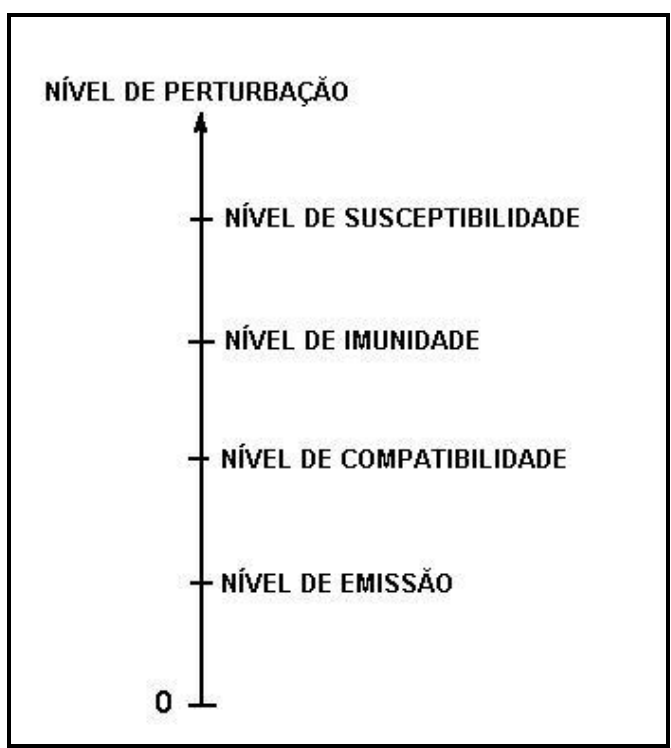

Figura 4.1 - Níveis de Compatibilidade Eletromagnética

Fonte: Bettega; Fiorina, 1999. (elaboração e tradução do autor)

Os níveis de perturbação são definidos como:

Nível de emissão: máximo nível autorizado para um consumidor ligado à rede pública ou para um dispositivo ligado a uma rede elétrica.

Nível de compatibilidade: máximo nível de distúrbio especificado que pode se esperar em um dado ambiente.

Nível de imunidade: nível de suportabilidade de um dispositivo ou sistema a um distúrbio.

Nível de susceptibilidade: nível a partir do qual um dispositivo ou sistema começa a apresentar mau funcionamento. 
Quando foram realizados os ensaios com os equipamentos eletromédicos, durante os anos de 2004, 2005 e parte de 2006, a edição válida na época havia sido publicada em 1997 e não incluía os ensaios que foram aplicados no Enerq-ct.

$\mathrm{Na}$ época, percebeu-se a necessidade de atualização dessa norma, com inclusão de testes que considerassem os limites de distorção harmônica, as interrupções e os afundamentos de tensão de curta duração.

Assim, a necessidade de atualização da norma era bastante clara, pois diversos fenômenos estudados e que não estavam incluídos na edição antiga, não eram ensaiados nos equipamentos eletromédicos a serem comercializados.

Felizmente, em setembro de 2006, a ABNT publicou uma nova versão da Norma NBR IEC 60601-1-2, tradução equivalente da Norma IEC 60601-1-2 (2001) e sua emenda de 2004.

Importantes mudanças foram introduzidas, entre elas merecem destaque 0 atendimento às normas, IEC 61000-3-2 - emissão de harmônicos de corrente e, IEC 61000-4-11 - ensaios de imunidade a interrupções e afundamentos de tensão de curta duração.

No entanto, segundo alguns fabricantes, a nova edição apresenta dificuldades para adequação de seus produtos à legislação, por estes quatro motivos (MARRONI, 2007):

$1^{\circ}$ ) falta de recursos para simulação desses ensaios durante a concepção do projeto, devido ao alto custo dos equipamentos necessários;

$2^{\circ}$ ) falta de conhecimento técnico por parte dos projetistas, relacionado aos ensaios e possíveis soluções para os problemas que possam ser encontrados;

$3^{\circ}$ ) devido à pequena quantidade de laboratórios credenciados pelo Inmetro, os fabricantes estão encontrando dificuldades para realização dos ensaios;

$\left.4^{\circ}\right)$ o custo dos ensaios praticados pelos laboratórios é muito elevado.

Para contornar essa situação, o Inmetro não está exigindo os ensaios de afundamentos de tensão para certificação dos equipamentos eletromédicos em função da inexistência de laboratórios credenciados que possuam equipamentos específicos a essa finalidade. Ressalta-se que essa informação foi fornecida por um fabricante de equipamentos eletromédicos. 


\subsubsection{Normas Específicas para Ventiladores Pulmonares}

Existem duas normas técnicas internacionais, as quais prescrevem as formas ideais de construção de ventiladores pulmonares para cuidados críticos: a IEC 60601-2-12 (2001) e a EN 794-1 (1997) com a Emenda A1-2000. Ambas fazem referência à Norma IEC 60601-1 (1988), no que se refere à segurança elétrica, salvo algumas exceções descritas na própria norma particular.

Por esse motivo, um ventilador pulmonar para cuidados críticos deve atender às prescrições de uma dessas normas e, simultaneamente, às Normas IEC 60601-11(2000) - Prescrições de segurança para sistemas eletromédicos e IEC 60601-1-2 (2001) - Compatibilidade eletromagnética - prescrições e ensaios.

Comparando as duas normas, chega-se à conclusão que a EN 794-1 é uma cópia da IEC 60601-2-12, com algumas adições.

A primeira é mais utilizada na Europa e a segunda, praticamente em todo o mundo. No Brasil, a norma equivalente é a ABNT NBR IEC 60601-2-12 (2004), que teve a primeira edição publicada em 1998 e a segunda em 2004.

A norma brasileira define os ventiladores para cuidados críticos como dispositivos médicos essenciais em toda unidade de terapia intensiva (UTI).

Aproximadamente metade dos pacientes em UTI recebe de parcial a completo suporte respiratório com esse equipamento. Considerando o estado de vulnerabilidade desses pacientes, a segurança do equipamento é de fundamental importância (ABNT NBR IEC 60601-2-12, 2004).

A seguir, apresentam-se algumas informações contidas nas normas brasileiras, em relação à segurança do paciente em casos de falhas no sistema de alimentação do ventilador pulmonar, um dos objetos de estudo deste trabalho.

A Cláusula 49 da ABNT NBR IEC 60601-1 trata da interrupção do fornecimento de energia elétrica. Em seguida, comenta-se os itens referentes a essa cláusula:

49.1 Dispositivos com rearme automático não deverão ser utilizados, tais como interruptores térmicos ou relés de sobrecorrentes, desde que possam causar riscos de segurança durante o rearme. A conformidade deste item deve ser verificada por ensaio funcional. 
49.2 O projeto do equipamento deve considerar que o restabelecimento de energia, após uma interrupção, não provoque outro risco de segurança que aquele já causado pela interrupção. Essa exigência também deverá ser comprovada a partir de ensaio funcional, efetuando-se a interrupção da energia e em seguida 0 restabelecimento.

49.3 Em caso de falha da rede de alimentação, o equipamento deve ser dotado de meios que removam as possibilidades de pressões mecânicas sobre o paciente. Da mesma forma que nos itens anteriores, a conformidade deverá ser verificada por ensaios funcionais.

A ABNT NBR IEC 60601-2-12 apresenta informações específicas sobre esse assunto. Comentários sobre os itens de segurança, relativos à interrupção de energia elétrica, são apresentados a seguir:

49.101 Caso a tensão da fonte de alimentação se reduza a valores abaixo do especificado pelo fabricante, uma sinalização sonora de alta prioridade deverá atuar pelo menos $120 \mathrm{~s}$. No caso em que a alimentação do ventilador seja comutada para uma fonte de alimentação elétrica interna, o alarme não deve atuar. Este último caso deverá ser anunciado por uma sinalização visual ou um alarme de baixa prioridade. A conformidade deverá, também, ser verificada por uma simulação de queda de tensão abaixo da faixa de alimentação, como indicado nas instruções do equipamento.

Dando seqüência, esta mesma norma apresenta:

40.102 Caso o ventilador for equipado com uma fonte de alimentação elétrica interna, deverá ser dotado de meios para que se possa verificar o estado de carga dessa fonte. Antes que essa fonte se apresente totalmente descarregada, um alarme de prioridade média, contido no ventilador, deverá anunciar uma falha iminente do sistema de alimentação. Esse alarme deverá passar para alta prioridade em caso da fonte de alimentação elétrica interna se descarregar completamente. A conformidade deverá ser verificada pela redução da tensão de alimentação a valores abaixo do mínimo especificado pelo fabricante. 
$49.103 \mathrm{O}$ projeto do ventilador deve considerar a possibilidade de se permitir a respiração espontânea quando a ventilação normal estiver comprometida por condições de falha na alimentação elétrica.

Embora não seja pertinente a este trabalho, destaca-se que os itens apresentados também se referem às falhas de alimentação do sistema pneumático (gases).

Observa-se, pelas duas normas apresentadas, a preocupação com a interrupção de energia elétrica, que poderá causar um problema ainda maior, como, por exemplo, a perda de parametrização do ventilador pulmonar.

No entanto, a não obrigatoriedade da existência de bateria interna para suprimento de energia em caso de interrupção da rede elétrica, conforme apresenta a cláusula 49.102, poderá colocar o paciente em elevado grau de risco.

Estes dois casos serão apresentados e discutidos no capítulo 6, a partir dos resultados dos ensaios que foram realizados nos equipamentos eletromédicos.

Ainda, sobre interrupção de energia elétrica, a EN 794-1 apresenta a cláusula 49, com as seguintes adições:

49.101 Respiração espontânea durante a falha de alimentação elétrica: o ventilador deve ser projetado considerando a possibilidade do paciente respirar espontaneamente em caso de falha na alimentação elétrica ou pneumática.

Durante a falha de alimentação elétrica, a resistência do sistema respiratório do ventilador (circuito respiratório) para inspirar e expirar não deve exceder valores especificados em $56.104\left(125 \mathrm{cmH}_{2} \mathrm{O}\right)$.

Para efeito desse requisito, condições de alimentação elétrica fora dos valores especificados pelo fabricante são consideradas como interrupção de alimentação elétrica.

Comparando as normas citadas para ventiladores pulmonares, percebe-se claramente que elas prescrevem cuidados somente com interrupções da alimentação elétrica, mas, não mencionam outros tipos de perturbações existentes na rede elétrica, tais como afundamentos e interrupções de tensão de curta duração. 


\subsubsection{Normas Específicas para Equipamentos de Monitorização Multiparamétrica de Paciente}

Não diferentes das normas particulares de ventilador pulmonar, as normas de oxímetros de pulso e monitores multiparamétricos se omitem com relação às prescrições de prevenção de saída de dados incorretos mediante a falta de qualidade de energia elétrica. Orientadas pela norma geral de segurança elétrica (IEC 60601-1), abordam somente interrupção de energia e alarmes de segurança.

A Norma ISO 9919 (2005) apresenta os requisitos para oxímetros de pulso. Embora seja uma norma relativamente nova, não aborda perturbações que prejudiquem a qualidade de energia elétrica e inicia as prescrições de segurança de alimentação elétrica pelos métodos de funcionamento mediante a interrupção do fornecimento de energia.

Prescrições relacionadas a interrupções de energia são tratadas na cláusula 49 dessa norma que adota as mesmas informações contidas na cláusula de mesmo número da IEC 60601-1, exceto pelos itens a seguir:

49.101 Condição de alarme em falha de energia: se o equipamento de oximetria de pulso for provido com uma condição de alarme fisiológico, deverá fornecer ao menos um sinal de alarme de média prioridade quando a tensão de alimentação se reduzir a valores abaixo do valor mínimo para operação normal.

49.102 Este item refere-se à operação do oxímetro de pulso após uma interrupção de energia elétrica:

49.102.1 Armazenamento de dados e configurações em casos de interrupção ou chaveamento automático.

Quando a alimentação de energia elétrica do oxímetro de pulso for interrompida por um tempo superior a $30 \mathrm{~s}$ ou se houver chaveamento automático para uma fonte de alimentação interna (bateria), todas as configurações e dados armazenados do paciente não devem ser alterados. 
49.102.2 Operação seguida de interrupções longas

O fabricante deverá considerar recursos que possam apresentar o estado de operação do equipamento após a interrupção da alimentação elétrica quando a chave liga/desliga permanecer na posição ligada e o restabelecimento ocorrer após um tempo superior a $30 \mathrm{~s}$.

Além de atender a itens normativos, o projeto e a construção do oxímetro de pulso devem conter medidas de segurança que incluam filtros de tensão e de corrente nos circuitos elétricos do equipamento. O objetivo é evitar o fornecimento de informações incorretas devido à ocorrência de falhas nos sensores de medição de $\mathrm{SpO}_{2}$ (saturação de oxigênio no sangue do paciente).

Outra norma internacional para monitorização multiparamétrica de pacientes é a IEC 60601-2-49 (2006). Ela segue a mesma orientação da Norma Geral IEC 60601-1, mas apresenta algumas prescrições de segurança elétrica, na cláusula 49.2, cujos comentários são apresentados abaixo:

a) caso ocorra uma interrupção da rede elétrica de alimentação do equipamento, por mais de $30 \mathrm{~s}$, todos os ajustes efetuados pelo operador, incluindo o modo de operação e todos os dados armazenados do paciente, não devem se alterar. Entretanto, o equipamento não deve funcionar durante a interrupção da rede elétrica;

b) Caso a interrupção da rede de energia elétrica dure mais de $30 \mathrm{~s}$, a operação subseqüente deve ser uma das seguintes apresentadas: reversão do ajuste padrão do fabricante para um dos ajustes prévios do usuário ou para o último ajuste utilizado.

c) Caso o equipamento possua uma fonte de alimentação elétrica interna e a rede de alimentação elétrica for interrompida, deverá continuar operando normalmente por meio de uma comutação automática para a fonte de alimentação elétrica interna. Nesse caso, o modo de operação, todos os ajustes do operador e os dados armazenados não devem se alterar. $O$ equipamento deve ser provido de um dispositivo que indique visualmente a operação de sua fonte de alimentação elétrica interna.

No Brasil, a norma específica para equipamentos de monitorização multiparamétrica é a ABNT NBR IEC 60601-2-49 (2003), equivalente à IEC 60601-2-49 editada em 2001. 


\subsubsection{Alarmes}

As normas para equipamentos eletromédicos fazem referência à Norma IEC 606011-8 (2006) no que se refere ao sistema de alarme.

Sabe-se que é possível um ventilador pulmonar falhar durante o seu funcionamento. Tal fato pode ser ocasionado por interferência de outros equipamentos instalados no mesmo local, por sua construção e, por sua fonte de alimentação, além de outras inúmeras causas. Independente da causa ou natureza da falha, o ventilador deve possuir um alarme para cada tipo de falha, de modo a avisar o operador sobre 0 problema ocorrido.

O uso de alarmes é o meio mais comum que um equipamento eletromédico tem como forma de aviso sobre ocorrências de irregularidades. Em geral, o alarme requer a intervenção do operador e não protege o paciente de ser submetido a um evento adverso, que poderá provocar danos ao seu organismo ou mesmo levá-lo a óbito.

\subsection{COMENTÁRIOS E DISCUSSÕES}

As normas brasileiras ABNT NBR 5410 e ABNT NBR 13534, atualizadas recentemente, garantem as condições mínimas de segurança que as instalações elétricas de baixa tensão deverão apresentar. No entanto, existe a necessidade de fiscalização intensiva para assegurar o cumprimento dessas normas, principalmente nos EAS, onde uma falha, decorrente de um erro de projeto ou proveniente de uma baixa qualidade dos serviços de manutenção, poderá colocar pacientes sob riscos elevados.

Para a garantia de segurança do operador, os fabricantes devem seguir as normas relativas aos equipamentos eletromédicos mencionadas neste capítulo. Para o paciente, estas normas representam condições de segurança mínimas, porém, algumas variáveis externas não controladas poderão comprometê-la. Dessa forma, a normalização precisa avançar mais nesse sentido.

Em função do conteúdo apresentado neste capítulo, pode-se questionar: 
1) De quem seria a responsabilidade pela fiscalização do cumprimento das normas técnicas referentes às instalações elétricas em EAS que já se encontram em funcionamento? Em caso de não conformidades, como proceder, pois, uma interdição total ou parcial traria um prejuízo ainda maior pelo não atendimento de pacientes que necessitam de internação.

2) Não resta dúvida que a evolução das normas aumenta a segurança dos equipamentos eletromédicos em função de maiores exigências. Mas, como é que os fabricantes se comportam diante de alterações que na maioria das vezes aumenta seus custos de produção?

3) Embora a nova edição da Norma NBR IEC 60601-1-2 (2006) exija os ensaios de afundamentos e interrupções de tensão, o Inmetro, segundo informações de um fabricante, não está exigindo-os em função da inexistência de laboratórios credenciados. Nesse caso, qual seria o procedimento correto? 


\section{PRINCIPAIS CARGAS POLUIDORAS UTILIZADAS NOS ESTABELECIMENTOS ASSISTENCIAIS DE SAÚDE (EAS)}

O avanço tecnológico está implicando na maior utilização de equipamentos sensíveis em todos os segmentos da sociedade, mas infelizmente, alguns deles podem ser prejudiciais ao aspecto relativo à qualidade da energia elétrica.

No caso dos equipamentos eletromédicos, sejam os conectados ao paciente ou aqueles que fornecem informações sobre o estado de saúde do doente, o resultado pode ser comprometedor. Neste último caso, em função de informações incorretas, procedimentos médicos inadequados poderão ser aplicados, comprometendo a vida do paciente. Como já mencionado, a maioria das perturbações é gerada internamente ao estabelecimento assistencial de saúde, pela comutação de cargas com elevada potência, variadores de velocidade para motores de indução e, principalmente, por equipamentos específicos a esses ambientes.

\subsection{RAIOS X}

Em 1995 comemorou-se 100 anos do descobrimento dos raios $\mathrm{X}$ pelo físico alemão Wilhelm Konrad Roentgen (1845-1923). Ao longo dos tempos, o uso deste equipamento possibilitou grande impulso nas técnicas de diagnose, devido a uma de suas características: possuir elevada penetração, possibilitando à biologia e à medicina a observação de órgãos internos sem necessidade de cirurgia. Na indústria mecânica e metalúrgica, permite a identificação de trincas internas em estruturas metálicas e na indústria alimentícia, contribui para o prolongamento do período de conservação de produtos perecíveis. Pertencem ao espectro de radiações eletromagnéticas que se diferem entre si pela freqüência e comprimento de onda. $A$ produção de raios $X$ é obtida por meio de uma fonte fornecedora de elétrons, os quais são acelerados em trajetória livre até chocarem-se com os átomos de um anteparo, provocando deslocamento de novos elétrons com a conseqüente emissão de energia.

Os equipamentos de raios $X$ possuem dois modos de operação: contínuo e momentâneo (SILVEIRA, 2002). A figura 5.1 apresenta as curvas de tensão e 
corrente, medidas no modo contínuo, em um equipamento de fabricação Philips modelo 711, com um analisador de qualidade de energia Fluke 43 B. A tensão de alimentação é trifásica 380V.



Figura 5.1 - Tensão e corrente durante o funcionamento em operação contínua (stand-by) Fonte: Pesquisa de campo.

Nota: Medição realizada com o analisador de qualidade de energia Fluke 43 B.

O valor do fator de crista da corrente é 3,4 e seu valor máximo, igual a 6,8 A, resulta em um valor eficaz de apenas $2 \mathrm{~A}$. Embora o valor da corrente no modo contínuo possua valor reduzido, possui harmônicos de corrente, conforme se observa na figura abaixo.

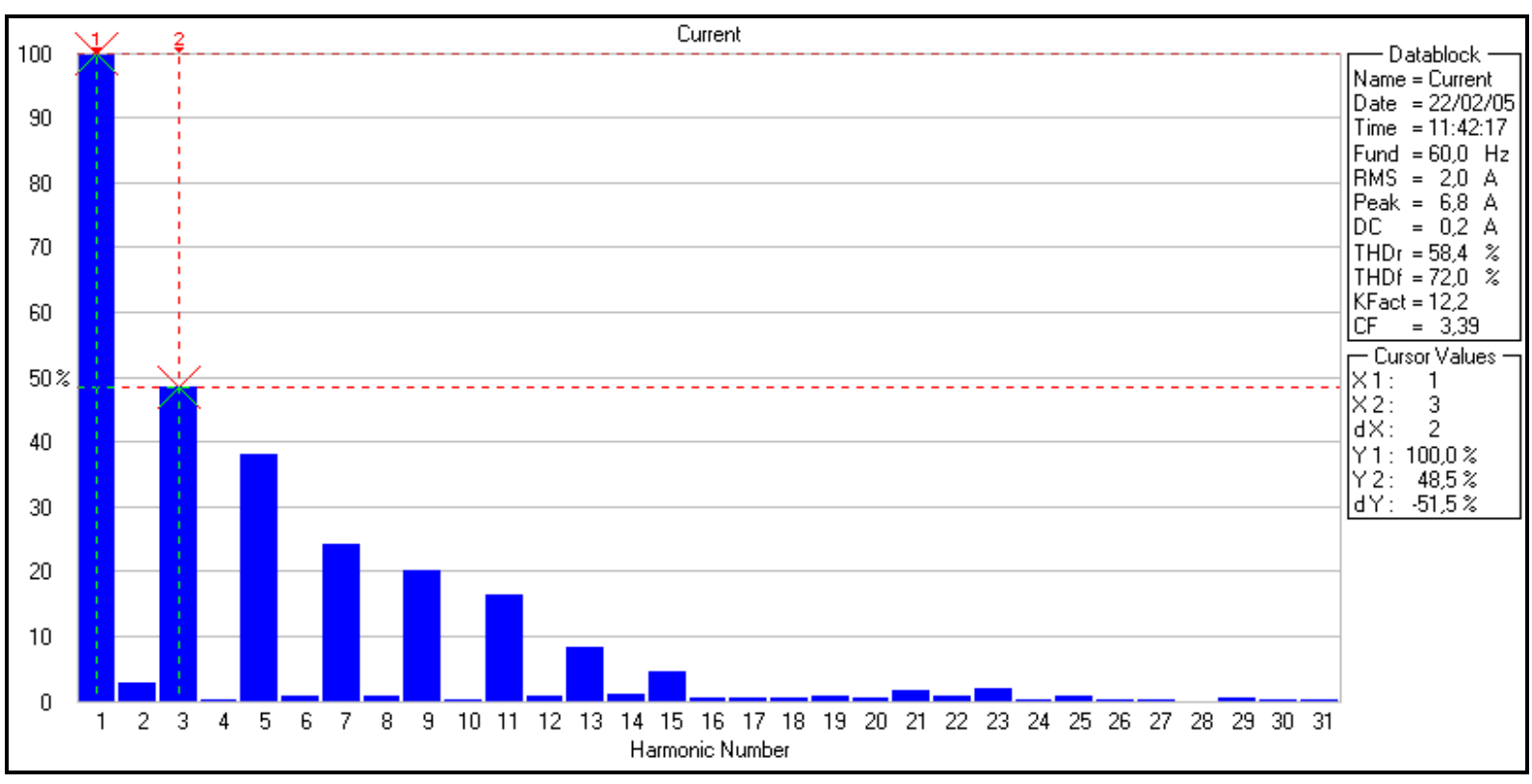

Figura 5.2 - Espectro de harmônicos de corrente durante o funcionamento contínuo

Fonte: Pesquisa de campo.

Nota: Medição realizada com o analisador de qualidade de energia Fluke 43 B. 
A tabela do gráfico expresso como figura 5.2 fornece algumas informações importantes:

a) distorção harmônica total de corrente em função da resultante: $T H D_{r}=$ $58,4 \%$;

b) distorção harmônica total de corrente em função da fundamental: $\mathrm{THD}_{\mathrm{f}}=$ $72,0 \%$;

c) CF: fator de crista $=3,39$;

d) Kfact: refere-se ao fator de desclassificação (Derating Transformer Factor) que deverá ser aplicado a um transformador que alimenta cargas nãolineares.

A presença de harmônicos de corrente provoca o aumento das perdas no ferro e no cobre, e nessas condições os transformadores poderão apresentar sobreaquecimento, alterando seu rendimento, diminuindo sua vida útil ou, até mesmo, provocando sua danificação (ANSI/IEEE C57.110, 1986).

Nessas condições, para mantê-lo em funcionamento sob condições aceitáveis, é necessário reduzir sua carga admissível.

Segundo recomendação da norma citada, o valor eficaz da máxima corrente, que um transformador trifásico, com ligação delta-estrela poderá fornecer é:

$$
I_{\max }(p u)=I_{n}\left[\frac{1,15}{1+0,15 K_{\text {fact }}}\right]^{1 / 2}
$$

onde:

$$
K_{f a c t}=\frac{\sum_{h=1}^{\infty} h^{2} H D_{I}^{2}}{\sum_{h=1}^{\infty} H D_{I}^{2}}
$$

sendo:

$I_{n}$ - corrente nominal do transformador;

$\mathrm{h}$ - ordem do harmônico de corrente;

$H D_{(I)}$ - distorção harmônica individual, de corrente. 
Para o caso apresentado acima, $\mathrm{K}_{\text {fact }}=12$,2, obtém-se por meio da equação 5.1, $I_{\max }=0,637 . I_{n}$, ou seja, o transformador deverá ser utilizado apenas com $63,7 \%$ de sua potência nominal.

O fator de distorção pode ser calculado por meio da equação A.20, do Anexo A:

$$
v=\frac{I_{1}}{I}=\frac{T H D r}{T H D_{f}}=\frac{0,584}{0,72}=0,8
$$

A figura 5.3, obtida da tela de potência do analisador Fluke 43 B, apresenta outros dados importantes para a análise desse equipamento:



Figura 5.3 - Tela de potência do analisador Fluke 43 B - medição monofásica Fonte: Pesquisa de campo.

Observa-se que o fator de potência total, considerando os harmônicos de corrente, é igual a 0,8. Sendo o fator de potência da fundamental igual a 1,0, obtém-se o mesmo valor do fator de distorção, utilizando a equação A.19, do Anexo A:

$$
v=\frac{F P}{\cos \phi_{1}}=\frac{0,8}{1}=0,8
$$


Durante a operação no modo momentâneo no instante da radiografia, a potência elétrica necessária é elevada, podendo produzir afundamentos de tensão de curta duração.

Um dos picos de corrente produzidos atingiu 168,9 A com tempo de duração de 4s, conforme se observa na figura 5.4.

Em função das necessidades para obtenção de uma boa radiografia, o radiologista seleciona parâmetros como: tensão de anôdo e corrente de filamento da válvula, além do tempo de exposição.

Embora neste caso se observe um afundamento de tensão igual a 11,6 V $(218,1$ 206,5), dependendo da potência de curto-circuito no local da instalação do equipamento, situações mais severas poderão ocorrer, prejudicando o funcionamento de equipamentos sensíveis ligados no mesmo centro de distribuição.

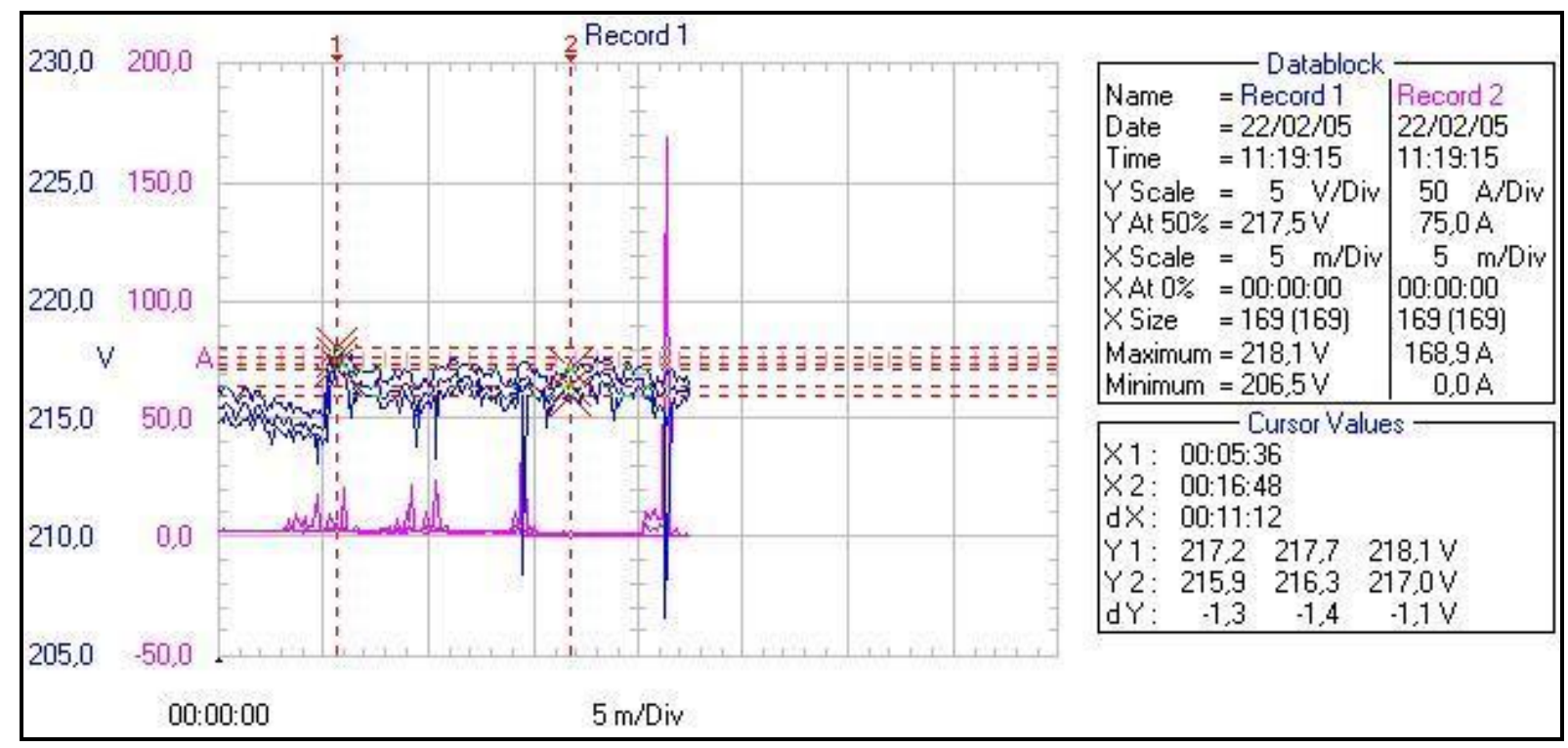

Figura 5.4 - Intensidade de corrente e o respectivo afundamento de tensão provocado durante o funcionamento momentâneo

Fonte: Pesquisa de campo.

Nota: Medição realizada com o analisador de qualidade de energia Fluke 43 B.

\subsection{MAMOGRAFIA}

Também denominados de mamógrafos, as unidades básicas para mamografia fornecem informações sobre a morfologia, anatomia e patologias das mamas, por meio de imagens radiográficas. Atualmente é um dos exames utilizados para a 
detecção e diagnóstico de câncer de mama, além de realizar avaliação de lesões nos seios.

A principal causa de morte relacionada ao câncer entre mulheres tem sido o de mama. Aproximadamente $90 \%$ das lesões, sejam benignas ou malignas, são descobertas por intermédio do apalpamento dos seios. Mas, na maioria das vezes, uma massa maligna, que não apresente dores como sintomas, quando detectada por apalpamento, pode ter se espalhado pelos nódulos linfáticos.

Portanto, o exame radiológico é atualmente a técnica mais precisa para descoberta de câncer em indivíduos que ainda não apresentam sintomas da doença, aumentando suas chances de sobrevivência (CALIL et al., 2002).

A figura 5.5 apresenta as formas de onda da tensão e da corrente em operação contínua. O equipamento é de fabricação Toshiba, modelo 4.00 .0029 , com tensão de alimentação monofásica $220 \mathrm{~V}$.



Figura 5.5 - Tensão e corrente durante o funcionamento em operação contínua (stand-by)

Fonte: Pesquisa de campo. Nota: Medição realizada com o analisador de qualidade de energia Fluke 43 B.

A mamografia também apresenta a corrente com componentes harmônicos, como se observa na figura 5.6. 




Figura 5.6- Espectro de harmônicos de corrente durante o funcionamento contínuo Fonte: Pesquisa de campo.

Nota: Medição realizada com o analisador de qualidade de energia Fluke 43 B.

Do gráfico da figura 5.6, obtém-se:

a) distorção harmônica total de corrente em função da resultante: $\mathrm{THD}_{\mathrm{r}}=46,8 \%$;

b) distorção harmônica total de corrente em função da fundamental: $T H D_{f}=$ $52,9 \%$;

c) CF: fator de crista $=3,39$;

d) $\mathrm{Kfact}=5,8$, podendo-se obter, da equação 5.1 , o valor de $I_{\max }=0,784$. $I_{n}$, ou seja, o transformador que alimenta este equipamento só poderá ser utilizado com $78,4 \%$ de sua potência nominal.

O fator de distorção pode ser calculado por meio da equação A.20, do Anexo A:

$$
v=\frac{I_{1}}{I}=\frac{T H D r}{T H D_{f}}=\frac{0,468}{0,529}=0,884
$$

A figura 5.7, obtida da tela de potência do analisador Fluke 43 B, apresenta outros dados importantes para a análise desse equipamento. 


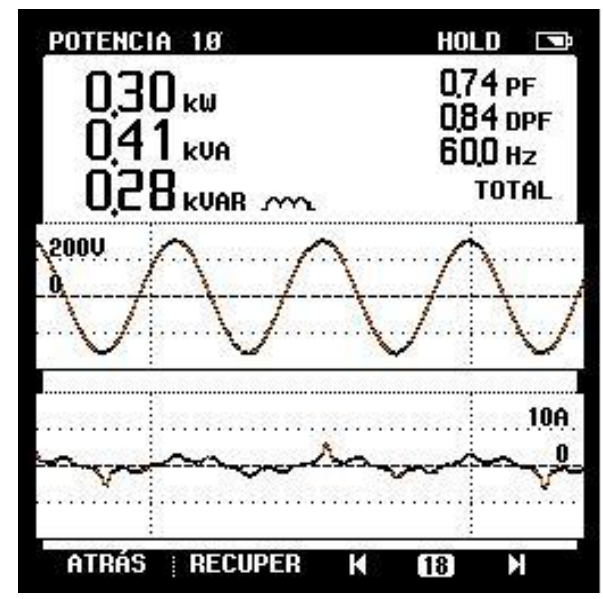

Figura 5.7 - Tela de potência do analisador Fluke 43 B - medição monofásica

Fonte: Pesquisa de campo.

Nota: Medição realizada com o analisador de qualidade de energia Fluke 43 B.

Observa-se que o fator de potência total, considerando os harmônicos de corrente, é igual a 0,74 . Sendo fator de potência da fundamental igual a 0,84 , obtém-se o mesmo valor do fator de distorção, utilizando a equação A.19, do Anexo A.

$$
v=\frac{F P}{\cos \phi_{1}}=\frac{0,74}{0,84}=0,88
$$

Durante a realização das radiografias, a corrente solicitada é de grande amplitude e com tempo de duração de alguns segundos, conforme se apresenta na figura 6.12.



Figura 5.8 - Intensidade de corrente durante o funcionamento momentâneo

Fonte: Pesquisa de campo.

Nota: Medição realizada com o analisador de qualidade de energia Fluke 43 B. 
Pela figura 5.8 observa-se que, durante o funcionamento contínuo (stand-by), a corrente apresentou um valor mínimo de 1,09 A, no entanto, durante a realização das radiografias, alcançou aproximadamente $30 \mathrm{~A}$. A duração do pico de corrente situa-se em torno de $4 \mathrm{~s}$.

\subsection{TOMOGRAFIA COMPUTADORIZADA}

É um dos métodos de exame mais confiáveis e seguros disponíveis na medicina moderna. Constitui-se em um equipamento de raios $\mathrm{X}$ que gira em torno do corpo do paciente, fazendo radiografias transversais.

Em seguida, essas radiografias são convertidas por um computador, nos chamados cortes tomográficos, ou seja, uma série de seções fatiadas que serão posteriormente montadas para formar uma imagem completa. Possui, portanto, um comportamento semelhante ao aparelho de raios $\mathrm{X}$, solicitando uma corrente totalmente distorcida, como se observa na figura 5.9. O equipamento é de fabricação Philips, modelo MX 8000 , trifásico $380 \mathrm{~V}$.

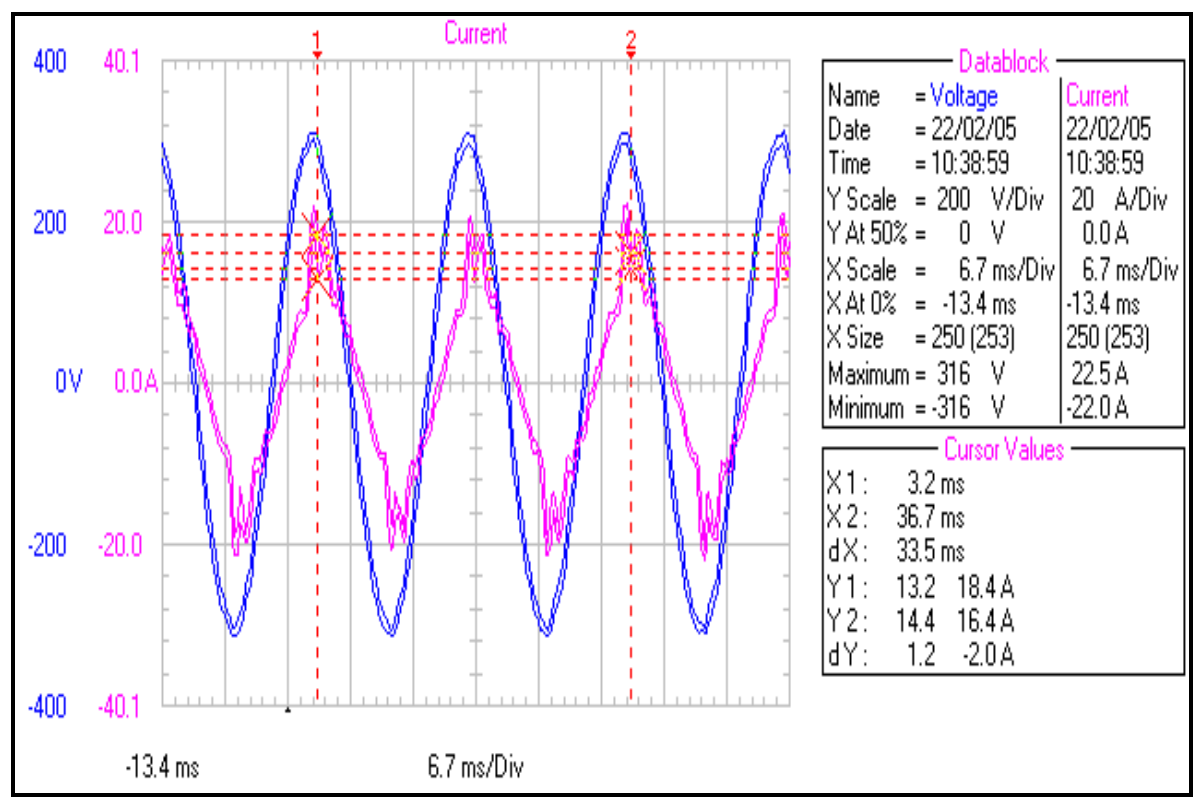

Figura 5.9 - Tensão e corrente durante o funcionamento em operação contínua (stand-by)

Fonte: Pesquisa de campo.

Nota: Medição realizada com o analisador de qualidade de energia Fluke 43 B. 
O valor máximo da corrente, durante o funcionamento contínuo é igual a 22,5 $\mathrm{A}$, valor superior ao de raios $X$, nas mesmas condições de operação. $O$ espectro de harmônicos da corrente, nessas condições, está apresentado na figura 5.10.

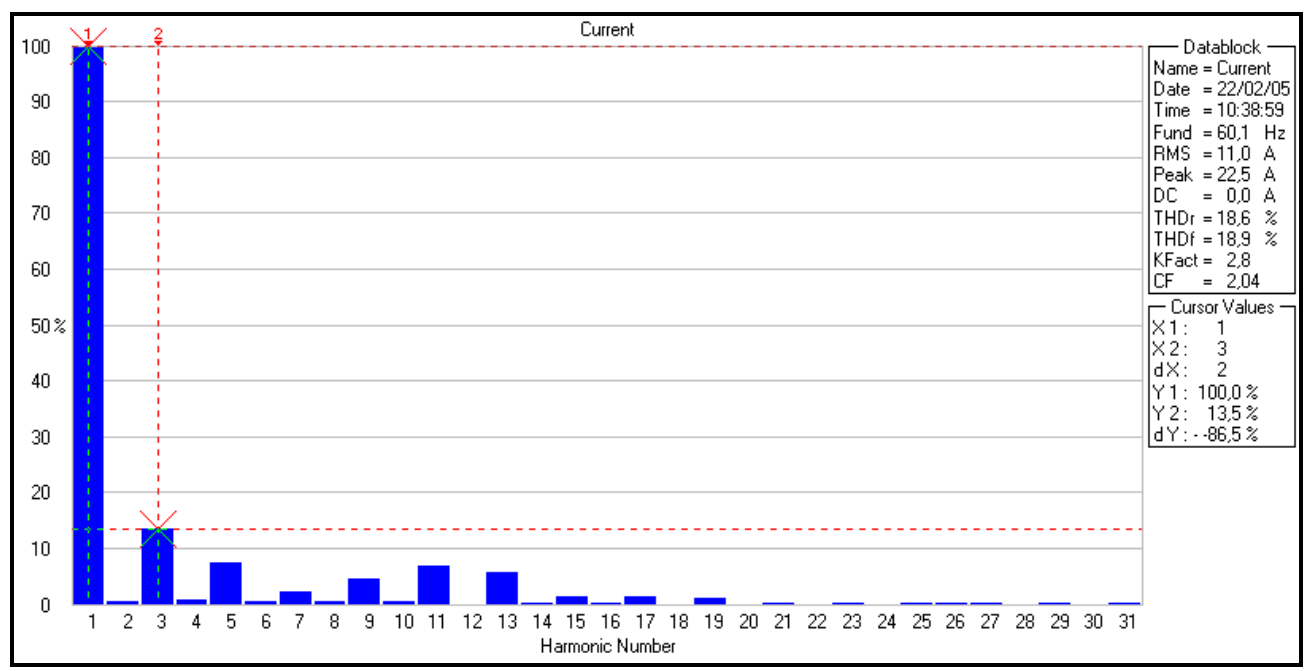

Figura 5.10 - Espectro de harmônicos de corrente durante o funcionamento contínuo Fonte: Pesquisa de campo.

Nota: Medição realizada com o analisador de qualidade de energia Fluke 43 B.

Do gráfico da figura 5.10, obtém-se:

a) distorção harmônica total de corrente em função da resultante: $\mathrm{THD}_{\mathrm{r}}=18,6 \%$;

b) distorção harmônica total de corrente em função da fundamental: $T_{\mathrm{f}} \mathrm{f}=$ $18,9 \%$;

c) CF: fator de crista $=2,04$;

d) $\mathrm{Kfact}=2,8$, podendo-se obter, da equação 5.1 , o valor de $I_{\max }=0,899 . I_{n}$, ou seja, o transformador que alimenta este equipamento só poderá ser utilizado com $89,9 \%$ de sua potência nominal.

O fator de distorção pode ser calculado por meio da equação A.20, do Anexo A:

$$
v=\frac{I_{1}}{I}=\frac{T H D r}{T H D_{f}}=\frac{0,186}{0,189}=0,984
$$

A figura 5.11, obtida da tela de potência do analisador Fluke $43 \mathrm{~B}$, apresenta outros dados importantes para a análise desse equipamento: 


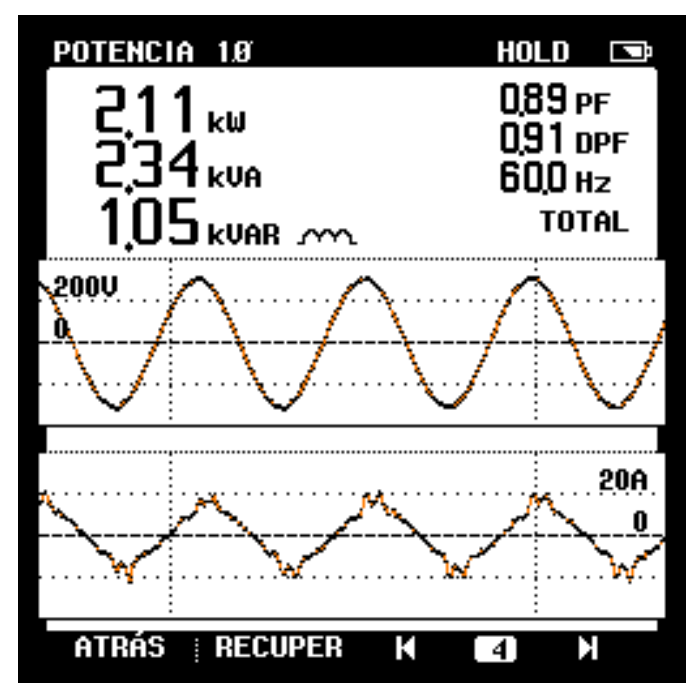

Figura 5.11 - Tela de potência do analisador Fluke 43 B - medição monofásica

Fonte: Pesquisa de campo.

Nota: Medição realizada com o analisador de qualidade de energia Fluke 43 B.

Observa-se que o fator de potência total, considerando os harmônicos de corrente, é igual a 0,89. Com base no fator de potência da fundamental igual a 0,91, obtém-se, praticamente, o mesmo valor do fator de distorção, utilizando a equação A.19, do Anexo A:

$$
v=\frac{F P}{\cos \phi_{1}}=\frac{0,89}{0,91}=0,978
$$

A intensidade de corrente, durante o funcionamento momentâneo, assume valores elevados de curta duração, que dependendo do dimensionamento do circuito de alimentação e da potência de curto-circuito, produzirá afundamentos de tensão.

A figura 6.6 apresenta esta situação onde se observa que o tempo de duração do pico de corrente, indicado pelos cursores, foi de $24 \mathrm{~s}$. 


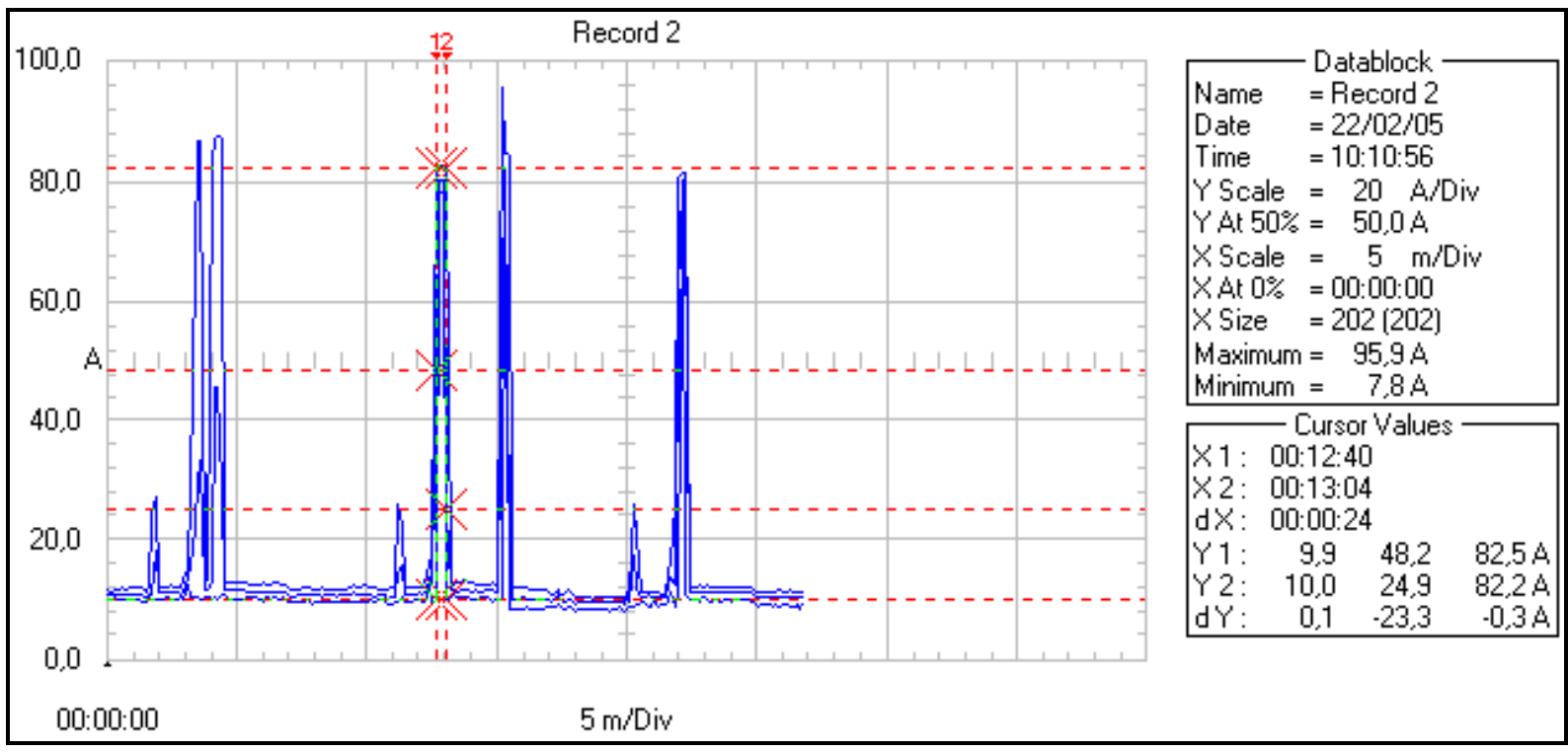

Figura 5.12- Intensidade de corrente durante o funcionamento momentâneo

Fonte: Pesquisa de campo.

Nota: Medição realizada com o analisador de qualidade de energia Fluke 43 B.

Durante o funcionamento contínuo (stand-by), o valor mínimo solicitado foi de 7,8 A, no entanto, no modo momentâneo, atingiu 95,9 A.

\subsection{RESSONÂNCIA MAGNÉTICA NUCLEAR}

Atualmente, a medicina pode contar com uma ferramenta moderna e precisa, com a finalidade de obtenção de uma imagem seccional do interior do corpo.

A imagem, obtida por meio de propriedades magnéticas, fornece aos médicos uma quantidade de informações detalhadas sobre a localização, tamanho e composição do tecido corporal a ser examinado, permitindo um diagnóstico rápido e preciso.

A ressonância magnética nuclear não utiliza raios $X$, mas sim as propriedades magnéticas do núcleo dos átomos que constituem todas as substâncias, incluindo, obviamente, aquelas que compõem o corpo humano.

A técnica fundamenta-se nestas três etapas: alinhamento, excitação e detecção de radiofreqüência (AMARO JR., 2001).

O alinhamento refere-se à propriedade magnética de núcleos de alguns átomos, que tendem a se orientar paralelamente a um campo magnético aplicado.

Por razões físicas e pela abundância, o núcleo do hidrogênio é o elemento utilizado para a produção de imagens em seres biológicos. 
Para que esses átomos sejam orientados numa certa direção é necessário um campo magnético intenso, habitualmente cerca de 1,5 T, ou seja, cerca de 30.000 vezes maior que o campo magnético da terra.

$\mathrm{Na}$ segunda etapa, denominada excitação, o núcleo do hidrogênio entra em vibração, com uma freqüência proporcional ao campo magnético a que está submetido. Para 1,5 T, por exemplo, a freqüência de vibração é de $63,8 \mathrm{MHz}$.

A partir de então, o equipamento emite uma onda eletromagnética nessa mesma freqüência, transferindo energia para os núcleos dos átomos de hidrogênio e produzindo o fenômeno de ressonância.

A informação para produção da imagem, na terceira etapa, é obtida pela detecção da radiofreqüência, pois, quando os núcleos recebem a energia proveniente do equipamento, tornam-se instáveis e ao retornarem ao seu estado inicial, emitem ondas eletromagnéticas na mesma freqüência, ou seja, $63,8 \mathrm{MHz}$.

Para realização do exame, não há necessidade de remoção das roupas, como em muitos casos de exames de raios $\mathrm{X}$, porém, todos os objetos metálicos que possam interferir no processo de imagem devem ser retirados.

Da mesma forma, placas dentárias, marca-passo ou prótese vascular, que não possam ser removidas, deverão ser informadas pelo paciente ao responsável pela execução do exame.

A figura 5.13 apresenta as formas de onda da tensão de alimentação e a respectiva corrente, de um equipamento, de fabricação Philips, modelo HR 8552, trifásico 380 V, em operação.



Figura 5.13 - Tensão e corrente durante a operação

Fonte: Pesquisa de campo.

Nota: Medição realizada com o analisador de qualidade de energia Fluke 43 B. 
Observa-se, pelo gráfico da figura 5.13, que o valor máximo da corrente atingiu 109 A e sua forma de onda não é periódica, pois sua amplitude se modifica a cada ciclo. A figura 5.14 apresenta o espectro de harmônicos da corrente durante a operação do equipamento.



Figura 5.14 - Espectro de harmônicos de corrente durante a operação

Fonte: Pesquisa de campo.

Nota: Medição realizada com o analisador de qualidade de energia Fluke 43 B.

Da figura 5.14 obtém-se informações importantes para análise da qualidade da energia elétrica:

a) distorção harmônica total de corrente em função da resultante: $\mathrm{THD}_{\mathrm{r}}=$ $18,1 \%$.

b) valor eficaz da corrente: $I=35,9 \mathrm{~A}$;

c) valor da fundamental de corrente: $I_{1}=35,3 \mathrm{~A}$;

d) $\mathrm{Kfact}=1,9$, podendo-se obter, da equação 5.1 , o valor de $I_{\max }=0.946 . I_{\mathrm{n}}$, ou seja, o transformador que alimenta este equipamento só poderá ser utilizado com $94,6 \%$ de sua potência nominal.

Utilizando a equação A.20, do Anexo A para o fator de distorção, obtém-se o valor:

$$
v=\frac{I_{1}}{I}=\frac{35,3}{35,9}=0,983
$$


A figura 5.15, obtida da tela de potência do analisador Fluke 43 B, apresenta outros dados importantes para a análise desse equipamento:

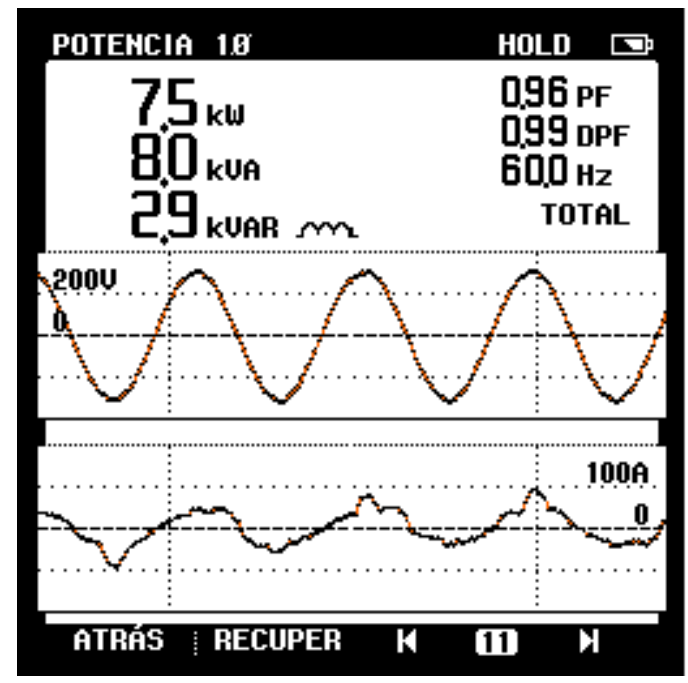

Figura 5.15 - Tela de potência do analisador Fluke 43 B - medição monofásica

Fonte: Pesquisa de campo.

Nota: Medição realizada com o analisador de qualidade de energia Fluke 43 B.

Observa-se que o fator de potência total, considerando os harmônicos de corrente, é igual a 0,96. Como o fator de potência da fundamental é igual a 0,99, obtém-se, praticamente, o mesmo valor do fator de distorção, utilizando a equação A.19, do Anexo A:

$$
v=\frac{F P}{\cos \phi_{1}}=\frac{0,96}{0,99}=0,969
$$

Embora não apresente picos de corrente durante um curto intervalo de tempo como os demais, a ressonância exige, da rede elétrica, uma elevada intensidade de corrente durante um longo intervalo de tempo, como se pode observar na figura 5.16 . 


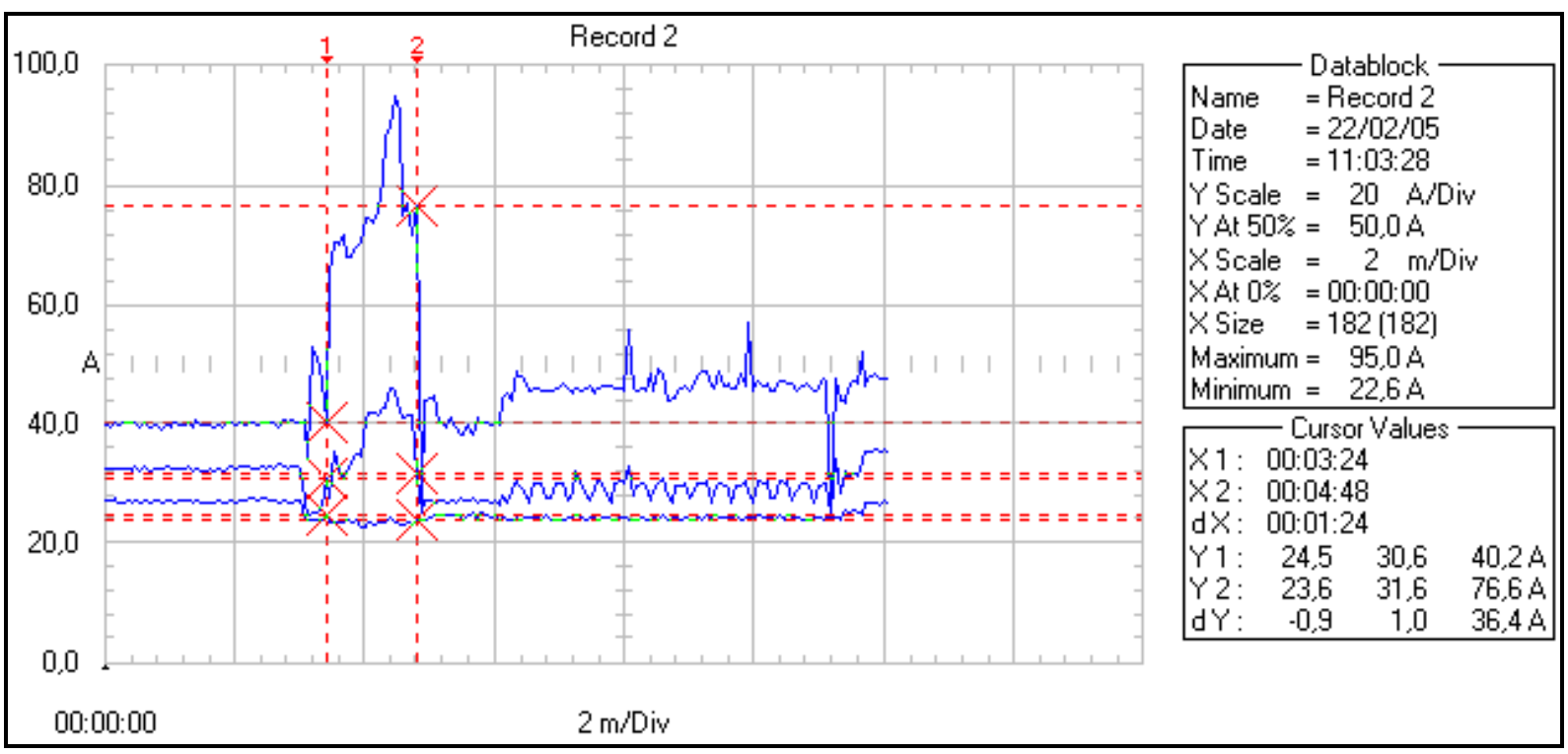

Figura 5.16 - Variação da corrente durante o funcionamento

Fonte: Pesquisa de campo.

Nota: Medição realizada com o analisador de qualidade de energia Fluke 43 B.

No modo contínuo (stand-by), o valor mínimo solicitado foi de 22,6 A e durante a realização do exame, o valor máximo alcançou $95 \mathrm{~A}$. Se o sistema de alimentação do equipamento não estiver dimensionado pela situação mais crítica, poderá ocorrer subtensão, prejudicando equipamentos sensíveis, ligados em circuitos adjacentes. $O$ tempo em que o equipamento permaneceu exigindo uma corrente elevada da rede elétrica foi de aproximadamente $90 \mathrm{~s}$, o que pode ser verificado pela distância entre os cursores 1 e 2 .

\subsection{MOTORES ELÉTRICOS DE INDUÇÃO}

Devido às excelentes qualidades, como: facilidade de transporte; ausência de poluição, preservando o homem e o meio ambiente; facilidade de comando e controle, dispensando armazenamento e apresentando baixo custo em relação às vantagens mencionadas, a eletricidade é a alternativa de energia preferida para ser transformada em outras formas, como térmica, luminosa, mecânica, etc. Para a transformação de energia elétrica em mecânica, utiliza-se o motor elétrico, que atualmente é, sem dúvida, o principal equipamento de uso final de energia elétrica. Seria atualmente impossível que a humanidade conseguisse viver sem esse equipamento (PROCEL, 1998). No Brasil, estima-se que na atividade industrial, mais 
de $50 \%$ da energia elétrica utilizada é transformada em energia mecânica, por intermédio dos motores elétricos (CRESTANI, 2005).

Dessa forma, pode-se assegurar que o progresso tecnológico está diretamente interligado à existência do motor, sempre associado à sua construção simples e robusta, a um custo reduzido e com grande flexibilidade de se adaptar aos acionamentos de máquinas e equipamentos industriais.

Além disso, o motor elétrico efetua a transformação de energia de maneira relativamente simples, exigindo uma instalação e manutenção de baixo custo; opera silenciosamente; ocupa espaço reduzido; apresenta vida longa e elevada eficiência. No entanto, para que todas essas vantagens possam tornar-se realidade, é importante que o motor seja alimentado por uma rede elétrica adequada e de boa qualidade, seja apropriado ao local onde será instalado e possua potência compatível com a carga que acionará.

Além da tensão e da freqüência, a rede de alimentação impõe ao motor certas limitações, no tocante às correntes durante a fase de partida, uma vez que são estes os principais distúrbios que ele causa à rede, em condições normais.

A corrente de partida, assumindo valores bem superiores à corrente nominal, deve ser considerada no dimensionamento do circuito terminal a fim de que a queda de tensão não seja elevada.

Os valores máximos limites, de corrente absorvida com o rotor bloqueado à tensão nominal, são especificados na Norma ABNT NBR 7094 (2000), em kVA/cv ou $\mathrm{kVA} / \mathrm{kW}$.

A referida norma exige também que seja expressa a relação entre a corrente de rotor bloqueado e a corrente nominal, na placa de identificação.

Esse valor não deve ser superior ao valor correspondente indicado na tabela 2 da ABNT NBR 7094. A figura 5.17 apresenta o comportamento da corrente na fase de partida. 


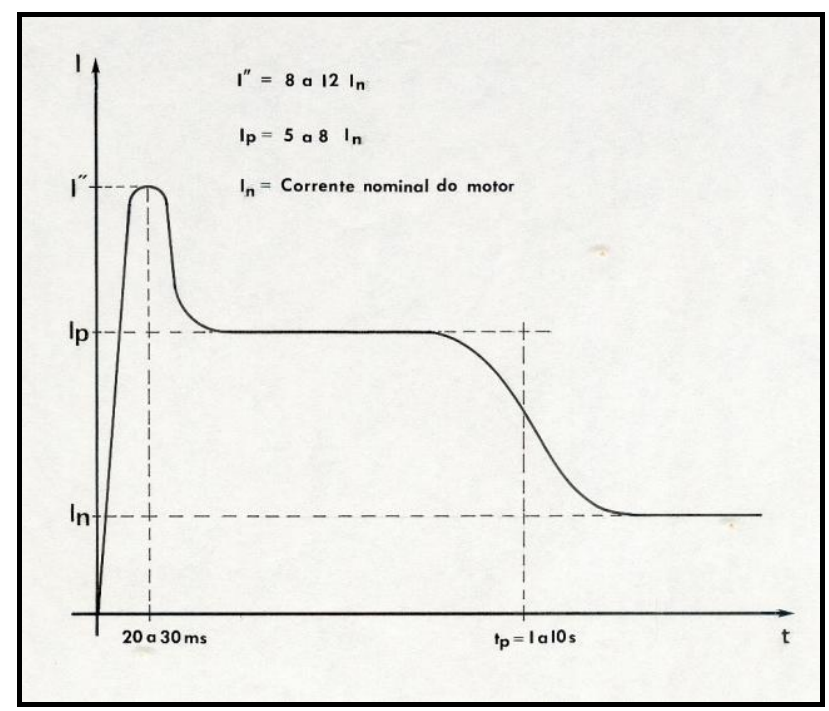

Figura 5.17 - Variação da corrente durante a partida

Fonte: Elaborada pelo autor.

A figura 5.18 apresenta a corrente durante a partida de um motor de indução trifásico, $1 \mathrm{cv}, 220 \mathrm{~V}$, que aciona um aspirador em aplicações médicas. A corrente de rotor bloqueado de $14 \mathrm{~A}$ se reduz para o valor da corrente nominal em 2,74 s, o que é suficiente para produzir, dependendo do dimensionamento do circuito, um afundamento de tensão prejudicial a outros equipamentos ligados ao mesmo circuito.

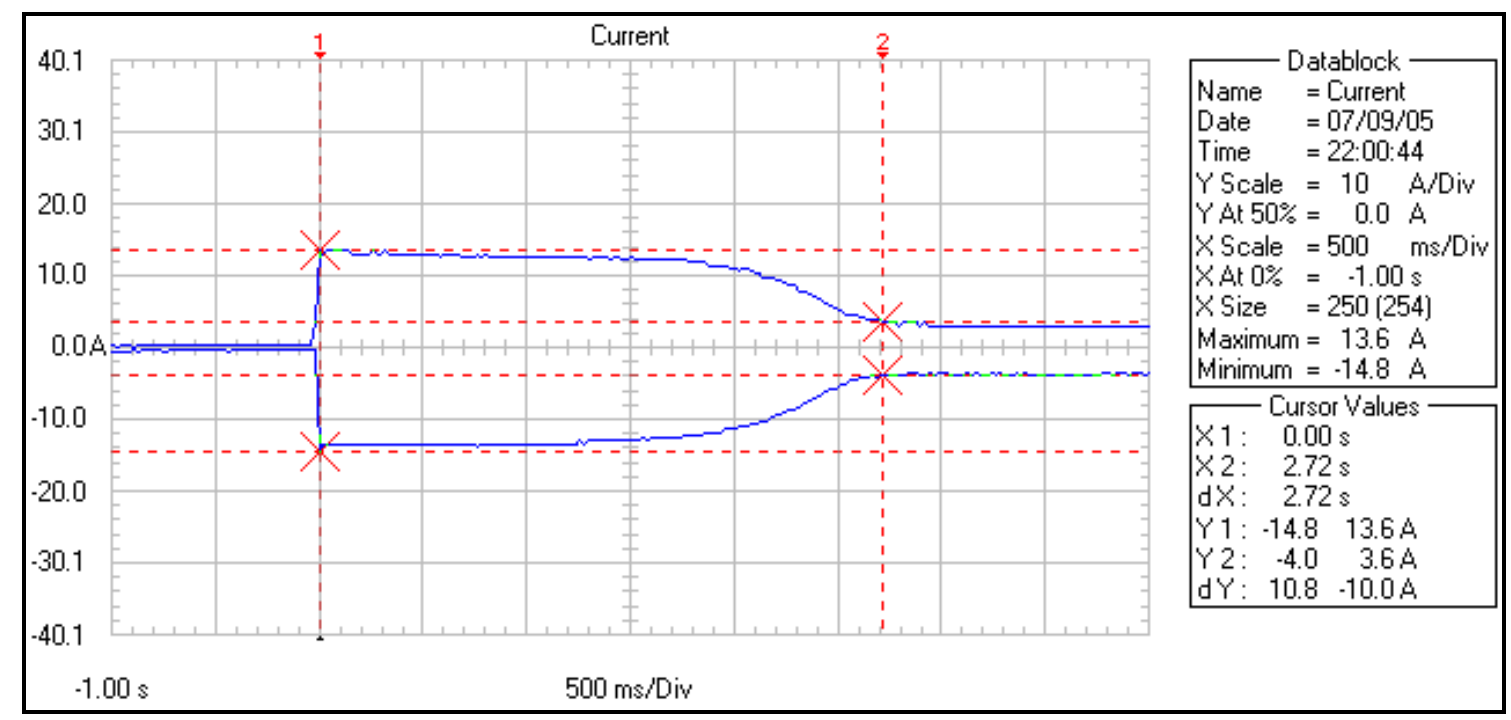

Figura 5.18- Variação da corrente durante a partida de um motor de indução - aspirador

Fonte: Pesquisa de campo.

Nota: Medição realizada com o analisador de qualidade de energia Fluke 43 B. 
Nas instalações hospitalares, os motores de indução são utilizados em muitos equipamentos, sendo que os de maior potência estão instalados geralmente nos setores de lavanderias, elevadores de passageiros, climatização, bombeamento d'água, entre outros (CALIL et al., 2002).

Os elevadores de passageiros são cargas com funcionamento intermitente, provocando uma grande quantidade de picos de corrente, principalmente durante os horários destinados à visitação de pacientes.

Dependendo do dimensionamento da rede de alimentação e da potência de curtocircuito no local da instalação do motor, afundamentos de tensão serão produzidos e, dependendo de sua intensidade, poderão prejudicar o funcionamento de cargas sensíveis, ligadas ao mesmo centro de distribuição.

A figura 5.19 apresenta as variações da corrente e da tensão durante o funcionamento de um elevador, acionado por meio de um motor trifásico de indução com potência de $12,5 / 20$ cv, 38/48 A, 885/1775 rpm, sob tensão de 220 V e ligação Dahlander.

Esse tipo de ligação permite que o motor opere em duas rotações. A partida efetuase na menor delas, com o objetivo de reduzir a potência e a corrente de partida.

Mesmo assim, os picos gerados são elevados o suficiente para produzir afundamentos de tensão de curta duração.



Figura 5.19- Variação da corrente e afundamentos de tensão provocados durante a partida de um elevador de passageiros

Fonte: Pesquisa de campo. Nota: Medição realizada com o analisador de qualidade de energia Fluke 43 B. 
Observa-se pelo gráfico, que o valor de fase da tensão durante a partida se reduziu para $115,4 \mathrm{~V}$, o que representa um afundamento de tensão de $10 \%$, ou seja, o valor remanescente foi de $90 \%$ do valor nominal da rede de alimentação.

Outro caso que se apresenta é uma bomba centrífuga responsável pelo recalque de água para um reservatório elevado de um EAS.

A bomba é acionada por um motor de indução trifásico de $30 \mathrm{cv}, 1765 \mathrm{rpm}, 380 \mathrm{~V}$, $42 \mathrm{~A}$, com partida realizada por intermédio de chave compensadora, ligada na derivação $80 \%$. As figuras 5.20 e 5.21 apresentam as curvas de tensão e de corrente em valores instantâneos, durante a fase de partida desse acionamento. As medições foram efetuadas no centro de distribuição do setor de utilidades.

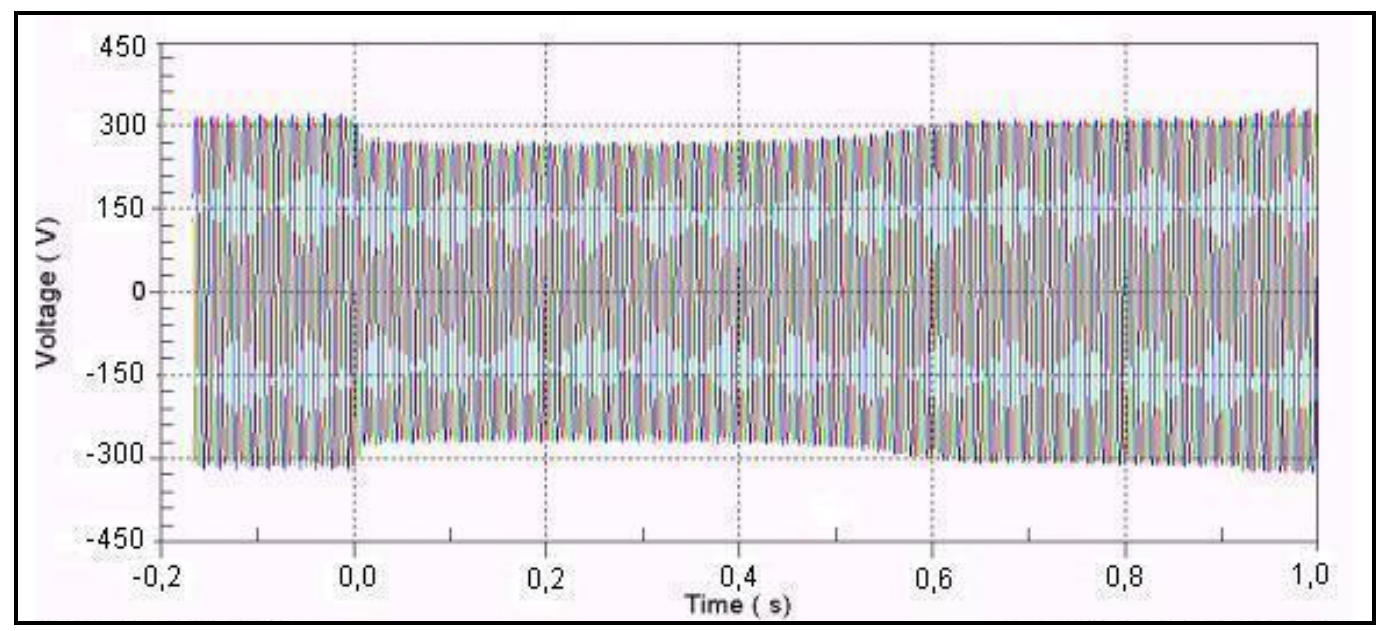

Figura 5.20 - Afundamento de tensão provocado durante a partida - valores instantâneos

Fonte: Pesquisa de campo.

Nota: Medição realizada com o registrador de parâmetros de qualidade de energia Reason RQE III.



Figura 5.21 - Variação da corrente durante a partida - valores instantâneos

Fonte: Pesquisa de campo. (medição realizada com o registrador o Reason RQE III). 
As figuras 5.22 e 5.23 apresentam as mesmas curvas expressas em valores eficazes de tensão e de corrente, respectivamente.

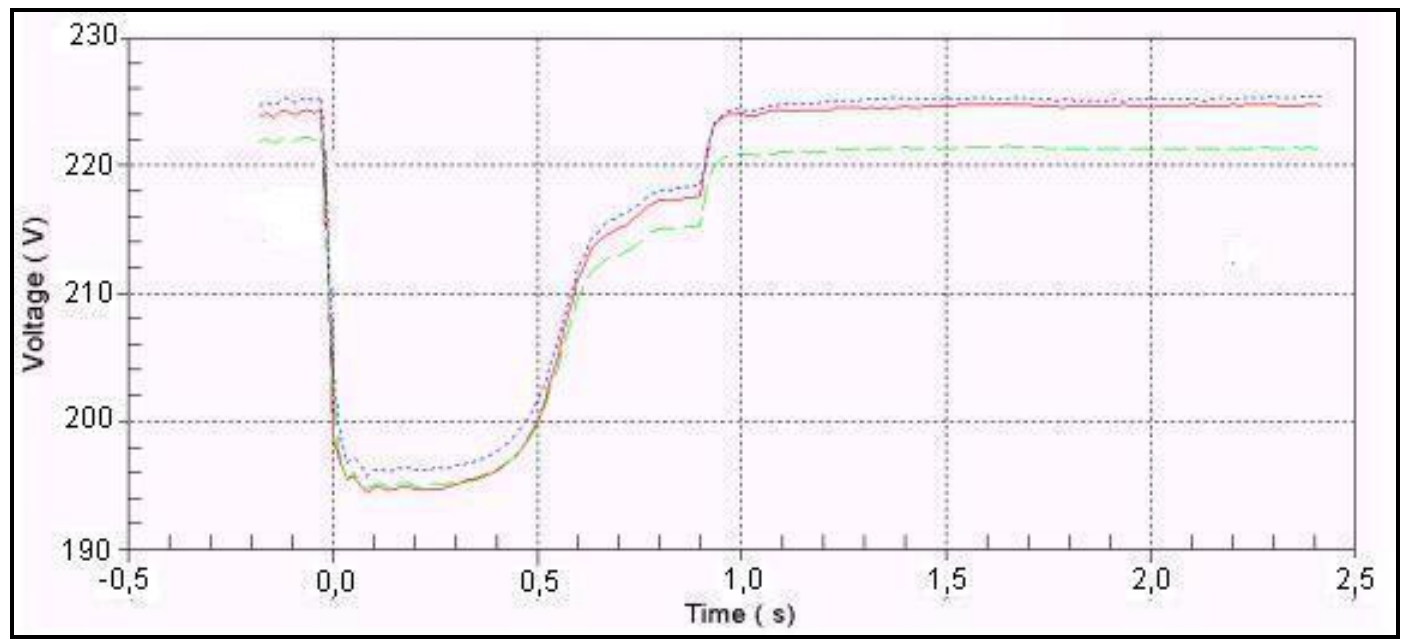

Figura 5.22 - Afundamento de tensão provocado durante a partida - valores eficazes

Fonte: Pesquisa de campo.

Nota: Medição realizada com o registrador de parâmetros de qualidade de energia Reason RQE III.

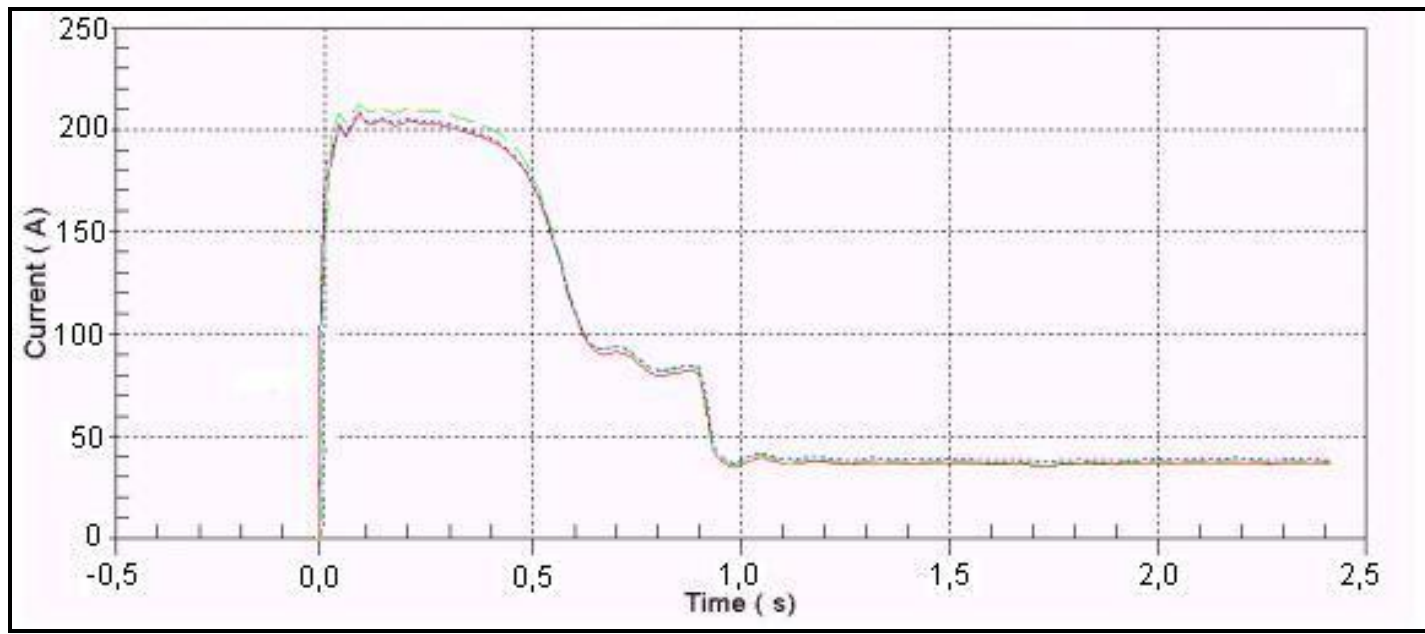

Figura 5.23 - Variação da corrente durante a partida - valores eficazes

Fonte: Pesquisa de campo.

Nota: Medição realizada com o registrador de parâmetros de qualidade de energia Reason RQE III.

Em observação às curvas, pode-se tirar as seguintes conclusões:

a) Pela figura 5.22, observa-se que, na partida, o valor remanescente da tensão foi de $194 \mathrm{~V}$, o que corresponde a $87,3 \%$ do valor nominal. A queda de tensão na partida foi de $222-194=28 \mathrm{~V}$ (fase verde). A situação mais crítica do afundamento de tensão durou aproximadamente $0,5 \mathrm{~s}$. 
b) O valor eficaz da corrente durante a partida atingiu aproximadamente $210 \mathrm{~A}$, ou seja, 5 vezes o valor da corrente nominal do motor. Esses valores foram obtidos em observação à figura 5.23. Sendo o dispositivo de comando uma chave compensadora conectada na derivação de $80 \%$, conclui-se que a corrente de rotor bloqueado desse motor é: $210 / 0,8^{2}=328 \mathrm{~A}$, ou seja, 7,8 vezes a corrente nominal.

c) a solução mais simples e de menor custo para a redução do afundamento de tensão seria alterar a conexão do autotransformador da chave compensadora de $80 \%$ para $65 \%$. Nesse caso, o novo valor da corrente de rotor bloqueado sob tensão reduzida seria de: $328 \times 0,65^{2}=138,5 \mathrm{~A}$. Considerando a impedância do circuito de alimentação do motor constante, a queda de tensão resultante seria apenas de $18,4 \mathrm{~V}$, o que corresponde a um valor remanescente de $203,6 \mathrm{~V}$, ou seja, $91,7 \%$ do valor nominal.

Da mesma forma que nas atividades industriais, os setores de utilidades dos EAS vêm cada vez mais utilizando sistemas eletrônicos de variação de velocidade, aplicados a motores de indução trifásicos.

Esses sistemas de variação contínua da velocidade, por meio de circuitos eletrônicos compostos de semicondutores de potência, proporcionam economia de energia elétrica, melhora no desempenho de equipamentos, redução dos custos de manutenção, eliminação da corrente de partida, entre outras vantagens.

No entanto, como normalmente os circuitos de entrada desses conversores são compostos de retificador a diodos e banco de capacitores de filtro, a corrente de entrada possui uma forma de onda não senoidal, contendo harmônicos de corrente. Esses harmônicos de corrente, circulando pelas impedâncias da rede de alimentação, provocam quedas de tensão harmônicas que distorcem a tensão de alimentação, podendo provocar falhas no funcionamento de equipamentos sensíveis, como os equipamentos eletromédicos.

A figura 5.24 apresenta as curvas de tensão e corrente de um sistema de bombeamento de água com vazão variável composto de um motor de indução, 10 cv, 27 A, 1760 rpm e FP=0,80, acionado por um conversor de freqüência parametrizado com rampa de aceleração de $5 \mathrm{~s}$.

A figura 5.25 apresenta o espectro dos harmônicos de corrente para o mesmo acionamento. 
Trata-se de um sistema extremamente flexível que ajusta a vazão, por meio da variação da rotação do motor, em função das necessidades de suprimento de água nos reservatório superiores do EAS.

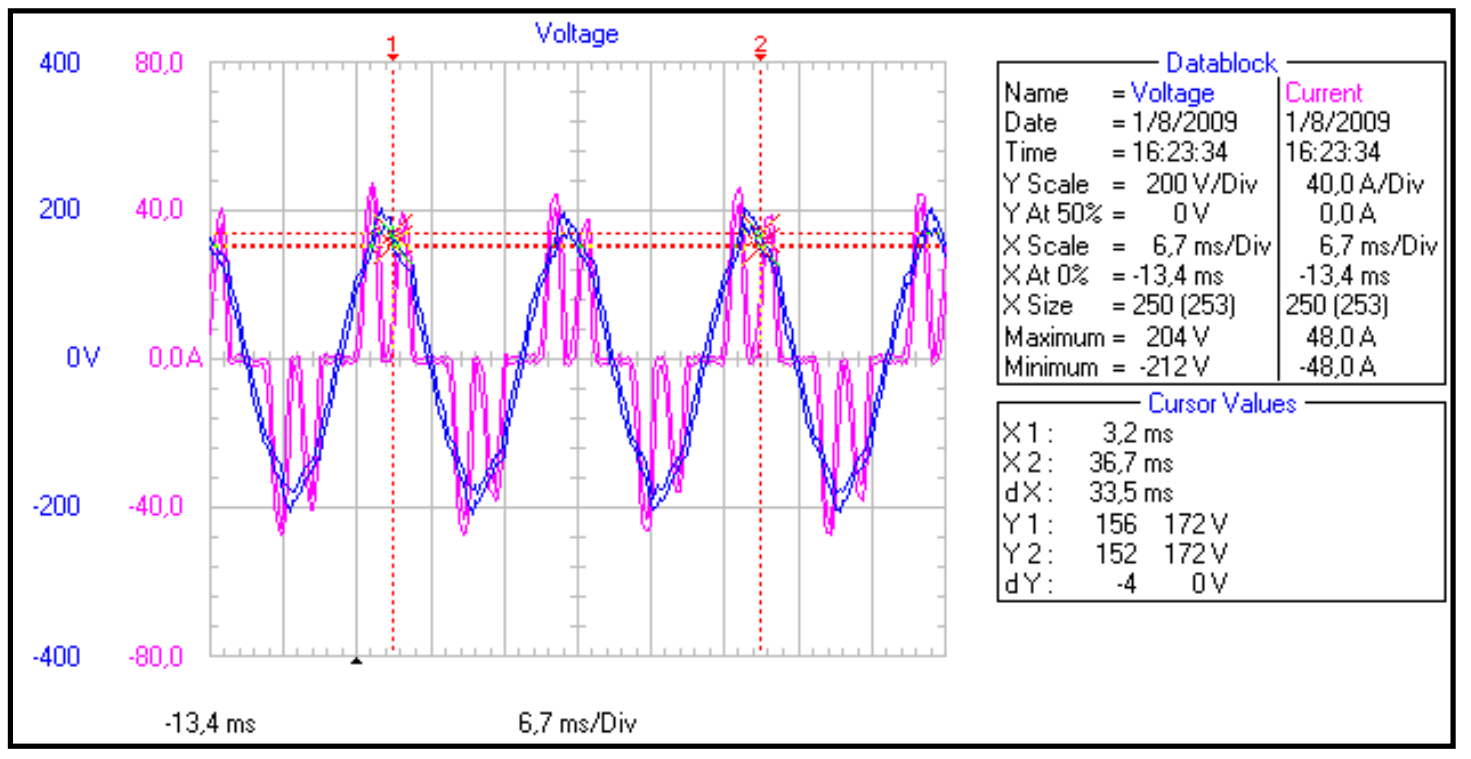

Figura 5.24 - Formas de onda de tensão e de corrente de um sistema de bombeamento composto por um motor de indução, acionado por conversor de freqüência

Fonte: Pesquisa de campo.

Nota: Medição realizada com o analisador de qualidade de energia Fluke 43 B.

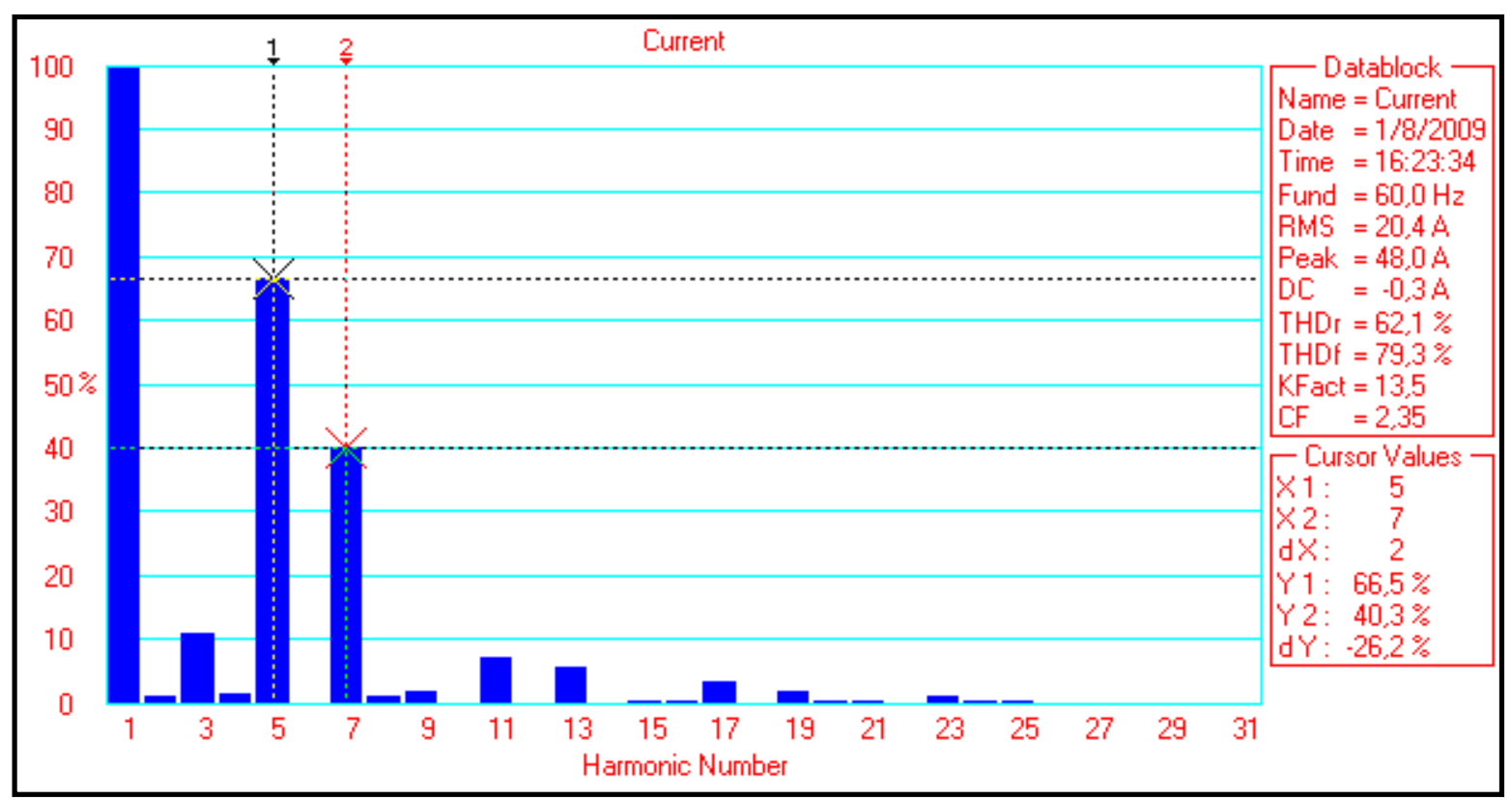

Figura 5.25 - Espectro dos harmônicos de corrente do mesmo acionamento

Fonte: Pesquisa de campo.

Nota: Medição realizada com o analisador de qualidade de energia Fluke 43 B. 
Do gráfico da figura 5.25, obtém-se:

a) distorção harmônica total de corrente em função da resultante: $\operatorname{THD}_{\mathrm{r}}=62,1 \%$;

b) distorção harmônica total de corrente em função da fundamental: $T H D_{f}=$ $79,3 \%$;

c) $\mathrm{CF}$ : fator de crista $=2,35$;

d) $K$ fact $=13,5$, podendo-se obter, da equação 5.1 , o valor de $I_{\max }=0,616$. $I_{n}$, ou seja, o transformador que alimenta este equipamento só poderá ser utilizado com $61,6 \%$ de sua potência nominal.

O fator de distorção pode ser calculado por meio da equação A.20, do Anexo A:

$$
v=\frac{I_{1}}{I}=\frac{T H D r}{T H D_{f}}=\frac{0,621}{0,793}=0,78
$$

A tela de potência do analisador Fluke 43 B está apresentada na figura 5.26, contendo informações importantes sobre as características desse acionamento:

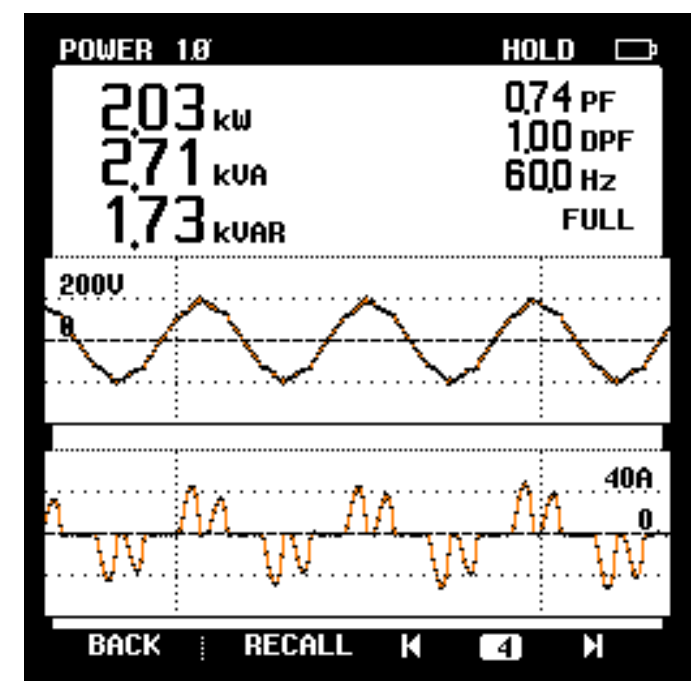

Figura 5.26 - Tela de potência do analisador Fluke 43 B - medição monofásica Fonte: Pesquisa de campo.

Nota: Medição realizada com o analisador de qualidade de energia Fluke 43 B.

Observa-se que o fator de potência total, considerando os harmônicos de corrente, é igual a 0,74 . Sendo o fator de potência da fundamental igual a 1,00, obtém-se, 
praticamente, o mesmo valor do fator de distorção, utilizando a equação A.19, do Anexo A:

$$
v=\frac{F P}{\cos \phi_{1}}=\frac{0,74}{1,00}=0,74
$$

Embora o conversor de freqüência não produza picos de corrente na fase de partida, pois a relação entre a tensão e a freqüência é mantida constante (controle escalar), durante o funcionamento a distorção harmônica de corrente é bastante elevada. Outra característica favorável do conversor é a correção do fator de potência para um valor unitário.

\subsection{COMPARAÇÃO ENTRE OS EQUIPAMENTOS ANALISADOS}

Uma comparação precisa entre os equipamentos poluidores e prejudiciais à qualidade da energia elétrica, que foram apresentados neste capítulo, necessita das condições das instalações elétricas onde os equipamentos encontram-se instalados. O mesmo equipamento instalado em locais diferentes (do mesmo EAS, ou em outros EAS), poderá apresentar-se com graus de perturbação diferentes. Naturalmente, quanto maior a potência de curto-circuito no local da instalação, os afundamentos de tensão de curta duração e as distorções harmônicas de tensão serão menores.

A tabela 5.1 apresenta algumas características dos equipamentos analisados e que são potenciais causadores de problemas de qualidade da energia elétrica. 
Tabela 5.1 - Características operacionais potenciais causadoras de problemas de qualidade da energia elétrica

\begin{tabular}{|c|c|c|c|c|}
\hline Equipamento & $\begin{array}{c}\text { Corrente momentânea / } \\
\text { duração: } \mathbf{I}_{\mathbf{m}}(\mathbf{A}) /(\mathbf{s})\end{array}$ & $\begin{array}{c}\text { Corrente de regime } \\
\text { permanente: } \mathbf{I}_{\mathbf{R P}}(\mathbf{A})\end{array}$ & $\mathbf{I}_{\mathbf{m}} / \mathbf{I}_{\mathbf{R P}}$ & $\begin{array}{c}\mathbf{T H D}_{(\mathbf{l})} \\
\mathbf{( \% )}\end{array}$ \\
\hline Raios X & $168 / 4$ & 1 & 168 & 72 \\
\hline Mamografia & $29,6 / 4$ & 1,09 & 27,15 & 52,9 \\
\hline Tomografia & $95,9 / 24$ & 7,8 & 12,29 & 18,9 \\
\hline Ressonância & $95 / 90$ & 22,6 & 4,2 & 18,4 \\
\hline Elevador & $181 / 5$ & 38 & 4,76 & - \\
\hline $\begin{array}{c}\text { Bomba com } \\
\text { rotação fixa }\end{array}$ & $210 / 1$ & 42 & 5 & - \\
\hline $\begin{array}{c}\text { Bomba com } \\
\text { rotação variável }\end{array}$ & $27 / 5$ & 27 & 1 & 79,3 \\
\hline
\end{tabular}

Fonte: Elaborada pelo autor a partir de resultados obtidos em pesquisa de campo.

Nota: $\mathrm{THD}_{(\mathrm{I})}$ - distorção harmônica total de corrente.

Observando os valores dessa tabela, pode-se tirar algumas conclusões:

1) Considerando os equipamentos que possuem funcionamento momentâneo com duração de até $5 \mathrm{~s}$, o equipamento de raios $\mathrm{X}$ e a mamografia parecem ser os com maiores probabilidades de provocar afundamentos de tensão. Tudo dependerá das condições da instalação elétrica no local. Para minimização dessas perturbações esses equipamentos, como já mencionado, deverão ser alimentados por circuitos exclusivos e dimensionados para a sua potência máxima (SANTANA, 1999).

2) Quanto às distorções harmônicas de corrente e que poderão provocar distorções harmônicas de tensão, o equipamento de raios $\mathrm{X}$, embora possua um valor de $\mathrm{THD}_{(I)}=72 \%$, sua corrente de regime permanente é extremamente baixa. O mesmo não acontece com a bomba com controle de velocidade que possui ambos os valores elevados, tornando-se, portanto, a carga mais crítica neste segundo aspecto. Para este caso, alguns fabricantes oferecem conversores de freqüência com filtros incorporados, o que minimiza significativamente a distorção harmônica de corrente.

\subsection{COMENTÁRIOS E DISCUSSÕES}

$\mathrm{Na}$ medicina moderna, a utilização de equipamentos de diagnóstico por imagem aumentou de forma considerável. Como apresentado, neste capítulo, tratam-se de 
equipamentos que demandam um elevado valor de potência em um curto intervalo de tempo.

Essas elevadas correntes poderão produzir afundamentos de tensão prejudiciais a outros equipamentos sensíveis utilizados nos EAS, bem como ao próprio equipamento gerador da perturbação.

Neste último caso, as imagens obtidas poderão não atender às necessidades do diagnóstico. Esse procedimento, além de expor o paciente a uma maior quantidade de radiação, caso alguns exames necessitem de novas radiografias, também resultará em uma menor vida útil do equipamento de diagnóstico por imagem.

Conclui-se, portanto, que o dimensionamento dos circuitos elétricos que irão alimentar esses equipamentos deverá ter critérios que levem em consideração a corrente necessária durante a operação momentânea e não a de modo contínuo (stand-by).

Os motores elétricos, embora sejam cargas que apresentem baixa sensibilidade a afundamentos de tensão quando alimentados diretamente à rede elétrica, tornam-se vulneráveis quando comandados por intermédio de conversores de freqüência.

A utilização demasidada de conversores de freqüência, além de outras cargas nãolineares, sem um estudo adequado da Qualidade da Energia Elétrica, também poderá trazer inconvenientes, pela geração de harmônicos de corrente altamente prejudiciais a equipamentos sensíveis utilizados em EAS, como será apresentado no capítulo 6. 


\section{OS EQUIPAMENTOS ELETROMÉDICOS ENSAIADOS}

Em função da facilidade de transporte, foram ensaiados equipamentos eletromédicos portáteis, de fabricação nacional, geralmente utilizados em Unidades de Terapia Intensiva e Centros Cirúrgicos. Depois de reunidos os aparelhos, os ensaios foram efetuados no Enerq-ct.

Seis equipamentos eletromédicos foram submetidos a testes: dois monitores multiparamétricos de fabricantes diferentes, dois oxímetros de pulso de fabricantes diferentes e dois ventiladores pulmonares de modelos diferentes de um mesmo fabricante. Foi verificado o comportamento desses equipamentos, alimentados com tensão de $110 \mathrm{~V} / 60 \mathrm{~Hz}$, em duas situações. Na primeira delas, os aparelhos foram submetidos a uma tensão de alimentação com elevado conteúdo harmônico, enquanto a segunda colocou-os sob a influência de afundamentos e interrupções de tensão de curta duração.

Enquanto alguns declaram este valor de $110 \mathrm{~V}$ como valor de placa, outros incorporam esse valor dentro da faixa de uso normal.

Dois termos muito utilizados em artigos técnicos ou em textos normativos costumam causar dúvidas ou interpretações incorretas: valor nominal e valor declarado (MARRONI, 2005). Por um lado, valor nominal compreende o valor numérico ideal e típico atribuído a uma grandeza, não contendo a informação de tolerância; por exemplo, no caso da tensão de alimentação, seriam os valores de $127 \mathrm{~V}, 220 \mathrm{~V}$, etc. Por outro lado, valor declarado é o valor indicado pelo fabricante do equipamento, para um determinado parâmetro, seja por intermédio de marcação no próprio equipamento ou por meio de informação no documento que o acompanha. Diferente do valor nominal, o valor declarado de um parâmetro pode vir acompanhado de sua tolerância.

Essa conceituação é importante para a correta interpretação de problemas decorrentes dos diferentes padrões de alimentação de equipamentos eletromédicos. Apesar de o Decreto Presidencial o 97280, de 16.12.1988, ter estabelecido o padrão a ser adotado no Brasil para as tensões de distribuição secundária em corrente alternada nas redes públicas: $380 \mathrm{~V} / 220 \mathrm{~V}$ e $220 \mathrm{~V} / 127 \mathrm{~V}$ em redes trifásicas; $440 \mathrm{~V} / 220 \mathrm{~V}$ e $254 \mathrm{~V} / 127 \mathrm{~V}$ em redes monofásicas, ainda são encontradas tensões de 
$115 \mathrm{~V}$ e $120 \mathrm{~V}$. Além disso, não se pode deixar de citar a crença existente sobre a tensão de $110 \mathrm{~V}$ por parte da população, incluindo a comunidade técnica e muitos fabricantes de produtos elétricos que, com freqüência, declaram a tensão de alimentação de seus equipamentos com esse valor. A Norma NBR IEC 60601-1 (1997) exige que todos os ensaios elétricos realizados em laboratório, para fins de certificação, devem ser efetuados na tensão de alimentação declarada pelo fabricante.

Se o fabricante declara a tensão de alimentação de seu equipamento sendo $110 \mathrm{~V}$, $115 \mathrm{~V}$ ou $120 \mathrm{~V}$, os ensaios devem ser realizados nesses valores, no entanto, essas condições não serão encontradas na utilização prática $(110 \mathrm{~V})$ ou então são encontradas em poucas cidades brasileiras ( $115 \mathrm{~V}$ e $120 \mathrm{~V}$ ).

A resolução no 505 da Aneel, publicada em 26.11.2001, estabelece as disposições relativas à conformidade dos níveis de tensão de energia elétrica em regime permanente. Além das tensões nominais padronizadas pelo Decreto № 97280, essa resolução apresenta as faixas de valores adequados, precários e críticos das tensões de leitura para as chamadas tensões não padronizadas, como sendo: ligação trifásica a 4 fios - 208V/120V, monofásicas - 230V/115V e 240V/120V (ANEEL, 2001).

No entanto, o Prodist - Procedimentos de Distribuição de Energia Elétrica no Sistema Elétrico Nacional, publicado em dezembro de 2008 pela Aneel, apresenta a tabela 11 com as tensões nominais $220 \mathrm{~V} / 110 \mathrm{~V}$.

Os testes foram realizados durante os anos de 2004, 2005 e no primeiro semestre de 2006. Em setembro de 2006, a Norma ABNT NBR IEC 60601-1-2 (2006) passou a exigir ensaios de imunidade segundo a Norma IEC 61000-4-11, a qual foi utilizada neste trabalho. No entanto, até hoje os fabricantes ainda alegam dificuldades para atendimento às exigências estabelecidas (MARRONI, 2007).

\subsection{MONITOR MULTIPARAMÉTRICO - FABRICANTE A}

É utilizado para monitoração contínua da atividade elétrica do tecido cardíaco, em centros cirúrgicos e unidades de terapia intensiva, juntamente com a monitoração de temperatura, respiração e outros parâmetros fisiológicos. Além da forma de onda do eletrocardiograma, pode indicar a freqüência cardíaca, assim como fornecer 
informações importantes, por exemplo, o nível de saturação de oxigênio no sangue arterial $\left(\mathrm{SpO}_{2}\right)$ e a pressão arterial (CALIL et al., 2002).

O coração humano é um órgão que desempenha a função de bomba hemohidráulica, bombeando sangue para todo o corpo, com objetivo de promover uma perfeita irrigação das células (KINDERMANN, 1995). As células encontram-se distribuídas em todo o corpo, portanto, o sangue deverá supri-las de nutrientes e oxigênio e, ao mesmo tempo, recolher o gás carbônico. Observa-se então que o funcionamento adequado e salutar das células dependerá de um correto funcionamento da bomba cardíaca.

Esse órgão é constituído por um músculo de cor roxa e formato cônico, tendo seu vértice apoiado sobre o diafragma. No corpo humano, situa-se entre os dois pulmões, estando deslocado ligeiramente para o lado esquerdo (MUEDRA, 1970). Apresenta uma camada muscular espessa revestida internamente por uma membrana denominada de miocárdio e, externamente, por outra membrana, o pericárdio.

Internamente, compõe-se de quatro cavidades: dois átrios e dois ventrículos, posicionados no lado direito e esquerdo do coração (KINDERMANN, 1995).

Em literaturas especializadas e mais antigas, os átrios são denominados por aurículas, pois sua face exterior assemelha-se a uma orelha carnosa (MUEDRA, 1970). Entre essas cavidades, localizadas do lado direito e esquerdo, não há comunicação, sendo que a passagem do átrio direito ao ventrículo direito é efetuada por uma válvula unidirecional denominada de tricúspide e da mesma forma, do átrio esquerdo para o ventrículo esquerdo, pela válvula bicúspide ou mitral.

A denominação tricúspide está fundamentada em relação ao seu formato de saco contendo três lingüetas que se fecham quando o sangue tenta retroceder. A válvula bicúspide possui apenas duas lingüetas, daí a sua denominação. Por apresentar-se também em forma de mitra, é denominada mitral.

Essas delicadas válvulas, fixadas nos orifícios aurículo-ventriculares, possuem reduzidas dimensões, sendo fixadas aos ventrículos mediante finos cordões, semelhantes a tendões brancos. A função de cada uma delas é a de impedir que o sangue do ventrículo retorne à aurícula, operando de forma semelhante às válvulas de retenção, utilizadas nos sistemas hidráulicos. Ainda, próximo aos pontos de saída, existem outras válvulas, tanto na artéria aorta, quanto na pulmonar. 
O formato dessas válvulas assemelha-se a três ninhos de andorinha, abertos para fora, atuando de forma a evitar que o sangue retroceda ao coração. Atuam de forma a se abrirem durante a contração do ventrículo e a se fecharem, durante sua expansão. São denominadas de sigmóideas ou semilunares, pois quando observadas de frente, notam-se os bordos arredondados.

A figura 6.1 (MUEDRA, 1970) apresenta um corte longitudinal do coração humano, contendo as válvulas e os grandes vasos.

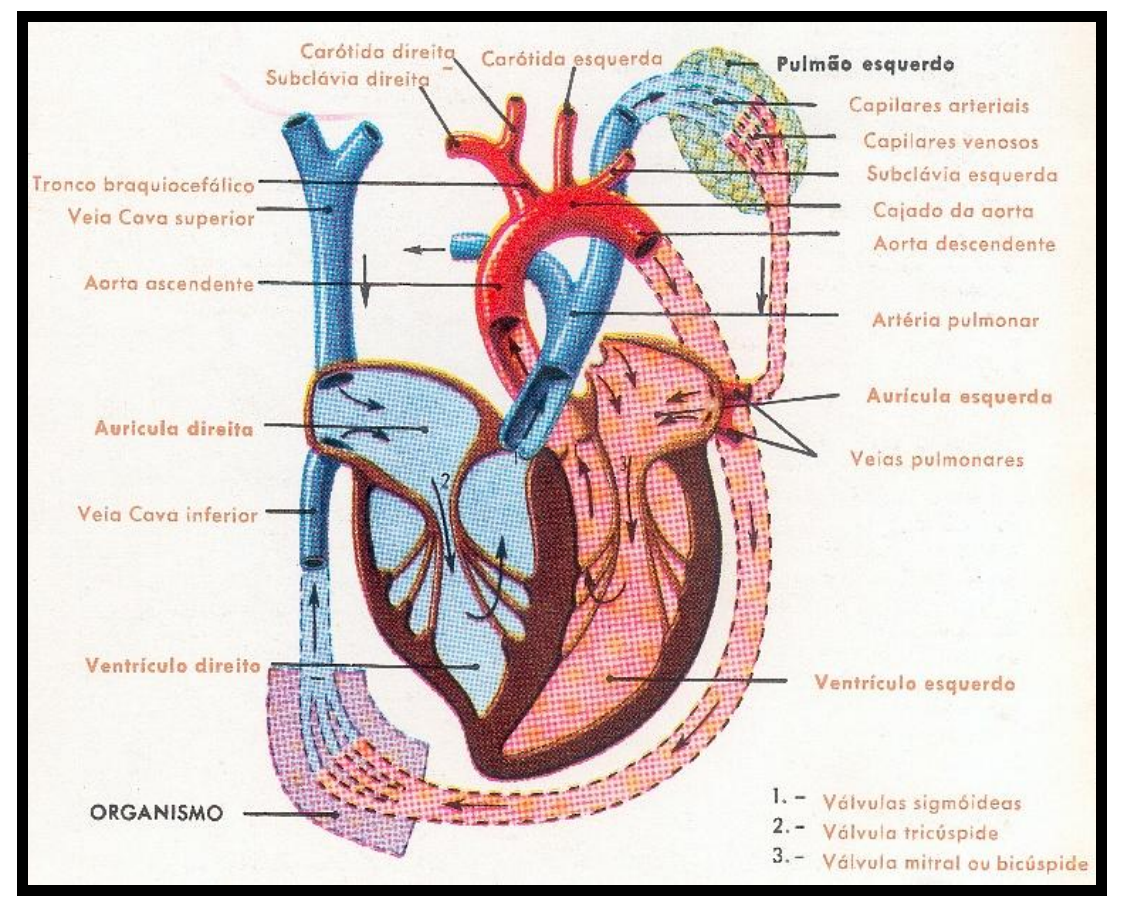

Figura 6.1- Corte longitudinal do coração, mostrando as válvulas e os grandes vasos Fonte: Muedra, 1970.

O equipamento utilizado nos ensaios efetua todas as medições de forma nãoinvasiva. Para evitar que o instrumento permanecesse conectado ao corpo humano durante os testes, utilizou-se um simulador de paciente, que gera pulsos de tensão semelhantes aos do coração, de forma estável e regular.

A figura 6.2 apresenta o simulador de paciente ligado ao monitor multiparamétrico. 




Figura 6.2 - Monitor multiparamétrico (fabricante A) conectado ao simulador de paciente Fonte: Pesquisa de campo.

O primeiro grupo de ensaios teve como objetivo verificar o funcionamento do monitor quando alimentado em rede elétrica contendo harmônicos de tensão, conforme se apresenta na tabela 6.1 .

O equipamento testado possui bateria interna para manutenção do seu funcionamento em casos de interrupção de energia elétrica. Em todos os ensaios, o aparelho foi alimentado com tensão de $110 \mathrm{~V}$.

Tabela 6.1 - Ensaios de harmônicos de tensão aplicados ao monitor multiparamétrico fabricante $A$

\begin{tabular}{|c|c|c|c|c|c|}
\hline Ensaio no & $\begin{array}{c}\text { Fundamental } \\
\text { (\%) }\end{array}$ & $\begin{array}{c}\mathbf{3}^{\mathbf{a}} \text { harmônica } \\
(\mathbf{\%})\end{array}$ & $\begin{array}{c}\mathbf{5}^{\mathbf{a}} \text { harmônica } \\
(\mathbf{\%})\end{array}$ & $\begin{array}{c}\mathbf{7}^{\mathbf{a}} \text { harmônica } \\
\text { (\%) }\end{array}$ & $\begin{array}{c}\text { THD }_{(\mathbf{V})} \\
\text { (\%) }\end{array}$ \\
\hline 1 & 100 & 3 & - & - & 3 \\
\hline 2 & 100 & 10 & - & - & 10 \\
\hline 3 & 100 & 20 & - & - & 20 \\
\hline 4 & 100 & 50 & - & - & 50 \\
\hline 5 & - & 100 & - & - & 100 \\
\hline 6 & 100 & 50 & 30 & 20 & 61,8 \\
\hline 7 & 100 & 70 & 50 & 30 & 91,5 \\
\hline
\end{tabular}

Fonte: Pesquisa de campo.

Notas: 1 o equipamento foi alimentado com tensão de $110 \mathrm{~V}$.

2. $T H D_{(V)}$ - distorção harmônica total, de tensão, em relação à fundamental. 
O máximo valor encontrado, para a $3^{\text {a }}$ harmônica de tensão, durante as medições em vários hospitais, foi de $3 \%$, portanto, os valores utilizados nos ensaios foram bem superiores, exatamente para verificar o comportamento do equipamento sob condições bem mais críticas. A figura 6.3 apresenta a forma de onda da tensão, com a maior distorção, dentre as aplicadas ao equipamento. Ela refere-se ao ensaio no 7 .

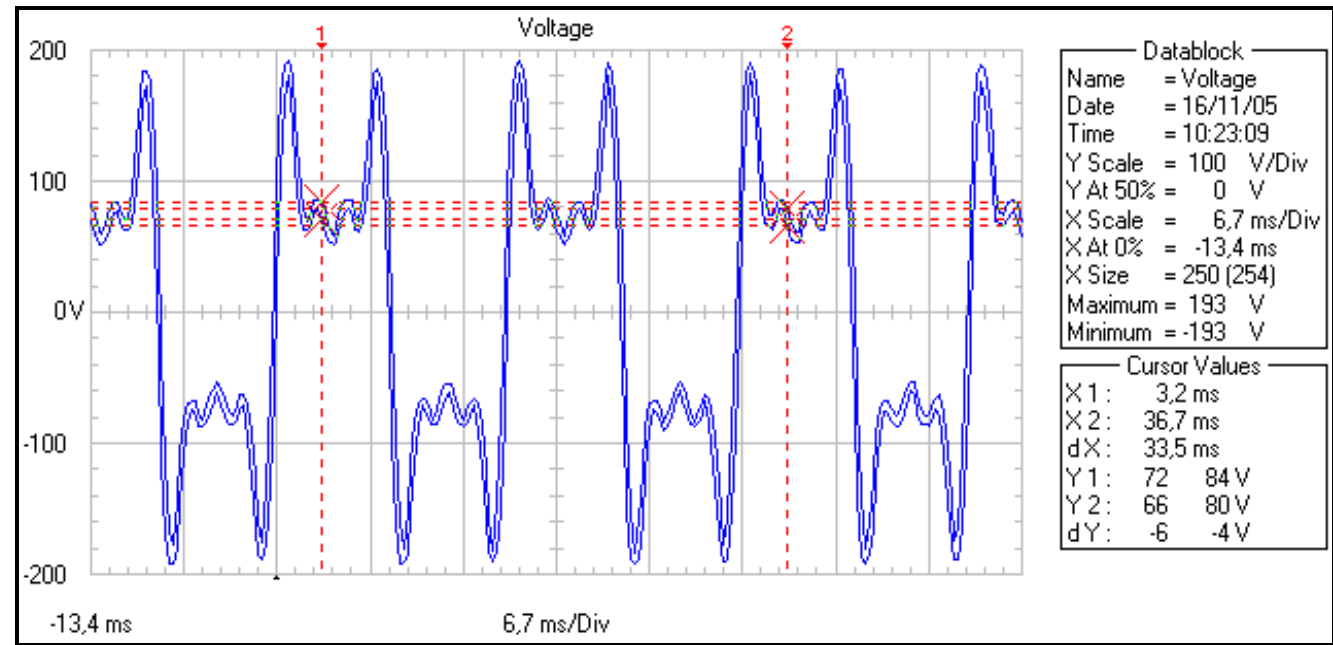

Figura 6.3 - Forma de onda de tensão distorcida pela presença de harmônicos - ensaio no 7 Fonte: Pesquisa de campo.

Para todos os casos ensaiados, o equipamento não apresentou interferências na forma de onda do eletrocardiograma, o que atesta a qualidade do equipamento a esse tipo de perturbação da rede elétrica.

O segundo grupo de ensaios foi referente a afundamentos de tensão de curta duração, semelhantes aos produzidos por equipamentos de raios $\mathrm{X}$, ressonância magnética nuclear e outros, cujos valores estão apresentados na tabela 6.2. 
Tabela 6.2 - Ensaios de afundamentos de tensão de curta duração aplicados ao monitor multiparamétrico - fabricante $A$

\begin{tabular}{|c|c|c|c|c|}
\hline $\begin{array}{c}\text { Afundamentos } \\
\text { nos }\end{array}$ & $\begin{array}{c}\text { Tensão de } \\
\text { afundamento (V) }\end{array}$ & $\begin{array}{c}\text { Tensão } \\
\text { remanescente (V) }\end{array}$ & $\begin{array}{c}\text { Tempo de } \\
\text { duração (s) }\end{array}$ & $\begin{array}{c}\text { Espaçamento } \\
\text { (s) }\end{array}$ \\
\hline 1,2 e 3 & 60 & 50 & 0,5 & 20 \\
\hline 4 & 90 & 20 & 0,5 & - \\
\hline 5 e 6 & 100 & 10 & 0,5 & 20 \\
\hline 7 e 8 & 110 & 0 & 1 & 20 \\
\hline 9 & 60 & 50 & 1 & 20 \\
\hline 10 & 80 & 30 & 1 & 20 \\
\hline 11 & 100 & 10 & 1 & 20 \\
\hline 12 & 110 & 0 & 1 & 20 \\
\hline
\end{tabular}

Fonte: Pesquisa de campo.

Nota: o equipamento foi alimentado com tensão de $110 \mathrm{~V}$.

Da mesma forma que no teste anterior, o equipamento não apresentou interferências no sinal gerado em sua tela. Nos afundamentos para $10 \mathrm{~V}$ e $0 \mathrm{~V}$ (interrupção) com duração de $1 \mathrm{~s}$, ocorreu transferência para a bateria, mas, mesmo assim, o sinal na tela se manteve constante e estável.

Os 12 afundamentos de tensão de curta duração produzidos e aplicados ao equipamento podem ser visualizados na figura 6.4.

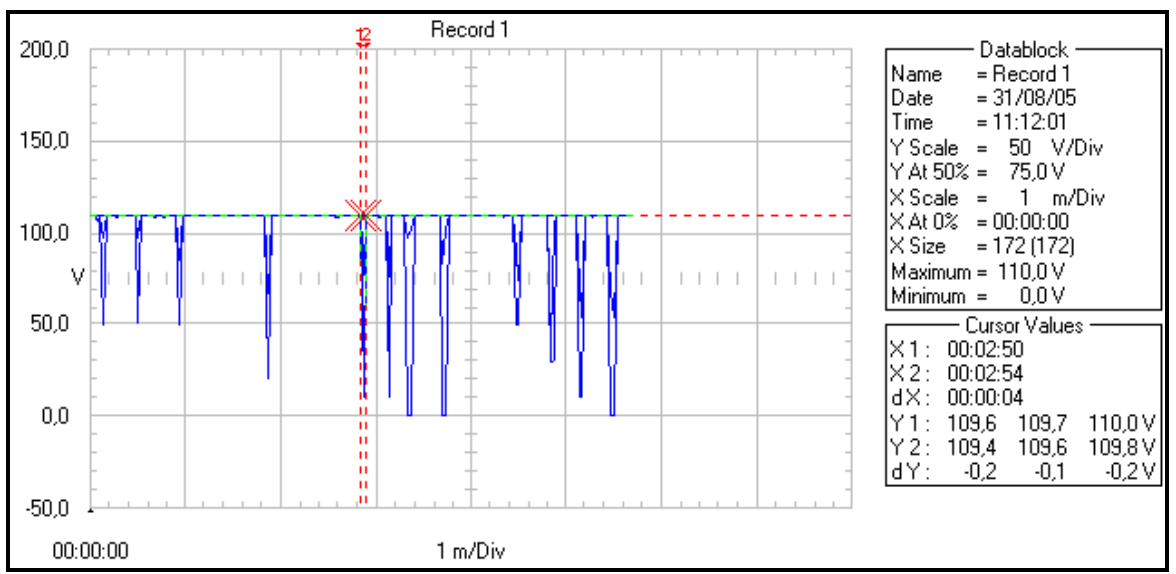

Figura 6.4 - Afundamentos de tensão de curta duração aplicados ao monitor multiparamétrico Fonte: Pesquisa de campo.

No terceiro grupo de ensaios foram aplicados afundamentos de tensão de curta duração, conforme as recomendações contidas no item 5.1 da Norma IEC 61000-411 (2000), cujos valores apresentam-se na tabela 1.1. Os ensaios incluíram todas as possibilidades, de forma que para cada valor de afundamento, todos os tempos de duração foram considerados. 
Em todos eles, o sinal do eletrocardiograma se manteve estável e sem alterações em sua forma de onda. Nos ensaios de tensão remanescente de $20 \%$, com duração de 180 ciclos e interrupções com durações de 25, 50 e 180 ciclos, ocorreram transferências para a bateria interna, mas nada se percebeu de alterações na forma de onda na tela do equipamento.

As figuras 6.5 a 6.8 mostram, respectivamente, alguns afundamentos e interrupções mais críticas que foram aplicados ao equipamento.

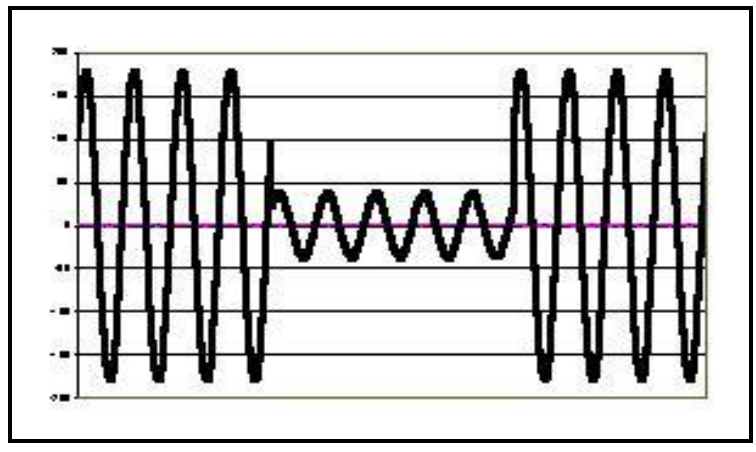

Figura 6.5 - Afundamento de $80 \%$ - 5 ciclos

Fonte: Pesquisa de campo.

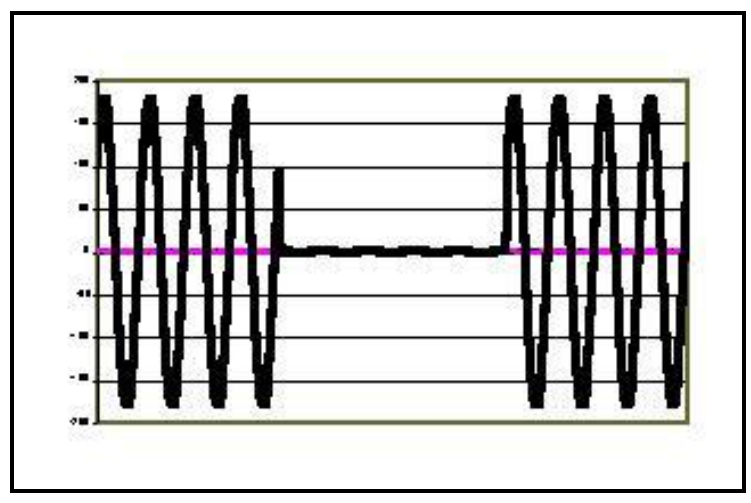

Figura 6.7 - Interrupção - 5 ciclos

Fonte: Pesquisa de campo.



Figura 6.6 - Afundamento de $80 \%$ - 50 ciclos Fonte: Pesquisa de campo.

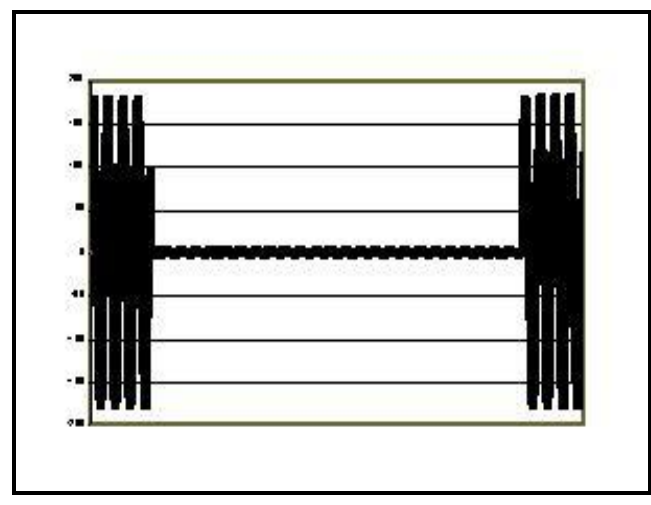

Figura 6.8 - Interrupção - 25 ciclos

Fonte: Pesquisa de campo.

Conclusões: em função dos ensaios realizados, pode-se concluir que esse monitor multiparamétrico é um equipamento que mantém seu funcionamento garantido quando submetido a tensões com elevado conteúdo harmônico e críticos afundamentos e interrupções de tensão de curta duração. Pode-se observar que a presença da bateria possibilitou os resultados obtidos. Foi enviado um relatório ao fabricante que ficou muito satisfeito com o comportamento do equipamento, pois, na época, estes tipos de ensaios ainda não eram exigidos por norma. 


\subsection{MONITOR MULTIPARAMÉTRICO - FABRICANTE B}

Trata-se de equipamento eletrônico totalmente microprocessado que incorpora diversas funções de medição de sinais vitais do paciente, além de ser um analisador de gases respiratórios. O campo de aplicações desse equipamento é bastante amplo, incluindo os setores de anestesia, terapia intensiva e outras aplicações. Pode ser fornecido para aplicações diferenciadas com opções dos parâmetros que serão monitorados. Está equipado com bateria para manutenção do seu funcionamento em caso de interrupção da energia elétrica.

A tabela 6.3 apresenta as grandezas monitoradas em função das versões do equipamento.

Tabela 6.3 - Parâmetros monitorados

\begin{tabular}{|l|}
\hline \multicolumn{1}{|c|}{ Versão básica } \\
\hline Eletrocardiograma (ECG) \\
\hline Saturação de oxigênio (SpO 2$)$ \\
\hline Pressão não invasiva (PNI) \\
\hline Temperaturas (Tl e T2) \\
\hline \multicolumn{2}{c|}{ Parâmetros opcionais } \\
\hline Analisador de gases $\left(\mathrm{O}_{2}, \mathrm{CO}_{2}, \mathrm{~N}_{2} \mathrm{O}\right.$, Agente anestésico) \\
\hline Pressões invasivas $(\mathrm{Pl}-1$ e Pl-2) \\
\hline
\end{tabular}

Fonte: Catálogo do fabricante.

A figura 6.9 apresenta o monitor multiparamétrico testado.



Figura 6.9 - Monitor multiparamétrico - fabricante B Fonte: Pesquisa de campo.

No primeiro grupo de testes, o equipamento foi alimentado com tensão de $110 \mathrm{~V}$, mas, contendo os mesmos componentes harmônicos daqueles apresentados na 
tabela 6.1. Em todos os ensaios, o equipamento não apresentou alteração nos valores informados, atestando a sua imunidade a este tipo de perturbação elétrica. O segundo grupo de ensaios foi referente aos mesmos afundamentos de tensão de curta duração, apresentados na tabela 6.2. A tabela 6.4, por sua vez, apresenta os resultados alcançados.

Tabela 6.4 - Afundamentos de tensão de curta duração aplicados ao monitor multiparamétrico - fabricante B

\begin{tabular}{|c|c|c|c|c|}
\hline $\begin{array}{c}\text { Afundamentos } \\
\mathbf{n} \mathbf{0} \text { s }\end{array}$ & $\begin{array}{c}\text { Tensão de } \\
\text { afundamento (V) }\end{array}$ & $\begin{array}{c}\text { Tensão } \\
\text { remanescente (V) }\end{array}$ & $\begin{array}{c}\text { Tempo de } \\
\text { duração (s) }\end{array}$ & $\begin{array}{c}\text { Espaçamento } \\
\text { (s) }\end{array}$ \\
\hline 1,2 e 3 & 60 & 50 & 0,5 & 20 \\
\hline 4 & 90 & 20 & 0,5 & - \\
\hline 5 e 6 & 100 & 10 & 0,5 & 20 \\
\hline 7 e 8 & 110 & 0 & 1 & 20 \\
\hline 9 & 60 & 50 & 1 & 20 \\
\hline 10 & 80 & 30 & 1 & 20 \\
\hline 11 & 100 & 10 & 1 & 20 \\
\hline 12 & 110 & 0 & 1 & \\
\hline
\end{tabular}

Fonte: Pesquisa de campo.

Notas: 1 . o equipamento foi alimentado com tensão de $110 \mathrm{~V}$.

2. apresentou falhas nos ensaios assinalados em vermelho.

Em todos os ensaios, nos quais a tensão remanescente foi inferior a $20 \mathrm{~V}$, a tela do equipamento apagou, voltando a funcionar após a transferência para a bateria. Os parâmetros indicados antes do evento não se apagaram, ou seja, as informações foram preservadas.

No terceiro grupo de ensaios foram aplicados afundamentos de tensão de curta duração conforme as recomendações contidas no item 5.1 da Norma IEC 61000-411 (2000), cujos valores apresentam-se na tabela 6.5:

Tabela 6.5 - Afundamentos de tensão de curta duração recomendados pela Norma IEC 61000-4-11, aplicados ao monitor multiparamétrico - fabricante B

\begin{tabular}{|c|c|c|}
\hline $\begin{array}{c}\text { Nível de tensão } \\
\text { remanescente }-\% \mathrm{~V}_{\mathrm{n}}\end{array}$ & $\begin{array}{c}\text { Tensão de afundamento } \\
\text { ou interrupção-\% } \% \mathrm{~V}_{\mathrm{n}}\end{array}$ & Duração-(ciclos) \\
\hline 80 & 20 & 0,5 \\
\hline 70 & 30 & 1 \\
& 60 & 5 \\
& 80 & 10 \\
& 100 & 25 \\
& & 50 \\
& & 180 \\
\hline
\end{tabular}

Fonte: Pesquisa de campo.

Notas: 1 o equipamento foi alimentado com tensão de $110 \mathrm{~V}$.

2. apresentou falhas nos ensaios assinalados em vermelho. 
Em todos os ensaios indicados em números vermelhos, a tela do monitor apagou, mas retornou em funcionamento, mantendo as mesmas informações registradas antes do evento.

Conclusões e medidas implementadas: o equipamento não apresentou irregularidades nos testes com harmônicos de tensão. No entanto, os afundamentos e interrupções de curta duração provocaram a interrupção temporária da tela do monitor. O fabricante foi informado sobre estes resultados e providenciou as alterações no circuito de alimentação do monitor. O equipamento retornou para novos ensaios e foi constatada a eliminação do problema.

\subsection{OXÍMETRO DE PULSO - FABRICANTE C}

É um equipamento utilizado na determinação do nível de saturação de oxigênio no sangue arterial $\left(\mathrm{SpO}_{2}\right)$, sendo esta quantificação executada de forma não-invasiva, por meio de sensores ópticos posicionados externamente ao paciente (CALIL et al., 2002). A utilização do oxímetro de pulso é considerada um procedimento padrão no monitoramento do nível de saturação de oxigênio sanguíneo em unidades de terapia intensiva, centros cirúrgicos, áreas de recuperação, unidades de pacientes com queimaduras graves, de cateterismo e em ambulâncias.

Sua característica não-invasiva torna desnecessária a retirada de sangue do paciente para a análise em laboratório. Outra característica favorável é a possibilidade de monitoramento contínuo e em tempo real, dos níveis de oxigenação no sangue, detectando de forma rápida eventuais reduções destes valores que possam resultar em riscos ao paciente.

A coloração do sangue varia em função dos diferentes níveis de oxigenação, apresentando o sangue com alta concentração de oxigênio, a coloração vermelha brilhante. A presença do gás carbônico no sangue altera a cor tendendo para um tom ligeiramente azulado.

Seu princípio de funcionamento apóia-se na espectrofotometria sanguínea que mede a luz transmitida ou refletida dos capilares do corpo humano, sincronizados com os batimentos cardíacos.

O equipamento testado é de fabricação nacional e não possui bateria para garantia de seu funcionamento durante interrupções de energia elétrica. É microprocessado e 
possui sistema de alarme para o caso de alteração dos parâmetros préestabelecidos.

Para evitar interferências, foi utilizado um simulador de paciente ligado ao equipamento. Em todos os testes, o equipamento foi alimentado com tensão $110 \mathrm{~V}$. A figura 6.10 apresenta o oxímetro ensaiado conectado ao simulador de paciente.



Figura 6.10 - Oxímetro de pulso (fabricante $\mathrm{C}$ ) conectado ao simulador de paciente Fonte: Pesquisa de campo.

No primeiro grupo de testes, o equipamento foi alimentado com tensões contendo harmônicos, conforme apresentado na tabela 6.6.

Tabela 6.6 - Ensaios de harmônicos de tensão aplicados ao oxímetro de pulso

\begin{tabular}{|c|c|c|c|c|c|}
\hline Ensaio no & $\begin{array}{c}\text { Fundamental } \\
(\%)\end{array}$ & $\begin{array}{c}\mathbf{3}^{\mathbf{a}} \text { harmônica } \\
(\mathbf{\%})\end{array}$ & $\begin{array}{c}\mathbf{5}^{\mathbf{a}} \text { harmônica } \\
(\mathbf{\%})\end{array}$ & $\begin{array}{c}\mathbf{7}^{\mathbf{a}} \text { harmônica } \\
(\mathbf{\%})\end{array}$ & $\begin{array}{c}\mathbf{T H D}_{(\mathbf{v})} \\
(\%)\end{array}$ \\
\hline 1 & 100 & 10 & - & - & 10 \\
\hline 2 & 100 & 20 & - & - & 20 \\
\hline 3 & 100 & 30 & - & - & 30 \\
\hline 4 & 100 & 70 & - & - & 70 \\
\hline 5 & 100 & 30 & 10 & 5 & 31,9 \\
\hline 6 & 100 & 50 & 30 & 10 & 59,1 \\
\hline 7 & 100 & 70 & 50 & 30 & 108,2 \\
\hline
\end{tabular}

Fonte: Pesquisa de campo.

Notas: 1. o equipamento foi alimentado com tensão de $110 \mathrm{~V}$.

2. $\operatorname{THD}_{(\mathrm{V})}$ - distorção harmônica total de tensão, em relação à fundamental.

3. apresentou falhas nos ensaios assinalados em vermelho. 
Durante os ensaios, o comportamento do aparelho se alterou, passando por um ponto bastante crítico. Observou-se a grande influência da $3^{\text {a }}$ harmônica, pois valores de até $50 \%$ da fundamental produzem interferências no visor do equipamento. Para valores acima de $70 \%$, o aparelho voltou a funcionar normalmente. A $5^{\underline{a}}$ e $7^{\underline{a}}$ harmônicas influenciam pouco no resultado final, sendo predominante a influência da $3^{\underline{a}}$ harmônica.

O segundo grupo de ensaios foi referente a afundamentos de tensão de curta duração, semelhantes aos produzidos por equipamentos de raios $X$, ressonância magnética nuclear e outros, cujos valores estão apresentados na tabela 6.7.

Tabela 6.7 - Ensaios de afundamentos de tensão de curta duração aplicados ao oxímetro de pulso - fabricante $\mathrm{C}$

\begin{tabular}{|c|c|c|c|c|c|}
\hline Ensaio no & $\begin{array}{c}\text { Quantidade de } \\
\text { afundamentos }\end{array}$ & $\begin{array}{c}\text { Tensão de } \\
\text { afundamento } \\
\text { (V) }\end{array}$ & $\begin{array}{c}\text { Tensão } \\
\text { remanescente } \\
\text { (V) }\end{array}$ & $\begin{array}{c}\text { Tempo de } \\
\text { duração } \\
\text { (s) }\end{array}$ & $\begin{array}{c}\text { Espaçamento } \\
\text { (s) }\end{array}$ \\
\hline 1 & 10 & 3,3 & 106,7 & 1 & 1 \\
\hline 2 & 10 & 5,5 & 104,5 & 1 & 1 \\
\hline 4 & 10 & 8,8 & 101,2 & 1 & 1 \\
\hline 5 & 10 & 11 & 99 & 1 & 1 \\
\hline
\end{tabular}

Fonte: Pesquisa de campo.

Nota: 1 . o equipamento foi alimentado com tensão de $110 \mathrm{~V}$.

2. apresentou falhas nos ensaios assinalados em vermelho.

No ensaio o 1 não se percebeu anormalidade alguma. Nos ensaios ํos 2 e 3, a tela se apresentou ligeiramente com brilho reduzido, mas os valores indicados não se alteraram.

Nos ensaios nos 4 e 5, o equipamento apresentou a tela piscante e os valores indicados foram se reduzindo até a atuação do alarme. $O$ aparelho necessitou ser desligado da rede para voltar a funcionar.

No terceiro grupo de ensaios foram aplicados afundamentos de tensão de curta duração, conforme as recomendações contidas no item 5.1 da Norma IEC 61000-411 (2000), cujos valores já foram apresentados na tabela 1.1.

Por tratar-se de um equipamento extremamente sensível aos afundamentos de tensão de curta duração, considerou-se conveniente a apresentação dos resultados mediante a tabela 6.8 . 
Tabela 6.8 - Ensaio de afundamento de tensão conforme Norma IEC 61000-4-11 e que foram aplicados ao oxímetro de pulso - fabricante $\mathrm{C}$

\begin{tabular}{|c|c|l|}
\hline $\begin{array}{c}\text { Nível de tensão } \\
\text { remanescente - } \\
\% \mathrm{~V}_{\mathrm{n}}\end{array}$ & $\begin{array}{c}\text { Tensão de } \\
\text { afundamento ou } \\
\text { interrupção-\% } \mathrm{V}_{n}\end{array}$ & \multicolumn{1}{c|}{ Duração-(ciclos) / ocorrência } \\
\hline 80 & 20 & $\begin{array}{l}\geq 5 \text { ciclos / o visor reduziu o brilho, mas não perdeu } \\
\text { as informações }\end{array}$ \\
\hline 70 & 30 & $\begin{array}{l}\geq 5 \text { ciclos / o visor reduziu o brilho, mas não perdeu } \\
\text { as informações }\end{array}$ \\
\hline 40 & 60 & $\begin{array}{l}10 \text { ciclos / travou e a tela apresentou caracteres } \\
\text { aleatórios (figura 6.11) } \\
\text { Necessitou ser desligado para retornar a funcionar. } \\
25,50 \text { e 180 ciclos / apagou, mas retornou à tela } \\
\text { principal. } \\
\text { Voltou a funcionar normalmente. }\end{array}$ \\
\hline 20 & 80 & $\begin{array}{l}\geq 10 \text { ciclos / travou e a tela apresentou caracteres } \\
\text { aleatórios (figura 6.11) } \\
\text { Necessitou ser desligado para retornar a funcionar. }\end{array}$ \\
\hline 0 & 100 & $\begin{array}{l}\geq 10 \text { ciclos / travou e a tela apresentou caracteres } \\
\text { aleatórios (figura 6.11) } \\
\text { Necessitou ser desligado para retornar a funcionar. }\end{array}$ \\
\hline
\end{tabular}

Fonte: Pesquisa de campo.

Notas: 1 o equipamento foi alimentado com tensão de $110 \mathrm{~V}$.

2. apresentou falhas nos ensaios assinalados em vermelho.

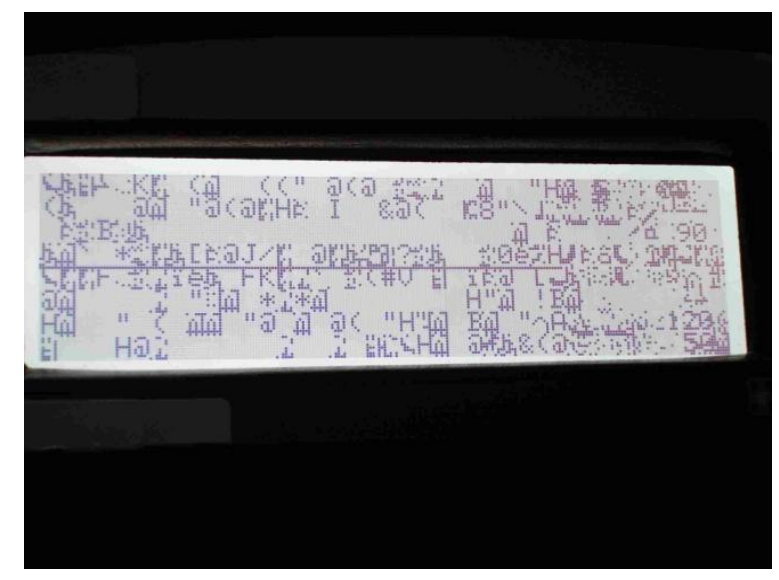

Figura 6.11 - Tela do oxímetro apresentando caracteres aleatórios

Fonte: Pesquisa de campo.

Conclusões e recomendações: trata-se de um equipamento mais sensível que os anteriores. Chegou a apresentar funcionamento incorreto em todos os três tipos de ensaios aplicados, comprometendo a área médica em relação a decisões que devam ser tomadas em função dos dados apresentados. A falta de bateria interna, para garantir o funcionamento do equipamento em casos de interrupção de energia, pode ser um dos motivos do mau desempenho do mesmo. O fabricante foi informado, mas não se manifestou em relação aos resultados. 


\subsection{OXÍMETRO DE PULSO - FABRICANTE B}

Oxímetros de pulso possuem a finalidade já apresentada. Para regularidade dos pulsos cardíacos, o fabricante forneceu um simulador de paciente específico para este tipo de equipamento. A figura 6.12 apresenta uma foto ilustrativa.



Figura 6.12 - Oxímetro de pulso - fabricante B

Fonte: Pesquisa de campo.

Esse equipamento possui bateria para o caso de interrupção de energia elétrica e foi submetido aos mesmos ensaios aplicados ao oxímetro de pulso - fabricante $\mathrm{C}$, conforme mostram as tabelas $6.6,6.7$ e 6.8. Em todos os ensaios, o equipamento foi alimentado com tensão de $110 \mathrm{~V}$.

Nos ensaios com tensões contendo conteúdo harmônico, o equipamento se comportou satisfatoriamente. Não se observou anormalidade que pudesse comprometer a estabilidade das indicações numéricas ou a forma de onda apresentada no monitor.

Concluiu-se, portanto, que o equipamento apresenta imunidade às distorções harmônicas de tensões a que foi submetido.

O segundo grupo de ensaios foi referente a afundamentos de tensão de curta duração, idênticos aos aplicados aos monitores multiparamétricos (figura 6.4).

A tabela 6.9 apresenta os resultados. A existência de algarismos em vermelho acusa casos de ocorrência de deformação na forma de onda do sinal no instante da aplicação do afundamento. Depois disso, o equipamento voltou a funcionar normalmente. 
Tabela 6.9 - afundamentos de tensão de curta duração aplicados ao oxímetro de pulso

- fabricante B

\begin{tabular}{|c|c|c|c|c|}
\hline $\begin{array}{c}\text { Afundamentos } \\
\text { nos }\end{array}$ & $\begin{array}{c}\text { Tensão de } \\
\text { afundamento (V) }\end{array}$ & $\begin{array}{c}\text { Tensão } \\
\text { remanescente (V) }\end{array}$ & $\begin{array}{c}\text { Tempo de } \\
\text { duração(s) }\end{array}$ & $\begin{array}{c}\text { Espaçamento } \\
\text { (s) }\end{array}$ \\
\hline 1,2 e 3 & 60 & 50 & 0,5 & 20 \\
\hline 4 & 90 & 20 & 0,5 & - \\
\hline 5 e 6 & 100 & 10 & 0,5 & 20 \\
\hline 7 e 8 & 110 & 0 & 1 & 20 \\
\hline 9 & 60 & 50 & 1 & 20 \\
\hline 10 & 80 & 30 & 1 & 20 \\
\hline 11 & 100 & 10 & 1 & 20 \\
\hline 12 & 110 & 0 & 1 & 20 \\
\hline
\end{tabular}

Fonte: Pesquisa de campo.

Notas: 1 o equipamento foi alimentado com tensão de $110 \mathrm{~V}$.

2. apresentou falhas nos ensaios assinalados em vermelho.

Nos ensaios de afundamentos de tensão de curta duração, segundo a Norma IEC 61000-4-11 (2000), para valores de tensões remanescentes iguais a $80 \%, 70 \%$, e $40 \%$ nada se observou de anormal no comportamento do equipamento.

Com tensão remanescente de $20 \%$ e duração de 25 ciclos, o visor se apagou, a bateria entrou em operação, os dados indicados não se perderam, mas a forma de onda na tela se alterou totalmente. O mesmo acontecimento ocorreu para a mesma tensão remanescente, mas, com durações de 50 e 180 ciclos.

Para os casos de interrupção (valor remanescente $=0$ ), o mesmo comportamento foi observado para tempos de duração de 10, 25, 50 e 180 ciclos.

A tabela 6.10 apresenta os resultados dos ensaios de afundamentos de tensão de curta duração, segundo a Norma IEC 61000-4-11(2000), mostrando em vermelho as situações nas quais o equipamento apresentou algum tipo de alteração em seu comportamento.

Tabela 6.10 - Afundamentos de tensão de curta duração recomendados pela Norma IEC 61000-4-11 e que foram aplicados ao oxímetro de pulso - fabricante B

\begin{tabular}{|c|c|c|}
\hline $\begin{array}{c}\text { Nível de tensão } \\
\text { remanescente }-\% \mathrm{~V}_{\mathrm{n}}\end{array}$ & $\begin{array}{c}\text { Tensão de afundamento } \\
\text { ou interrupção-\% } \% \mathrm{~V}_{\mathrm{n}}\end{array}$ & Duração-(ciclos) \\
\hline 80 & 20 & 0,5 \\
\hline 70 & 30 & 1 \\
\hline 40 & 60 & 5 \\
\hline 20 & 80 & 10 \\
& 100 & 25 \\
& & 50 \\
& & 180 \\
\hline
\end{tabular}

Fonte: Pesquisa de campo.

Notas: 1 . o equipamento foi alimentado com tensão igual a $110 \mathrm{~V}$.

2. apresentou falhas nos ensaios assinalados em vermelho. 
Conclusões e recomendações: o fabricante foi comunicado dos resultados apresentados por seu equipamento e informou que iria verificar em seu setor de engenharia qual seria a possível causa do problema detectado.

\subsection{VENTILADOR PULMONAR - FABRICANTE B, MODELO A}

A ventilação pulmonar natural é produzida pela ação espontânea da musculatura respiratória que, ao se contrair, provoca uma queda de pressão entre as cavidades pulmonares e o ambiente externo, permitindo a entrada do ar atmosférico.

A essa fase do processo respiratório denomina-se inspiração. A expulsão do ar dos pulmões é provocada pelo fenômeno inverso, ou seja, o relaxamento da mesma musculatura provoca um aumento de pressão das cavidades pulmonares em relação ao meio externo. Esta fase é denominada de expiração (CALIL et al., 2002).

O ventilador pulmonar tem como objetivo proporcionar ventilação pulmonar artificial em pacientes com insuficiência respiratória em função de enfermidades, efeito anestésico, etc.

Pode também, ser utilizado para proporcionar um descanso aos músculos respiratórios até a total recuperação do paciente e retorno ao processo de ventilação natural. A insuficiência respiratória poderá também ser induzida e geralmente associada a procedimentos cirúrgicos para obtenção de analgesia, relaxamento muscular e redução da função metabólica.

A maioria dos ventiladores promove uma fonte de pressão positiva para fornecimento de ar aos pulmões do paciente e, em seguida, retira a pressão para que ocorra a expiração. A interligação do equipamento ao paciente poderá ocorrer por via oral, nasal ou tubo de traqueostomia.

O ventilador testado é um equipamento de fabricação nacional, totalmente microprocessado e projetado para aplicações de insuficiência respiratória em pacientes pediátricos e adultos com massa corporal entre 6 a $180 \mathrm{~kg}$.

Trata-se de um equipamento bastante prático, possuindo controles digitais diretos para os principais parâmetros ventilatórios.

O disparo dos ciclos é por pressão e, por possuir um monitor de ventilação incorporado, permite um amplo acompanhamento das condições do paciente, aumentando a segurança. 
Além disso, um completo sistema de alarmes audiovisuais, com mensagem escrita na tela de controles, faz uma pronta identificação da condição de alarme.

Possui bateria interna para evitar a interrupção do seu funcionamento em caso de falta de energia elétrica.

Simulou-se a presença dos pulmões por intermédio de um balão de borracha especial, próprio para essa finalidade e fornecido pela mesma empresa que fabricou o equipamento.

A figura 6.13 mostra o ventilador pulmonar submetido aos testes.

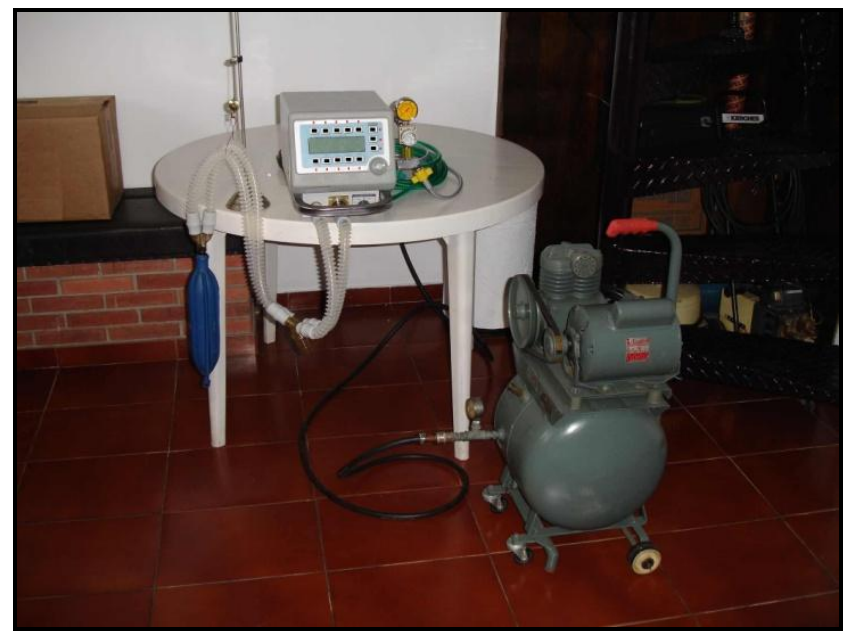

Figura 6.13 - Ventilador pulmonar - fabricante B, modelo A

Fonte: Pesquisa de campo.

Os parâmetros configurados antes dos ensaios foram:

-Modalidade de ventilação PLV - ventilação liberada por pressão.

-Pressão inspiratória: $17 \mathrm{cmH}_{2} \mathrm{O}$.

-Pressão residual voluntária (PEEP): $0 \mathrm{cmH}_{2} \mathrm{O}$.

-Freqüência: 10 rpm (respiração por minuto).

-Relação: 1:2.

-Circuito respiratório adulto.

-Resistência: $20 \mathrm{cmH}_{2} \mathrm{O}$.

-Tempo inspiratório: 1,17 s.

-Tempo expiratório: 2,35 s.

-Fluxo PLV: 791/min. 
No primeiro grupo de testes, o equipamento foi alimentado com tensão de $110 \mathrm{~V}$, mas contendo componentes harmônicos, conforme apresenta a tabela 6.11.

Tabela 6.11 - Ensaios com harmônicos de tensão aplicados ao ventilador pulmonar fabricante B, modelo A

\begin{tabular}{|c|c|c|c|c|c|}
\hline Ensaio no & $\begin{array}{c}\text { Fundamental } \\
(\%)\end{array}$ & $\begin{array}{c}\mathbf{3}^{\mathbf{a}} \text { harmônica } \\
(\%)\end{array}$ & $\begin{array}{c}\mathbf{5}^{\mathbf{a}} \text { harmônica } \\
(\%)\end{array}$ & $\begin{array}{c}\mathbf{7}^{\mathbf{a}} \text { harmônica } \\
(\%)\end{array}$ & $\begin{array}{c}\mathbf{T H D}_{(\mathbf{)})} \\
(\%)\end{array}$ \\
\hline 1 & 100 & 3 & - & - & 3 \\
\hline 2 & 100 & 10 & - & - & 10 \\
\hline 3 & 100 & 20 & - & - & 20 \\
\hline 4 & 100 & 30 & - & - & - \\
\hline 5 & 100 & 50 & - & - & 50 \\
\hline 6 & 100 & 30 & 10 & 5 & 31,9 \\
\hline 7 & 100 & 50 & 30 & 10 & 59,1 \\
\hline 8 & 100 & 70 & 50 & 30 & 91,4 \\
\hline
\end{tabular}

Fonte: Pesquisa de campo.

Nota: 1. o equipamento foi alimentado com tensão de $110 \mathrm{~V}$.

2. $\mathrm{THD}_{(\mathrm{V})}$ - distorção harmônica total, de tensão, em relação à fundamental.

A figura 6.14 apresenta a forma de onda da corrente quando o equipamento é alimentado com tensão senoidal.

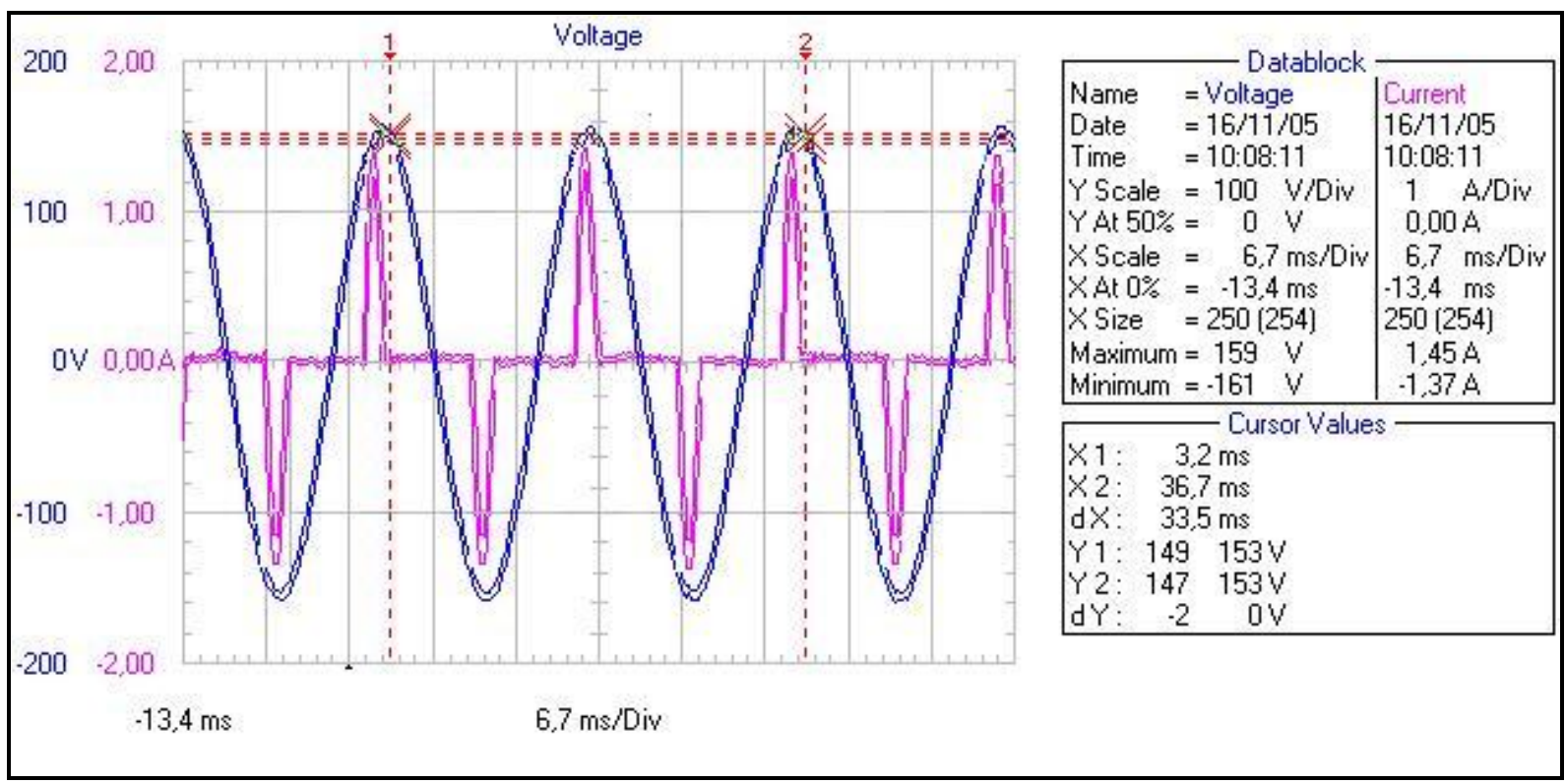

Figura 6.14 - Forma de onda da corrente com tensão senoidal

Fonte: Pesquisa de campo.

A título de comparação, são observadas na figura 6.15 as formas de onda da tensão e da corrente referentes ao ensaio ํㅜ 7 . 


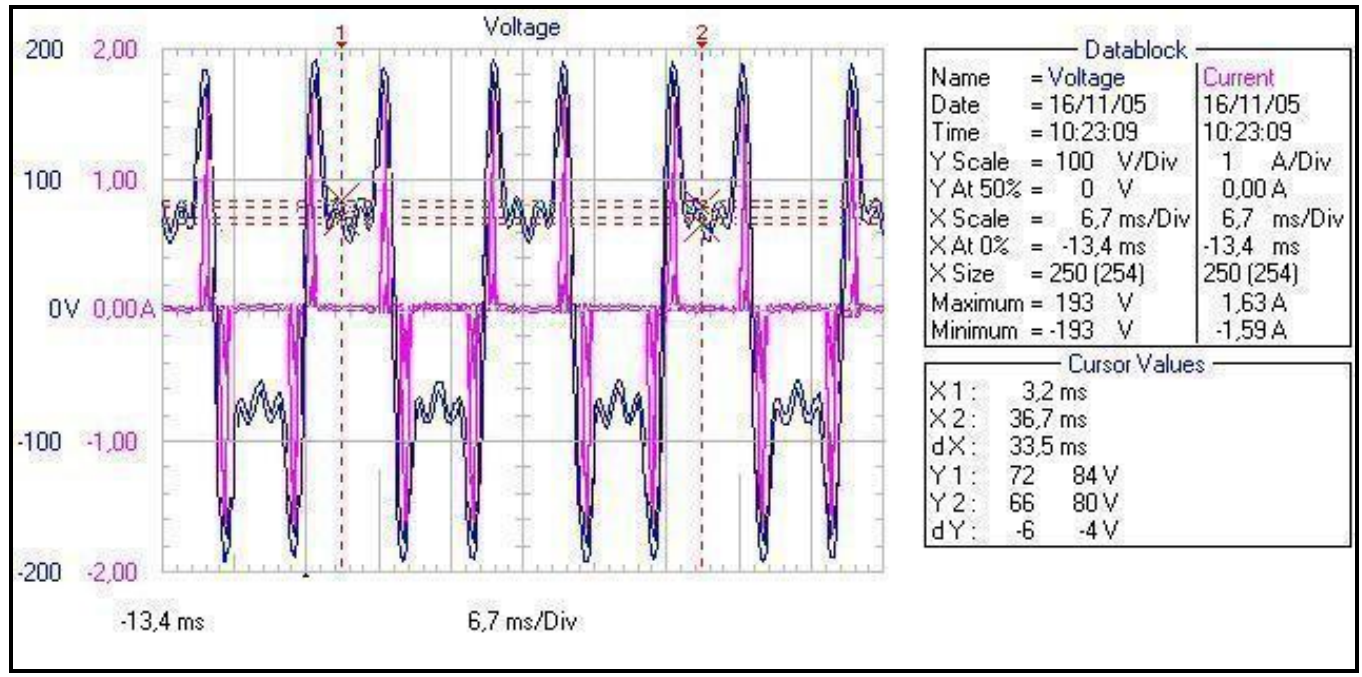

Figura 6.15 - Forma de onda da corrente com tensão distorcida

Fonte: Pesquisa de campo.

Embora se note significativa alteração na forma de onda da corrente entre a alimentação senoidal e a alimentação com tensão totalmente distorcida, não se observou qualquer alteração na regularidade dos ciclos de ventilação do equipamento.

O manômetro digital, instalado na parte frontal, indicou os mesmos valores em todos os ensaios. Dessa forma, pôde-se comprovar sua imunidade quando submetido a tensões fortemente distorcidas.

O segundo grupo de ensaios foi referente a afundamentos de tensão de curta duração, semelhantes aos produzidos por equipamentos de raios $\mathrm{X}$, ressonância magnética nuclear e outros, cujos valores estão apresentados na tabela 6.12 .

Tabela 6.12 - Ensaios de afundamentos de tensão de curta duração aplicados ao ventilador pulmonar

\begin{tabular}{|c|c|c|c|c|c|}
\hline Ensaio no & $\begin{array}{c}\text { Quantidade de } \\
\text { afundamentos }\end{array}$ & $\begin{array}{c}\text { Tensão de } \\
\text { afundamento } \\
(\mathbf{V})\end{array}$ & $\begin{array}{c}\text { Tensão } \\
\text { remanescente } \\
(\mathbf{V})\end{array}$ & $\begin{array}{c}\text { Tempo de } \\
\text { duração (s) }\end{array}$ & $\begin{array}{c}\text { Espaçamento } \\
\text { (s) }\end{array}$ \\
\hline 1 & 10 & 11 & 99 & 3 & 1 \\
\hline 2 & 10 & 22 & 88 & 3 & 1 \\
\hline 3 & 10 & 33 & 77 & 3 & 1 \\
\hline 4 & 10 & 44 & 66 & 3 & 1 \\
\hline 5 & 10 & 55 & 55 & 3 & 1 \\
\hline 6 & 10 & 11 a 110 & 99 a 0 & 3 & 60 \\
\hline
\end{tabular}

Fonte: Pesquisa de campo.

Notas: 1. o equipamento foi alimentado com tensão de $110 \mathrm{~V}$.

2. apresentou falhas no ensaio assinalado em vermelho. 
As figuras 6.16 e 6.17 apresentam os afundamentos de tensão de curta duração aplicados ao equipamento, referentes aos ensaios $n^{\circ} \div 5$ e 6 .



Figura 6.16 - Afundamentos de tensão do ensaio no5

Fonte: Pesquisa de campo.

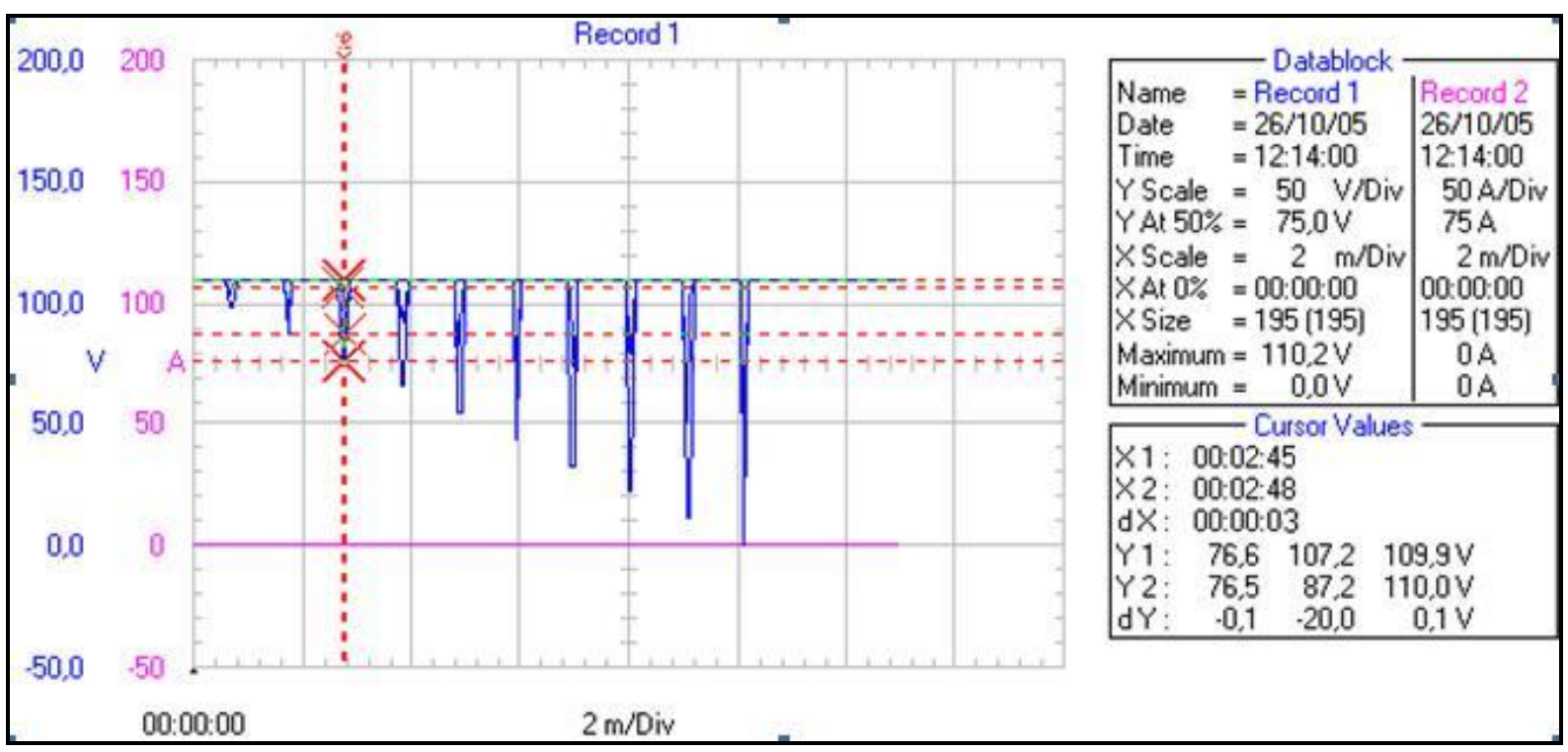

Figura 6.17 - Afundamentos de tensão do ensaio no6

Fonte: Pesquisa de campo.

No ensaio $n^{\circ}$ 6, o equipamento apresentou funcionamento irregular para os afundamentos de $77 \mathrm{~V}, 88 \mathrm{~V}, 99 \mathrm{~V}$ e interrupção. Os problemas apresentados incluem travamentos, bloqueios de válvula expiratória e ausência de atuação do sistema de alarme. 
No terceiro grupo de ensaios foram aplicados afundamentos de tensão de curta duração, em conformidade com as recomendações contidas no item 5.1 da Norma IEC 61000-4-11 (2000). O comportamento do equipamento é mostrado na tabela 6.13 .

Tabela 6.13 - Afundamentos de tensão de curta duração recomendados pela Norma IEC 61000-4-11 e que foram aplicados ao ventilador pulmonar

\begin{tabular}{|c|c|c|}
\hline $\begin{array}{c}\text { Nível de tensão } \\
\text { remanescente }-\% \mathrm{~V}_{n}\end{array}$ & $\begin{array}{c}\text { Tensão de afundamento } \\
\text { ou interrupção-\% } \mathrm{V}_{\mathrm{n}}\end{array}$ & Duração- (ciclos) \\
\hline 80 & 20 & 0,5 \\
\hline 70 & 30 & 1 \\
\hline 40 & 60 & 5 \\
\hline 20 & 80 & 10 \\
& 100 & 25 \\
& & 50 \\
& & 180 \\
\hline
\end{tabular}

Fonte: Pesquisa de campo.

Notas: 1 . o equipamento foi alimentado com tensão de $110 \mathrm{~V}$.

2. apresentou falhas nos ensaios assinalados em vermelho.

Os valores de pressão e vazão de ar foram monitorados com um medidor de fluxo ligado ao duto de saída do equipamento (circuito de inspiração).

O equipamento suportou sem alterações os afundamentos de $20 \%, 30 \%$ e $60 \%$ para todas as durações, ou seja, de 0,5 a 180 ciclos. O mesmo ocorreu para afundamentos de $80 \%$ e interrupções com tempos de duração de $0,5,1$ e 5 ciclos.

Quando analisados afundamentos de $80 \%$ e interrupções, com tempo de duração igual ou superior a 10 ciclos, o equipamento apresentou vários problemas, que poderão colocar sob risco o paciente a ele ligado, com destaque para estes itens:

1- o funcionamento foi interrompido, embora a bateria estivesse carregada. Os parâmetros definidos não se perderam, mas o alarme não foi acionado;

2- em alguns ensaios, considerando o instante da aplicação dos afundamentos ou interrupções, a válvula expiratória se manteve permanentemente aberta, lançando para o ambiente todo ar/oxigênio injetado nos pulmões. O sistema de alarme também não foi acionado, e o equipamento teve de ser desligado da rede de alimentação e reprogramado para retornar à operação; 
3- da mesma forma que no item 2, ocorreram casos em que o equipamento travou continuando a injetar ar/oxigênio com a válvula expiratória permanentemente fechada. $O$ alarme não foi acionado e o equipamento também precisou ser desligado da rede e reprogramado. $O$ medidor de pressão indicou um valor bem superior que o valor ajustado. Nestes casos, a pressão máxima alcançada dependerá da regulagem da válvula de máxima pressão.

As figuras 6.18 e 6.19 apresentam as formas de onda do afundamento e interrupção para duração de 10 ciclos. A partir desse tempo de duração, o equipamento começou a apresentar as irregularidades mencionadas.

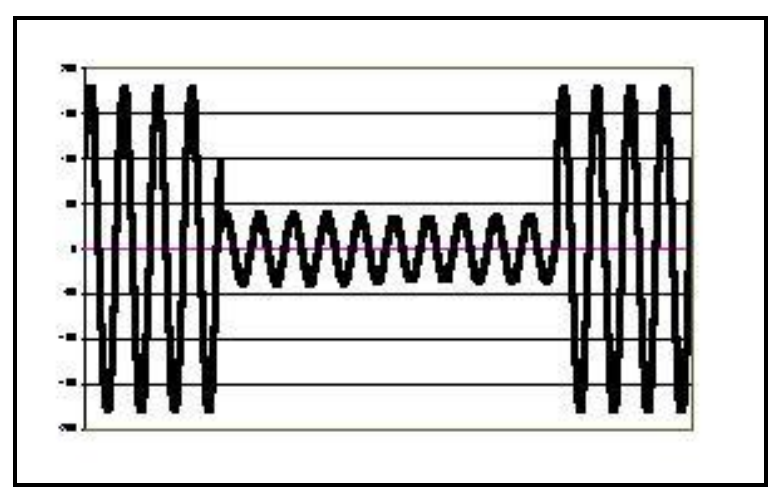

Figura 6.18 - Afundamento de $80 \%$ - 10 ciclos Fonte: Pesquisa de campo.

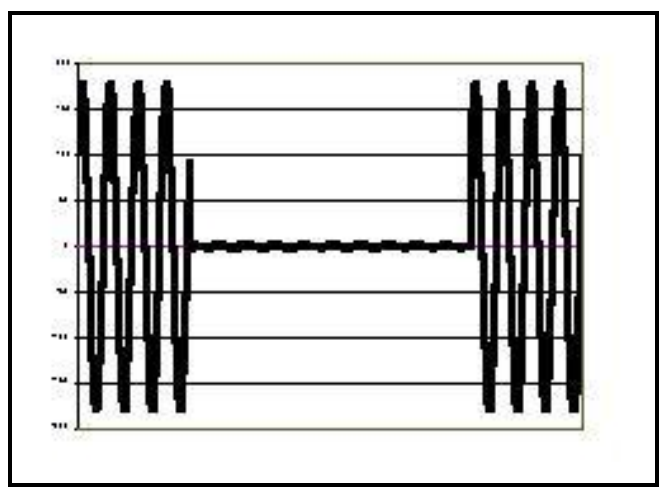

Figura 6.19 - Interrupção - 10 ciclos

Fonte: Pesquisa de campo.

Conclusões e medidas implementadas: o equipamento testado apresentou funcionamento insatisfatório nos ensaios de afundamentos de tensão, colocando sob risco de morte pacientes em tratamento ou recuperação de enfermidades em centros cirúrgicos, ou em unidades de terapia intensiva.

Após apresentação dos resultados ao fabricante, investiu-se na procura da causa do problema, chegando-se à conclusão de ser a fonte de alimentação a responsável. Após substituição da fonte original, com comutação por relé eletromecânico, por outra com comutação estática, online, o equipamento passou pelos mesmos testes e não apresentou mais os problemas anteriores.

O departamento de engenharia do fabricante esteve presente nos ensaios e pode verificar as falhas mencionadas.

O novo tipo de fonte de alimentação já está sendo incorporado aos novos equipamentos, no entanto, não se tem como alterar as unidades instaladas por todo o País, por isso, poderão continuar apresentando os riscos mencionados. 


\subsection{VENTILADOR PULMONAR - FABRICANTE B, MODELO B}

É um equipamento integrado para insuficiência respiratória de pacientes em unidades de terapia intensiva. A tela do monitor apresenta valores numéricos para: freqüência, tempo inspiratório, tempo expiratório, relação inspiração/expiração, fluxos, pressões inspiratórias máxima e de platô, volumes inspirado e expirado, volume minuto, complacência estática, complacência dinâmica, trabalho inspiratório, resistência das vias aéreas, pressão de oclusão, além de outras informações.

Trata-se de um equipamento construído com a mais alta tecnologia microprocessada atual. Possui oito modalidades de ventilação: VCV/Assist. PCV/AV ${ }^{\circledR}, P C V / A s i s t$, PLV/Assist (neonatal), SIMV/V, SIMV/P $®, B I P V \otimes, C P A P$ e PSV.

O equipamento apresenta ainda as seguintes funções:

- recurso de nebulização com fluxo sincronizado com a inspiração;

- recurso de insuflação de gás traqueal com fluxo sincronizado com o final de expiração;

- misturador $\mathrm{Ar} / \mathrm{O}_{2}$ eletrônico integrado ao ventilador com ajuste de $21 \%$ a $100 \%$ de $\mathrm{O}_{2}$;

- compensação automática da complacência do circuito respiratório;

- pausa expiratória para determinação do auto - PEEP;

- pausa inspiratória de 5 segundos para determinação da pressão de platô;

- permite $100 \%$ de $\mathrm{O}_{2}$ temporizado em 80 segundos;

- sistema de seleção que permite acessar e ajustar todos os controles por meio de um único botão;

- $\quad$ seleção automática do modo do paciente: adulto, infantil ou neonatal e dos valores médios recomendados para volume corrente, freqüência e fluxo inspiratório, em função do peso informado pelo operador, no momento em que o ventilador é ligado;

- ajuste automático modalidade x peso;

- $\quad$ sistema de proteção contra apnéia (backup) nas modalidades que exigem esforço inspiratório para o início dos ciclos;

- completo sistema de alarmes audiovisuais com mensagens escritas na tela de controle, para pronta identificação da condição de alarme; 
- todos os controles e parâmetros monitorados são apresentados em monitor LCD colorido de $15 "$.

Antes dos ensaios, o equipamento foi parametrizado com os seguintes valores:

- Modalidade de ventilação: VCV.

- Volume inspiratório: $1500 \mathrm{ml}$.

- Freqüência respiratória: $10 \mathrm{rpm}$.

- Fluxo: $401 / \mathrm{min}$.

- PEEP: $5,0 \mathrm{cmH}_{2} \mathrm{O}$.

- Pressão limite: $70 \mathrm{cmH}_{2} \mathrm{O}$.

- Quantidade de $\mathrm{O}_{2}: 60 \%$.

- Pausa e Trigger: off.

- Fluxo base: $41 / \mathrm{min}$.

- Tipo de fluxo: onda quadrada.

Esse aparelho foi alimentado com tensão de $110 \mathrm{~V}$ e também possui bateria interna para manutenção do funcionamento em caso de falta de energia elétrica.

A figura 6.20 apresenta o equipamento no instante em que era testado no Enerq-ct.

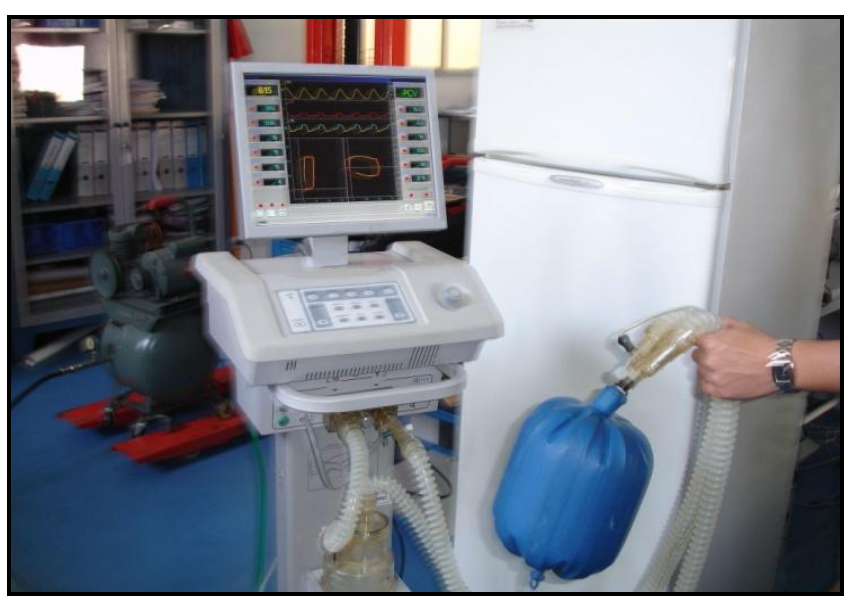

Figura 6.20 - Ventilador pulmonar- fabricante B, modelo B Fonte: Pesquisa de campo.

Conclusões: o equipamento foi submetido às mesmas perturbações idênticas às aplicadas aos demais. Em todos os testes, seu comportamento não apresentou irregularidades. 
O fabricante acompanhou os testes e mostrou-se satisfeito com o desempenho do seu equipamento.

\subsection{COMENTÁRIOS E DISCUSSÕES}

Dos seis equipamentos testados, somente dois não apresentaram problemas de funcionamento: o monitor multiparamétrico do fabricante $\mathrm{A}$ e o ventilador pulmonar do fabricante $B$, modelo $B$. O oxímetro de pulso - fabricante $C$, que não possui bateria interna, foi aquele que apresentou o maior número de falhas, tanto nos ensaios com harmônicos de tensão quanto nos de afundamentos e interrupções de tensão de curta duração.

Se utilizado em centros cirúrgicos ou unidades de terapia intensiva, pode provocar dúvidas em relação ao estado de saúde do paciente a quem ele estiver conectado. $O$ caso mais grave, sem dúvida, ocorreu com o ventilador pulmonar do fabricante $B$, modelo $A$.

Embora seja um equipamento de sustentação de vida, apresentou uma série de problemas, incluindo travamentos, perda de parâmetros previamente selecionados e falhas no sistema de alarme.

Todos estes casos, com certeza, colocarão o paciente em risco de óbito.

O fabricante interessado na melhoria desse equipamento providenciou a substituição da fonte de alimentação por um modelo imune às perturbações aplicadas.

No entanto, equipamentos fabricados antes da alteração da fonte de alimentação e ainda em uso nos EAS, podem apresentar os riscos já mencionados.

Todos os ensaios que foram apresentados foram realizados antes da atualização da Norma NBR IEC 60601-1-2 (2006), que passou a exigir testes de afundamentos e interrupções de tensão de curta duração, conforme estabelece a Norma IEC 610004-11(2000).

Acredita-se que, com essa medida, os equipamentos eletromédicos, fabricados depois da atualização da norma, passem a apresentar maior imunidade a essas perturbações, embora os fabricantes aleguem as dificuldades mencionadas em Marroni (2007).

Em relação aos resultados apresentados, algumas questões devem ser mencionadas: 
1) Como proceder com os equipamentos eletromédicos antigos que atualmente não atendem mais à normalização vigente e que representam riscos? Retirá-los de operação e substituí-los por novos seria a decisão mais racional. Mas, de onde viriam os recursos para substituição de uma enorme quantidade de equipamentos espalhados por todo o País?

2) Qual seria o procedimento correto, que o fabricante do ventilador pulmonar do fabricante $\mathrm{B}$, modelo $\mathrm{A}$ deveria tomar sabendo que a substituição da fonte de alimentação tornou seu equipamento imune aos afundamentos e interrupções de tensão de curta duração? Qual das duas opções abaixo deve ser tomada?

a) Solicitar aos seus clientes que enviem o equipamento para que a fonte de alimentação seja substituída pelo novo modelo e correr o risco de assumir uma responsabilidade legal sobre essa atitude?

b) Incentivar seus clientes que substituam esses equipamentos por outros que já incorporem o novo modelo de fonte de alimentação, mas, sem mencionar o fato? 


\section{MEIOS DE ELIMINAÇÃO OU MINIMIZAÇÃO DAS PERTURBAÇÕES ELÉTRICAS}

Este capítulo apresenta alguns meios para eliminação ou minimização das perturbações que foram apresentadas em capítulos anteriores e que poderão ser aplicadas nas redes elétricas dos circuitos de distribuição das concessionárias, nas instalações internas dos EAS ou, até mesmo, nos equipamentos eletromédicos.

\subsection{AFUNDAMENTOS E INTERRUPÇÕES DE TENSÃO DE CURTA DURAÇÃO}

Os afundamentos e interrupções de tensão de curta duração vêm sendo considerados como um dos problemas mais comuns encontrados nos sistemas elétricos de potência e estão relacionados ao aspecto da qualidade de energia elétrica.

As conseqüências e as providências para eliminação desses fenômenos, bem como, suas causas, são tarefas complexas de serem realizadas.

As atividades industriais, comerciais ou de serviços, que utilizam cada vez mais equipamentos sensíveis, podem apresentar falhas de operação, resultando em grandes prejuízos financeiros, ou no caso dos EAS, na perda de vidas.

Nos Estados Unidos, reportagem publicada no The Wall Street Journal e na revista Newsweek Magazine revela que os prejuízos decorrentes de falhas em equipamentos eletrônicos, provocadas por perturbações da rede elétrica, principalmente por afundamentos de tensão de curta duração, causados por curtoscircuitos nos sistemas de transmissão e distribuição, podem chegar a vinte bilhões de dólares por ano (ABREU,1999).

Algumas informações mencionam valores de 26 bilhões de dólares, considerando o tempo perdido e a redução de rendimento dos equipamentos (BOLLEN, 2000; BRUNSICKLE, 2001).

Descargas atmosféricas nas linhas de transmissão e distribuição são as principais causas de curtos-circuitos, que por sua vez se tornam a principal fonte de afundamentos de tensão de curta duração. No Brasil, estima-se que os prejuízos 
ocasionados por afundamentos de tensão de curta duração alcancem o valor de dois bilhões de dólares por ano (ABREU,1999).

Há algumas décadas, este assunto não se constituía em preocupação, pois os equipamentos utilizados possuíam menor sensibilidade, e os dispositivos desenvolvidos a partir da eletrônica de potência não haviam alcançado patamares expressivos (LELES FILHO; OLIVEIRA; COSTA, 2005).

Os afundamentos ou interrupções de tensão de curta duração podem prejudicar o funcionamento ou danificar as cargas sensíveis que utilizam microprocessadores ou eletrônica de potência.

Da mesma forma que na indústria, vislumbram-se duas possibilidades de ocorrências em um EAS.

A primeira delas refere-se às alterações que os equipamentos poderão sofrer sem, no entanto, apresentarem interrupção em seu funcionamento. A título de exemplo, pode-se mencionar: alteração nos valores dos parâmetros previamente estipulados; fornecimento de dados incorretos, entre outros.

A segunda possibilidade ocorre quando o equipamento sofre a total interrupção, deixando, por exemplo, de executar funções vitais.

Difícil é afirmar qual das duas poderá ocasionar efeitos mais graves, pois ambas poderão provocar riscos de vida aos pacientes dependendo do procedimento médico que estiver sendo realizado.

Outro parâmetro importante na determinação dos impactos provocados está relacionado à freqüência de ocorrência desse fenômeno, que corresponde à quantidade de vezes que o mesmo acontece em um período de tempo.

A primeira idéia de se estudar valores de tolerância aos afundamentos de tensão para equipamentos computadorizados foi apresentada em 1978 por Thomas Key, cujos resultados foram divulgados pela CBEMA - Computer and Business Eletronics Manufacturers Association (IEEE Sd 446, 1995; LEE; ALBU; HEYDT, 2004).

Esse estudo, realizado para verificar a confiabilidade do suprimento de energia elétrica para instalações militares, levou Key à conclusão que afundamentos de tensão de curta duração poderiam prejudicar o funcionamento de grandes computadores utilizados nos sistemas de fornecimento de dados e controle de equipamentos. 
A qualidade da energia elétrica fornecida pelas concessionárias é de extrema importância em função da crescente dependência mundial da eletricidade em todos os setores.

O estudo dos fenômenos de qualidade de energia elétrica, em geral, contribui para uma evolução tecnológica rápida e eficiente.

\subsubsection{Possíveis causas dos afundamentos de tensão de curta duração}

Atribui-se ao curto-circuito a principal causa destes fenômenos. O elevado valor da corrente elétrica ocasiona grandes quedas de tensão nas impedâncias dos sistemas elétricos.

Basicamente, embora existam outras causas, o curto-circuito ocorre de forma acidental pela falha da isolação elétrica entre partes do circuito que se encontram sob diferença de potencial.

Muitas dessas falhas são provocadas pelas sobretensões originadas por descargas atmosféricas, mas a isolação também pode ser degradada pela ação do tempo, da temperatura, da umidade, da luz solar e de outros agentes físicos. Impactos mecânicos provocados por equipamentos de escavação, veículos ou o ataque de animais, também provocam sua danificação.

\subsubsection{Meios de eliminação ou minimização}

Diversos estudos nesta direção vêm sendo realizados. O foco principal das pesquisas é verificar se o afundamento de tensão provoca algum tipo de falha no equipamento que se transforme em um problema.

Como já mencionado, o curto-circuito constitui-se na ocorrência básica determinante do afundamento de tensão. Nesse instante, o valor da tensão cai a zero ou assume valores muito baixos.

Em redes de topologia radial, a atuação dos dispositivos de proteção poderá provocar a interrupção de energia. Em redes com topologia em malhas, por outro lado, o curto-circuito provocará apenas um afundamento de tensão. 
No entanto, dependendo do valor resultante, poderão exceder aos parâmetros de qualidade suportáveis e provocar danos e falhas em equipamentos.

As técnicas utilizadas para minimização desses efeitos podem, de um modo geral, serem classificadas em: preventiva ou corretiva (SOUZA, 2000).

A solução preventiva está ligada à utilização de equipamentos que tenham características de não provocar afundamentos de tensão.

Normalmente é utilizada em instalações novas ou na substituição de equipamentos já instalados. A título de exemplo, pode-se citar: redução da possibilidade de curtocircuito, dispositivos para redução da corrente de partida de motores de indução, entre outras.

A solução corretiva adota técnicas ou equipamentos que reduzem ou eliminem essas perturbações sem, no entanto, exigir a substituição dos equipamentos existentes.

Algumas técnicas preventivas podem ser observadas a seguir.

\subsubsection{Redução da possibilidade de curto-circuito}

É uma forma de se reduzir não só a freqüência dos afundamentos de tensão de curta duração, mas também a freqüência de longas interrupções.

Trata-se de uma maneira bastante eficiente para se obter melhoria significativa na qualidade do fornecimento de energia elétrica.

Em redes de distribuição de energia elétrica incluem, entre outras medidas: substituição de linhas aéreas por condutores subterrâneos; utilização de condutores revestidos com materiais isolantes, em linhas aéreas; implementação de uma rígida política de podas em árvores, já que os galhos provocam curtos fase-terra; melhoria dos sistemas de aterramento, reduzindo as sobretensões de origem atmosférica ou manobras; aumento do nível de isolação dos condutores; aumento na freqüência de manutenção e inspeção das redes elétricas. 


\subsubsection{Redução do tempo de supressão do evento}

Este procedimento não reduz o número de eventos, mas sim, a sua severidade, pela limitação da duração do afundamento.

Em redes de baixa (até $1 \mathrm{kV}$ ) ou média tensão (acima de $1 \mathrm{kV}$ até $36,2 \mathrm{kV}$ ), conta-se com fusíveis limitadores dos tipos $\mathrm{NH}$ ou $\mathrm{HH}$ respectivamente, que são capazes de eliminar a falta, em menos de $4 \mathrm{~ms}$ com significativa redução do valor da corrente.

A figura 7.1 apresenta a corrente presumida, que existiria sem a presença do fusível, e a corrente de corte. Observa-se, portanto, que o efeito limitador desses fusíveis é obtido pelas excelentes qualidades do elemento fusível e pela presença de areia de fina granulometria.

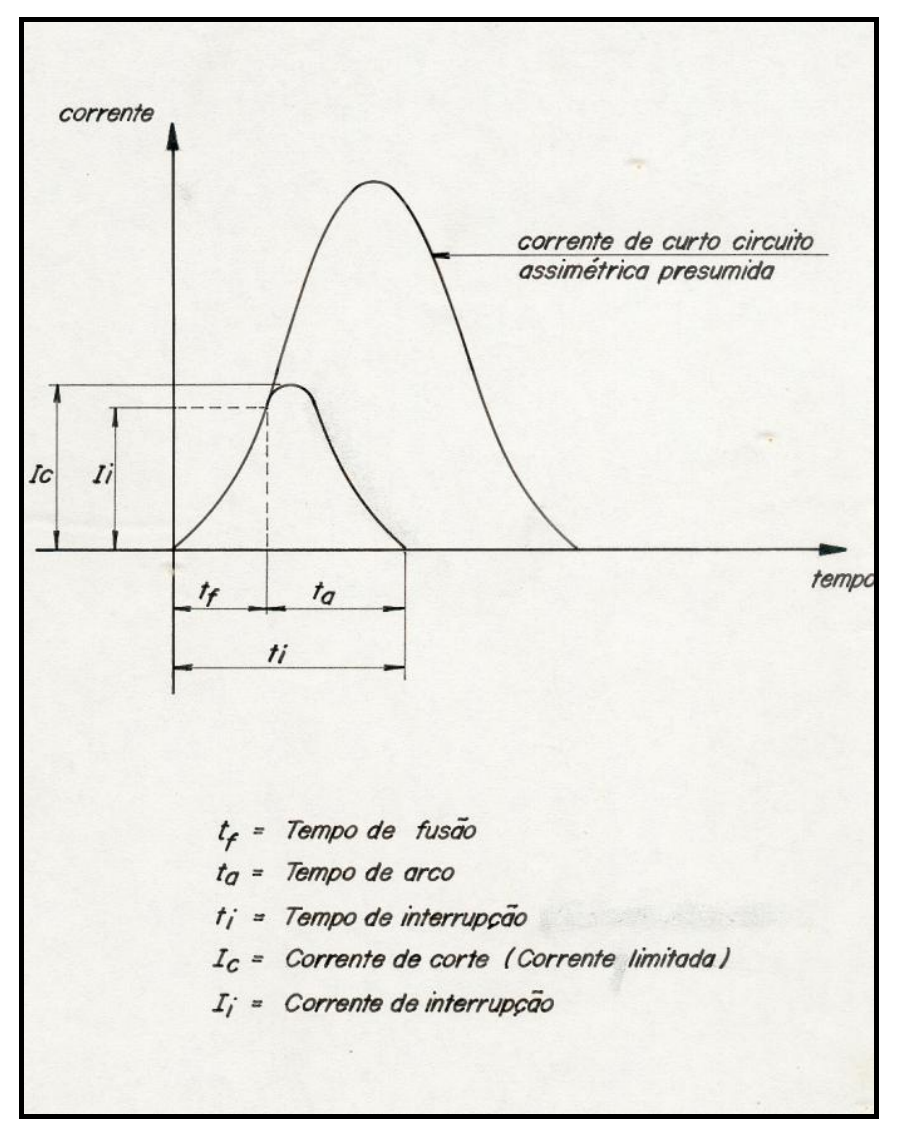

Figura 7.1 - Forma de atuação dos fusíveis limitadores

Fonte: Cotrim, 1993. (adaptação do autor)

Em caso de possibilidade de falha do dispositivo de proteção logo à frente da falta, é fundamental a utilização de dispositivo de retaguarda corretamente coordenado de forma a garantir a seletividade entre ambos. 


\subsubsection{Outras medidas preventivas}

Algumas alterações nos sistemas de distribuição poderão minimizar a severidade dos eventos. Algumas delas podem se tornar inviáveis em função de seu custo. Podem ser:

- instalação de gerador próximo às cargas sensíveis; - separação de barramentos ou subestações na trajetória do suprimento, como forma de limitar a quantidade de alimentadores na área desprotegida, ou seja, exposta ao afundamento de tensão;

- alimentar o barramento de suprimento de cargas sensíveis por duas ou mais subestações, ou seja, a ocorrência de afundamento em uma subestação será eliminado pela outra, sendo melhor o efeito de minimização quando as subestações possuírem sistemas de alimentação independentes.

\subsubsection{Fornecimento de energia elétrica de alta qualidade}

A iniciativa de se desenvolver o primeiro projeto de fornecimento de energia elétrica de alta qualidade, nos Estados Unidos da América do Norte, foi apresentado em 1999. A concessionária de energia elétrica AEP - American Electric Power e a Siemens Power Transmission \& Distribution foram as responsáveis pela realização desse projeto, para alimentação de 11 indústrias com diferentes tipos de cargas e diferentes necessidades de qualidade de energia (VOLLKOMMER, 1999).

$O$ objetivo foi fornecer aos consumidores desse complexo uma energia denominada de premium, ou seja, de máxima qualidade a custo acessível.

Em maio de 2003, projeto semelhante realizado na Alemanha foi apresentado no $17^{\circ}$ Cired - Congresso Internacional de Redes Elétricas de Distribuição, em Barcelona na Espanha. Trata-se de uma solução personalizada, adotada pela concessionária alemã Drewag para o fornecimento de energia elétrica de alta qualidade às instalações industriais de um consórcio formado pelas empresas Infineon, AMD e DuPont (KLINGER; OTTO; RADTKE, 2003).

Estudos realizados por concessionárias de fornecimento de energia elétrica mostram que os consumidores industriais e comerciais estão exigindo um serviço de 
qualidade superior ao que hoje é oferecido e, portanto, esse tipo de fornecimento deve crescer nos próximos anos.

À parte do custo desta energia, os usuários que mais necessitam de alta qualidade são os motivadores deste tipo de fornecimento, podendo-se inserir neste conjunto os EAS.

\subsubsection{Bobina de Petersen}

O Brasil possui milhares de quilômetros de linhas de distribuição aéreas, muitas delas instaladas em locais com elevado índice cerâunico.

Estudos realizados por concessionárias de distribuição apontam a causa principal de desligamentos como a falta à terra, que por sua vez é atribuída às descargas atmosféricas.

A corrente do raio é de curtíssima duração, mas provoca uma sobretensão seguida de uma corrente subseqüente de freqüência fundamental, que causa danos e atuação dos sistemas de proteção.

Devido a esse fato, várias medidas para melhoria do sistema vêm sendo tomadas e quase todas em direção ao aumento da isolação das estruturas que suportam as redes elétricas, já que possuem o neutro solidamente aterrado.

Ultimamente, vários fatores estão preocupando o desempenho dessas redes, entre eles: o aumento da sensibilidade dos consumidores às variações e interrupções momentâneas da energia elétrica; a segurança pessoal; a qualidade de energia elétrica; a mensuração do desempenho por intermédio dos índices de continuidade oficiais, além de outras exigências do consumidor final e da nova legislação brasileira para o mercado de energia elétrica (COSTA, 1995; ANEEL, 2000).

Reconhece-se, por meio da literatura especializada, que grandes esforços foram direcionados em pesquisas e estudos para a melhoria do desempenho dos sistemas de distribuição.

Algumas concessionárias alteraram os padrões construtivos de suas linhas de forma a suportarem as descargas atmosféricas laterais, grandes causadoras de desligamentos.

Vários estudos atualmente vêm sendo desenvolvidos na aplicação de pára-raios de resistência não-linear ao longo da rede elétrica; utilização de blindagem nos cabos 
pára-raios; melhoria da resistência de aterramento nas bases dos postes; alterações nas formas construtivas de cruzetas e mãos francesas; utilização de materiais isolantes; condutores isolados e muitos outros.

Todos esses estudos foram desenvolvidos para o sistema com neutro solidamente aterrado que é a tecnologia utilizada no sistema brasileiro.

Uma proposta para melhoria do desempenho de nossas redes aéreas, reduzindo afundamentos e interrupções de tensão de curta duração, é apresentada por COSTA (1995), que propõe a alteração do sistema aterrando-se o neutro com uma bobina supressora de arco, conhecida como bobina de Petersen.

A denominação dessa bobina provém do idealizador da idéia, o alemão W. Petersen, que iniciou os trabalhos teóricos em 1916, apresentando-os em revistas especializadas da Alemanha e os resultados de pesquisas foram divulgados em 1919, nesse mesmo país.

Petersen realizou um trabalho pioneiro e sem similar, por intermédio do qual uma única pessoa analisou os fatores fundamentais e propôs uma solução criativa apresentando uma exposição teórica e clara sobre o seu invento (WILLHEIM; WATERS; 1956).

Durante o funcionamento normal de uma rede elétrica, o método de aterramento do neutro não possui influência significativa.

No entanto, durante a ocorrência de faltas à terra, as conseqüências dependem principalmente das formas de se aterrar o neutro, afetando características de operação do sistema no tocante às sobretensões e às intensidades de corrente resultantes.

As sobretensões, originadas por descargas atmosféricas diretas ou indiretas, manobras, descargas entre enrolamentos primário e secundário dos transformadores, além de outras causas, provocam a degradação das isolações, reduzindo sua vida útil e provocando maior número de falhas e desligamentos.

Aterrando-se, o neutro solidamente reduz-se às sobretensões temporárias ou permanentes que ocorrem durante as faltas à terra, mais comuns de ocorrerem.

Caso o neutro não seja conectado à terra, como nos sistemas com neutro não aterrado ou flutuante, sobretensões elevadas surgirão na ocorrência de faltas à terra.

Por outro lado, o neutro solidamente aterrado permite a circulação de correntes de faltas à terra com elevado valor, que podem provocar conseqüências drásticas, 
como: elevadas tensões de passo, toque ou transferida, perigosas para pessoas e animais; danos irreparáveis em equipamentos e instalações, além de incêndios e perturbações em equipamentos eletrônicos sensíveis.

Para redução destes riscos, é necessário desligar o sistema com defeito o mais rápido possível, por meio de dispositivos de proteção às sobrecorrentes.

Conclui-se que o consumidor final será afetado, principalmente os usuários que utilizam processos industriais automatizados ou cargas sensíveis como nos EAS.

Nota-se, portanto, um conflito entre as topologias de aterramento do neutro: quando se utiliza o neutro solidamente aterrado, reduz-se, de certa forma, as sobretensões, mas, originam-se elevadas correntes, que necessariamente deverão ser eliminadas pelo desligamento do circuito.

Ao se isolar o neutro, tem-se baixas corrente de curto fase-terra, mas, elevadas sobretensões.

Em função dos inconvenientes apresentados, muitas propostas procuram o meio termo, aconselhando a inserção de resistores ou reatores em série com o neutro.

Entretanto, a forma de se aterrar o neutro deverá atender às características particulares do sistema elétrico.

As normas brasileiras e internacionais classificam o aterramento do neutro, de uma forma em geral, em dois tipos: neutro solidamente aterrado - TT e neutro isolado IT.

Quando se introduz intencionalmente uma impedância ou, não se realiza conexão alguma entre o neutro e a terra, o sistema é denominado como neutro isolado.

Variando-se o valor da resistência ou reatância inserida no neutro, obtém-se outras denominações, no entanto, as configurações mais utilizadas em todo o mundo são:

- neutro não aterrado, também denominado de neutro flutuante;

- neutro aterrado por resistência de baixo valor;

- neutro aterrado por reatância de baixo valor;

- neutro aterrado por bobina de Petersen e;

- neutro diretamente aterrado ou solidamente aterrado.

Comparativamente, cada sistema possui suas vantagens e desvantagens, recaindo a escolha no conhecimento do comportamento de cada um deles; nas características da rede elétrica, cujo neutro quer-se ou não aterrar; nas restrições da legislação, caso existam; nos aspectos de segurança de pessoas e animais ou até 
de equipamentos; das exigências quanto à continuidade de serviço, além da capacitação do corpo técnico de operação, manutenção entre outros aspectos.

A tabela 7.1 apresenta as principais características de cada um deles, principalmente no aspecto de continuidade de serviço durante a primeira falta à terra.

Após uma análise dessa tabela, verifica-se que o melhor desempenho dos sistemas de distribuição, quanto às interrupções, sejam momentâneas ou de longa duração, é obtido utilizando-se o neutro aterrado por meio da bobina de Petersen.

Tabela 7.1 - Comportamento dos sistemas de distribuição em função do aterramento do neutro

\begin{tabular}{|c|c|c|c|c|}
\hline $\begin{array}{c}\text { Esquema de } \\
\text { aterramento do } \\
\text { neutro }\end{array}$ & $\begin{array}{c}\text { Possibilidade } \\
\text { de continuidade } \\
\text { de serviço } \\
\text { durante a } \\
\text { primeira falta à } \\
\text { terra }\end{array}$ & $\begin{array}{c}\text { Possibilidade de } \\
\text { ocorrer } \\
\text { sobretensões } \\
\text { transitórias }\end{array}$ & $\begin{array}{c}\text { Valor da } \\
\text { corrente fase- } \\
\text { terra }\end{array}$ & Conclusões gerais \\
\hline $\begin{array}{l}\text { Neutro não } \\
\text { aterrado }\end{array}$ & SIM & SIM & BAIXO & $\begin{array}{l}\text { Pela possibilidade de } \\
\text { sobretensões } \\
\text { transitórias só deve ser } \\
\text { aplicado em } \\
\text { alimentadores curtos }\end{array}$ \\
\hline $\begin{array}{l}\text { Neutro aterrado por } \\
\text { resistência de } \\
\text { baixo valor }\end{array}$ & NÃO & NÃO & MÉDIO & $\begin{array}{c}\text { Interrupções de } \\
\text { sistemas com menores } \\
\text { danos }\end{array}$ \\
\hline $\begin{array}{l}\text { Neutro aterrado por } \\
\text { bobina de Petersen }\end{array}$ & SIM & NÃO & BAIXO & $\begin{array}{c}\text { Fornece a melhor } \\
\text { continuidade de serviço } \\
\text { de todos os esquemas }\end{array}$ \\
\hline $\begin{array}{c}\text { Neutro solidamente } \\
\text { aterrado, } \\
\text { distribuído e multi- } \\
\text { aterrado }\end{array}$ & NÂO & NÃO & ALTO & $\begin{array}{l}\text { Maior nível de distúrbios } \\
\text { e paralisações do } \\
\text { sistema elétrico }\end{array}$ \\
\hline $\begin{array}{c}\text { Neutro solidamente } \\
\text { aterrado não } \\
\text { distribuído }\end{array}$ & NÃO & NÃO & ALTO & $\begin{array}{c}\text { Maior nível de distúrbios } \\
\text { e paralisações do } \\
\text { sistema elétrico }\end{array}$ \\
\hline $\begin{array}{c}\text { Neutro aterrado por } \\
\text { reatância de baixo } \\
\text { valor }\end{array}$ & NÃO & NÃO & MÉDIO & $\begin{array}{l}\text { Paralisações do sistema } \\
\text { com menores danos }\end{array}$ \\
\hline
\end{tabular}

Fonte: Costa, 1995.

Quando o sistema elétrico opera com neutro isolado ou não aterrado e ocorre uma falta à terra, as únicas correntes em circulação serão capacitivas, com uma pequena componente de perdas ativas.

Aterrando-se o neutro, surge uma corrente elétrica nele, cuja natureza dependerá do tipo de impedância instalada.

Conforme a figura 7.2, no ponto de defeito a corrente total será a soma vetorial das correntes capacitivas e da corrente de neutro. 
Se o neutro for aterrado por meio de uma reatância indutiva, ocorrerá a possibilidade de dimensioná-la de tal forma que a corrente indutiva pelo neutro assuma o mesmo valor, em módulo, da corrente capacitiva total.

Sendo estas duas correntes opostas, no ponto de ocorrência do curto-circuito o valor da corrente resultante será teoricamente igual a zero (WINTER, 1993).

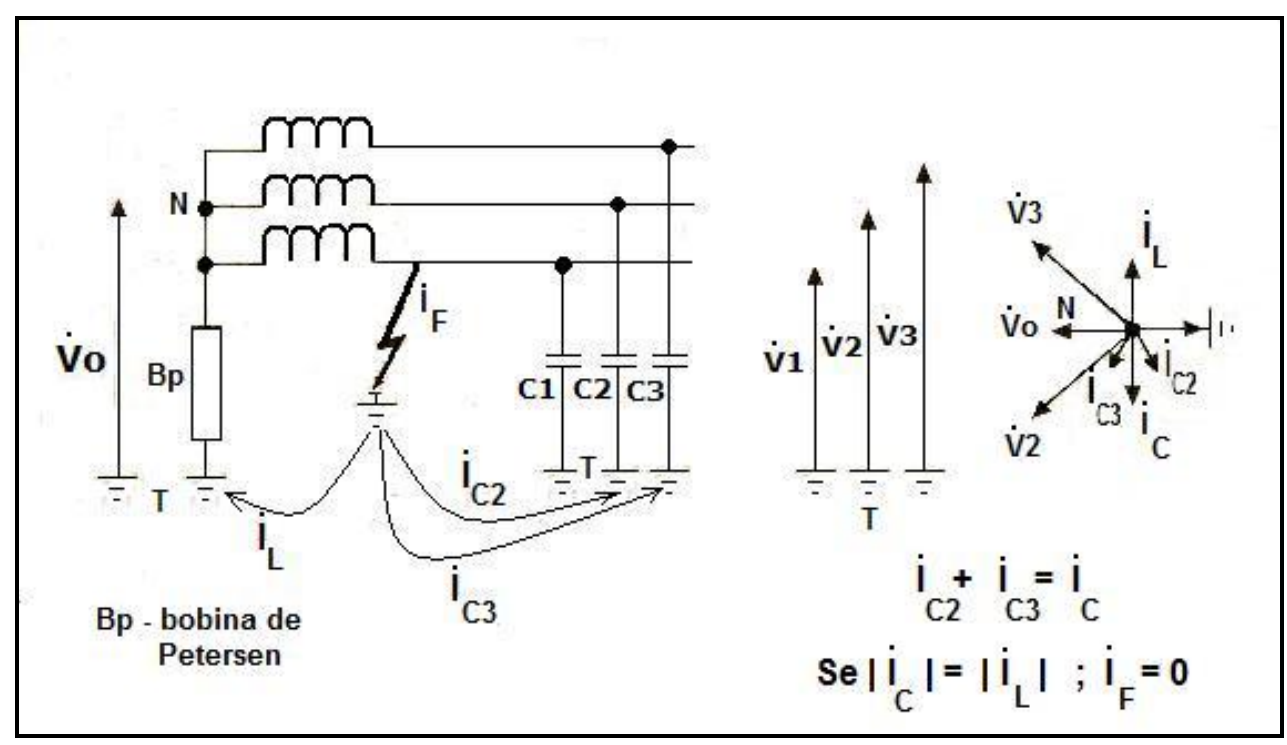

Figura 7.2 - Princípio de funcionamento da bobina de Petersen

Fonte: Costa, 1995. (adaptação do autor)

Dessa forma, não surgirá arco elétrico no ponto de contato da fase com a terra. Em função dessa característica, a bobina de Petersen é freqüentemente denominada na literatura especializada por: bobina de extinção ou supressão de arco, bobina de compensação, bobina ressonante, neutralizador de falta à terra, etc.

Conclui-se que a grande vantagem desse esquema de aterramento é a eliminação da corrente de freqüência fundamental, no ponto onde ocorre a falta à terra.

Portanto, trata-se de uma opção a ser utilizada nos sistemas de distribuição aéreos brasileiros para melhoria da qualidade de energia, reduzindo as interrupções e afundamentos de tensão de curta duração.

Em países da Europa como França, Itália, Espanha e Inglaterra essa opção já está sendo utilizada, enquanto outros países europeus estão em processo de conversão total ou parcial do aterramento do neutro, migrando do sistema solidamente aterrado para a bobina de Petersen.

Muitas vezes denominado de aterramento ressonante, é também encontrado na China e em Israel (ROBERTS; ALTUVE; HOU, 2001). 
7.1.2.6 Redução da corrente de partida de motores de indução trifásicos

Quando as características da rede de alimentação ou de outros consumidores ligados a ela não suportam os transitórios de partida, usam-se dispositivos de partida destinados a reduzir transitoriamente a tensão nos terminais dos motores elétricos e conseqüentemente, a corrente de partida.

Por se tratarem de técnicas amplamente conhecidas e utilizadas há muitos anos, apresentam-se no Anexo $D$ detalhes dessas modalidades.

7.1.2.7 Conexão de equipamentos atenuadores entre os equipamentos sensíveis e a rede de alimentação

Na maior parte dos afundamentos de tensão nos sistemas de potência, uma tensão significativa ainda é mantida nos terminais das cargas, porém, insuficiente para seu funcionamento.

Atualmente, vários métodos corretivos armazenadores de energia são utilizados para suprimento do afundamento de tensão (GALASSI, 2006).

Alguns desses equipamentos são os UPS - Uninterruptable Power Supply, utilizados geralmente em equipamentos de baixa potência ou os DVR - Dynamic Voltage Restorer, para equipamentos ou instalações maiores.

Os UPS, também denominados de no-breaks, são opções para se evitar oscilações e picos de tensão além, obviamente, das interrupções de energia elétrica (KUSKO; THOMPSON, 2007).

Os fabricantes e fornecedores, que não são poucos, afirmam que em função da má qualidade da energia comercial fornecida no Brasil é sempre conveniente optar-se por equipamentos com proteção contra variações de tensão.

Outra característica importante é o circuito estabilizador que evita a entrada da bateria para casos de variações de tensão que ocorrem com freqüência.

A bateria somente será exigida em casos de interrupção no fornecimento de energia elétrica. São três as categorias de no-beaks encontradas no mercado: online, offline e line interactive (DUGAN; MCGRANAGHAN; BEATY, 1996).

Os modelos online são os mais antigos e considerados, por muitos especialistas, como os mais seguros. 
Os offline chegam a custar três vezes menos e por isso são recomendados principalmente para equipamentos de informática.

Os line interactive possuem características e preços intermediários entre os dois modelos anteriores.

Em muitos casos, pode-se utilizar diferentes modelos, associados na mesma rede, estabelecendo padrões diversificados em função das necessidades dos equipamentos.

Os online possuem baterias alimentadas pela rede elétrica que permanecem conectadas o tempo todo e em funcionamento com o sistema.

Em caso de interrupção ou afundamento, as baterias suprem o sistema por um tempo pré-determinado, evitando a interrupção das cargas.

A autonomia é determinada pela quantidade de baterias utilizadas. Esses equipamentos recebem corrente alternada e possuem a saída também em corrente alternada, geralmente do tipo senoidal. Em função do acionamento imediato em caso de interrupção e afundamentos de tensão de curta duração, esses equipamentos representam uma opção mais segura para os EAS. Desse modo, as baterias devem manter os equipamentos eletromédicos em funcionamento até a entrada do gerador de emergência.

Os do tipo offline são também denominados de short breaks, e possuem um sistema de chaveamento que aciona a bateria por ocasião de uma interrupção de energia.

Atualmente, os computadores e os equipamentos com microprocessadores utilizam as chamadas fontes chaveadas que aceitam pequenas oscilações com tolerância de até $8 \mathrm{~ms}$. Portanto, se a bateria for acionada em um tempo inferior a este valor, não ocorrerá risco para o sistema.

É o tipo de no-breaks utilizado em todo o mundo, principalmente em redes de grandes proporções. Nesse caso, é fundamental que esteja totalmente sincronizado com a rede e seja do tipo estabilizado, afirmam os fabricantes.

Os modelos interativos também exigem um período de comutação. São acionados tão logo ocorre a interrupção de energia. Possuem um inversor que converte a tensão contínua das baterias em tensão alternada.

No entanto, em muitos casos, os UPS mostram-se ineficientes do ponto de vista econômico, em função dos elevados custos de operação (GALASSI, 2006). 
A evolução dos dispositivos de eletrônica de potência com elevada velocidade e capacidade de comutação, a disponibilidade de microprocessadores dedicados e de reduzido custo, além do desenvolvimento de novas tecnologias de controle, permitiu o desenvolvimento de soluções específicas, como o DVR - Dynamic Voltage Restorer.

Segundo informações em Praven et al. (2004), o primeiro equipamento foi instalado em 1996 pela empresa Westinghouse, em Carolina do Sul, Estados Unidos. A partir dessa data, a experiência adquirida permitiu que vários aparelhos fossem instalados com diversas técnicas de controle e configurações.

Comercialmente são encontrados condicionadores do tipo DVR para instalações com tensão até $230 \mathrm{kV}$, para cargas com potência limite de $100 \mathrm{MVA}$. No entanto, os fabricantes se concentraram em equipamentos com potências a partir de 2 MVA, valor este que não se adéqua às necessidades brasileiras.

A Escola Politécnica da Universidade de São Paulo vem, há alguns anos, desenvolvendo um mini DVR que certamente atenderá a consumidores que necessitam de um equipamento com potência inferior aos modelos oferecidos pelos principais fabricantes internacionais (MATAKAS et al., 2004).

Segundo SILVA (1999), a potência das cargas sensíveis, utilizadas no parque industrial brasileiro, dificilmente ultrapassa aos $500 \mathrm{kVA}$. Esse é um fator que muitas vezes dificulta a aquisição do equipamento.

O DVR é um conversor que utiliza eletrônica de potência e possui alta velocidade de chaveamento. Esse equipamento é conectado em série com o sistema de distribuição que alimenta a instalação com cargas sensíveis (GARCIA; PEEL; GURLASKIE, 1999).

Ele injeta no sistema uma tensão compensadora, em sincronismo com a tensão da rede elétrica, com objetivo de corrigir afundamentos e elevações de tensão de curta duração.

Possuem três partes componentes:

a) os inversores à base de eletrônica de potência;

b) o sistema de armazenamento de energia, e;

c) o transformador de injeção em série. 
O módulo inversor é constituído por três unidades monofásicas independentes do tipo PWM - Pulse Width Modulation, sendo alimentados pelo sistema de armazenamento de energia. A tensão de compensação, sintetizada por meio dos inversores, é injetada no sistema de distribuição pelo transformador de injeção em série. A figura 7.3 apresenta o esquema básico de funcionamento de um DVR.

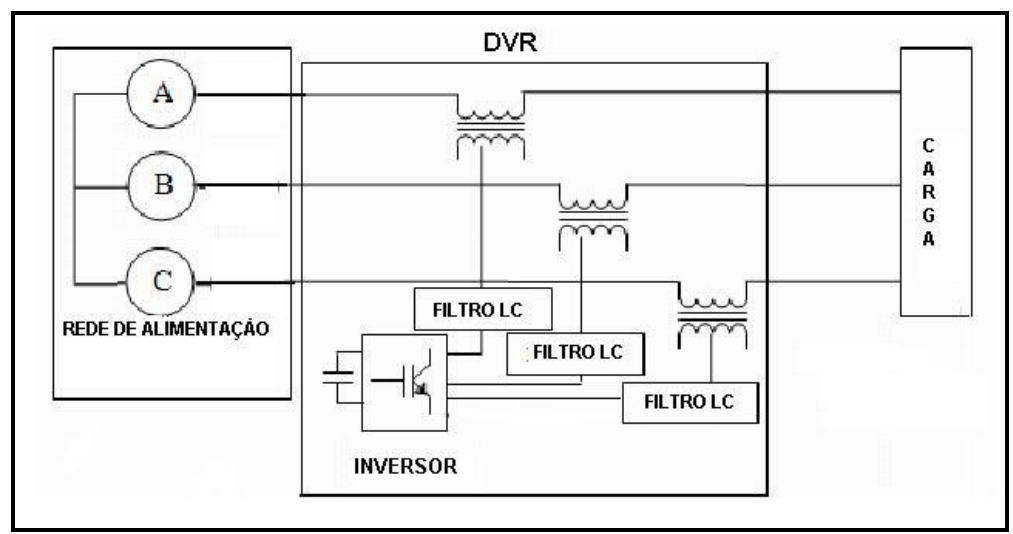

Figura 7.3 - Princípio básico de um DVR

Fonte: Garcia; Peel; Gurlaskie, 1999. (adaptação do autor)

Quando a tensão sofre um afundamento devido, por exemplo, a uma falta no sistema de transmissão ou distribuição, injeta-se uma tensão de compensação restaurando a tensão na carga sensível, evitando sua interrupção.

A figura 7.4 apresenta um diagrama de blocos do DVR, mostrando que o sistema de armazenamento de energia é constituído por capacitores que mantêm a tensão constante no barramento de corrente contínua.

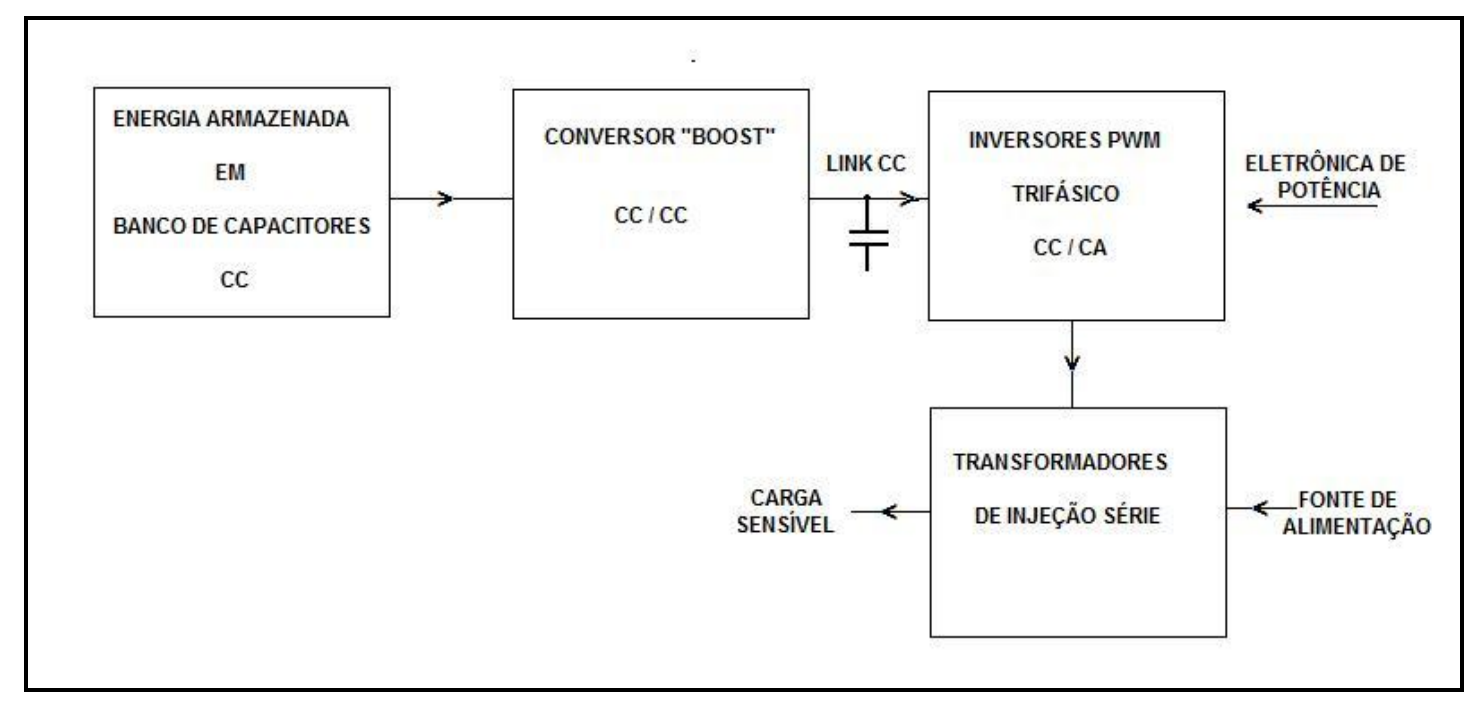

Figura 7.4 - Diagrama de blocos funcional de um DVR

Fonte: Garcia; Peel; Gurlaskie, 1999. (adaptação do autor) 
A energia armazenada é injetada nos inversores por meio de um conversor "boost", $\mathrm{CC} / \mathrm{CC}$.

Sua função é regular a tensão sobre o capacitor de corrente contínua, que se comporta como uma fonte de tensão constante para os três inversores monofásicos, que sintetizam a forma de onda determinada pelo sistema de controle digital do DVR.

O sistema de controle compara a tensão de entrada com o sinal de referência e efetua o controle dos inversores de forma a manter a tensão de saída, do lado da carga, dentro das especificações previamente ajustadas no DVR.

A saída dos inversores é aplicada ao transformador de injeção e o valor da tensão injetada depende da relação de transformação desse transformador.

O enrolamento primário do mesmo está conectado em série com o circuito de distribuição. A relação de transformação deve ser tal que o valor da máxima corrente de carga do circuito de alimentação não provoque sobrecarga nos circuitos dos inversores e atenda às necessidades da carga.

Três fatores são normalmente considerados na definição de uma aplicação particular de um DVR (GARCIA; PEEL; GURLASKIE, 1999):
a) potência da carga;
b) tipos de afundamentos de tensão experimentados pela instalação elétrica e;
c) nível de tensão necessário para manter a carga em funcionamento durante um afundamento de tensão.

Em condições normais de operação, sem afundamentos e elevações de tensão, é injetada uma pequena tensão para compensar a reatância série do transformador de injeção e as perdas existentes no equipamento.

Um fator importante no dimensionamento do DVR é a sensibilidade da carga a ser protegida. Algumas cargas utilizadas em controle de processo suportam até $0,3 \mathrm{pu}$ de afundamento da tensão com pequena duração, no entanto, cargas mais sensíveis podem apresentar funcionamento incorreto com $0,1 \mathrm{pu}$, com a mesma duração. 
Como o DVR deve suprir apenas o complemento da forma de onda da tensão durante um afundamento, sua potência nominal é usualmente bem inferior à potência da carga que está protegendo.

A maioria desses condicionadores é dimensionada para corrigir afundamentos entre 0,25 a 0,50 pu da tensão nominal, o que corresponde a uma potência entre $25 \%$ a $50 \%$ da potência da carga.

A potência nominal do DVR é determinada pelo produto, da máxima tensão injetada, pela corrente nominal da carga.

No entanto, os condicionadores baseados neste princípio devem retirar da própria rede onde estão instalados a potência ativa necessária para a compensação.

Sem um sistema de armazenamento de energia que a acumule durante os períodos de normalidade, o sistema corre o risco de entrar em colapso.

O armazenamento de energia em volantes de inércia (flywheels) é uma técnica utilizada há muito tempo para a estabilidade de picos de potência mecânica (ROLIM et al., 2003).

Esses sistemas acumulam a energia retirando-a lentamente da rede e a armazenam no volante para depois retorná-la durante uma solicitação instantânea de elevado valor (KUSKO; THOMPSON, 2007).

Os volantes de inércia utilizados atualmente, geralmente operam em baixa velocidade.

Numa máquina elétrica existe a possibilidade de se acumular energia cinética em suas partes girantes. Desta forma, pode-se utilizar esta energia, de forma eficiente, mesmo quando a tensão do sistema elétrico se reduz a valores muito baixos.

Aplicações deste sistema são encontradas em vários trabalhos internacionais (WEISSBACH; KARADY; FARMER, 2001).

O princípio básico consiste em armazenar energia em volantes de inércia com massa elevada girando a baixas velocidades ou volantes de inércia com pequena massa girando a elevadas velocidades.

O valor da energia cinética armazenada no volante é dado pela equação 7.1 :

$$
E_{C}=\frac{1}{2} J \omega^{2}
$$


sendo:

$\mathrm{E}_{\mathrm{C}}$ - energia cinética armazenada;

$\mathrm{J}$ - momento de inércia do volante;

$\omega$ - velocidade angular do volante.

Observa-se, portanto, que a influência da energia armazenada dependerá muito mais da velocidade do que da massa do volante. No entanto, a operação em altas velocidades poderá trazer problemas de desgastes e vibrações.

A quantidade de energia $\left(\Delta \mathrm{E}_{\mathrm{C}}\right)$ absorvida, ou fornecida em um intervalo de tempo $(\Delta t)$, dependerá da variação de rotação sofrida pelo volante.

Neste caso, o valor da potência mecânica média será:

$$
P=\frac{\Delta E_{C}}{\Delta t}=\frac{1}{2} J \cdot \frac{\left(\omega_{2}^{2}-\omega_{1}^{2}\right)}{\Delta t}
$$

O desenvolvimento de materiais compostos à base de fibras de vidro e de carbono permitiu a confecção de volantes de inércia de grandes dimensões, capazes de operar a velocidades de $60.000 \mathrm{rpm}$, correspondendo a uma velocidade tangencial de $1 \mathrm{~km} / \mathrm{s}$ (EMANUEL; ORR; CYGANSKI, 1993).

A energia armazenada nestes casos torna o sistema competitivo em relação a outros sistemas, tais como, supercapacitores, baterias químicas e Superconducting Magnetic Energy Storage, conhecido pela sigla SMES.

As perdas devidas ao atrito viscoso com o ar são minimizadas pela operação do volante no vácuo.

Nos Estados Unidos da América do Norte, a empresa Active Power instalou o sistema flywheel em dois EAS, no ano de 2004 (ACTIVE POWER, 2004). Num deles, o Fairview Hospital, com 478 leitos, foram instaladas duas unidades em locais separados. O outro, o Rebsamen Medical Center, ao adquirir equipamentos novos de ressonância magnética nuclear e tomografia computadorizada, optou pela aquisição de um condicionador dinâmico com potência de 300 kVA.

O fabricante informa que o sistema flywheel oferece significativa economia de espaço e redução de custos de manutenção em relação aos sistemas UPS que utilizam baterias. Além desse motivo, ressalta-se que é uma aplicação ideal para 
ambientes hospitalares onde uma contaminação de produtos tóxicos e corrosivos, provenientes das baterias, poderia provocar graves conseqüências.

Um projeto desenvolvido no Brasil (SILVA NETO et al., 2003) utiliza uma máquina de relutância variável (MRV) como motor ou gerador, em função da sua robustez, perda nula, pela ausência de corrente de excitação e sua eficiente atuação, em elevadas rotações (FERREIRA et al., 1995).

O sistema com um DVR, utilizando um armazenador cinético de energia (flywheel), pode ser visto na figura 7.5 (SILVA NETO et al., 2003).

Os principais componentes podem ser identificados como: conversor de acoplamento com a rede elétrica; elo de corrente contínua; conversor de acionamento da máquina de relutância variável; e o volante de inércia (flywheel):



Figura 7.5 - Compensador dinâmico com armazenador cinético de energia Fonte: Silva Neto et al., 2003.

Outra aplicação semelhante é apresentada por BONATTO et al. (2003).

Um equipamento de $250 \mathrm{kVA} / 380 \mathrm{~V}$ foi instalado por uma concessionária paulista em um grande consumidor industrial, com histórico de reclamações de perturbações caracterizadas por variações momentâneas de tensão que provocavam grandes prejuízos em função das paralisações em seu processo de produção automatizado. O equipamento fornecido pela Sotrec/Caterpillar integra as funções de regulação de tensão, correção do fator de potência, filtragem ativa de harmônicos e UPS, permitindo desta forma a correção de uma grande variedade de distúrbios. 
7.1.2.8 Sistemas de compensação de energia reativa em tempo real

Os afundamentos de tensão de curta duração são em boa parte causados pelas próprias cargas da instalação, durante a partida direta de motores elétricos e variações bruscas de carga.

Nos EAS, o fenômeno pode ser provocado por equipamentos típicos desses ambientes, como: equipamentos de raios $X$, tomógrafos, ressonância magnética nuclear, entre outros.

Em geral, estas condições são caracterizadas por um baixo fator de potência e alta necessidade de potência reativa.

Os sistemas convencionais de compensação de energia reativa, até então utilizados, compõem-se de um controlador do fator de potência e alguns capacitores.

Estes são conectados à rede elétrica por intermédio de contatores eletromecânicos. No entanto, o tempo de descarga dos capacitores resulta em tempos de comutação superiores a $60 \mathrm{~s}$ (HEINRICH, 2006).

As correntes de chaveamento podem assumir valores de até 200 vezes a corrente nominal do capacitor.

A figura 7.6 apresenta a corrente de excitação de um capacitor manobrado por contator e a 7.7, o respectivo transitório de tensão (DUGAN; MCGRANAGHAN; BEATY, 1996).

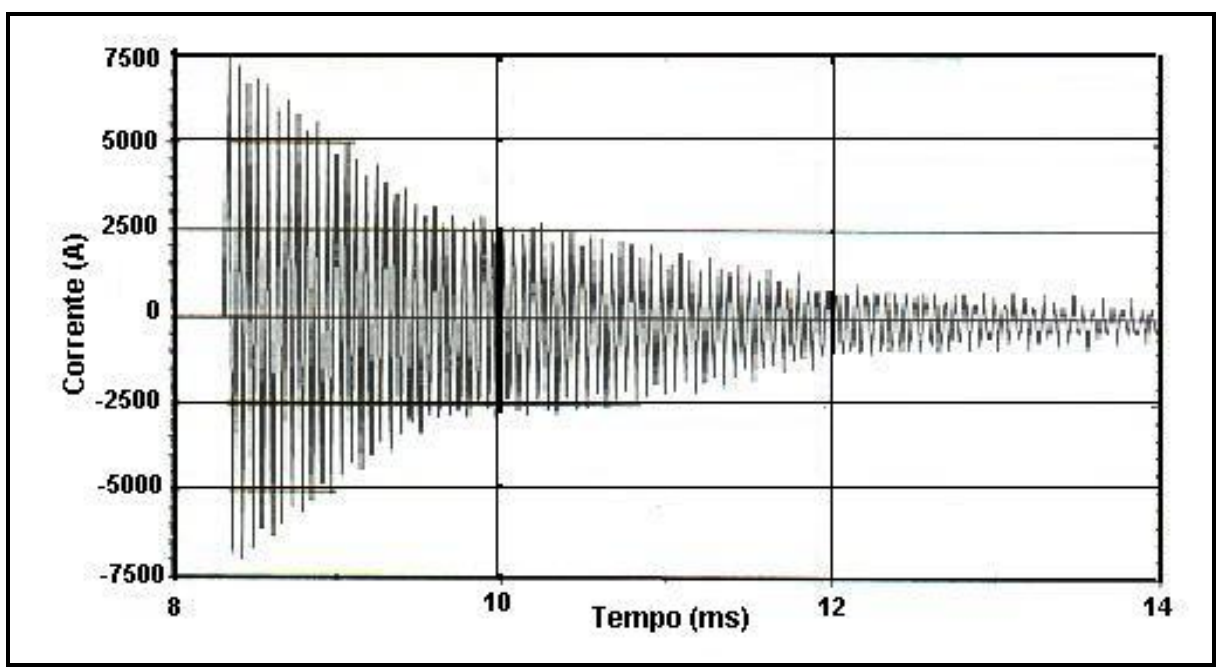

Figura 7.6 - Transitório de corrente provocado em um capacitor manobrado por contator Fonte: Dugan; Mcgranaghan; Beaty, 1996. 


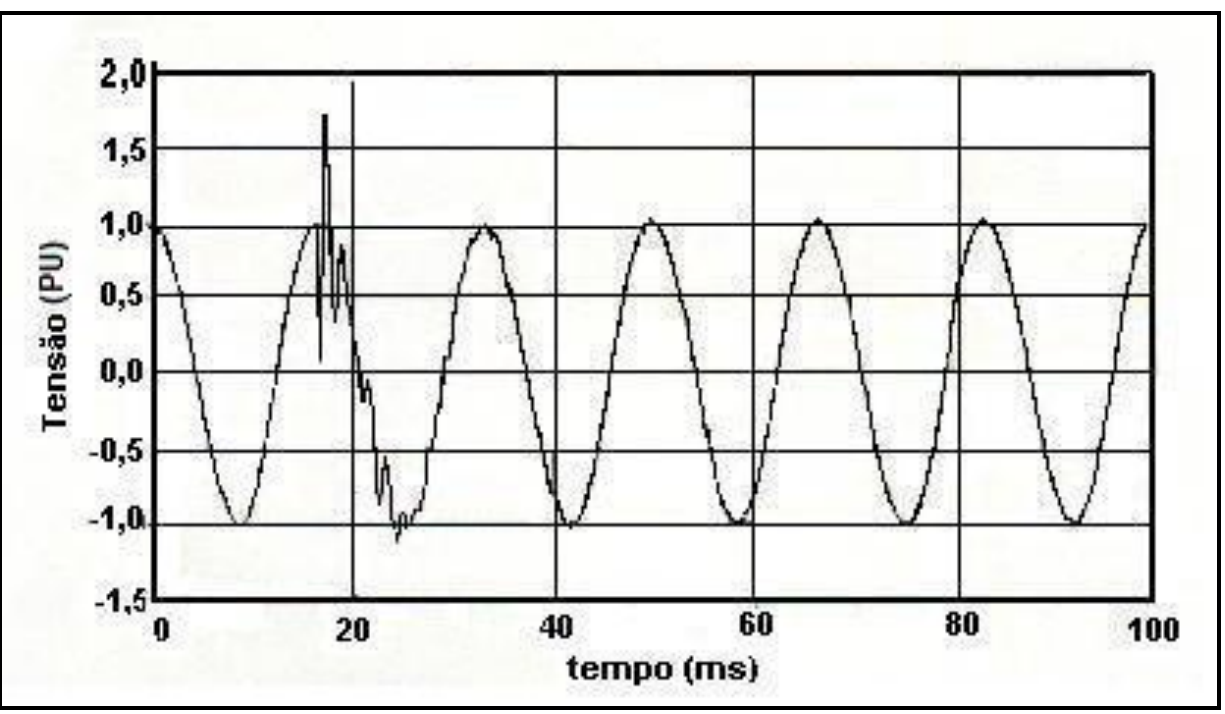

Figura 7.7 - Transitório de tensão provocado pela manobra de um capacitor por meio de contator

Fonte: Dugan; Mcgranaghan; Beaty, 1996.

Contatores especiais para manobra de capacitores utilizam resistores de amortecimento pré-inseridos, chegando a reduzir significativamente o valor dessa corrente.

No entanto, sempre ocorrerá um pico de corrente durante a fase de energização. A figura 7.8 apresenta as duas condições de manobra de um capacitor de $12,5 \mathrm{kVAr} / 380 \mathrm{~V} / 18 \mathrm{~A}$ por meio de contatores, sem e com resistências de amortecimento (HEINRICH, 2006).



Figura 7.8 - Manobra de capacitor, sem e com resistências de amortecimento Fonte: Heinrich, 2006.

Atualmente, novas aplicações exigem cada vez mais tecnologias que respondam em tempo real. Nesses casos, sistemas de compensação de energia reativa em tempo real utilizam módulos eletrônicos tiristorizados, substituindo os dispositivos eletromecânicos mais lentos. 
Normalmente instalados no secundário de transformadores de distribuição ou próximos a centros de distribuição de carga, oferecem múltiplas soluções para problemas de qualidade de energia elétrica, tais como: afundamentos de tensão, subtensões, flutuações de tensão (flicker), fator de potência, harmônicos, transientes, liberação de potência nos transformadores, controle e regulação de tensão, entre outras (HEINRICH, 2006).

Tecnologia de manobra ultra-rápida presente nesses equipamentos atua nessas situações especiais, conectando grupos de capacitores necessários, em até 1 ciclo (16 ms), suprindo toda a energia reativa necessária ao evento, reduzindo ou, em muitos casos, eliminando o afundamento de tensão.

Os motores de indução, presentes em todas instalações, quando partem necessitam de grande quantidade de potência reativa.

A corrente de rotor bloqueado desses motores pode atingir de 6 a 7 vezes o valor da corrente nominal, conforme especifica a ABNT NBR 7094 (2000).

Dependendo da potência do motor e das condições de dimensionamento da rede de alimentação, ocorrerão afundamentos de tensão, que além de prejudicar outras cargas ligadas ao circuito, reduzirão o conjugado de partida do motor que necessitará de um tempo maior para acelerar a carga.

Com a compensação de energia reativa em tempo real assegurada, será reduzido o afundamento de tensão durante a fase de partida, conforme se apresenta na figura 7.9 (ELSPEC, 2008).

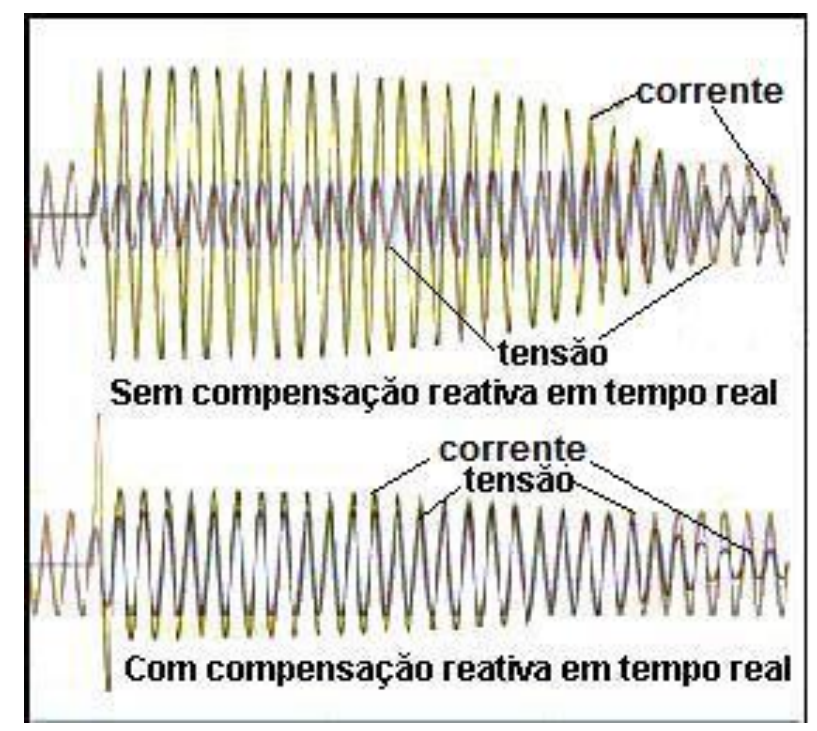

Figura 7.9 - Redução do afundamento de tensão

Fonte: Elspec, 2008. 
A figura 7.10 (ELSPEC, 2008) apresenta as variações de tensão e corrente durante a partida direta de um motor de indução com $125 \mathrm{cv}$ de potência.

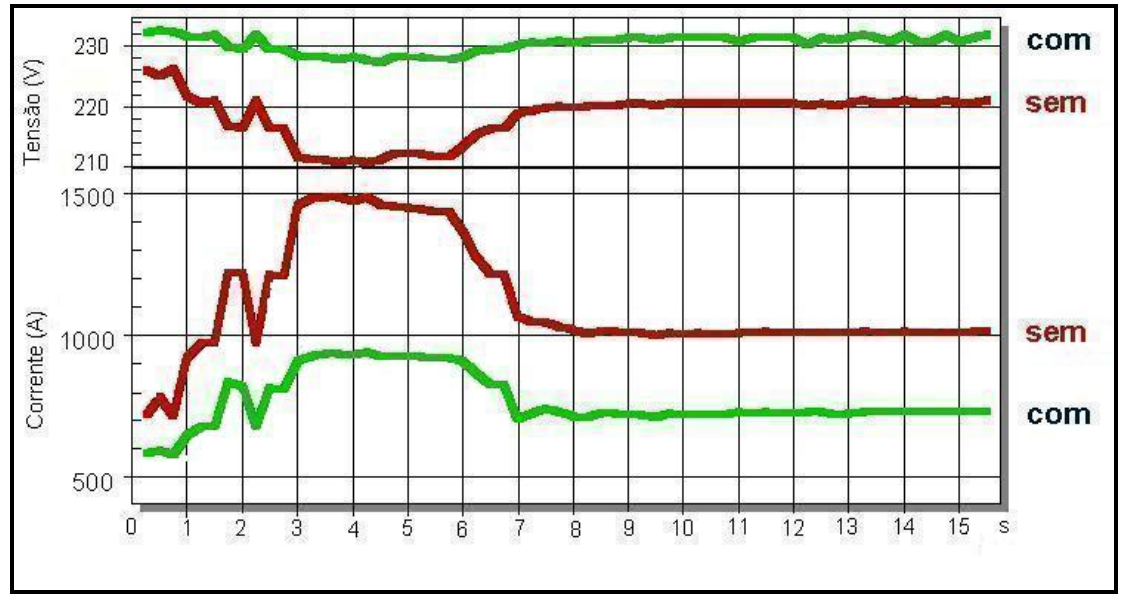

Figura 7.10 - Afundamentos de tensão durante a partida direta de um motor de indução de $125 \mathrm{cv}$. Curva verde: com compensação de reativos. Curva vermelha: sem compensação de reativos

Fonte: Elspec, 2008.

A manobra dos capacitores é efetuada com a utilização de chaves estáticas de última geração, efetuando a conexão e a desconexão precisamente no instante em que a corrente passa pelo zero (zero-crossing).

Essa moderna tecnologia de manobra evita os transientes causados por sistemas típicos de correção do fator de potência, manobrados por contatores eletromecânicos, aumentado significativamente a vida útil dos componentes do sistema.

A figura 7.11 apresenta uma comparação entre os transientes de tensão provocados pelo sistema de manobra com dispositivos eletromecânicos em relação ao manobrado com chaves estáticas.

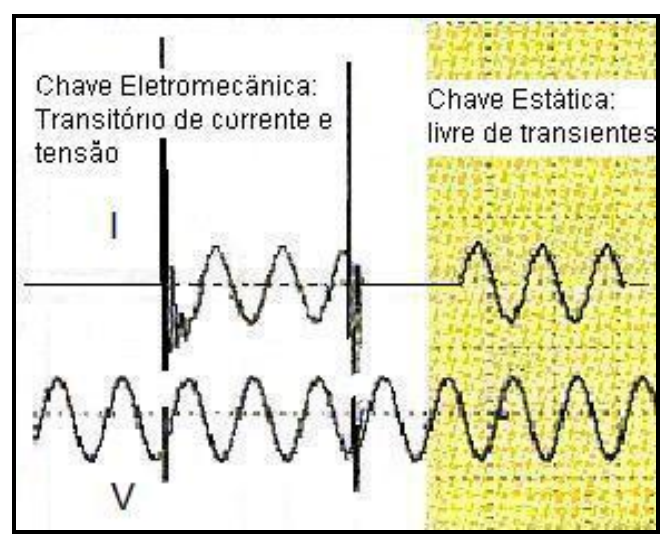

Figura 7.11 - Esquerda: manobra com dispositivo eletromecânico. Direita: manobra com chave estática

Fonte: Elspec, 2008 
O equipamento mencionado é equipado com um exclusivo sistema SCAN, que efetua a proteção dos capacitores, evitando explosões e contribui para o aumento da vida útil desses equipamentos. Além disso, reduz o valor da corrente média e minimiza os efeitos de aquecimento.

O elemento de comando, responsável pelas manobras, possui ilimitado número de operações e insere um grupo de capacitores enquanto outro está sendo desconectado.

Essa operação, que ocorre em períodos da ordem de alguns segundos, promove um rodízio dos grupos sem mudança do valor total dos reativos necessários.

Esse tipo de equipamento tem sido instalado em atividades industriais, comerciais, hospitais, sistemas de transporte ferroviário e em locais com cargas sensíveis, garantindo aos usuários, além da correção do fator de potência e isenção de multas e vantagens adicionais como: economia de energia, aumento da qualidade de energia elétrica, tratamento de harmônicos e prevenção de afundamentos de tensão.

\subsubsection{Aperfeiçoamento da imunidade dos equipamentos}

Atualmente, no contexto brasileiro, poucos projetos consideram a sensibilidade que equipamentos e sistemas apresentam em relação a afundamentos de tensão. No entanto, em função de prejuízos envolvidos, precauções dessa natureza se tornarão procedimentos obrigatórios para engenheiros de desenvolvimento e de aplicação.

Serão eles os responsáveis pelo desenvolvimento de sistemas e equipamentos menos sensíveis a problemas de qualidade de energia elétrica.

O custo-benefício certamente estará envolvido nesse processo (CALDON; FAURI; FELLIN, 1999). Parece ser a solução mais eficiente contra os danos causados a equipamentos pelos afundamentos de tensão.

No entanto, essa medida pode levar muitos anos para se chegar a um resultado satisfatório. Além do mais, o consumidor perceberá o problema somente após a instalação dos equipamentos. 


\subsection{HARMÔNICOS}

As perturbações devido aos harmônicos de corrente tornaram-se importantes a partir da década de 80, quando os equipamentos eletrônicos tiveram grande desenvolvimento e aplicações, em substituição aos equipamentos elétricos e eletromecânicos (BOLLINGER, 1991).

Como os equipamentos eletrônicos, principalmente os que utilizam componentes microprocessados, são bastante sensíveis às perturbações já mencionadas, seus usuários iniciaram um processo de reclamações nas concessionárias, em relação à qualidade da energia fornecida, porém, na maioria dos casos, os equipamentos ligados à rede eram os próprios causadores dos problemas apresentados (ALVES, 1996).

Para melhor entendimento do assunto, no Anexo A estão apresentados os principais conceitos sobre harmônicos.

\subsubsection{Possíveis causas de harmônicos de corrente}

Os conversores estáticos de potência são atualmente as principais fontes de harmônicos de corrente nas aplicações atuais.

Englobam os inversores e os retificadores, podendo ser encontrados para diversas faixas de potência (BARBOSA, 1995). São classificados de acordo com o número de pulsos do conversor, conforme a equação 7.3 , no qual as amplitudes teóricas dos harmônicos de corrente decrescem em proporção inversa de sua ordem (PHIPPS; NELSON; SEM, 1994).

$$
h=p k \pm 1
$$

sendo:

$\mathrm{h}$ - ordem do harmônico;

p - número de pulsos do conversor;

k - números inteiros $(1,2,3 \ldots)$. 
Os de grande potência são em geral da ordem de megawatts como, por exemplo, os utilizados em galvanoplastia, indústrias químicas e de alumínio.

Na prática, conversores de 6, 12, 24, e 36 pulsos são os mais utilizados.

Acima de 6 pulsos são constituídos por transformadores em paralelo, com diferentes deslocamentos angulares. A figura 7.12 apresenta um sistema de retificação de 24 pulsos.

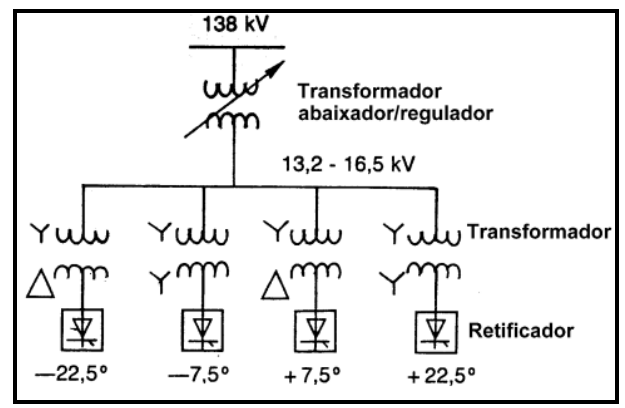

Figura 7.12 - Sistema de retificação de 24 pulsos

Fonte: Barbosa, 1994.

Em geral, os conversores de média potência possuem potências da ordem de quilowatts e sua aplicação na indústria aumenta a cada dia, principalmente para controle de velocidade de motores de indução. Como vantagens decorrentes da sua utilização, podemos mencionar a flexibilidade produtiva e a economia de energia elétrica.

Os avanços na tecnologia dos semicondutores de potência permitiram grande oferta desses equipamentos, para as mais variadas aplicações, a um custo inferior aos cobrados por tradicionais sistemas de corrente contínua, considerando que eles têm a mesma finalidade.

No entanto, alguns aspectos relacionados ao impacto que esses equipamentos estão causando nas redes de distribuição, principalmente em relação aos harmônicos, vêm sendo motivo de grande preocupação.

A maioria desses equipamentos apresenta uma corrente de entrada com forma de onda não senoidal (ROSSA; TORRI, 2000). A topologia do circuito de entrada, mais encontrado, é basicamente a de uma ponte retificadora de diodos, que dependendo da potência do conversor de freqüência, poderá ser monofásica ou trifásica, e um capacitor de filtro instalado na saída desse retificador, denominado de circuito intermediário, conforme ilustra a figura 7.13. 




Figura 7.13 - Circuito de potência típico dos conversores de freqüência Fonte: Rossa; Torri, 2000.

Normalmente, os harmônicos de ordem par possuem amplitudes desprezíveis, assim como as de ordem múltiplas de três, para os casos de alimentação trifásica.

Durante o funcionamento, ocorre uma deformação na forma de onda da tensão, devido à queda na impedância série da rede, que na maioria das vezes é representada pela impedância série de transformadores e da impedância dos condutores elétricos.

\subsubsection{Meios de eliminação ou minimização}

Em geral, com a proliferação de cargas não-lineares nos sistemas elétricos, as instalações, tanto das concessionárias de energia como das unidades consumidoras, passaram a conviver com o problema de distorção harmônica de tensão e suas conseqüências.

Os efeitos podem ser os mais variados possíveis, como: imprecisão dos instrumentos de medição de energia, do tipo indutivo; ressonância paralela entre cargas indutivas e capacitivas; falha em equipamentos de proteção microprocessados; sobrecargas em transformadores, incluindo também, o mau funcionamento dos equipamentos sensíveis utilizados nos EAS, além de outros aspectos.

Extensivos trabalhos de pesquisa vêm sendo realizados na última década, com objetivo de quantificação dos problemas associados a cargas não-lineares (GRUZS, 1990; EMANUEL; ORR; CYGANSKI,1993). 
A constatação é que esses distúrbios podem ser atribuídos aos componentes, reativos e harmônicos, gerados pela alimentação desses equipamentos (RIBEIRO, 2003).

As conseqüências observadas pela existência de harmônicos de corrente são:

- distorção da forma de onda de tensão, no ponto de acoplamento comum com a concessionária;

- circulação de harmônicos de corrente no condutor neutro de sistemas trifásicos a quatro fios, e;

- interferência em outros instrumentos ou equipamentos conectados a essas redes elétricas.

Várias técnicas ou equipamentos são utilizados na minimização ou eliminação das perturbações ocasionadas por harmônicos de corrente. Da mesma forma que foi apresentada nos afundamentos de tensão, também possuem abordagem preventiva ou corretiva (SOUZA, 2000).

A solução preventiva está ligada à utilização de equipamentos que tenham características de não gerar harmônicos de corrente.

Normalmente é utilizada em instalações novas ou na substituição de equipamentos em funcionamento.

Entre algumas soluções, pode-se citar: equipamentos que se apresentam à rede, com características resistivas, transformadores com ligações especiais, etc.

A solução corretiva utiliza técnicas ou equipamentos que reduzem ou eliminem essas perturbações sem, no entanto, exigir a substituição dos equipamentos existentes.

Os mais utilizados são os filtros passivos, encontrados em diversas configurações e constituídos basicamente de indutores e capacitores e, os filtros ativos, que incorporam circuitos eletrônicos, semicondutores de potência, filtros e armazenadores de energia, capazes de compensar a potência reativa e os harmônicos de corrente das cargas não-lineares.

A seguir serão apresentadas algumas formas, mais encontradas, de eliminação ou minimização de harmônicos de corrente. 


\subsubsection{Filtros Passivos}

Os filtros passivos são projetados para permitir a passagem ou rejeição de sinais em uma dada freqüência. Eles caracterizam-se pelo uso de elementos passivos, como resistores, indutores e capacitores (KUSKO; THOMPSON, 2007).

É uma das práticas mais utilizadas no Brasil, em grandes instalações industriais ou ainda, em subestações conversoras para sistemas de transmissão em corrente contínua.

Os filtros de banda são aplicados para a absorção ou rejeição de faixas de freqüências: passa baixa, passa alta e rejeição de banda. Quando as freqüências possuem valores próximos, o filtro é denominado de corte. Trata-se do tipo mais comum utilizado, em especial, o de sintonia simples, que é mais econômico e, em geral, suficiente.

Na presença de um conteúdo harmônico distribuído em várias freqüências múltiplas da fundamental, pode ser necessário um filtro de sintonia múltipla, sintonizado para cada freqüência que se deseja filtrar.

A freqüência de ressonância dos filtros dessintonizadores ou anti-ressonantes deve ser selecionada de forma que fique imediatamente abaixo do primeiro harmônico significativo da instalação, impossibilitando a ressonância paralela entre o transformador e os capacitores, geralmente utilizados na correção do fator de potência.

Os filtros de absorção são classificados em (KUSKO, 1996):

- 1름 ordem: combinação de capacitor em série com resistor;

- $2^{a}$ ordem: resistor em paralelo com indutor e ambos em série com capacitor;

- 3ํㅡㄹ ordem: resistor em série com capacitor e ambos em paralelo com indutor

e, todos em série com outro capacitor;

A ordem do filtro refere-se à quantidade de armazenadores de energia.

Da mesma forma, o equacionamento resultante para os filtros de $1^{\underline{a}}, 2^{\underline{a}}$ e $3^{a}$ ordem também é composto por equações de $1^{\underline{a}}, 2^{\underline{a}}$ e $3^{\underline{a}}$ ordem, respectivamente.

O filtro de corte possui dois armazenadores de energia e a equação resultante é de primeira ordem, devido à ausência de componente dissipativo.

A utilização de filtros para redução da distorção harmônica proporciona várias vantagens adicionais, entre elas: melhoria do fator de potência; redução de corrente de retorno pelo neutro; liberação de potência nos transformadores e nos sistemas de 
distribuição, além de eliminar ressonâncias altamente prejudiciais nos sistemas elétricos. Um dos tipos utilizados é o LC, conforme se apresenta na figura 7.14.

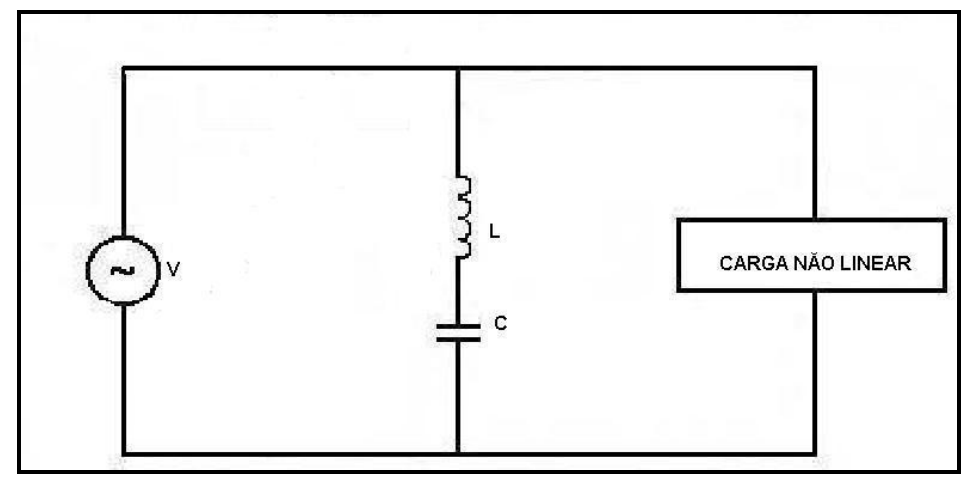

Figura 7.14 - Filtro passivo do tipo LC série

Fonte: Kusko; Thompson, 2007. (adaptação do autor)

Essa solução constitui-se na inserção de um circuito LC série, ligado em paralelo com a carga poluidora. Nesse caso, os valores de $L$ e $C$ são tais que a impedância do filtro seja a mais baixa possível para a freqüência que se quer eliminar.

Se a impedância da fonte for de valor reduzido, haverá necessidade da instalação de outro filtro LC paralelo, ligado em série com a carga e sintonizado para a mesma freqüência.

Com este arranjo, o componente harmônico de corrente será obrigado a retornar pelo filtro série (que está ligado em paralelo com a carga), uma vez que para essa freqüência, o filtro paralelo apresentará uma impedância elevada.

A impedância do filtro ligado em série deverá ser tal que não produza uma queda de tensão acentuada na carga. A figura 7.15 apresenta este caso:

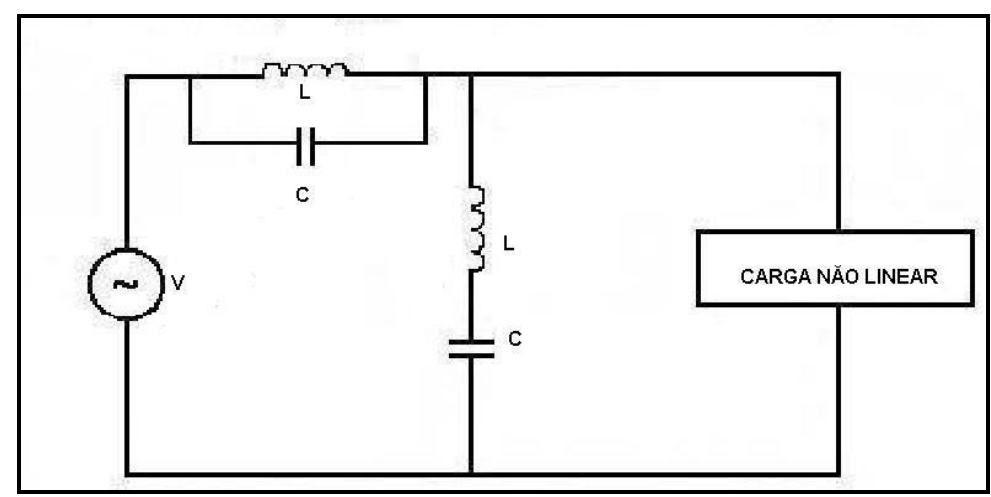

Figura 7.15 - Filtros passivos do tipo LC série e paralelo

Fonte: Kusko; Thompson, 2007. (adaptação do autor) 


\subsubsection{Filtros Ativos}

Embora sejam bastante empregados, os filtros passivos, em diversas configurações e constituídos basicamente por indutores e capacitores, apresentam algumas desvantagens em relação aos ativos: são mais volumosos, possuem características de compensação fixas e, podem entrar em ressonância com a rede de alimentação. Os filtros ativos de potência podem ser definidos como equipamento ou sistema que incorpora circuitos eletrônicos, semicondutores de potência, filtros e elementos armazenadores de energia, capazes de compensar, não só a distorção harmônica, como também a potência reativa e o desequilíbrio de tensões (RIBEIRO, 2003; KUSKO, THOMPSON, 2007).

Quando comparados aos filtros passivos, apresentam melhores desempenhos na compensação.

Por tratar-se de uma solução dinâmica e com possibilidade de ajustes, os filtros ativos atualmente têm sido objetivo de muitas publicações técnicas e aplicações.

No entanto, em muitos casos, embora sejam mais eficientes que os filtros passivos, os filtros ativos apresentam algumas desvantagens que se tornam superadas pela utilização dos filtros híbridos.

Estes últimos constituem-se numa combinação de filtros ativos e passivos, que apresentam melhores resultados do que aqueles que seriam apresentados por cada tipo separadamente.

Outro tipo que ainda pode encontrar-se é o denominado de filtro ativo universal, constituído pela combinação de filtros ativos, série e paralelo.

Em geral, os filtros ativos são classificados em vários tipos, em função do nível de potência, técnicas de controle, número de fases, entre outras características.

Várias formas de classificação dos filtros ativos podem ser encontradas em artigos técnicos (SINGH; AL-HADDAD; CHANDRA, 1999; EL-HABROUK; DARWISH; MEHTA, 2000).

As topologias utilizadas para filtros ativos são: paralelo, série e híbrido (RIBEIRO, 2003).

Os do tipo paralelo são mais utilizados para eliminação de harmônicos de corrente, compensação de potência reativa e correção de desequilíbrios em sistemas trifásicos. 
A figura 7.16 apresenta uma das configurações mais utilizadas para este tipo de filtro.

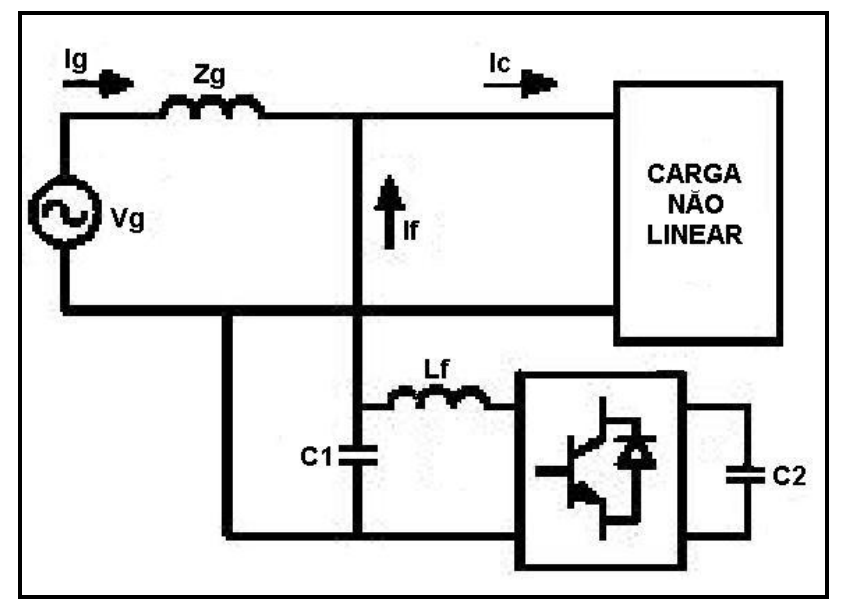

Fig. 7.16 - Configuração básica de um filtro ativo paralelo

Fonte: Singh; Al-Haddad; Chandra, 1999. (adaptação do autor)

A configuração básica de um filtro série está apresentada na figura 7.17.

Normalmente, ele é conectado em série, entre a fonte e a carga, geralmente com auxílio de um transformador de acoplamento.

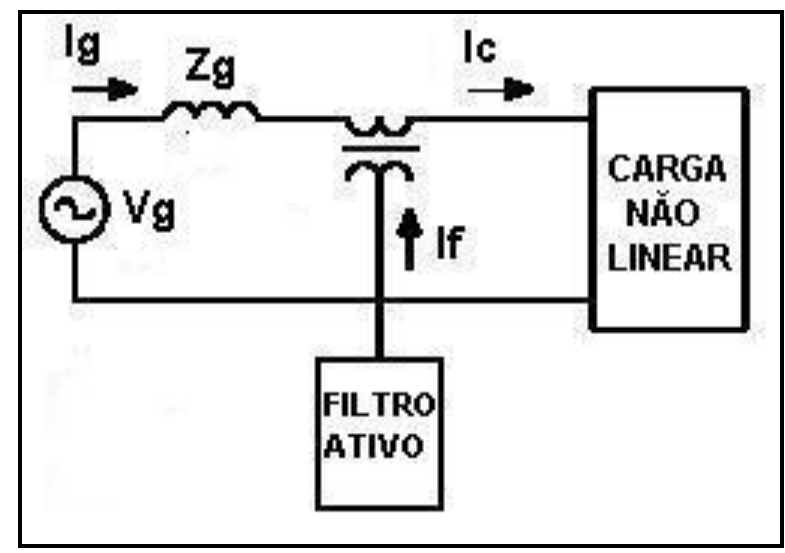

Fig. 7.17 - Configuração básica de um filtro ativo série

Fonte: Singh; Al-Haddad; Chandra, 1999. (adaptação do autor)

São menos comuns que os do tipo paralelo, pois necessitam suportar a corrente de carga, no entanto, são ideais para eliminação de harmônicos de tensão e correção de desequilíbrios de fase em sistemas trifásicos. 
São encontradas várias topologias para os filtros ativos híbridos, que vêm se tornando usuais em função da redução de potência, dimensões e custo dos dispositivos semicondutores empregados na parte ativa do filtro. A figura 7.18 apresenta uma topologia que combina um filtro ativo série com um filtro passivo ligado em paralelo.

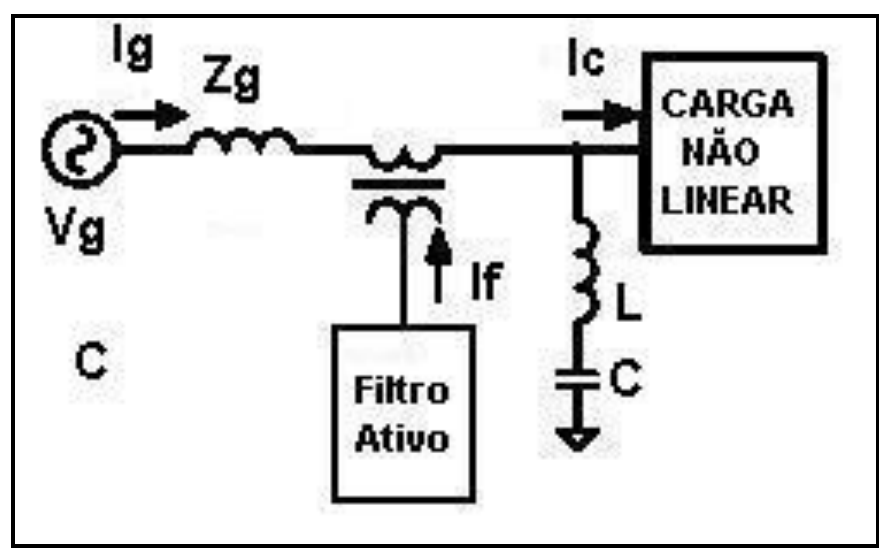

Figura 7.18 - Filtro híbrido

Fonte: Singh; Al-Haddad; Chandra, 1999. (adaptação do autor)

\subsubsection{Transformadores com ligações especiais}

A figura 7.19 apresenta um transformador delta-estrela alimentando cargas monofásicas não-lineares, ligadas nas fases e no condutor neutro, como ocorre atualmente na maioria dos sistemas de distribuição (SCHONEK, 2001).

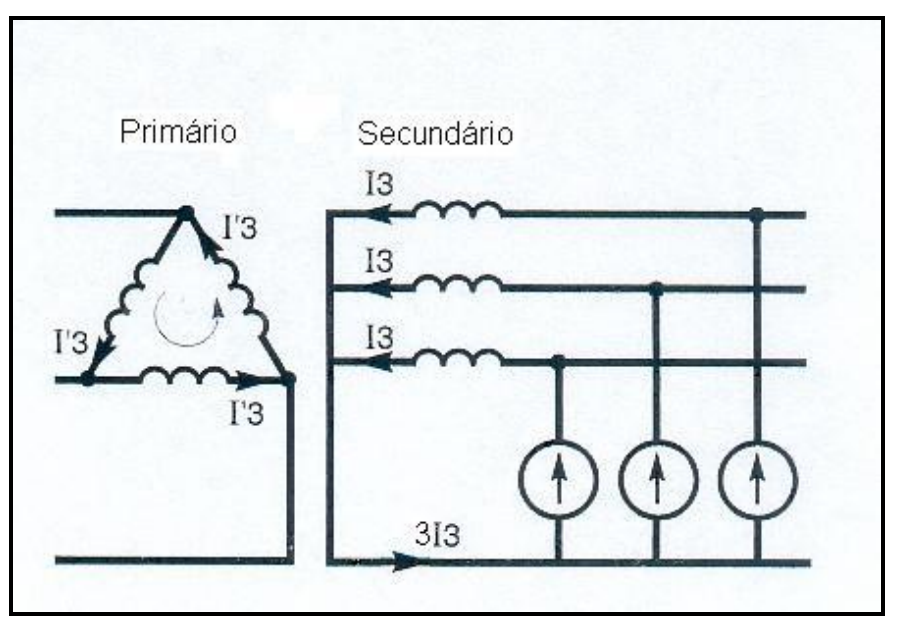

Figura 7.19 - Transformador delta-estrela

Fonte: Schonek, 2001. (adaptação do autor) 
Nos enrolamentos secundários, os harmônicos de corrente de $3^{\mathrm{a}}$ ordem se adicionam e retornam pelo condutor neutro, podendo produzir sobreaquecimento e interferências em equipamentos sensíveis, uma vez que a freqüência dessas correntes é três vezes superior ao valor da fundamental.

No circuito primário, considerando as correntes de fase com valores iguais, que se anulam em cada nó da ligação delta, não ocorre a circulação de correntes de linha. No entanto, elas provocarão um aquecimento adicional no transformador pelo fato de circularem pela bobinas que compõem os enrolamentos primários.

Esse fato vem atualmente sendo encontrado em transformadores que alimentam sistemas de iluminação fluorescente com reatores eletrônicos.

Considera-se agora um transformador com secundário ligado em ziguezague, alimentando as mesmas cargas. Observa-se pela figura 7.20 que os harmônicos de corrente de $3^{\text {a }}$ ordem se anulam, pois as bobinas secundárias são ligadas de maneiras opostas. Nesse caso, considerando novamente estas correntes idênticas, não haverá circulação de corrente de $3^{\mathrm{a}}$ ordem no condutor neutro e no primário do transformador.

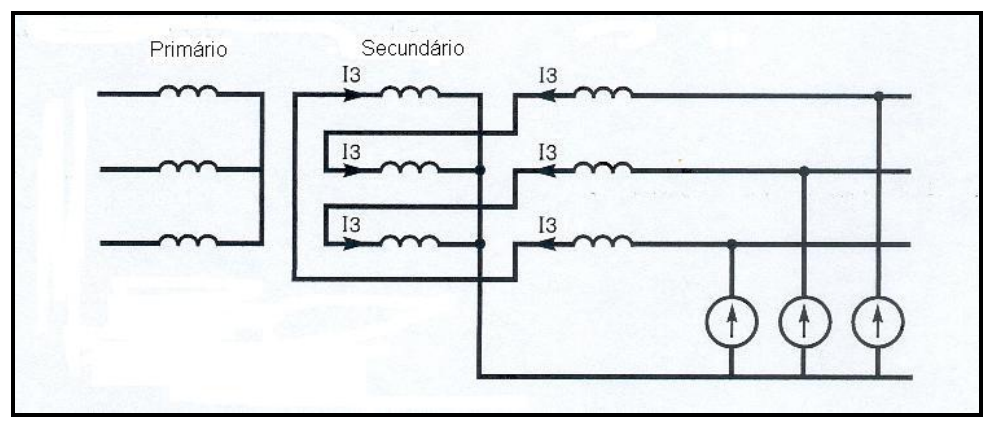

Figura 7.20 - Transformador com secundário em ligação ziguezague

Fonte: Schonek, 2001. (adaptação do autor)

Sistemas de retificação de 12 pulsos são alimentados por meio de transformadores com dois secundários, um deles ligado em estrela e o outro em triângulo. A defasagem de $30^{\circ}$ resultante entre as correntes secundárias produz o cancelamento entre os harmônicos de $5^{\mathrm{a}}$ e $7^{\mathrm{a}}$ ordem da corrente primária. Este sistema pode ser utilizado com grandes vantagens em sistemas de controle de velocidade de motores de indução com elevada potência, bem como em outras aplicações com conversores estáticos (KUSKO, THOMPSON, 2007). 
A figura 7.21 apresenta a conexão do transformador ao retificador:

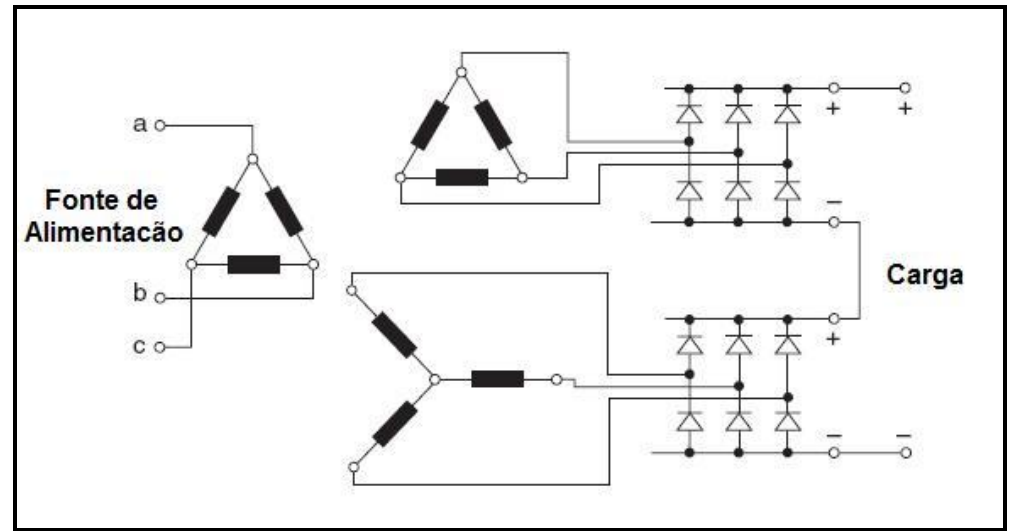

Figura 7.21 - Transformador com dois enrolamentos secundários

Fonte: Kusko; Thompson, 2007. 


\section{CONCLUSÕES}

Acredita-se que os resultados obtidos pelo desenvolvimento deste trabalho atingiram o objetivo proposto, ou seja, comprovar falhas em equipamentos eletromédicos quando alimentados por redes elétricas que contenham perturbações geradas por outras cargas típicas desses ambientes, ou provocadas pela concessionária de distribuição de energia elétrica.

Para se alcançar o objetivo proposto, foi desenvolvida uma metodologia específica, apresentada no capítulo 1, que utilizou os mesmos tipos de perturbações existentes nos EAS para, em seguida, serem reproduzidas em fontes de tensão específicas e aplicadas nos equipamentos eletromédicos.

Complementando o trabalho, também se analisou a qualidade e o atendimento às normas específicas das instalações elétricas, de vários EAS, apresentadas no capítulo 3.

As principais contribuições deste trabalho estão relacionadas a seguir.

\subsection{A QUALIDADE DA ENERGIA ELÉTRICA NOS ESTABELECIMENTOS ASSISTENCIAIS DE SAÚDE (EAS)}

$\mathrm{Na}$ grande maioria das vezes, perturbações elétricas são geradas no interior de EAS pela comutação de cargas com elevada potência, ou pelo uso, cada vez maior, de cargas não-lineares.

Medições elétricas e análises do comportamento de equipamentos específicos desses ambientes, como: raios $\mathrm{X}$, mamografia, tomografia e ressonância magnética nuclear mostraram os tipos de perturbações que podem ser provocadas na rede elétrica, e suas conseqüências no funcionamento de outros equipamentos sensíveis instalados nesses locais.

Equipamentos de uso geral, instalados nesses estabelecimentos, acionados por motores elétricos, dependendo de sua potência e forma de utilização, também poderão gerar perturbações prejudiciais a outros equipamentos. 
Este estudo serviu como base para o desenvolvimento de uma metodologia que reproduzisse perturbações semelhantes, em fontes de tensão específicas para essa finalidade, instaladas no Laboratório de Qualidade de Energia da Escola Politécnica - Enerq-ct.

As IEM de baixa freqüência conduzidas pela rede elétrica, do tipo distorção harmônica de tensão, afundamentos e interrupções de curta duração, foram escolhidas pelos motivos apresentados no capítulo 1.

\subsection{INSTALAÇÕES ELÉTRICAS DOS ESTABELECIMENTOS ASSISTENCIAIS DE SAÚDE (EAS)}

Nos estabelecimentos visitados, sejam públicos ou do setor privado, em poucos se percebeu a preocupação com a qualidade e segurança das instalações elétricas. No capítulo 3 foram apresentados dois casos que confirmam esta afirmação. As pesquisas realizadas in loco constroem um panorama do estado atual das instalações elétricas nos EAS do País. Em muitos casos, bastante degradadas, essas instalações não atendem aos requisitos mínimos recomendados pelas normas técnicas da Associação Brasileira de Normas Técnicas, destacados a seguir. De modo geral, pode-se dizer que os problemas encontrados são similares, entre os quais, os mais freqüentes foram:

a) falta de identificação dos circuitos nos painéis de distribuição;

b) tomadas somente com dois pólos, demonstrando inexistência do condutor de proteção;

c) sistema de aterramento com configuração TN-C, não admitido em EAS, segundo a Norma NBR 13534;

d) grande quantidade de condutores elétricos sem cobertura, instalados de forma aparente, sem a preocupação com a danificação da isolação, contrariando os métodos de instalação apresentados na NBR 5410/2004; 
e) sistema de proteção contra descargas atmosféricas em desacordo com a Norma NBR 5419;

f) inexistência de desenhos e esquemas atualizados, dificultando os serviços de manutenção.

A maior parte desses casos não está relacionada somente à falta de recursos financeiros, mas sim, à falta de mão-de-obra qualificada e treinada.

Muitos eletricistas não possuem formação técnica e nem sequer conhecem as exigências da NR 10. Embora muitos não saibam, o treinamento tornou-se obrigatório a todos os profissionais envolvidos com eletricidade.

Apesar de o prazo para o treinamento ter se encerrado em 08 de dezembro de 2006, muitos EAS ainda não providenciaram para os seus funcionários o treinamento de 40 horas, que é o tempo mínimo exigido para a realização do curso básico.

$\mathrm{Na}$ grande maioria dos estabelecimentos visitados, inexiste um responsável pelas instalações e manutenção elétrica, com formação superior na área. Muitas decisões são tomadas pela própria administração dos hospitais, normalmente exercida por profissionais da área de saúde, que muitas vezes desconhecem os perigos do uso incorreto da eletricidade, tanto para os funcionários quanto para os pacientes que ali são submetidos à intervenção cirúrgica ou a tratamento de saúde.

No entanto, como comentado no capítulo 3, tais problemas relatados anteriormente constituem apenas uma "ponta do iceberg" visto que esta questão não é a única, considerando a existência de outros problemas nos EAS, tais como: falta de investimentos para aquisição de novos equipamentos; falta de mão-de-obra qualificada; falta de recursos para treinamentos; falta de recursos financeiros para aquisição de medicamentos; falta de capacidade para atendimento de pacientes; contaminação hospitalar, além de outros. Não restam dúvidas que esses problemas são relacionados à atividade principal dos EAS e normalmente recebem maior prioridade. Acredita-se, também, que muitas vezes as instalações elétricas não recebem o cuidado necessário em função das 
dificuldades que ocasionaria uma interrupção de energia, necessária aos serviços de manutenção ou reformas.

Pelas observações apresentadas, conclui-se que a aprovação do projeto e a aceitação da obra de um EAS pelo órgão competente, Anvisa, deverá ser bastante rígida, pois, depois de sua entrada em operação, serviços de atendimento a não conformidades tornam-se muito difíceis de serem realizados.

\subsection{EQUIPAMENTOS ELETROMÉDICOS}

A medicina moderna vem cada vez mais utilizando equipamentos com tecnologia eletrônica totalmente microprocessados e extremamente sensíveis às perturbações existentes nos sistemas elétricos atuais.

Os profissionais da área da saúde habituaram-se a confiar nesses equipamentos, tomando decisões baseadas nas informações por eles fornecidas, sem imaginar que, muitas vezes, poderão fornecer resultados incorretos em função das péssimas condições das instalações elétricas e da baixa qualidade da energia elétrica de suprimento.

Normalmente, encontram-se equipamentos com tecnologia de ponta instalados em EAS e que, no entanto, não atendem ao mínimo das exigências normativas. Outro risco existente, e conseqüentemente fatal, está relacionado à interrupção ou travamento de equipamentos de sustentação de vida, normalmente utilizados nas unidades de terapia intensiva como, por exemplo, os ventiladores pulmonares.

A demora no atendimento para eliminação do defeito e o tempo envolvido na nova parametrização são fatores que poderão ocasionar inclusive o óbito do paciente. $\mathrm{Na}$ análise de equipamentos utilizados em EAS, este trabalho apresenta falhas, do tipo travamento, em um ventilador pulmonar de fabricação nacional quando submetido a afundamentos e interrupções de tensão de curta duração. 
O fabricante do ventilador pulmonar acompanhou os resultados e demonstrou interesse em solucionar o problema, embora, na época em que foi realizada a pesquisa de campo, a norma específica para esse tipo de equipamento ainda não solicitasse esse ensaio. Após intensivos testes, concluiu-se que a principal causa do problema estava na fonte de alimentação, cujo sistema de transferência para a bateria interna era realizado por meio de relé eletromagnético (offline).

O tempo necessário para a transferência, neste caso, era superior ao tempo de duração dos afundamentos de tensão de curta duração gerados, e o restabelecimento da alimentação da rede elétrica produzia os travamentos mencionados no capítulo 6 . Novos testes foram feitos no mesmo equipamento após a substituição do tipo de fonte para um modelo online, desde então, a bateria passou a permanecer permanentemente conectada e o problema parece ter desaparecido.

Observa-se, portanto, a contribuição prestada ao fabricante do equipamento que não imaginava que falhas desse tipo pudessem ocorrer durante os afundamentos ou interrupções de tensão de curta duração.

Outros equipamentos, como: oxímetro de pulso e monitor multiparamétrico, embora não sendo equipamentos de sustentação de vida, também apresentaram problemas e seus fabricantes foram comunicados.

A partir de setembro de 2006, a nova edição da Norma NBR IEC 60601-1-2 incluiu, entre os ensaios obrigatórios, o de imunidade aos afundamentos e interrupções de tensão de curta duração e, o de limites de emissão de harmônicos de corrente. No entanto, os fabricantes alegam possuírem dificuldades de atendimento à nova edição, as quais são mencionadas por Marroni (2007).

Nesse caso, questiona-se como devem ficar as certificações fornecidas pelo Inmetro, para que a Anvisa autorize a comercialização dos equipamentos. 


\subsection{RELIGAMENTO DE CIRCUITOS DE DISTRIBUIÇÃO}

As concessionárias, preocupadas com a redução das interrupções permanentes de energia elétrica, vêm utilizando religadores ou disjuntores com capacidade para re-energização da rede elétrica em caso de defeitos temporários.

Essa prática tem reduzido a duração das interrupções desnecessárias, convertendo-se em benefícios para os consumidores, e para as concessionárias significa melhora nos valores de seus indicadores de continuidade. Esses equipamentos podem ser instalados tanto em subestações quanto em circuitos de distribuição, basicamente em redes aéreas com circuitos radiais.

Normalmente, os religadores são projetados para uma seqüência de religamentos de até quatro operações, mas, caso a falta persista, uma operação final de abertura bloqueará a seqüência.

Na primeira operação, denominada de instantânea, o tempo de interrupção de energia dependerá das características construtivas do disjuntor e da tecnologia de extinção do arco elétrico. No Brasil, é uma prática comum a existência de disjuntores associados a relés de religamento, operando como religadores. Quatro tipos de tecnologias para extinção do arco elétrico são utilizados nos disjuntores: óleo mineral, ar atmosférico, hexafluoreto de enxofre e vácuo.

Dependendo do meio extintor, a distância entre os contatos do disjuntor na posição aberta é característica fundamental para o isolamento da rede elétrica.

Quanto maior essa distância, maior será o tempo necessário ao religamento. Todos os tempos necessários ao primeiro religamento, para as várias tecnologias existentes, mostram que se encontram na faixa crítica e podem provocar falhas no funcionamento de equipamentos eletromédicos, principalmente nos ventiladores pulmonares. Cabe então, para circuitos contendo EAS, uma reavaliação desse conceito de proteção, considerando o religamento do circuito e o restabelecimento de energia por parte das concessionárias, pois, muitas vezes, a interrupção permanente de energia poderá ser menos prejudicial que religamentos rápidos. Uma preocupação com 
ajuste do "tempo morto" poderia evitar a ocorrência de falhas nestes equipamentos eletromédicos.

\subsection{NORMALIZAÇÃO}

A Norma NBR 13534, publicada em novembro de 1995 foi atualizada. A segunda edição foi publicada em 28 de janeiro de 2008 e entrou em vigor seis meses depois. Um dos grandes avanços técnicos dessa norma foi 0 reconhecimento de que certos equipamentos eletromédicos, principalmente os microprocessados, podem apresentar falhas em seu funcionamento quando submetidos a afundamentos e interrupções de tensão de curta duração.

Considerando esse fato, a norma incluiu na tabela AA.101 - Classificação dos serviços de segurança necessários em locais médicos, apresentada no capítulo 4, as classes:

0 - alimentação disponível sem interrupção;

0,15 - alimentação disponível automaticamente em até $0,15 \mathrm{~s}$;

No entanto, quem definiria estas classes, uma vez que os fabricantes desconhecem o comportamento de seus equipamentos quando submetidos a estas perturbações?

A nova edição da Norma NBR 13534 considera apenas: falta de tensão, mencionada no item 6.6.6.102.1 e, queda de tensão, mencionada no item 6.6.6.102.2. Afundamentos e interrupções de tensão de curta duração não são mencionados, no entanto, podem provocar falhas em equipamentos eletromédicos.

Outra preocupação seria em relação aos EAS existentes e que não atendem nem à primeira edição de 1995 desta norma. Mas, qual seria o prazo para adequação à segunda edição? 
A nova edição também não incluiu informações sobre os limites de harmônicos de tensão e de corrente nas instalações elétricas dos EAS, fato que também poderá levar ao mau funcionamento de alguns equipamentos, como foi verificado neste trabalho.

A Norma NBR 5410 - Instalações Elétricas de Baixa Tensão, mesmo em sua última edição que entrou em vigor em 2005, não menciona requisitos para a instalação elétrica de equipamentos de raios $X$ e outros cuja elevada potência solicitada durante um curto intervalo de tempo provoca as perturbações que foram apresentadas. A seção 6.5 dessa norma, com denominação de Outros componentes, apresenta somente prescrições específicas para circuitos que alimentam motores elétricos, baterias de acumuladores e tomadas de corrente. Em decorrência da ausência dessas informações, não seria conveniente incluir na nova edição da NBR 13534 requisitos para instalações elétricas desses equipamentos, de forma a evitar que eles prejudiquem os equipamentos eletromédicos, instalados em EAS?

A série de Normas IEC 60601, adotada no Brasil como NBR IEC 60601, omitese com relação às prescrições de cuidados necessários à análise de dados incorretos ou de falha de equipamentos mediante a falta de qualidade de energia elétrica, relacionadas às perturbações às quais os equipamentos foram submetidos, conforme apresenta este trabalho.

Orientada pela norma geral, a série de normas supracitada aborda somente interrupção de energia e alarmes de segurança. Conclui-se, que essas normas oferecem uma garantia de segurança para os operadores de equipamentos eletromédicos, no entanto, para a segurança dos pacientes, as normas ainda precisam evoluir.

Como mencionado no capítulo 6, perturbações oriundas da rede elétrica dos EAS poderão causar danos irreversíveis a pacientes submetidos a intervenções cirúrgicas ou a tratamentos médicos. 


\subsection{FISCALIZAÇÃO DOS EAS}

A Anvisa é o órgão responsável pela aprovação dos projetos de EAS, cujas diretrizes constam na resolução RDC ํo 50 .

O referido regulamento técnico destina-se ao planejamento, programação, elaboração, avaliação e aprovação de projetos físicos de EAS, com abrangência em todo o território nacional, tanto na área pública quanto privada, compreendendo:

a) as construções novas;

b) áreas a serem ampliadas em EAS já existentes;

c) reformas de EAS já existentes e prédios que anteriormente não eram destinados à área de saúde.

No entanto, a Anvisa não possui um corpo técnico específico para vistoria das instalações elétricas, por isso, a aprovação ao término da obra fica condicionada à apresentação de um laudo elétrico, elaborado, na maioria das vezes, por profissionais da área de eletricidade.

\subsection{HOME CARE}

Esta modalidade de atendimento à saúde, prestada na residência do paciente, vem aumentando em todo o mundo, inclusive no Brasil, em função das inúmeras vantagens que já foram apresentadas. No entanto, instalações envolvendo equipamentos eletromédicos sensíveis devem ficar condicionadas à vistoria das instalações elétricas antes da entrada em funcionamento. Neste caso, a concessionária também deverá ser comunicada, evitando desligamentos da energia elétrica, bem como a operação de religadores. 


\subsection{COMENTÁRIOS}

\subsubsection{Literatura Técnica a Respeito do Assunto}

Temas envolvendo a "Qualidade de Energia Elétrica em EAS" não são encontrados com facilidade, talvez em função do pequeno número de profissionais interessados nessa área de pesquisa. No entanto, uma grande quantidade de publicações a respeito do mesmo assunto, em aplicações industriais, comerciais e de serviços, encontra-se disponível em anais de congressos ou na literatura especializada. Este último fato foi um dos motivos que levou o autor a desenvolver este trabalho.

\subsubsection{Dificuldades Encontradas}

Durante a realização deste trabalho, várias dificuldades foram encontradas, entre as quais pode-se destacar:

a) inexistência de normas específicas sobre o comportamento de equipamentos eletromédicos quando submetidos às perturbações existentes nos próprios ambientes onde se encontram instalados;

b) comportamento diversificado em função da tecnologia de fabricação, o que dificulta a aplicação de ensaios padronizados para todos os tipos de equipamentos eletromédicos;

c) muitos fabricantes não quiseram ceder seus equipamentos para testes, com receio de que fossem encontrados problemas que pudessem gerar implicações com a justiça, devido a acidentes ocasionados pelo mau funcionamento desses equipamentos;

d) autorização para se efetuar medições em EAS com o objetivo da determinar as cargas poluidoras que degradam a qualidade de energia elétrica;

e) permissão para realização de vistorias nas instalações elétricas nos ambientes visitados na pesquisa de campo, como forma de verificação do atendimento às normas pertinentes. 
Pode-se justificar as dificuldades mencionadas nos dois últimos itens acima devido ao fato que, na maioria das vezes, os EAS são de propriedade ou administrados por profissionais da área de saúde que, na maioria dos casos, não possuem entendimento sobre o assunto apresentado e, portanto, não dão o devido valor às contribuições recebidas com os resultados desta pesquisa.

\subsubsection{Continuidade das Pesquisas}

Deixa-se como sugestão para continuidade deste trabalho:

a) aplicação de testes envolvendo as perturbações que aqui não foram estudadas, tais como: elevação momentânea de tensão (swell), flutuações de tensão (flicker), entre outras;

b) testes envolvendo outros equipamentos eletromédicos, que aqui não foram considerados;

c) testes envolvendo equipamentos de ultrassonografia e outros de diagnóstico por imagem;

d) verificação do comportamento dos equipamentos de diagnóstico por imagem de grande potência, instalados em EAS, quando submetidos às perturbações por eles provocadas;

e) projeto e desenvolvimento de condicionadores ativos de energia para serem utilizados na alimentação de equipamentos eletromédicos portáteis, utilizados na assistência à saúde de pacientes internados em suas residências. A finalidade desses equipamentos seria evitar que eventuais perturbações conduzidas pela rede elétrica da concessionária produzam falhas nos equipamentos eletromédicos, principalmente naqueles de sustentação de vida. 


\section{REFERÊNCIAS}

ABREU, J. P. et al. Medidas para reduzir o impacto de depressões de tensão na produção. Revista Eletricidade Moderna. São Paulo: Aranda Editora. n. 300, p.100106, mar. 1999.

ACTIVE POWER. Power quality for healthcare facilities using flywheel energy storage. Disponível em: $<$ http://www.touchbriefings.com/download.cfm?filelD=2401>. Acesso em: 10 nov. 2008.

AGÊNCIA NACIONAL DE ENERGIA ELÉTRICA. PRODIST - Procedimentos de distribuição de energia elétrica no sistema elétrico nacional. Módulo 8 Qualidade de Energia Elétrica. Brasília, 2008. 53 p.

AGÊNCIA NACIONAL DE ENERGIA ELÉTRICA. Resolução n. 24 - Disposições relativas à continuidade da distribuição de energia elétrica às unidades consumidoras. Brasília, 2000. 19 p.

AGÊNCIA NACIONAL DE ENERGIA ELÉTRICA. Resolução n. 505 - Disposições relativas à conformidade dos níveis de tensão de energia elétrica em regime permanente. Brasília, 2001. $15 \mathrm{p}$.

AGÊNCIA NACIONAL DE VIGILÂNCIA SANITÁRIA - ANVISA. Aspectos de segurança na utilização de equipamentos eletromédicos. Boletim informativo de tecnovigilância. Brasília, abr. 2004. 
AGÊNCIA NACIONAL DE VIGILÂNCIA SANITÁRIA - ANVISA. RDC 50 Regulamento Técnico para planejamento, programação, elaboração e avaliação de projetos físicos de estabelecimentos assistenciais de saúde. Brasília, p.137, 2002. $144 \mathrm{p}$.

AGÊNCIA NACIONAL DE VIGILÂNCIA SANITÁRIA. Disponível em: $<$ http://www.anvisa.gov.br/institucional/anvisa/apresentacao.htm> . Acesso em: 10 fev. 2005.

ALDABÓ, R. Qualidade na energia elétrica. São Paulo: Artliber Editora, 2001. p. 49.

ALVES, M. F. Qualidade de energia e o impacto sobre o sistema consumidor. Revista Eletricidade Moderna. São Paulo: Aranda Editora, n. 267, p.109-116, jun.1996.

AMARO JR. E.; YAMASHITA, H. Aspectos básicos de tomografia computadorizada e ressonância magnética. Revista Brasileira de Psiquiatria. São Paulo, v. 23, 2001.

AMERICAN NATIONAL STANDARD INSTITUTE. ANSI/IEEE C57.110: Recommended practice for establishing transformer capability when supplying nonsinusoidal load currents. New York, 1986. 14 p.

ASSOCIAÇÃO BRASILEIRA DE NORMAS TÉCNICAS. NBR 5410: Instalações Elétricas de Baixa Tensão. Rio de Janeiro, 2004. 208 p.

NBR 13249: Cabos e cordões flexíveis para tensões até $750 \mathrm{~V}$. Especificação. Rio de Janeiro, 2000. 14 p.

NBR 13534: Requisitos específicos para instalação em Estabelecimentos Assistenciais de Saúde. Rio de Janeiro, 2008. 21 p. 
NBR 14039: Instalações elétricas de média tensão (de 1,0 kV a 36,2 kV). Rio de Janeiro, 2005. 87 p.

- NBR 7094: Máquinas elétricas girantes - motores de indução especificação. Rio de Janeiro, 1996. 50 p. Emenda, 2000. 5 p.

NBR IEC 60439-1: Conjuntos de manobra e controle de baixa tensão Parte 1. Rio de Janeiro, 2003. $76 \mathrm{p}$.

NBR IEC 60601-1: Equipamento eletromédico. Parte 1: Prescrições gerais para segurança. 1. ed. Rio de Janeiro, 1994. 149 p. Emenda, 1997, 33 p.

. NBR IEC 60601-1-2: Equipamento eletromédico. Parte 1-2: Prescrições gerais para segurança - Norma colateral: Compatibilidade eletromagnética Prescrições e ensaios. Rio de Janeiro, 2006. 93 p.

NBR IEC 60601-2-12: Equipamento eletromédico. Parte 2-12: Prescrições particulares para segurança de ventilador pulmonar - ventiladores para cuidados críticos. Rio de Janeiro, 2004. 40 p.

NBR IEC 60601-2-49: Equipamento eletromédico. Parte 2-49: Prescrições particulares para segurança de equipamento para monitorização multiparamétrica de paciente. Rio de Janeiro, 2003. 34 p.

. NBR NM 247 - 3: Cabos isolados com policloreto de polivinila (PVC) para tensões nominais até 450/750V, inclusive. Parte 3: Condutores isolados (sem cobertura). Rio de Janeiro, 2002. 3 p.

ATLAS. Segurança e medicina do trabalho. 63. ed. São Paulo: Equipe Atlas, 2009. p. 108. 
BARBOSA, M. A. Soluções para os problemas causados por retificadores de potência. Revista Eletricidade Moderna. São Paulo: Aranda Editora. n. 252, p. 2636, mar. 1995.

BETTEGA, E.; FIORINA, J. N. Active harmonic conditioners and unity power factor rectifiers. Cahier Technique Merlin Gerin. Grenoble, France, 1999. n.183. p.32.

BOLLEN, M. H. J. Understanding power quality problems: voltage sags and interruptions. New York: IEEE, p. 3, 21-22, 139-251, 2000.

BOLLINGER, F. Harmônicas em instalações de computadores: casos reais e recomendações. Revista Eletricidade Moderna. São Paulo: Aranda Editora, n. 206, p.24-28, maio 1991.

BONATTO, B. D. et al. Aplicação tecnológica de equipamento de condicionamento de energia elétrica. In: V SBQEE - SEMINÁRIO BRASILEIRO DE QUALIDADE DE ENERGIA ELÉTRICA. Anais... Aracaju, 2003.

BRUNSICKLE, W. E.; LUCKJIFF, G. A.; SCHNEIDER, R. S.; MCGRANAGHAN, M. F. Dynamic sag correctors: cost-effective industrial power line conditioning. New York: IEEE Transactions on Industry Application, v. 37, n. 1 p. 212-217, Jan./Feb. 2001.

CALDON, R.; FAURI, M.; FELLIN, L. Voltage sag effects on continuos industrial processes: desensitizing study for textile manufacture. In: SECOND INTERNATIONAL CONFERENCE ON POWER QUALITY: End-use Applications and Perspectives. Study Committee 36 Coloquium and Meetings. Anais... Atlanta, 1992. p. D13.1-D13.6. 
CALIL, S. J. et al. Equipamentos médico-hospitalares e o gerenciamento da manutenção. Ministério da Saúde. Brasília, p. 9, 345-357, 471-490, 491-504, 653682, 683-720, 2002.

CARPINELLI, G. Some considerations on probabilistic aspects and harmonic standards. In: NINTH INTERNATIONAL CONFERENCE ON HARMONICS AND QUALITY OF POWER. Anais... Orlando, v. 1, p. 254-256. Digital Object Identifier: 10.1109/ICHQP.2000.897034, 2000.

CONRAD, L. E. IEEE Std 493. The Gold Book. IEEE. New York, v. 30, n. 3, p. 805821, May 1994.

COPPER DEVELOPMENT ASSOCIATION INC. A power quality primer. Disponível em: <http://www.copper.org/applications/electrical/pg/primer.html>. Acesso em: 10 jan. 2008.

COSTA, P. F. Aterramento do neutro dos sistemas de distribuição brasileiros uma proposta de mudança. 1995. 106 p. Dissertação (Mestrado). UFMG Universidade Federal de Minas Gerais, Belo Horizonte, 1995.

COTRIM, A. A. M. B. Instalações Elétricas. 2. ed. São Paulo: Makron Books, 1993. p. 371-378.

CRESTANI, M.S. A constante evolução dos acionamentos. Revista Eletricidade Moderna. São Paulo: Aranda Editora, n. 375, p. 6, jun. 2005.

DECKMANN, S.M. Nova abordagem para atenuação do efeito flicker nas redes. Revista Eletricidade Moderna. São Paulo: Aranda Editora, n. 326, p.112-121, maio 2001. 
DOUGHERTY, J.G.; STEBBINS, W.L. Power Quality: a utility and industry perspective. In: TEXTILE, FIBER UND FILM INDUSTRY TECHNICAL CONFERENCE. IEEE: Annual 6-8 May 1997. p. 5. 10 p. New York. DOI 10.1109/TEXCON.1997.598528.

DRANETZ BMI. Handbook of Power Signatures. Edison, NJ, USA. 1997. Chapter 3. p. 66-72: 8800 Power Scope Graphs. Chapter 4. p.111-118: 8010 PQNode Graphs. Chapter 5. p.209- 220: 4800 Power Scope Graphs.

. Power Quality Analysis. Edison, NJ, USA. 1998. Chapter 1. p. 13, 51-53:

Fundamentals of Power Quality. Chapter 3. p. 144: Waveforms. Chapter 5. p. 235 : Case Studies.

DUGAN, R. C.; MCGRANAGHAN, M. F.; BEATY, H. W. Electrical Power Systems Quality. New York: McGraw-Hill, p.15,16, 48, 50, 130, 132, 1996.

EL-HABROUK, M.; DARWISH, M.K.; MEHTA, P. Active Power Filters: a review. IEEE Proceedings of Electric Power Applications. New York, v.147, n.5. p.403413, Sept. 2000.

ELSPEC. Disponível em: <www.açaoenge.com.br >. Acesso em: 20 fev. 2007.

EMANUEL, A. E.; ORR, J. A.; CYGANSKI, D. A survey of harmonic voltages, currentes at the customer's bus. IEEE Transactions on Power Delivery. New York, v.8, n.1, p.411-421, Jan. 1993.

EUROPEAN COMMUNITTEE FOR ELECTROTECHNICAL STANDARDIZATION. EN 50160: Voltagem characteristics of electricity supplied by public distribution systems. Brussels, 1994. 
EUROPEAN STANDARD. EN 794-1: Lung ventilators. Part 1: Particular requirements for critical care ventilators (includes Amendment A1: 2000). Berlin, 1997. 48 p.

FERREIRA, C. A. et al. Detailed study of a $30-40 \mathrm{~kW}$ switched reluctance startes/generator for a gas turbine engine application. IEEE Transactions on Industry Applications. New York, v. 31, p. 553-561, 1995.

FIORINA, J. N. Inverters and harmonics - case studies of non-linear loads. Cahier Technique Merlin Gerin. Grenoble, p. 5. n. 159, Sept. 1993.

GALASSI, M. Projeto e construção de um restaurador dinâmico de tensão. 2006. 116 p. Dissertação (Mestrado). EPUSP - Escola Politécnica da Universidade de São Paulo, São Paulo, 2006. p. 11, 23.

GARCIA, F. R.; PEEL, M.; GURLASKIE, G. Aplicação de equipamentos a base de eletrônica de potência. In: III SBQEE - SEMINÁRIO BRASILEIRO DE QUALIDADE DE ENERGIA ELÉTRICA. Anais... Brasília, 1999.

GRUZS, T. M. A survey of neutral currente in three-phase computer power systems. IEEE Transactions on Industry Applications. New York, v. 26, n. 4, p. 719-725, July/Aug. 1990.

HARVEY, J. et al. Electrical Power Distribution System. IEEE Recommended Pratice for Electric Systems in Health Care Facilities. New York: IEEE Press Marketing, p. 39-90,1997.

HEINRICH, H. J. Compensação dinâmica de reativos em aplicações de baixa tensão. Revista Der Elektro und Gebäudetechniker. Maio 2006. Disponível em $<$ www.de-online.de $>$. Acesso em: 10 jan. 2006. 
HEINTEL, R. E.; CREDICO, J. Medical equipment and instrumentation. IEEE Recommended Pratice for Electric Systems in Health Care Facilities. New York: IEEE Press Marketing, p.341-394, 1997.

HOFFMANN, B. Notícias Hospitalares. №40, Ano 4, mar./abr.2003. Disponível em $<$ http://www.noticiashospitalares.com.br/mar2003/pgs/emdia.htm>. Acesso em: 11 fev. 2009.

INSTITUTE OF ELECTRICAL AND ELECTRONICS ENGINEERS. IEEE Std. 446: Recommended Practice for Emergency and Stand-by Power Systems for Industrial and Comercial Aplications. IEEE Orange Book. New York, 1995. 320 p.

. IEEE Std. 519: Recommended Practices and Requirements for Harmonic Control in Electrical Power Systems. New York, 1992. 112 p.

IEEE Std. 602: Recommended Practice for Electric Systems in Health Care Facilities. IEEE White Book. New York, 2007. 482 p.

. IEEE Std. 1159: Recommended Practice for Monitoring Electric Power Quality. New York, p. 21. 1995. 70 p.

Probabilistic aspects task force of harmonics working group: Time-varying harmonics. Part I: Caracterizing measured data. IEEE Transactions on Power Delivery. n. 3, New York, p. 938-944, July 1998.

. Probabilistic aspects task force of harmonics working group: Time-varying harmonics. Part II: Harmonic summation and propagation. IEEE Transactions on Power Delivery. New York, 1998. 
INTERNATIONAL ELECTROTECHNICAL COMISSION. IEC 60050-161: International Electrotechnical Vocabulary. Chapter 161: Electromagnetic Compatibility. Geneva, Aug. 1990. 73 p.

. IEC 60146-1-1: Semiconductor convertors; general requirements and line commutated convertors. Part 1-1: Specifications of basic requirements. Geneva, 1996. $3 \mathrm{p}$.

. IEC 60364: Electrical Installations of Buildings. Part 7-710: Requirements for special installations or locations - Medical locations. Geneva, 2002. 39 p.

. IEC 60601-1: Medical electrical equipment. Part 1: General requirements for safety. Geneva, 1988. p. 349.

. IEC 60601-1-8: Medical electrical equipment. Part 1-8: General requirements for basic safety and essential performance - Collateral Standard: General requirements, tests and guidance for alarm systems in medical electrical equipment and medical electrical systems. 1. ed. Geneva, 2003, 155 p. Emenda, $2006.11 \mathrm{p}$.

. IEC 60601-2-12: Medical electrical equipment. Part 2-12: Particular requirements for the safety of lung ventilators - Critical care ventilators. Geneva, 2001. $38 \mathrm{p}$.

. IEC 60601-2-49: Medical electrical equipment. Part 2-49: Particular requirements for the safety of multifunction patient monitoring equipment. Geneva, 2006. $93 \mathrm{p}$.

IEC 61000-3-2: Consolidated Edition Electromagnetic Compatibility (EMC).

Part 3-2: Limits for harmonic currente emission in low-voltage supply systems for equipment with rated currente £ 16 A. Geneva, 2005. 57 p. 
. IEC 61000-3-4: Electromagnetic compatibility (EMC). Part 3-4: Limitation of emission of harmonic currents in low-voltage power supply systems for equipment with rated current greater than 16 A. Geneva, 1998. $29 \mathrm{p}$.

IEC 61000-3-6: Eletromagnetic compatibility (EMC). Part 3: Limits Seccion 6: Assessment of emission limits for distorting loads in MV and HV power systems - Basic EMC publication. Geneva, 1996. 58 p.

. IEC 61000-4-11: Testing and Measurement Techniques - voltage dips, short interruptions and voltage variations immunity tests. Geneva, 2000. 43 p.

IEC 61000-4-30: Testing and Measurement Techniques - Power quality measurement methods. Geneva, 2008. 40 p.

IEC 61010-1: Safety requirements for electrical equipment for measurement, control, and laboratory use. Part 1: General requirements. Geneva, 1990. 94 p.

INTERNATIONAL ORGANIZATION FOR STANDARDIZATION. ISO 9919: Medical electrical equipment - Particular requirements for the basic safety and essential performance of pulse oximeter. Geneva, 2005. 81 p.

KEEBLER, P. Power Quality for Healthcare Facilities. EPRI - Electric Power Research Institute. 2007. Disponível em: <http://www.leonardo-energy.org>. Acesso em: set. 2008. 24 p.

KINDERMANN, G. Choque Elétrico. Porto Alegre: Sagra Luzatto, p. 28-36, 1995.

KLINGER, S.; OTTO, F.; RADTKE, H. J. Tailor-made solutions in response to increased demands on supply quality. In: 17th CIRED - INTERNATIONAL CONFERENCE ON ELECTRICITY DISTRIBUTION. Barcelona, 2003. 
KOJOVIC, L. J.; HASSLER, S. Application of currente limiting fuses in distribution systems for improved power quality and protection. IEEE Transactions on Power Delivery. New York, v.12, n. 2, p.791-800, Apr. 1997.

KUSKO, A. Design of Power Harmonic Filters. In: POWER QUALITY CONFERENCE. Paris, p.339-346. Nov. 1990.

KUSKO, A.; THOMPSON, M.T. Power Quality in Electrical Systems. New York: McGraw Hill, p.18-20, 75-98, 120-122, 129-141, 2007.

LEBORGNE, R. C. Uma contribuição à caracterização da sensibilidade de processos industriais frente a afundamentos de tensão. 2003. 142 p. Dissertação (Mestrado). Universidade Federal de Itajubá, Itajubá, p. 72-89, 2003.

LEE, G.; ALBU, M.; HEYDT, G. A Power Quality Index Based on Equipment Sensivity, Cost and Network Vulnerability. IEEE Transactions on Power Delivery. New York, v.19, n.3, p.1504-1510, July 2004.

LELES FILHO, A. F.; OLIVEIRA, M.A.; COSTA, A.G.V. Metodologia de análise de variações momentâneas de tensão em sistemas elétricos de potência. In: VI SBQEE - SEMINÁRIO BRASILEIRO DE QUALIDADE DE ENERGIA ELÉTRICA. Anais... Belém, 2005.

MARRONI, A. C. O que há de novo na NBR IEC 60601-1-2. Disponível em: $<$ http://banasmetrologia.com.br/textos. asp?codigo=1955\&secão=revista $>$. Acesso em: 20 jan. 2007.6 p.

MARRONI, A. C. Problemas de segurança e desempenho em equipamentos eletromédicos associados aos diferentes padrões de alimentação elétrica. 2005. 121 p. Dissertação (Mestrado). Escola Politécnica da Universidade de São Paulo, São Paulo, p. 2-4, 2005. 
MARTINON, J.; POISSON, O. ; DE CHATEAUVIEUX, F. Conhecendo melhor os afundamentos de tensão e as interrupções momentâneas. Revista Eletricidade Moderna. São Paulo: Aranda Editora, n. 315, p. 66-78, Jun. 2000.

MATAKAS JR., L. et al. Mini-DVR - Dynamic voltage restorer with functions of reactive compensation and active harmonic filters. In: IEEE/PES Transmission and Distribution Conference - Latin America. São Paulo, 2004.

MCGRANAGHAN, M. F. Overview of Power Quality Standard. Disponível em: $<$ www.pqnet.eletrotek.com/pqnet/main/standard/paper/overview.htm>. Acesso em: 15 fev. 2005.

MCGRANAGHAN, M. F.; MUELLER D. R.; SAMOTEJ, M. J. Voltage Sags in Industrial Systems. IEEE Transactions on Industry Applications. New York, v. 29, n. 2, p. 397-403, Mar. 1993.

MIGUEL, A.A.P; MEDINA, N.B.; ANTÓN, M.L. La amenaza de los armónicos y sus soluciones. Madrid: Editora Centro Espanõl de Información del Cobre, p.19-38, 142145, 2007.

MUEDRA; V. S. J. Atlas de Anatomia Humana. Rio de Janeiro: Editora ÍberoAmericano Ltda, Série E, n.1, 1970.

NAGAI, S. E.; OLIVEIRA JR, N.; ABREU, J. P. G. A influência dos soft-starters na qualidade da energia elétrica. In: III SBQEE - SEMINÁRIO BRASILEIRO DE QUALIDADE DE ENERGIA ELÉTRICA. Anais... Brasília, Editora Íbero-Americano Ltda.

ONG, S. J. B.; YEONG, J. C. An overwiew of international harmonics standards and guidelines (IEEE, IEC, EN, ER, and STC) for low voltages system. In: 8th IPEC - 
INTERNATIONAL POWER ENGINEERING CONFERENCE. Anais... Singapore, p. 602-607, 2007.

PHIPPS, J.; NELSON, J.; SEM, P. Power quality and harmonic distortion on distribution systems. IEEE Transactions on Industry Applications. New York, v. 30, n. 2, p. 476-484, Mar./Apr.1994.

PINTO, A. L. T. et al. Segurança e medicina do trabalho. São Paulo: Saraiva, p.188-202, 2008.

PIRES NETO; F. M. et al. Telecomando e monitoramento de religadoras automáticas via comunicação celular. In: XV SENDI - SEMINÁRIO NACIONAL DE DISTRIBUIÇÃO DE ENERGIA ELÉTRICA. Anais... Salvador, 2002.

POMIGLIO, J. A. Harmônicos. O Setor Elétrico. São Paulo: Atitude Editorial Ltda. n. 3, p.18-23, abr. 2006.

PRAVEEN, J. et al. Review of dynamic voltage restorer for quality Improvement. In: IEEE INDUSTRIAL ELECTRONICS SOCIETY ANNUAL CONFERENCE. New York, v.1. p.749-754, 2004.

PROGRAMA NACIONAL DE CONSERVAÇÃO DE ENERGIA ELÉTRICA PROCEL. Guia Operacional de Motores Elétricos. Brasília, 1998.

RAMIREZ, E. F. F. Metodologia de priorização de equipamentos médicos para programas de manutenção preventiva em hospitais. 1996. 165 p. Dissertação (Mestrado). Unicamp - Universidade Estadual de Campinas, Campinas, 1996.

RIBEIRO, E. R. Filtros Ativos Série para Compensação de Harmônicas de Tensão. 2003. 213 p. Tese (Doutorado). UFSC - Universidade Federal de Santa Catarina. Florianópolis, p.1-2, 6-18, 2003. 
RIBEIRO, P. F. An overview of probabilistic aspects of harmonics: state of the art and new developments. IEEE Power Engineering Society General Metting. New York, v. 3, p. 2243-2246, June, 2005. Digital Object Identifier: 10.1109/PES.2005.1489555.

ROBERTS, J.; ALTUVE, H. J.; HOU, D. Análise dos métodos de proteção contra faltas à terra nos sistemas da distribuição aterrados, não aterrados e compensados. Schweitzer Engineering Laboratories Inc. Pullmann, WA, USA, p.78, 2001. Disponível em: <www.selinc.com.br >. Acesso em: 20 jun. 2008.

ROSSA, A. J.; TORRI, P.J. Fator de potência e distorção harmônica em instalações com conversores de freqüência. Revista Eletricidade Moderna. São Paulo: n. 316, p. 38-57, Aranda Editora, 2000.

SANTANA, C. J. R. Instalações elétricas hospitalares. 2. ed. Porto Alegre: Editora Pontifícia Universidade Católica do Rio Grande do Sul, p.11, 25-26, 149, 1999.

SCHONEK, J. The singularities of the third harmonic. Cahier Technique Merlin Gerin. Grenoble, p.11. n. 202, Feb. 2001.

SERSEN, E.; VORSIC, J. Quality of electricy supply as a service. In: ICREPQ INTERNATIONAL CONFERENCE ON RENEWABLE ENERGIES AND POWER QUALITY. Valencia, 2009. Disponível em: <http://www.icrepq.com/icrepq-08/235sersen.pdf $>$ Acesso em: 10 nov. 2008. 6 p.

SILVA NETO, J.L. et al. Compensador dinâmico de afundamentos de tensão com armazenamento cinético de energia. In: XVII SNPTEE - SEMINÁRIO NACIONAL DE PRODUÇÃO E TRANSMISSÃO DE ENERGIA ELÉTRICA. Anais... Uberlândia, 2003. 
SILVA, S. M. Estudo e projeto de um restaurador dinâmico de tensão. 1999. 196

p. Dissertação (Mestrado). UFMG - Universidade Federal de Minas Gerais, Belo Horizonte, 1999.

SILVEIRA, M. Qualidade de energia elétrica em estabelecimentos assistenciais de saúde. 2002. 141 p. Dissertação (Mestrado). Universidade Salvador. Salvador, p.3,10,51, 2002.

SINGH, B.; AL-HADDAD, K.; CHANDRA, A. A review of active filters for power quality improvement. IEEE Transactions on Industrial Electronics. New York, v. 46, n. 5, p. 960-971, Oct.1999.

SOUZA, F.P. Correção do fator de potência para instalações de baixa potência empregando filtros ativos. 2000. 210 p. Tese (Doutorado). UFSC - Universidade Federal de Santa Catarina, Florianópolis, 2000.

STAROSTA, J. Medições em instalações elétricas: quantidade x qualidade. $\mathbf{O}$ Setor Elétrico. São Paulo: Atitude Editorial Ltda. n. 23, p. 64-70, dez. 2007.

THOMAS, S. K.; LAI, J. S. Comparison of Standards and Power Supply Design Options for Limiting Harmonic Distortion in Power Systems. IEEE Transactions on Industry Applications. New York, v. 29, n. 4, p. 688-695, July/Aug. 1993.

UNIMED. Home Care. Disponível em: <http://www.unimedrc.com.br> Acesso em: 11 fev. 2009.

VOLLKOMMER, H. Complexo industrial tem energia premium. Revista Eletricidade Moderna. São Paulo: Aranda Editora. n. 307, p. 66, out. 1999.

WEISSBACH, R. S.; KARADY, G. G.; FARMER, A. G. A combined uninterruptible power suply and dymamic voltage compensator using a flywheel energy storage 
system. IEEE transactions on Power Delivery. New York, v. 16, n. 2, p. 265-270, 2001.

WILLHEIM, R; WATERS, M. Neutral grounding in high voltage transmission. New York: Elsevier Publishing Company, 1956.

WINTER, K. M. Swedish distribution networks - a new method for earthfault protection in cable and overhead systems. In: THE FIFTH INTERNATIONAL CONFERENCE ON DEVELOPMENTS IN POWER SYSTEM PROTECTION. York, IEEE Conference Publications no 368. p. 268-270, 1993. 


\section{ANEXO A - CONCEITOS SOBRE HARMÔNICOS}

Harmônicos são tensões ou correntes senoidais que possuem freqüências múltiplas da freqüência para a qual o sistema está designado a operar, denominada de fundamental, normalmente $50 \mathrm{~Hz}$ ou $60 \mathrm{~Hz}$ (IEEE Std 1159,1995).

As cargas, até então denominadas "tradicionais", tais como: iluminação incandescente, aparelhos de aquecimento resistivo, etc. são lineares, pois sua impedância é praticamente constante, independente da tensão.

A corrente nessas cargas é sempre proporcional à tensão, ou seja, para tensão senoidal, a corrente também será senoidal, embora possam estar defasadas, em função de sua natureza: resistiva, indutiva ou capacitiva.

A figura A.1 apresenta as formas de onda das tensões e correntes resultantes.

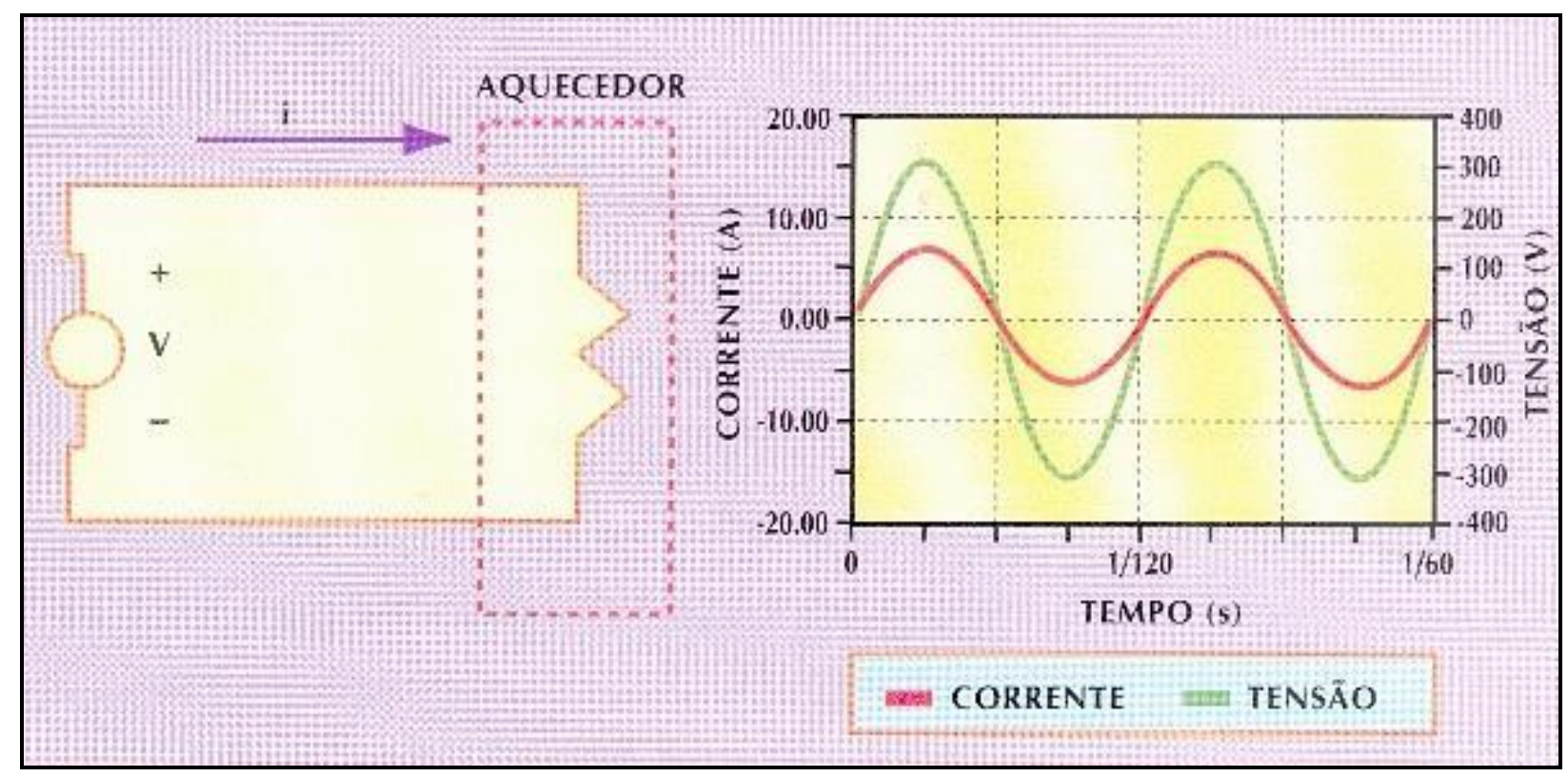

Figura A.1 - Tensão e corrente em uma carga linear

Fonte: Miguel; Medina; Antón, 2007.

Já nas cargas denominadas não-lineares, essa proporcionalidade não existe, pois a relação entre a tensão e a corrente pode modificar bastante. Por exemplo, no caso da saturação de um transformador ou, no caso de retificadores, que podem conduzir a corrente durante apenas uma parte do ciclo. Para ambas as situações, mesmo que a tensão seja senoidal, a corrente não será, conforme apresenta a figura A.2: 


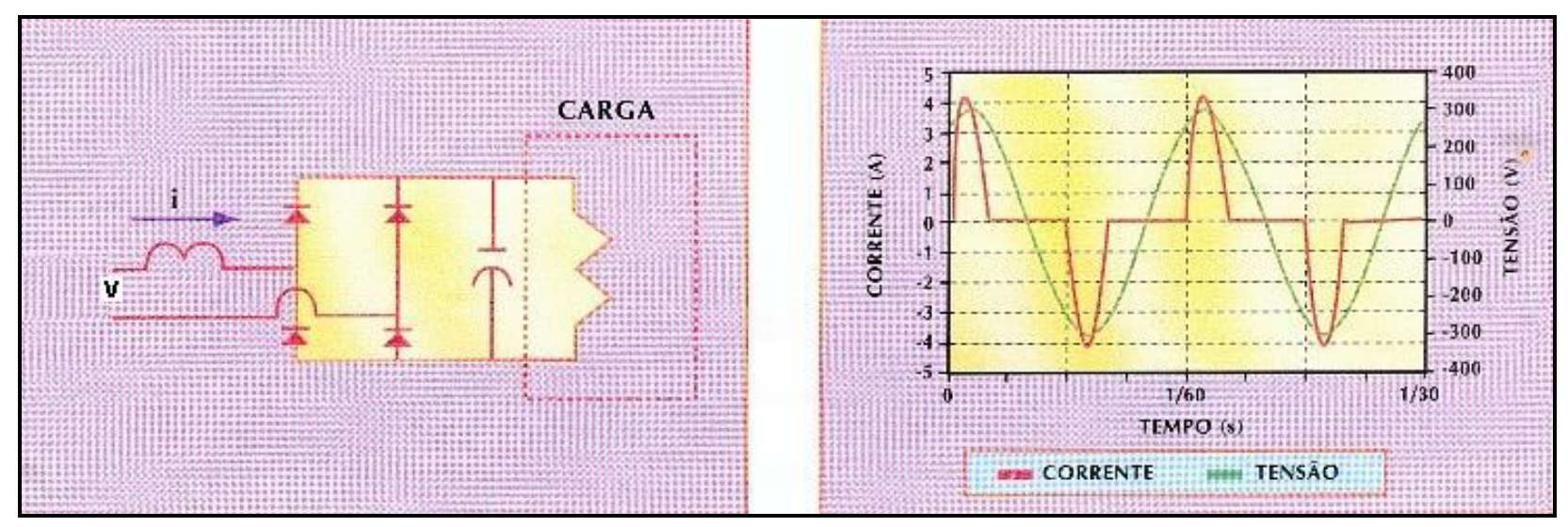

Figura A.2 - Tensão e corrente em uma carga não-linear

Fonte: Miguel; Medina; Antón, 2007.

Os harmônicos de corrente elevam a temperatura de condutores e de rotores de motores, aumentando as perdas elétricas, ou podem provocar sobretensões nos locais onde estão instalados capacitores, pelo efeito de ressonância. Os harmônicos de tensão não são produzidos pelos alternadores das usinas geradoras de energia, as quais geram tensões virtualmente senoidais, enquanto os de corrente são geradas por cargas não-lineares, que atualmente estão sendo utilizadas nas mais diversas aplicações.

Joseph Fourier (1768-1830), matemático francês, provou que todas as funções periódicas não senoidais podem ser representadas por uma soma de termos senoidais, de freqüências e amplitudes variáveis. $O$ primeiro desses termos à freqüência de recorrência da função é denominado de fundamental e, os outros, com múltiplas freqüências da fundamental, são chamados de harmônicos. Uma componente de corrente contínua pode completar esses termos. A teoria pode ser expressa pela equação A.1:

$$
y(t)=Y_{o}+\sum Y_{h} \cdot \sqrt{2} \cdot \operatorname{sen}\left(h \cdot \omega_{1} \cdot t-\phi_{h}\right)
$$


sendo:

$y(t)$ - função periódica não senoidal;

$Y_{0}$ - valor do componente de tensão ou de corrente contínua;

$\mathrm{Y}_{\mathrm{h}(\mathrm{V}) ;(\mathrm{l})}$ - valor eficaz do componente harmônico de tensão ou de corrente, de ordem $\mathrm{h}$;

$\mathrm{h}$ - ordem do harmônico;

$\omega_{1}$ - freqüência angular da fundamental;

$\phi_{h}$ - defasagem do harmônico de tensão ou de corrente, de ordem $h$.

Ordem do harmônico é um número inteiro obtido pelo quociente da freqüência desse harmônico, pela freqüência da componente fundamental, conforme equação A.2:

$$
h=\frac{f_{h}}{f_{1}}
$$

sendo:

$\mathrm{h}$ - ordem do harmônico;

$f_{h}-$ freqüência do harmônico, de ordem $h$;

$f_{1}-$ freqüência da fundamental.

A figura A.3 apresenta uma forma de onda distorcida e seus componentes harmônicos.

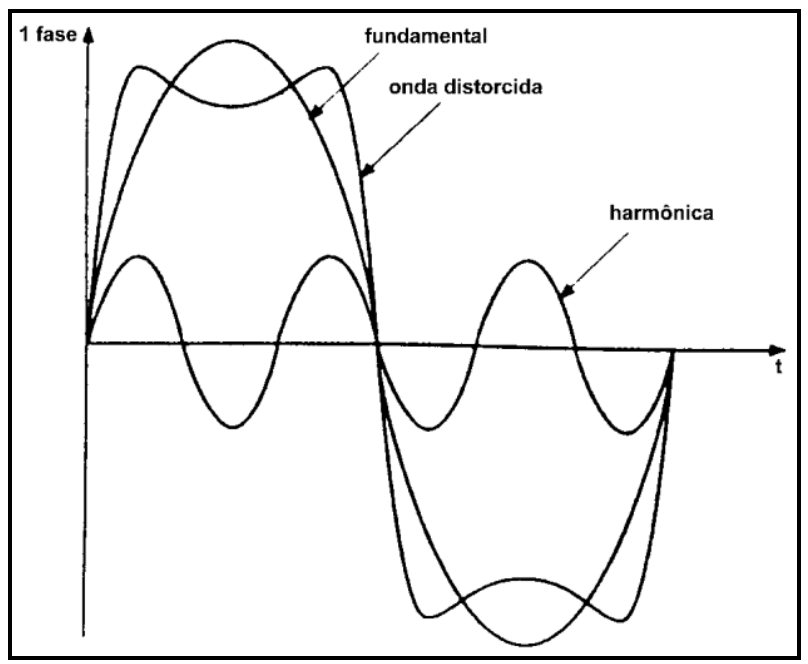

Figura A.3 - Forma de onda distorcida e seus componentes harmônicos

Fonte: Miguel; Medina; Antón, 2007. 
Os harmônicos são classificados quanto à sua ordem, freqüência e seqüência, conforme apresenta a tabela A.1:

Tabela A.1 - Classificação dos harmônicos característicos

\begin{tabular}{|c|c|c|}
\hline Ordem & Freqüência (Hz) & Seqüência \\
\hline 1 & 60 & + \\
\hline 2 & 120 & - \\
\hline 3 & 180 & + \\
\hline 4 & 240 & - \\
\hline 5 & 300 & 0 \\
\hline 6 & 360 & \\
\hline$H$ & h.60 & \\
\hline
\end{tabular}

Fonte: Miguel; Medina; Antón (2007).

A situação ideal seria a existência somente do harmônico de ordem 1, ou seja, com freqüência igual a $60 \mathrm{~Hz}$, denominado de fundamental. Observa-se a existência de harmônicos de ordem ímpar, que são encontrados nas instalações elétricas em geral e os pares, encontrados somente em casos de assimetria, devido à presença de corrente contínua.

As seqüências, por sua vez, poderão ser positiva, negativa ou nula (zero). No caso de um motor elétrico, os harmônicos de corrente, de seqüência positiva superiores à fundamental, tenderiam a girá-lo em velocidade superior à nominal, provocando aquecimento por sobrecorrentes, acarretando a redução da sua vida útil; os de seqüência negativa tenderiam a girar o motor no sentido inverso ao do campo girante produzido pela fundamental, resultando em uma ação de frenagem, reduzindo o conjugado e provocando também aquecimentos indesejáveis.

Os harmônicos de corrente de seqüência zero somam-se algebricamente nos circuitos que contém o condutor neutro, provocando correntes elevadas, em muitos casos até superiores aos valores das correntes de fase.

Os Analisadores de Qualidade de Energia, como o Fluke 43B, efetuam a decomposição de um sinal em seus componentes harmônicos, representando-o sob a forma de um gráfico de barras, denominado de espectro harmônico. Cada barra representa um 
harmônico, com sua freqüência, valor eficaz e defasagem. A figura A.4 apresenta uma forma de onda distorcida e seu respectivo espectro de harmônicos.


Figura A.4 - Forma de onda distorcida e seu respectivo espectro de harmônicos

Fonte: Pesquisa de campo.

Nota: Medições realizadas com analisador de qualidade de energia Fluke 43B.

Harmônicos são expressos, em geral, em termos de seu valor eficaz, pois o aquecimento produzido pela onda distorcida está relacionado a ele.

Para uma onda puramente senoidal, o valor eficaz é igual ao valor máximo dividido por raiz quadrada de dois. Para uma forma de onda distorcida, sob condições de regime permanente, a energia total dissipada por efeito Joule é a soma das energias dissipadas pelos componentes harmônicos. Desta forma:

$$
\begin{gathered}
R I^{2} t=R I_{(1)}^{2} t+R I_{(2)}^{2} t+\ldots+R I_{(h)}^{2} t \\
I^{2}=I_{(1)}^{2}+I_{(2)}^{2}+\ldots+I_{(h)}^{2}
\end{gathered}
$$

portanto:

ou ainda : $\quad I=\sqrt{\sum_{h=1}^{\infty} I_{(h)}^{2}}$

sendo:

I - corrente expressa em valores eficazes. 
O valor eficaz de uma forma de onda distorcida pode ser medido diretamente com instrumentos específicos (true rms), bem como por meios térmicos ou, ainda, com analisadores de espectro.

Define-se a distorção harmônica individual como a relação entre o valor eficaz de tensão ou corrente de cada harmônico em relação à fundamental (IEEE Std 519, 1992; PHIPPS; NELSON; SEM, 1994) ou à resultante (IEC 60050-161, 1990; FIORINA, 1993).

Segundo a primeira definição, adotada pelo Cigré - Conférence Internationale des Grands Réseaux Életriques, a distorção harmônica individual é calculada pela expressão:

$$
H D_{(V) ;(I)}=\frac{Y_{h(V) ;(I)}}{Y_{1(V) ;(I)}}
$$

A distorção harmônica total é aquela que quantifica o efeito térmico de todos os harmônicos. Seu valor é obtido pela relação entre o valor eficaz de todos os harmônicos, de tensão ou de corrente, em relação (MIGUEL; MEDINA; ANTÓN, 2007):

1- à fundamental - definição adotada pelo Cigré e pelas normas americanas ANSI/IEEE;

2- à resultante - definição adotada pela IEC - International Eletrotechnical Comission.

Segundo a primeira definição, a distorção harmônica total é calculada pela expressão:

$$
\operatorname{THD}_{(V) ;(I)}=\frac{1}{Y_{1(V) ;(I)}} \sqrt{\sum_{h=2}^{\infty} Y_{h(V) ;(I)}^{2}}
$$

sendo:

$H D_{(V) ;(l)}$ - distorção harmônica individual, de tensão ou de corrente, respectivamente;

$\mathrm{THD}_{(\mathrm{V}) ;(I)}$ - distorção harmônica total, de tensão ou de corrente, respectivamente; 
$Y_{h(V) ;(I)}$-valor eficaz do harmônico de tensão ou de corrente, respectivamente de ordem $\mathrm{h} \geq 2$;

$Y_{1(V) ;(l)}-$ valor eficaz da tensão ou da corrente fundamental, respectivamente.

Outro fator, também indicativo do nível de distorção da forma de onda, é o fator de crista. Ele relaciona o valor máximo da tensão ou da corrente e o seu valor eficaz, conforme expressão:

$$
F_{c(V) ;(I)}=\frac{Y_{M(V) ;(I)}}{Y_{(V) ;(I)}}
$$

Para um sinal senoidal, o fator de crista é igual a $\sqrt{2}$ e para algumas outras formas de onda pode chegar a mais de 4 .

Nos estudos de sistemas contendo harmônicos, deve-se ressaltar a diferença entre fator de potência total (FP) e fator de potência da fundamental ( $\left.\cos \varphi_{1}\right)$, também denominado de fator de deslocamento que é igual ao cosseno do ângulo de defasagem entre a tensão e a corrente, fundamentais.

Por definição, fator de potência é a relação entre a potência ativa e a potência aparente que são consumidas por um equipamento ou dispositivo, independentemente das formas de ondas de tensão e corrente (DUGAN; MCGRANAGHAN; BEATY, 1996):

$$
F P=\frac{P}{S}=\frac{\frac{1}{T} \int v_{i}(t) i_{i}(t) d t}{V I}
$$

sendo:

V - tensão de entrada - valor eficaz;

I - corrente de entrada - valor eficaz

Se as formas de onda da tensão e da corrente forem senoidais, a equação A.9 torna-se igual ao cosseno do ângulo de defasagem entre essas grandezas. 


$$
F P=\cos \phi
$$

Neste caso, a figura A.5 apresenta a relação entre as potências:

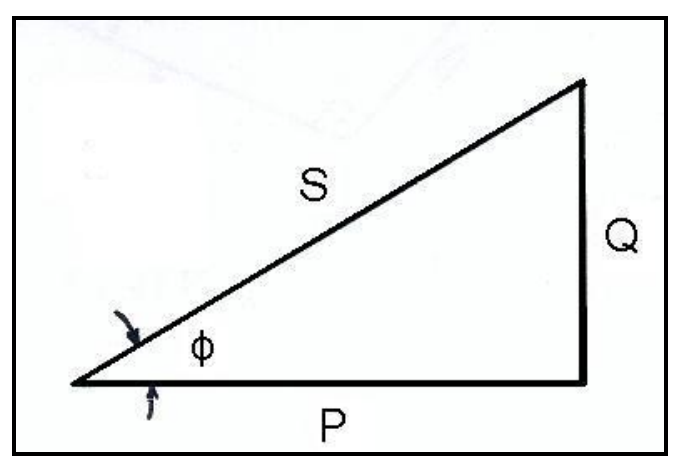

Figura A.5 - Triângulo das potências

Fonte: Elaborada pelo autor a partir da equação A.11.

Potência Aparente (S): potência total disponibilizada pela rede elétrica.

Potência Ativa (P): parte da potência aparente que é transformada em trabalho útil.

Potência Reativa $(\mathbf{Q})$ : potência que não é transformada em trabalho útil, devido à defasagem angular entre tensão e a corrente de entrada.

Do triângulo, obtém-se a seguinte relação:

$$
S=\sqrt{P^{2}+Q^{2}}
$$

Se a tensão de entrada for senoidal (somente $V_{1}$ ), mas a corrente de entrada possui harmônicos, o resultado será:

$$
i(t)=i_{1}(t)+\sum_{h=2}^{\infty} i_{h}(t)
$$

sendo:

$i(t)$ - corrente total de entrada - valor instantâneo;

$\mathrm{i}_{1}(\mathrm{t})$ - corrente na freqüência da fundamental - valor instantâneo;

$\Sigma \mathrm{i}_{h}(\mathrm{t})$ - somatório dos harmônicos de corrente - valores instantâneos- $(h \geq 2)$.

Em valores eficazes, a equação será: 


$$
I^{2}=I_{1}^{2}+\sum_{h=2}^{\infty} I_{h}^{2}
$$

Como a transferência de potência ativa ocorre somente para harmônicos de tensão e corrente da mesma ordem, a potência média de entrada fica definida por:

$$
P=V I_{1} \cos \phi_{1}
$$

Nos sistemas de potência, a tensão de entrada normalmente não sofre distorção, de forma que $V$ é praticamente igual a $V_{1}$ :

Substituindo as equações (A.13) e (A.14) em (A.9), tem-se:

$$
F P=\frac{I_{1}}{\sqrt{I_{1}^{2}+\sum_{h=2}^{\infty} I_{h}^{2}}} \cdot \cos \phi_{1}
$$

ou:

$$
F P=\frac{1}{\sqrt{1+\frac{\sum_{h=2}^{\infty} I_{h}^{2}}{I_{1}^{2}}}} \cos \phi_{1}
$$

portanto:

$$
F P=\frac{1}{\sqrt{1+T H D_{(I)}^{2}}} \cdot \cos \phi_{1}
$$

Da equação (A.17), conclui-se que, duas condições são importantes para se ter um fator de potência unitário:

- deslocamento nulo entre a tensão de entrada e a fundamental da corrente de entrada ( $\cos \phi=1)$; e

- ausência de harmônicos de corrente.

No último caso citado, a relação entre as potências pode ser obtida pela figura A.6: 


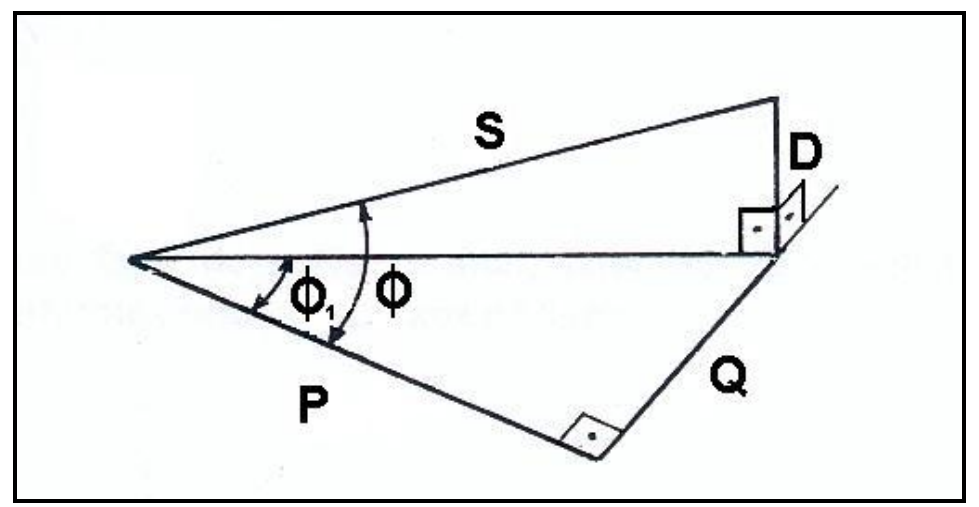

Figura A.6 - Relação entre as potências

Fonte: Dugan; Mcgranaghan; Beaty, 1996.

$$
S=\sqrt{P^{2}+Q^{2}+D^{2}}
$$

Potência Aparente (S): potência total disponibilizada pela rede elétrica.

Potência Ativa (P): parte da potência aparente que é transformada em trabalho útil.

Potência Reativa de Deslocamento $(\mathbf{Q})$ : potência que não é transformada em trabalho útil, devido à defasagem angular entre tensão e corrente na freqüência fundamental.

Potência Reativa de Distorção (D): potência que não é transformada em trabalho útil, devido à presença de harmônicos de corrente.

Fator de Potência Total (FP): relação entre a potência ativa e a potência aparente total (inclui os harmônicos).

Fator de deslocamento ( $\left.\cos \phi_{1}\right)$ : ou fator de potência da fundamental é o cosseno do ângulo formado pelas grandezas fundamentais $(60 \mathrm{~Hz})$ de tensão e corrente.

Ainda, de acordo com a IEC 60146-1-1 (1996), a relação entre o FP e o cos $\phi_{1}$ recebe 0 nome de fator de distorção:

$$
v=\frac{F P}{\cos \phi_{1}}
$$


A partir das equações A.15 e A.17, conclui-se que o fator de distorção também pode ser calculado pelas duas formas apresentadas na equação A.20:

$$
v=\frac{I_{1}}{I}=\frac{1}{\sqrt{1+T H D_{I}^{2}}}
$$

A figura A.7, obtida a partir da equação A.20, apresenta a relação entre o fator de distorção e a distorção harmônica total de corrente:

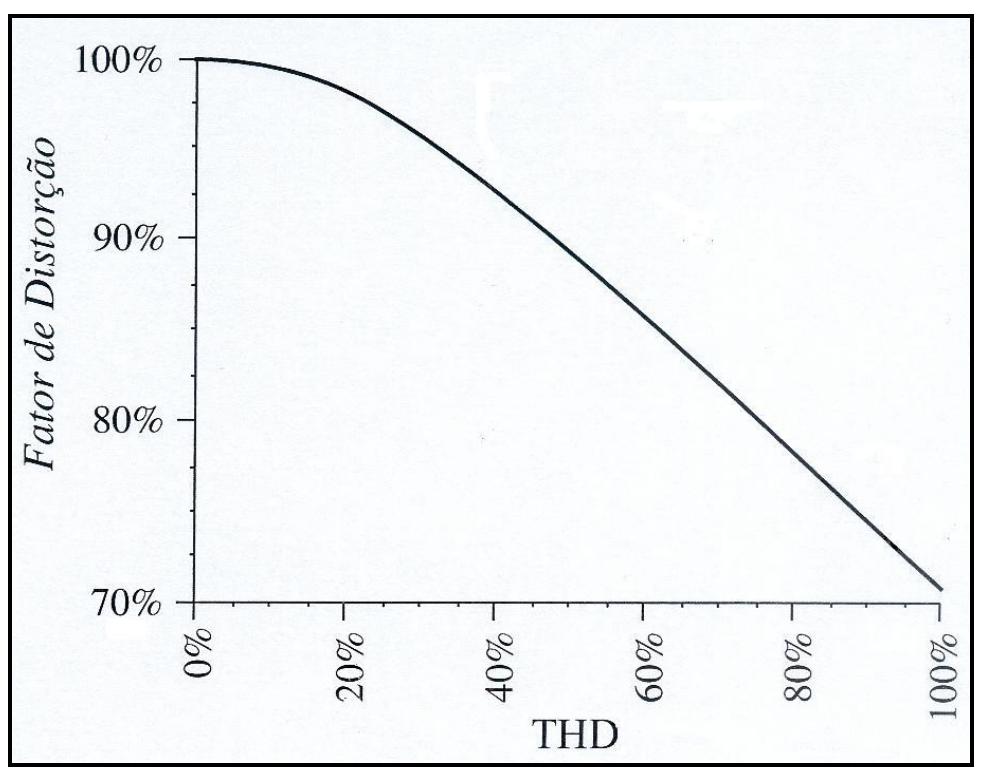

Figura A.7 - Relação entre o fator de distorção e a distorção harmônica total de corrente Fonte: Elaborada pelo autor a partir da equação A.20. 


\section{ANEXO B - MEDIDAS ELÉTRICAS}

\section{B.1 A DEFINIÇÃO DO INSTRUMENTO}

Pelo fato de as medições elétricas serem praticadas há muitos anos pelas concessionárias, com finalidades de faturamento e cobrança da energia elétrica fornecida, o conceito dessas medições parece associar-se mais ao aspecto quantitativo.

No entanto, as medições não possuem como objetivo somente a quantificação da energia elétrica, mas também podem ser indicadoras do comportamento das instalações ou dos equipamentos elétricos, por meio de aspectos qualitativos (STAROSTA, 2007).

Instrumentos eletromecânicos, muito utilizados no passado, ainda são úteis na avaliação instantânea dos valores eficazes da tensão ou da corrente, desde que bem calibrados.

Os eletrônicos, com tecnologia analógica ou digital possibilitam, com equivalente grau de precisão, se conhecer num único instrumento, além dos valores das tensões e correntes, os valores das potências, distorções harmônicas da tensão e da corrente e, de outras grandezas elétricas.

Se a medição tiver de ser realizada por um período de tempo, outros aspectos devem ser considerados, como:

a) modo da medição: no domínio do tempo ou da freqüência;

b) tipo da carga: linear ou não-linear;

c) tempo de medição: dependente do regime de trabalho da carga;

d) capacidade de aquisição das informações: leitura e gravação;

e) algoritmos utilizados para a obtenção indireta de grandezas;

f) normas às quais o instrumento deverá atender;

g) outras informações. 
A medição de grandezas elétricas em regime senoidal pode ser realizada, considerando duas possibilidade:

Domínio do tempo: o sinal senoidal é apresentado diretamente como em um osciloscópio e tem por objetivo a análise das formas de onda ciclo a ciclo, podendo apresentar simultaneamente na mesma base de tempo, formas de onda da tensão e da corrente. Para este modo de medição é importante que a taxa de amostragem do instrumento seja adequada, pois, caso contrário, alguns fenômenos não serão gravados. As medições no domínio de tempo são utilizadas em todos os casos onde se deseja analisar os fenômenos relacionados à qualidade de energia elétrica.

Domínio da freqüência: as grandezas elétricas são apresentadas em valores eficazes, integrados entre dois instantes, relacionados a um período. A cada um desses períodos um valor é registrado e armazenado, ficando o acesso aos registros, dependente da capacidade de memória do instrumento. Este modo de medição é útil na análise de variáveis relacionadas ao consumo de energia, como: potências ativa e reativa, fator de potência, corrente, tensão, etc. Conclui-se que o período de integração considerado deve ser suficientemente menor que o tempo de operação da carga que se deseja obter o seu comportamento.

Para a medição de cargas não-lineares, deverão ser utilizados equipamentos "true rms", que respondem a formas de onda com freqüências diferentes daquela da fundamental. A utilização de equipamentos inadequados para medição de cargas não-lineares introduzirá erros de leitura que aumentam em função da distorção harmônica da carga. Em função das necessidades, define-se o tipo do instrumento e a metodologia a ser utilizada. Ainda há de se considerar que, embora as medições sejam realizadas por um período relativamente longo, muitos fenômenos relacionados à qualidade de energia elétrica podem não ser encontrados em função de uma intermitência indefinida.

A Norma IEC 61000-4-30 (2008) define os métodos de medida e interpretação dos resultados de parâmetros de qualidade de energia elétrica, para redes de suprimento com tensão alternada, tanto em $50 \mathrm{~Hz}$ quanto em $60 \mathrm{~Hz}$. 


\section{B.2 SEGURANÇA NAS MEDIÇÕES ELÉTRICAS}

Nas últimas décadas, a utilização da energia elétrica aumentou consideravelmente em todas as atividades, em função das diversas aplicações disponíveis.

A maior quantidade de energia a ser transportada exige equipamentos e condutores elétricos com maiores seções transversais, aumentando o valor da potência envolvida em caso de curto-circuito.

A comutação de cargas com elevada potência, descargas atmosféricas e outros fenômenos elétricos podem ocasionar elevados surtos de tensão que, combinados com procedimentos ou equipamentos de medição inadequados, provocam arcos elétricos, ocasionando acidentes de elevada gravidade ou morte.

Em face ao exposto, os padrões internacionais de segurança, especificamente para instrumentos de medição, tornaram-se bem mais rigorosos que no passado.

Em 1990 a IEC substituiu a antiga Norma IEC 348 por outra bem mais rigorosa, a IEC 61010-1 (1990) que vem sendo utilizada como referência em outras normas nacionais, como:

ANSI/ISA - S82.01-94, nos Estados Unidos da América do Norte.

CAN C22.2 no 1010.1-92, no Canadá.

EN 61010-1, na Europa.

Essa norma especifica categorias de sobretensão baseadas na distância do local de medição em relação à fonte de alimentação. As categorias mais elevadas situam-se mais próximas do ponto de suprimento de energia e, portanto, exigem maiores proteções. Essas categorias são:

Categoria IV - refere-se ao nível do sistema de distribuição da concessionária, tanto em fornecimento com condutores aéreos quanto em subterrâneos. Esta categoria atualmente não está incluída na norma.

Categoria III - inclui os sistemas de distribuição principais e auxiliares, internos a edificações. Esses circuitos são normalmente separados da fonte de alimentação por, 
pelo menos, um transformador. Estão incluídos os painéis de distribuição, os circuitos alimentadores e as derivações curtas.

Categoria II - inclui os circuitos terminais que alimentam tomadas de corrente a mais de $10 \mathrm{~m}$ de distância dos locais classificados com Categoria III ou, $20 \mathrm{~m}$ dos locais Categoria IV.

Categoria I - circuitos localizados no interior de equipamentos eletrônicos.

Segundo essa norma, os instrumentos de medição são testados com os valores de impulso de tensão apresentados na tabela B1.

Tabela B.1 - Valores da tensão de pulso em função da categoria do instrumento de medição

\begin{tabular}{|c|c|c|}
\hline CATEGORIA & IMPULSO (V) & IMPEDÂNCIA DA FONTE ( $\mathbf{(})$ \\
\hline II-600V & 4000 & 12 \\
\hline II-1000V & 6000 & 12 \\
\hline III-600V & 6000 & 2 \\
\hline III-1000V & 8000 & 2 \\
\hline
\end{tabular}

Fonte: IEC 61010-1, 1990.

Para atendimento à Norma IEC 61010-1, os espaçamentos entre as partes internas do instrumento, que estão sob diferença de potencial, foram aumentados, de forma a suportarem maiores picos de tensão.

Muitos acidentes graves, muitas vezes fatais, têm ocorrido ultimamente pela falta de treinamento ou utilização incorreta dos instrumentos de medidas elétricas.

Nestes casos, a ocorrência de um curto-circuito pode resultar na formação de arcos elétricos que se deslocam em direção à pessoa que executa as medições.

As intervenções em instalações elétricas energizadas, como é o caso de medições elétricas, em circuitos com tensão igual ou superior a $50 \mathrm{~V}$ em corrente alternada, ou $120 \mathrm{~V}$ em corrente contínua, poderão ser realizadas somente por trabalhadores que atendam ao que estabelece o item 10.8 da NR 10 (PINTO et al., 2008). 


\section{B.3 OS INSTRUMENTOS UTILIZADOS}

\section{B.3.1 ANALISADOR DE QUALIDADE DE ENERGIA MODELO 43B}

\section{FABRICANTE: FLUKE CORPORATION - USA}

O equipamento analisador de potência e qualidade de energia elétrica da marca Fluke, modelo 43B, está de acordo com os padrões ANSI/ISA S82.01-1994, EN/IEC 61.010-1 (1993), CAN/CSA-C22 010.1-92, UL 3111-1, tendo sido aprovado para medições em equipamentos elétricos, em redes monofásicas ou trifásicas equilibradas.



Figura B.1 - Analisador de qualidade de energia - Fluke modelo 43B Fonte: Catálogo do fabricante.

Especificações de segurança: segundo o fabricante, este equipamento foi projetado e testado para utilização em medições Categoria III (até 600 Vrms), com freqüências variando de 0 a $66 \mathrm{kHz}$. Essa categoria de instalação refere-se ao nível de distribuição e aos circuitos de instalações elétricas fixas no interior de edifícios. 
Especificação das funções: a tabela B.1 apresenta as especificações do equipamento, com os respectivos desvios percentuais para cada parâmetro de medição:

\section{Tabela B.2 - Especificações do Fluke 43B}

\begin{tabular}{|c|c|}
\hline Especificações & Desvio \\
\hline Tensão (V) & $\pm 1 \%$ \\
\hline Intensidade de Corrente (A) & $\pm 1 \%$ \\
\hline Freqüência $(\mathrm{Hz})$ & $\pm 0,5 \%$ \\
\hline Potência Ativa (W) & $\pm 2 \%$ \\
\hline
\end{tabular}

Fonte: Catálogo do fabricante.

O equipamento Fluke 43B opera em condições de temperatura de 0 a $50{ }^{\circ} \mathrm{C}$ com umidade relativa do ar de até $95 \%$. A altitude de funcionamento fica limitada a $600 \mathrm{~V}$ até $2.000 \mathrm{~m}$ e $400 \mathrm{~V}$ de 2.000 a $4.500 \mathrm{~m}$.

O Índice de Proteção - IP do equipamento é 51 . O fabricante também informa que o equipamento, bem como seus acessórios, estão em conformidade com a CEE 89/336 no tocante à imunidade eletromagnética.

As especificações das grandezas elétricas são válidas para sinais com freqüência fundamental entre 40 e $70 \mathrm{~Hz}$. As faixas de leituras são:

Tensão CA (rms): $5 \mathrm{~V}$ a $500 \mathrm{~V}$.

Corrente (rms): 50 A a 500 kA.

Fator de Crista: 1,0 a $10,0( \pm 5 \%)$.

Potências ativa, reativa e aparente: 250 (W,VAr,VA) a 250 (MW,MVAr,MVA).

Fator de potência de deslocamento $\left(\cos \varphi_{1}\right): 0,25$ a 1,00 .

Fator de potência total: 0,00 a 1,00.

Harmônicos de tensão, corrente e potência: até a $51^{\underline{a}}$.

O equipamento ainda registra: variações momentâneas de tensão (sag e swell), fenômenos transitórios de curta duração, correntes de partida de motores elétricos e excitação de transformadores, além de apresentar a função de osciloscópio, para análise de formas de onda. 
O Fluke 43B efetua medições instantâneas de resistência elétrica, capacitância e temperatura, podendo inclusive gravar a variação dessas grandezas ao longo do tempo.

O equipamento vem acompanhado de software para análise das grandezas medidas em um PC.

\section{B.3.2 MEDIDOR DE GRANDEZAS ELÉTRICAS COM MEMÓRIA - SMART METER}

Fabricante: IMS - Indústria de Micro Sistemas Eletrônicos Ltda. Porto Alegre, RS.



Figura B.2 - Medidor de grandezas elétricas Smart Meter

Fonte: Catálogo do fabricante.

Esse instrumento registra em memória interna, não volátil, as seguintes grandezas elétricas em redes monofásicas ou trifásicas:

Tensões, correntes e freqüência.

Potências, ativa, reativa e aparente.

Harmônicos ímpares de tensão e corrente até a $31^{\text {a }}$ ordem.

Além das grandezas citadas, ainda fornece medições de corrente de neutro, datas e falta de energia da rede elétrica. Os dados armazenados são transferidos para um microcomputador por intermédio de um software analisador gráfico que acompanha 0 instrumento. 
As principais características são:

- precisão: 0,5\%;

- medidor de múltiplas grandezas elétricas, polifásico com 2 ou 3 elementos de medição, três ou quatro fios (ligação delta ou estrela);

- medidor para ligação direta:

1. entrada de corrente: 0,05 a 5 A, por intermédio de TC interno;

2. entrada de tensão: 50 a 500 VCA, alta impedância.

- calcula:

1. fator de potência;

2. THD, harmônicos ímpares até a 31 $31^{a}$, para tensão e corrente;

3. a média das grandezas: tensão, corrente potência e fator de potência.

- velocidade de comunicação programável em 9600, 19200 ou 38400 bits por segundo;

- uma porta serial RS 232 e uma porta serial RS 485;

- protocolo de comunicação MODBUS RTU;

- proteção IP 51;

- peso $1 \mathrm{~kg}$;

- temperatura de operação: 0 a 55ํㅜ;

- entrada de tensão de alimentação: 90 a 270 VCA / CC;

- consumo: 10 VA.

\section{B.3.3 REGISTRADOR ELETRÔNICO - MARH 21}

Fabricante: RMS - Indústria de Equipamentos Eletrônicos Ltda. Porto Alegre, RS.

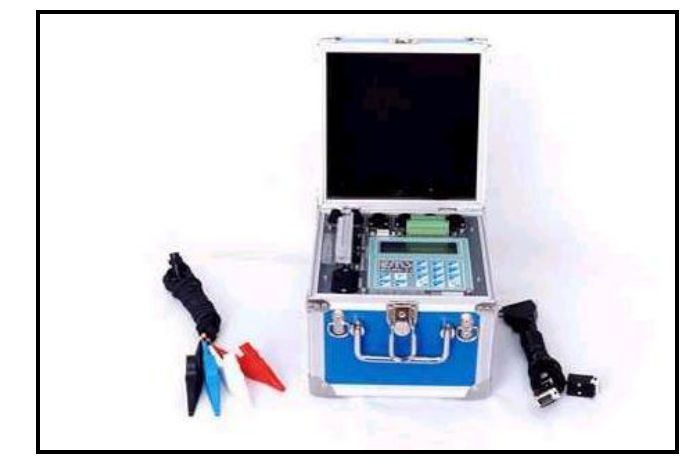

Figura B.3 - Registrador eletrônico - Mahr 21

Fonte: Catálogo do fabricante. 
Trata-se de um medidor/registrador eletrônico em tempo real para análise de sistemas elétricos monofásicos, bifásicos e trifásicos em baixa, média e alta tensão. Suas principais aplicações são:

- monitoramento da qualidade de energia elétrica em sistemas de distribuição;

- campanhas de controle de perturbações na rede elétrica incluindo flutuações de tensão, harmônicos, transientes, afundamentos e elevações momentâneas de tensão.

A análise dos dados registrados é efetuada com o programa Anawin, desenvolvido especialmente para este equipamento.

$O$ instrumento mede e registra as seguintes grandezas elétricas:

- Tensões, correntes, potências ativa, reativa e aparente, distorções harmônicas totais e individuais de tensão e de corrente, fator de potência, potência reativa para correção do fator de potência.

- Exatidão: classe 0,5 para tensões e correntes e classe 1 para potências (IEC 60348).

Faixas de medição: 0 a 600 Vrms - ligação direta ou 0 a 999,9 kVrms, via TPs.

0 a 11 Arms - ligação direta ou 0 a 999,9 kArms, via TCs.

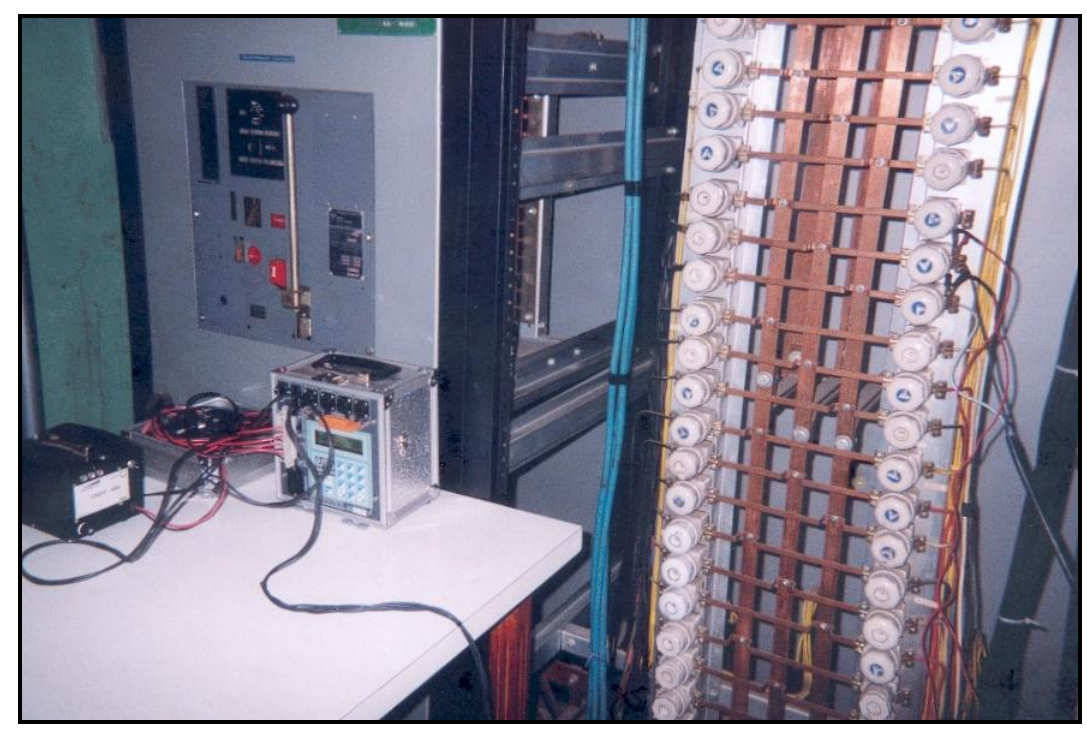

Figura B.4 - Equipamento instalado na Subestação de um EAS Fonte: Pesquisa de campo. 


\section{ANEXO C - DETERMINAÇÃO DO GRAU DE DESEQUILÍBRIO DE TENSÕES PELO MÉTODO DAS COMPONENTES SIMÉTRICAS}

$\mathrm{V}_{1}=213,8 \mathrm{~V} ; \mathrm{V}_{2}=215,9 \mathrm{~V} ; \mathrm{V}_{3}=216,8 \mathrm{~V}$

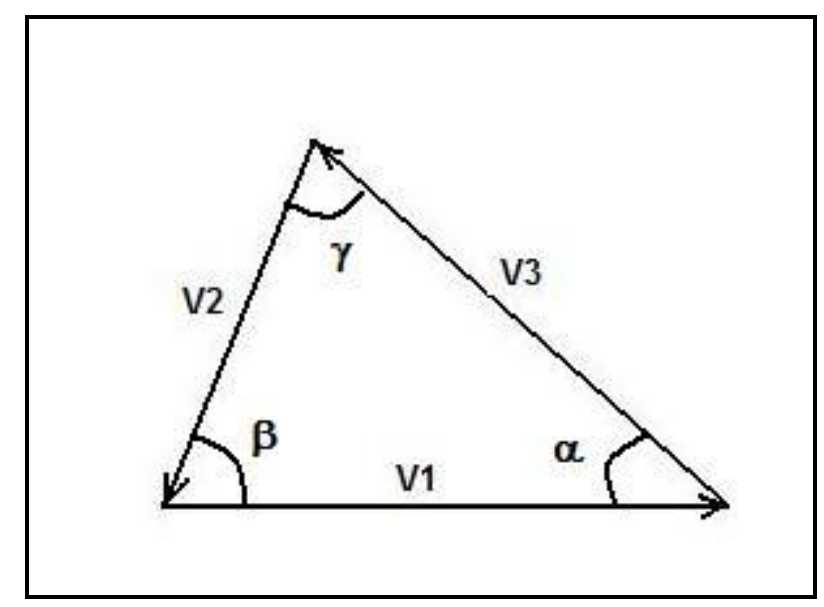

Pela lei dos cossenos:

$\propto=\arccos \left[\frac{V_{3}^{2}+V_{1}^{2}-V_{2}^{2}}{2 V_{3} V_{1}}\right]=\arccos \left[\frac{216,8^{2}+213,8^{2}-215,9^{2}}{2.216,8.213,8}\right]=60,18^{\circ}$

$\gamma=\arccos \left[\frac{V_{2}^{2}+V_{3}^{2}-V_{1}^{2}}{2 V_{2} V_{3}}\right]=\arccos \left[\frac{215,9^{2}+216,8^{2}-213,8^{2}}{2.215,9.216,8}\right]=59,22^{\circ}$

$\beta=180^{\circ}-(\alpha+\gamma)=180^{\circ}-\left(60,18^{\circ}+59,22^{\circ}\right)=60,60^{\circ}$

Então:

$\mathrm{V}_{1}=213,8\left\llcorner 0^{\circ} \mathrm{V}\right.$;

$V_{2}=215,9\left\llcorner\left(-180^{\circ}-\beta\right)=215,9\left\llcorner-119,4^{\circ} \mathrm{V}\right.\right.$;

$V_{3}=216,8\left\llcorner(180-\alpha)=216,8\left\llcorner 119,82^{\circ} \mathrm{V}\right.\right.$.

Efetuando o cálculo pelas componentes simétricas:

$V_{1(+)}=1 / 3\left(V_{1}\left\llcorner 0^{\circ}+V_{2}\left\llcorner\left(-60^{\circ}+\beta\right)+V_{3}\left\llcorner\left(60^{\circ}-\alpha\right)=\right.\right.\right.\right.$

$1 / 3\left(213,8\left\llcorner 0^{\circ}+215,9\left\llcorner\left(-60^{\circ}+60,60^{\circ}\right)+216,8\left\llcorner\left(60^{\circ}-60,18^{\circ}\right)=215,49\left\llcorner 0,140^{\circ}\right.\right.\right.\right.\right.$

$\mathrm{V}_{1(-)}=1 / 3\left(\mathrm{~V}_{1}\left\llcorner 0^{\circ}+\mathrm{V}_{2}\left\llcorner(60+\beta)+\mathrm{V}_{3}\llcorner-(60+\alpha)=\right.\right.\right.$

$1 / 3\left(213,8\left\llcorner 0^{\circ}+215,9\left\llcorner\left(60^{\circ}+60,60^{\circ}\right)+216,8\left\llcorner-\left(60^{\circ}+60,18^{\circ}\right)=1,77\llcorner-162,79\right.\right.\right.\right.$

Grau de desequilíbrio de tensão $(\%)=\left(\mathrm{V}_{1(-)} / \mathrm{V}_{1(+)}\right) \cdot 100=(1,77 / 215,49) \cdot 100=0,821 \%$ 
Os valores das componentes simétricas de seqüências positiva, negativa e zero podem ser, também, obtidas por meio do simulador Vector, conforme se apresenta na figura C.1:

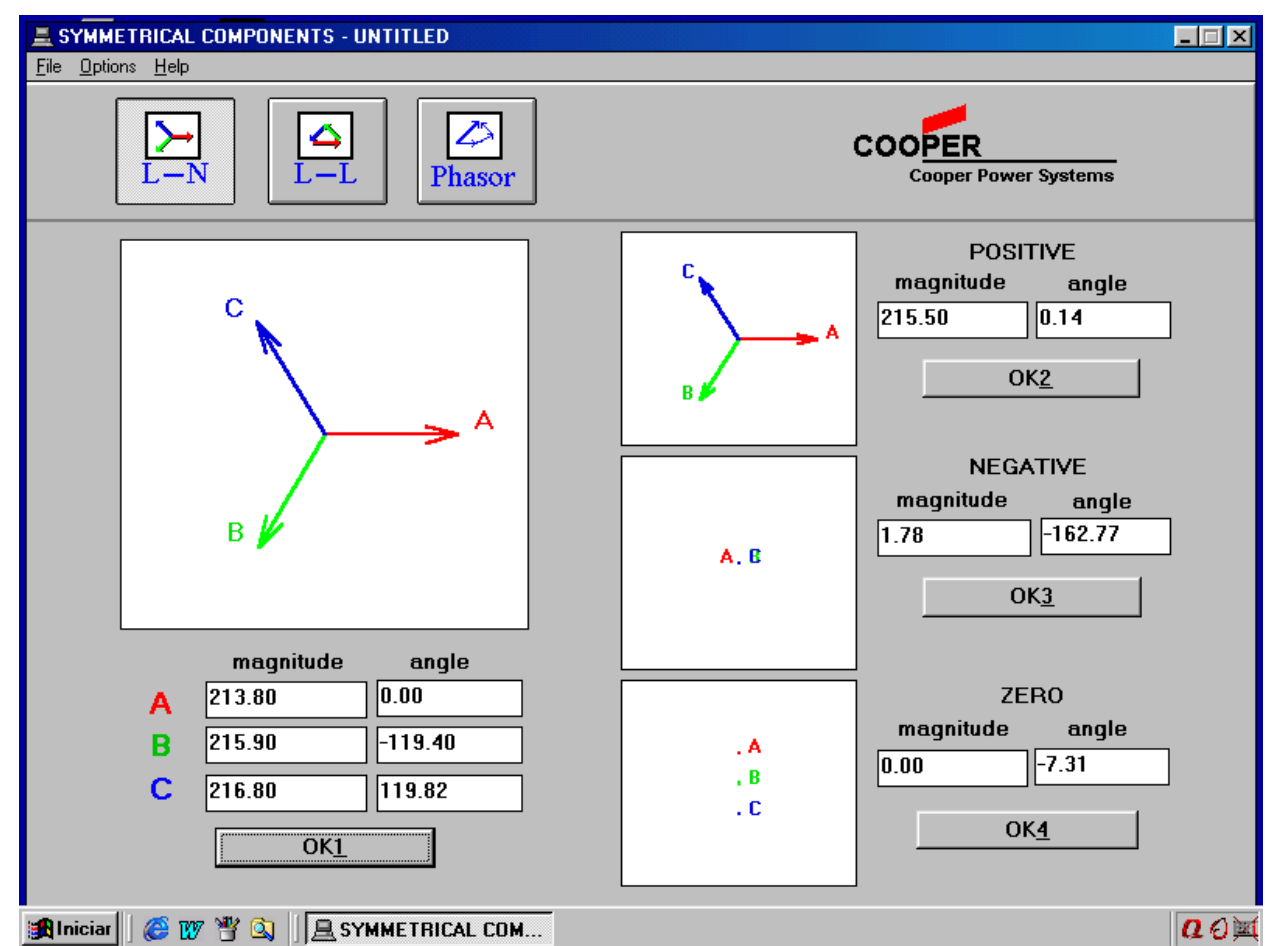

Figura C.1 - Tela do simulador Vector Fonte: Cooper Power Systems.

Observa-se que os valores obtidos para as seqüências positiva e negativa da tensão são praticamente os mesmos que os calculados. 


\section{ANEXO D - MÉTODOS DE PARTIDA À TENSÃO REDUZIDA PARA MOTORES DE INDUÇÃO COM ROTOR EM GAIOLA}

Os métodos usuais de partida à tensão reduzida para motores de indução com rotor em gaiola são:

a) Partida estrela-triângulo:

Durante a fase de arranque, uma chave estrela-triângulo liga os terminais do motor em estrela, e após a sua aceleração, bem próximo à rotação nominal, essa chave é comutada manualmente ou automaticamente para triângulo, assumindo o motor, suas características de plena tensão.

Para a utilização deste método, é necessário que os motores possuam 6 ou 12 terminais de saída, o que acontece naturalmente para máquinas com várias possibilidades de tensões de alimentação, que estão na relação $1 / \sqrt{3}$.

Durante a fase de partida, a corrente de rotor bloqueado se reduz teoricamente a $1 / 3$ do seu valor a plena tensão, conforme se apresenta na figura D.1.

O mesmo acontece com o conjugado motor, na fase de partida. A comutação de estrela para triângulo deveria ocorrer após o conjunto motor-carga alcançar, pelo menos, 90\% da velocidade final.

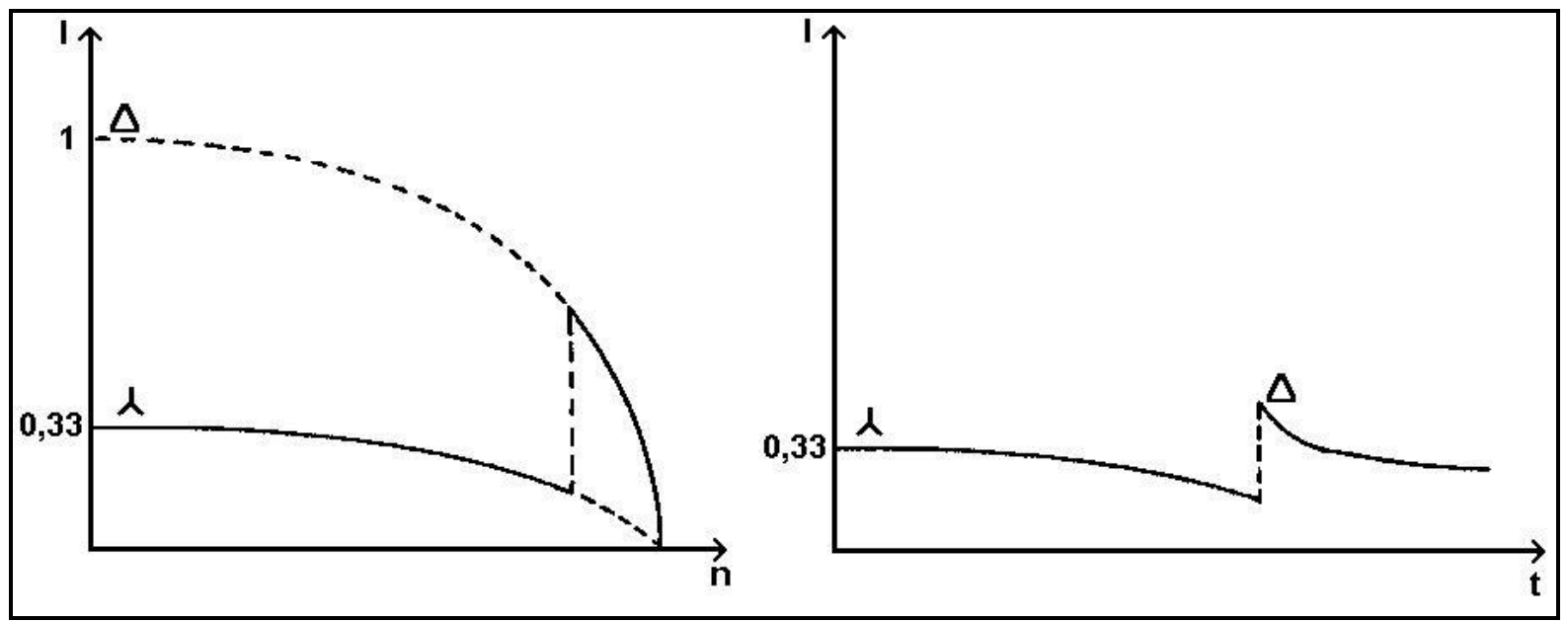

Figura D.1- Variação da corrente, com a rotação e, no tempo, para uma partida estrela-triângulo Fonte: Adaptada do Manual de chaves de partida - WEG. 
No entanto, caso o motor ligado em estrela não possua conjugado suficiente para atender esta condição, no instante da comutação para triângulo, ocorrerá um pico de corrente intenso, podendo provocar problemas mecânicos na máquina acionada, além de afundamentos de tensão de curta duração na rede de alimentação.

A figura D.2 apresenta essa situação para um motor de indução de $100 \mathrm{cv} / 380 \mathrm{~V}$ acionando um compressor de ar.

Observa-se que, no momento da comutação para triângulo, a corrente alcançou $437 \mathrm{~A}$ durante $0,5 \mathrm{~s}$ :

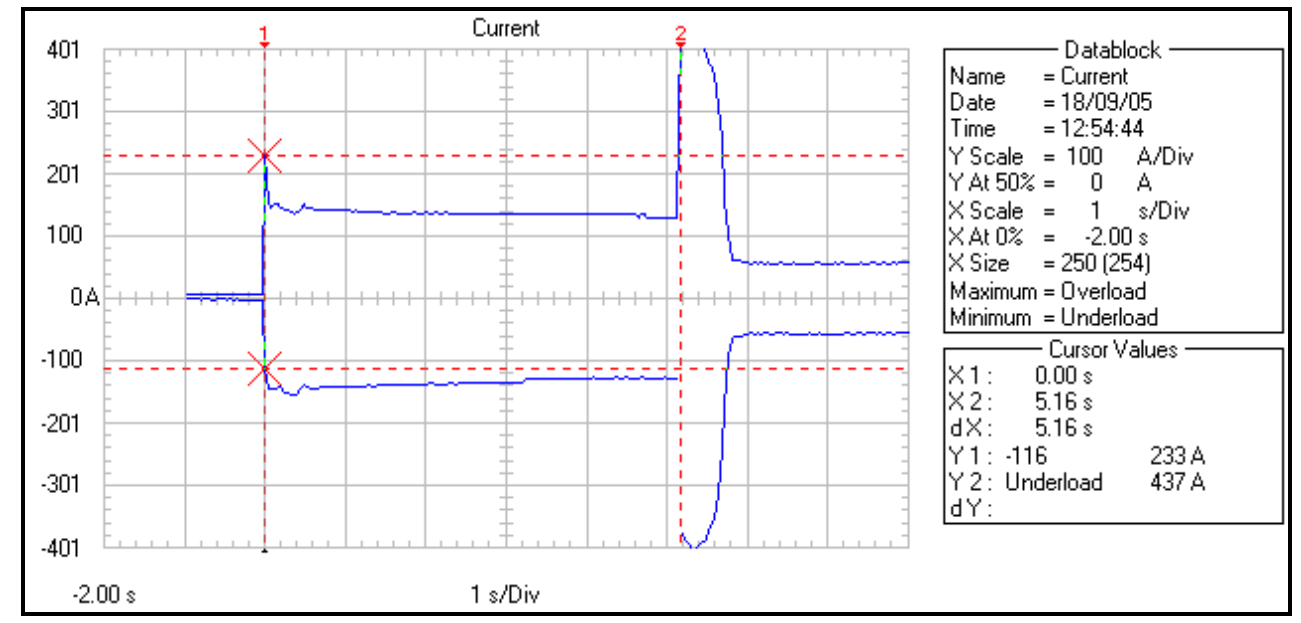

Figura D.2- Partida estrela-triângulo com problemas de arranque

Fonte: Medida realizada com analisador de qualidade de energia Fluke 43B

b) Partida com chave compensadora:

É um dispositivo que alimenta, na fase de partida, o motor com tensão reduzida, por meio de um autotransformador.

Após a aceleração, o autotransformador é desconectado e o motor alimentado à plena tensão.

Para a aplicação do referido método, não existem restrições quanto ao número de bornes, o qual será conectado para receber a tensão nominal da rede de alimentação. 
Os autotransformadores são dotados de vários terminais, para que se possa escolher o valor da redução de tensão adequada. A corrente e o conjugado de rotor bloqueado se reduzem na relação da redução de tensão elevada ao quadrado, por exemplo:

Tensão (pu)

(em relação ao valor nominal)

0,80

0,65

\section{Redução da corrente e do conjugado de} rotor bloqueado

0,64 do valor a plena tensão

0,42 do valor a plena tensão

A figura D.3 apresenta as variações da corrente com a rotação e com o tempo para uma partida com chave compensadora em função das derivações do autotransformador.

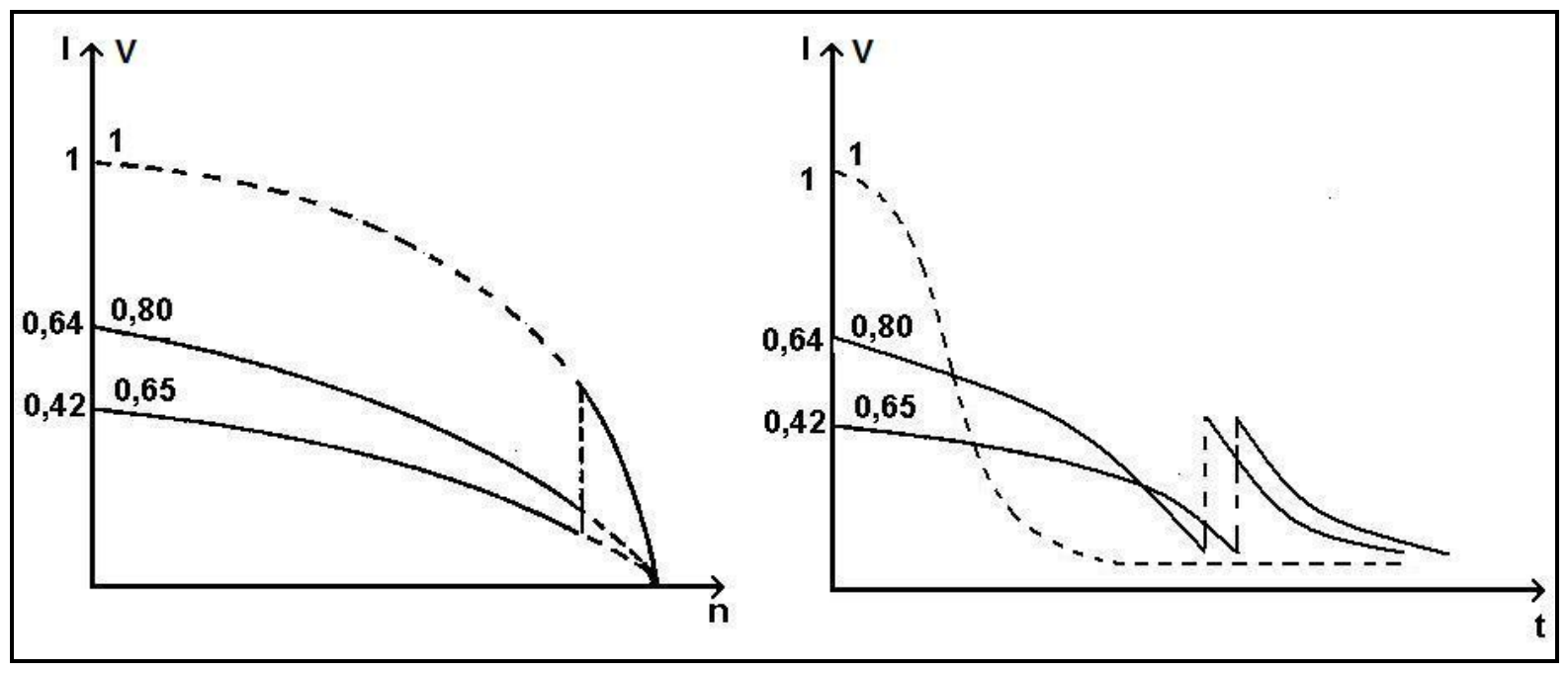

Figura D.3 - Variações da corrente na fase de partida

Fonte: Adaptada do Manual de chaves de partida - WEG.

c) Comparativo entre chaves estrela-triângulo e compensadora:

Apresenta-se, por meio da tabela D.1, os principais itens de comparação entre os dois métodos de partida mencionados. 
Tabela D.1 - Comparação entre partida estrela-triângulo e compensadora

\begin{tabular}{|c|c|c|}
\hline Critério & Chave estrela-triângulo & Chave compensadora \\
\hline Custo & Menor & $\begin{array}{l}\text { Muito maior devido ao } \\
\text { autotransformador }\end{array}$ \\
\hline Peso e dimensões & Menor & $\begin{array}{l}\text { Muito maior devido ao } \\
\text { autotransformador }\end{array}$ \\
\hline $\begin{array}{l}\text { Redução da corrente de rotor } \\
\text { bloqueado }\end{array}$ & Fixo $=1 / 3$ & $\begin{array}{c}\text { Ajustável em função das } \\
\text { derivações do autotransformador }\end{array}$ \\
\hline Ligação do motor & 6 ou 12 terminais & Qualquer \\
\hline
\end{tabular}

Fonte: Adaptada do Manual de chaves de partida - WEG.

d) Efeito sobre o conjugado:

Em todos os métodos de partida à tensão reduzida, a redução da corrente de rotor bloqueado é conseguida por maio da redução do conjugado do motor.

Para que os picos de corrente sejam atenuados, é necessário que a comutação da ligação de partida para a posição de marcha seja efetuada somente após o motor ter atingido aproximadamente 90 a 95\% da sua rotação nominal.

Para o caso de máquinas que partem praticamente sem carga, o método à tensão reduzida não apresenta problemas, pois mesmo com a redução de conjugado, na fase de partida, o motor consegue acionar a carga.

Para máquinas que partem praticamente sob carga, ou o conjugado resistente aumenta significativamente à medida que a velocidade cresce, os métodos apresentados não devem ser empregados.

e) Soft-starters:

Este método configura-se como uma solução simples que a cada dia vem se tornando mais acessível para "suavizar" a partida de motores de indução trifásicos (NAGAl; OLIVEIRA JR; ABREU, 1999).

Como já mencionado, os motores assíncronos trifásicos de rotor em gaiola apresentam picos indesejáveis de corrente e conjugado, quando utilizados com dispositivos com partida direta. 
Para contornar esse inconveniente, utilizam-se os métodos de partida já apresentados, como estrela-triângulo, chave compensadora, etc.

Esses métodos conseguem uma redução na corrente de partida, porém a comutação é efetuada por degraus de tensão.

Em aplicações modernas são utilizados soft-starters, que por meio de comando microprocessado controlam tiristores que ajustam a tensão enviada ao estator do motor. Dessa forma, consegue-se reduzir os elevados conjugados de aceleração do motor e o valor da corrente de partida, protegendo a máquina acionada de desgastes mecânicos e a rede elétrica, de afundamentos de tensão na fase de partida. Este método de partida traz como vantagens adicionais maiores intervalos entre manutenções, maior segurança operacional e redução de paradas inesperadas por defeitos mecânicos.

O controle da tensão é obtido variando-se o ângulo de disparo dos tiristores ligados em antiparalelo, como se observa na figura D.4:

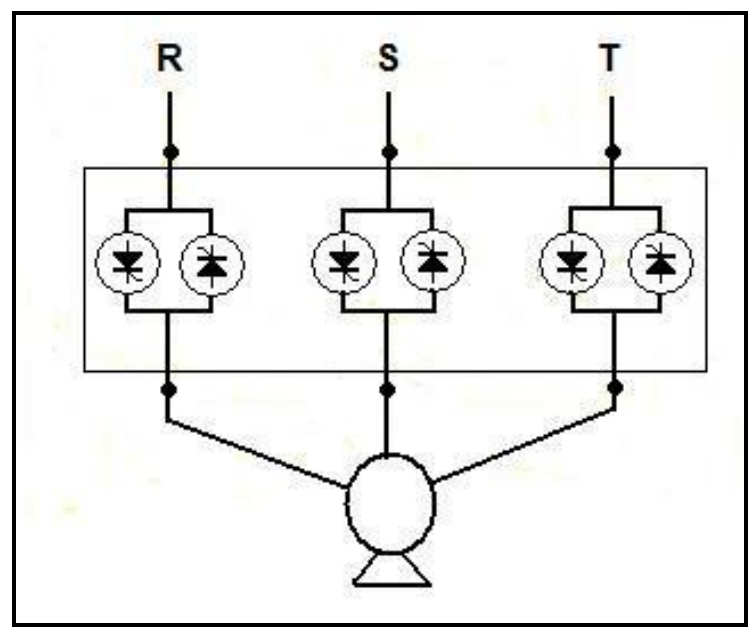

Figura D.4 - Configuração básica da unidade de potência do soft-starter Fonte: Nagai; Oliveira; Abreu, 1999.

Em modelos mais sofisticados, vários modos de programação são disponibilizados, tanto na partida quanto na parada:

-Partida: rampa de tensão, limite de corrente e impulso de tensão.

-Parada: rampa de tensão e frenagem com corrente contínua.

-Em regime: economia de energia e controle do fator de potência. 
A figura D.5 apresenta a forma de onda da tensão gerada pelo soft-starter durante um processo de aceleração:

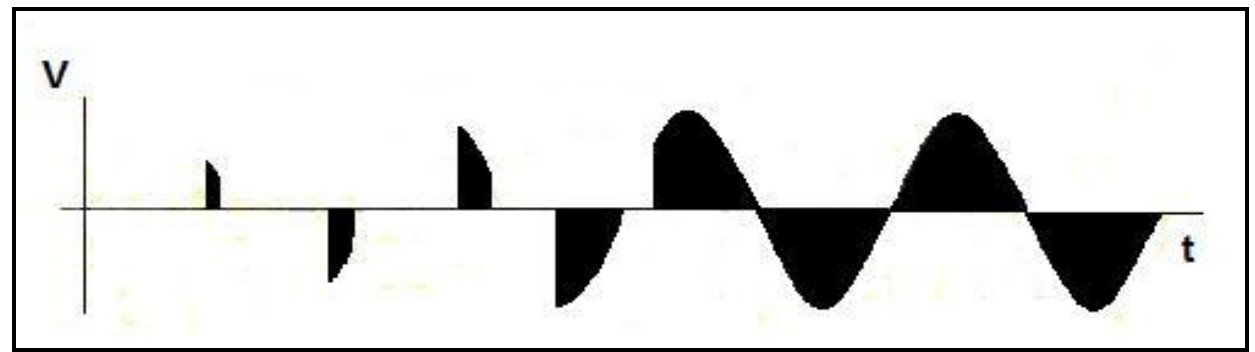

Figura D.5 - Forma de onda da tensão gerada pelo soft-starter durante o processo de aceleração

Fonte: Nagai; Oliveira; Abreu, 1999.

As figuras D.6 e D.7 apresentam as curvas de partida de um acionamento, por intermédio de soft-starter, nos modos com rampa de tensão e limitação de corrente.

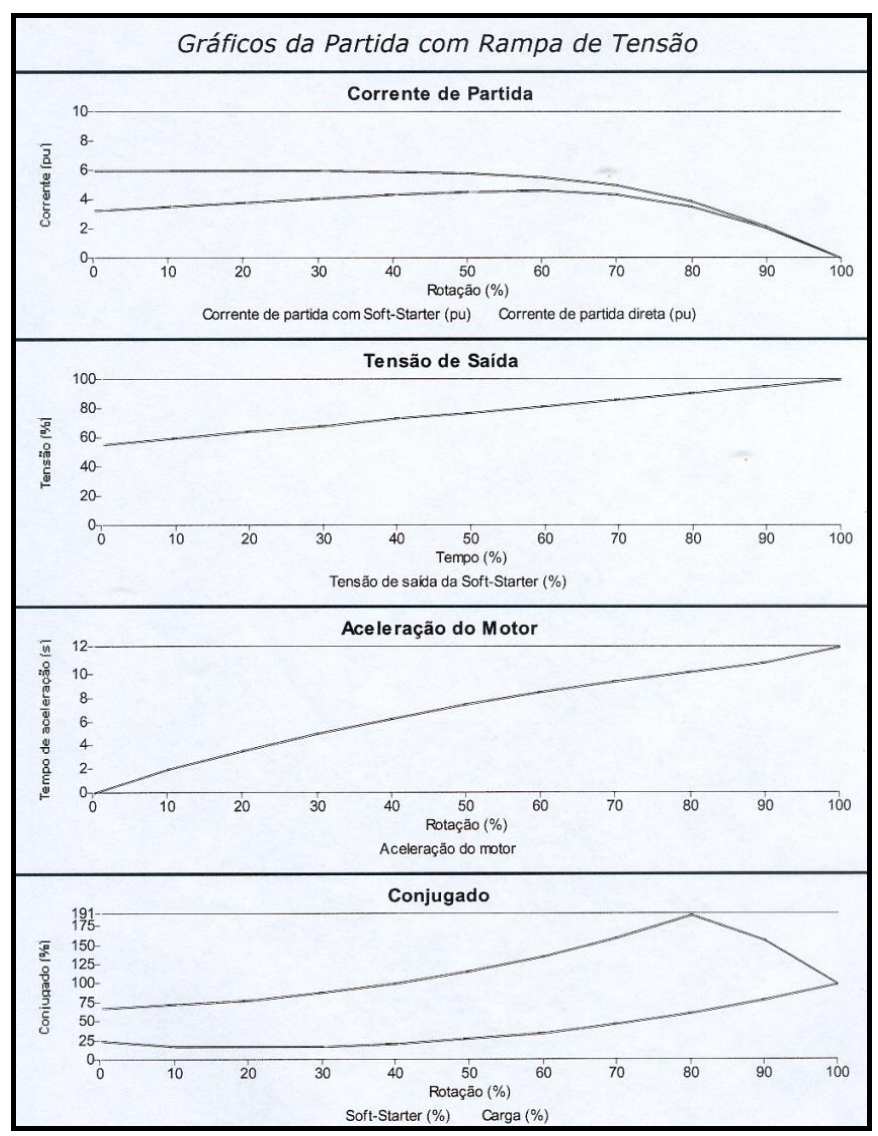

Figura D.6 - Curvas de partida com soft-starter - modo com rampa de tensão Fonte: Adaptada do Manual de Drives - WEG. 


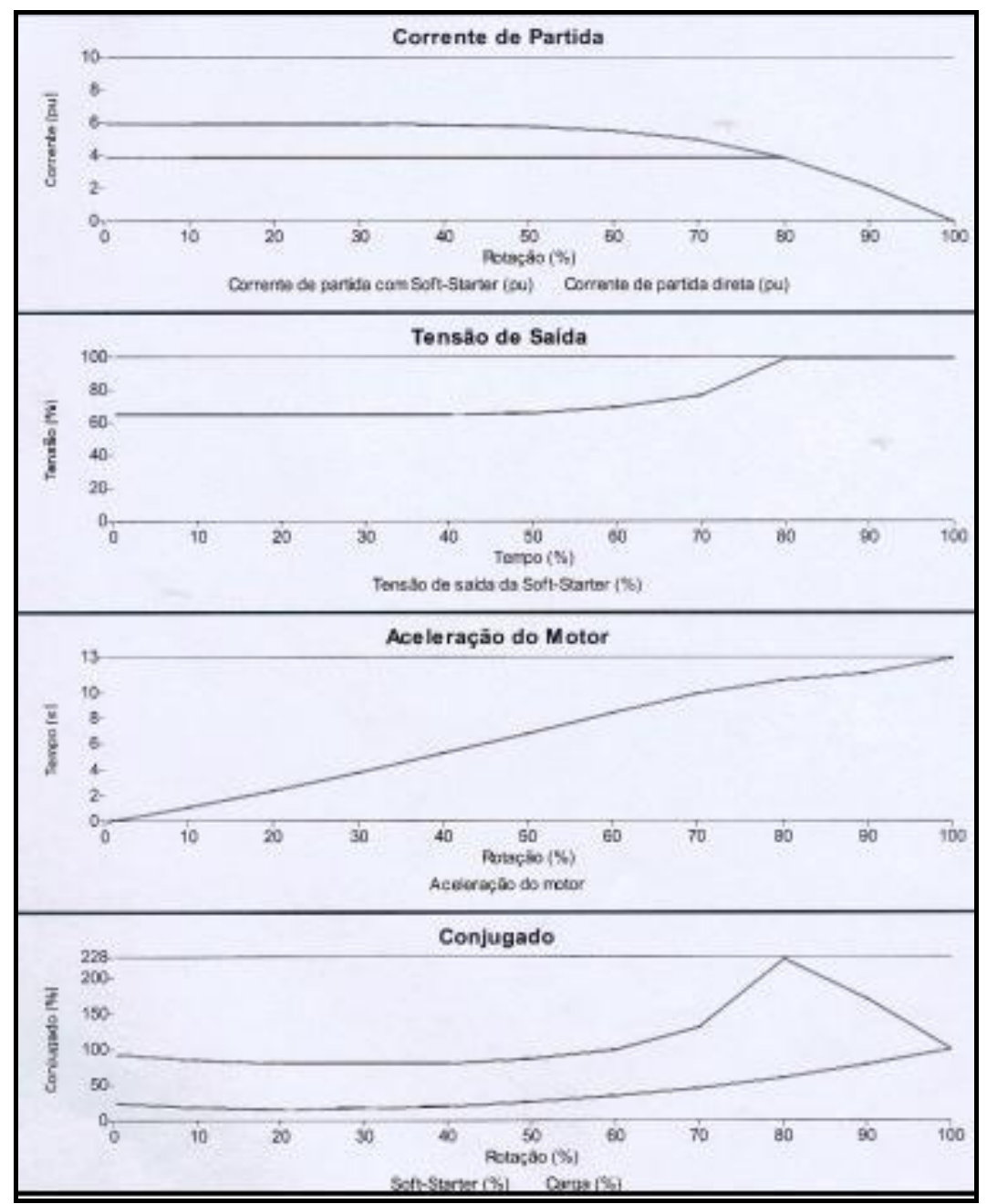

Figura D.7 - Curvas de partida com soft-starter - modo de limitação de corrente Fonte: Adaptada do Manual de Drives - WEG. 